\title{
Strategic asset allocation \& asset liability management
}

Citation for published version (APA):

Hoevenaars, R. P. P. M. (2008). Strategic asset allocation \& asset liability management. [Doctoral Thesis, Maastricht University]. Universiteit Maastricht. https://doi.org/10.26481/dis.20080118rh

Document status and date:

Published: 01/01/2008

DOI:

10.26481/dis.20080118rh

Document Version:

Publisher's PDF, also known as Version of record

\section{Please check the document version of this publication:}

- A submitted manuscript is the version of the article upon submission and before peer-review. There can be important differences between the submitted version and the official published version of record.

People interested in the research are advised to contact the author for the final version of the publication, or visit the DOI to the publisher's website.

- The final author version and the galley proof are versions of the publication after peer review.

- The final published version features the final layout of the paper including the volume, issue and page numbers.

Link to publication

\footnotetext{
General rights rights.

- You may freely distribute the URL identifying the publication in the public portal. please follow below link for the End User Agreement:

www.umlib.nl/taverne-license

Take down policy

If you believe that this document breaches copyright please contact us at:

repository@maastrichtuniversity.nl

providing details and we will investigate your claim.
}

Copyright and moral rights for the publications made accessible in the public portal are retained by the authors and/or other copyright owners and it is a condition of accessing publications that users recognise and abide by the legal requirements associated with these

- Users may download and print one copy of any publication from the public portal for the purpose of private study or research.

- You may not further distribute the material or use it for any profit-making activity or commercial gain

If the publication is distributed under the terms of Article $25 \mathrm{fa}$ of the Dutch Copyright Act, indicated by the "Taverne" license above, 
STRATEGIC ASSET ALLOCATION

$\&$

ASSET LIABILITY MANAGEMENT 



\title{
STRATEGIC ASSET ALLOCATION \\ $\&$ \\ ASSET LIABILITY MANAGEMENT
}

\author{
PROEFSCHRIFT
}

ter verkrijging van de graad van doctor aan de Universiteit Maastricht op gezag van de Rector Magnificus, Prof. Mr. G.P.M.F. Mols,

volgens het besluit van het College van Decanen, in het openbaar te verdedigen op vrijdag 18 januari 2008 om 10.00 uur

door

Roy Peter Maria Mathieu Hoevenaars 


\section{Promotoren:}

Prof. dr. F.C. Palm

Prof. dr. P.C. Schotman

Prof. dr. T.B.M. Steenkamp (Vrije Universiteit Amsterdam)

\section{Beoordelingscommissie:}

Prof. dr. C.G. Koedijk (voorzitter)

Prof. dr. C.G.E. Boender (Vrije Universiteit Amsterdam)

Prof. dr. J.-P. Urbain

Prof. dr. L.M. Viceira (Harvard Business School, Harvard University, USA)

Prof. dr. C.C.P. Wolff

Strategic Asset Allocation and Asset Liability Management

ISBN 978-90-9022575-3

Copyright (C)2008 Roy Hoevenaars

Cover design: based on painting of Henk Severens

All rights reserved. No part of this publication may be reproduced or transmitted in any form or by any means electronic or mechanical, including photocopying, recording, or by any information storage and retrieval system, without permission in writing from the author. 
To my mother, my father, Juliette and Joyce 



\section{Preface}

This $\mathrm{PhD}$ dissertation has its origin in the revived academic interest in portfolio choice for long-term investors at the beginning of this century, and my daily work in strategic asset allocation and asset liability management at ABP. The thesis is the result of four and a half years of part-time research at the Quantitative Economics and Finance departments at the University of Maastricht. When I started the research in March 2003, I was fascinated by the bridge between econometric theory and investment practice which I experienced in the previous two years of quant research.

Since the early work of Merton and Samuelson it is widely advocated that optimal portfolio choice is horizon dependent under time-varying investment opportunities. The 2002 book of John Campbell and Luis Viceira was a big inspiration for my research. They considered important points for long-term investors. Among them, the risk of stocks, bonds and T-bills at various investment horizons. For instance, stocks exhibit lower annualized risk at longer horizons due to mean reversion. I was challenged by the application of their research to a realistic pension fund with fair value inflation-linked pension liabilities and an investment universe that goes beyond stocks, bonds and T-bills. What are the building blocks of a pension fund's investment framework? Which alternative asset classes add value for long-term assetliability investors? Are inflation hedge properties of assets also horizon dependent? And, how robust are time diversification properties of assets (e.g. mean reversion in stock returns) to parameter uncertainty in the underlying models? These questions were the first steps in writing this Ph.D. dissertation. The result is in front of you.

I owe thanks to a number of people who supported, encouraged and motivated me in many ways. They inspired me to conduct the research next to my daily work at ABP. I am greatly indebted to my promotors Franz Palm, Peter Schotman and Tom Steenkamp for all the effort and time they invested in me. Thank you for the opportunity to do part-time research and the confidence you showed in me. You were a great team, and you helped me in building a bridge between theory and 
practice. Dear Franz, you motivated me at important points in time. You taught me to consider the research from a broader perspective, and at the same time your constructive and critical feedback challenged me a lot. Dear Peter, you inspired me in the many challenging discussions we had during our research projects. You taught me to be self-critical upon the research, and to concisely document the research. Your econometric knowledge and enthusiastic research ideas encouraged me. Dear Tom, you stimulated me to examine the applicability of academic models to practical investment problems in the fields of asset allocation and asset liability management. You challenged me to translate theoretical model outcomes into realistic policy recommendations, thanks.

A next word of gratitude goes to my colleagues at ABP and the University of Maastricht for their understanding and creating a pleasant working environment. I thank my roommate at the University Nils Kok for all his inspiring power-lunches and our conversations. A special word of thank goes to Roderick Molenaar and Eduard Ponds. You were my co-authors on a number of articles and you motivated me during our joint research projects. Thank you for the encouragement, support, advice and critical discussions during the whole Ph.D. project and everything you taught me. Furthermore, I have certainly benefited from fruitful discussions with Ralph Koijen and Luis Viceira on early versions on chapters two, three and five of this dissertation. I have also benefited from my participation in Netspar and Netspar events, and from challenging questions and insightful conversations with colleagues and other academics and practicioners, especially Rob Bauer, Michael Brandt, Frank de Jong and Olaf Sleijpen. I would also like to thank ABP for providing the opportunity and support for writing this thesis.

Mijn laatste woorden van dank gaan uit naar mijn familie die het meest belangrijk voor mij is, en zich tegelijkertijd waarschijnlijk afvraagt waar ik nu eigenlijk al die tijd mee bezig was. Zeer grote dank gaat naar mijn ouders. Jullie onvoorwaardelijke liefde, begrip en medeleven maken mij tot wie ik ben. Het vertrouwen dat jullie in mij hebben en het besef dat jullie altijd voor mij klaar staan zijn een enorme steun. Ik dank ook mijn zus Juliette, Paul, Rob en Nicolette voor jullie aanmoediging, vertrouwen en interesse. Joyce, een woord van dank is niet genoeg om uit te drukken wat je voor me betekent. Je liefde en vertrouwen geven me de kracht om mijn ambities waar te maken. Je steun en begrip gaven mij de mogelijkheid om dit proefschrift te realiseren. Bedankt voor de uitdagingen die we samen aangaan. Zonder jullie steun zou dit proefschrift er niet zijn geweest.

\section{Roy Hoevenaars}

Maastricht, November 2007 


\section{Contents}

Preface vii

1 Introduction 1

1.1 Strategic asset allocation and asset liability management . . . . . . 2

1.2 Outline ...................... 6

2 Strategic asset allocation with liabilities $\quad 9$

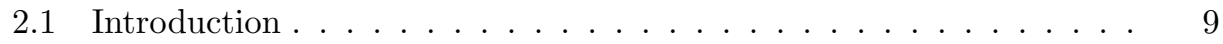

2.2 Portfolio choice . . . . . . . . . . . . . . . . . . . 12

2.3 Return dynamics . . . . . . . . . . . . . . . . . . . . . . 18

2.3 .1 Model . . . . . . . . . . . . . . . . . . . . 18

2.3 .2 Data . . . . . . . . . . . . . . . . . 20

2.3 .3 Estimation results . . . . . . . . . . . . . . . . 24

2.4 Term structures of assets and liabilities $\ldots \ldots \ldots \ldots . \ldots 27$

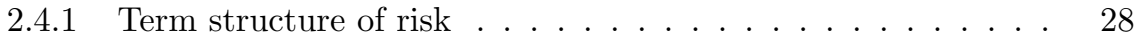

2.4 .2 Risk diversification . . . . . . . . . . . . . . 30

2.4 .3 Inflation hedging qualities $\ldots \ldots \ldots \ldots \ldots$

2.4.4 Real interest rate hedging qualities . . . . . . . . . . . 34

2.5 Strategic asset liability management . . . . . . . . . . . 36

2.5.1 Hedge portfolios . . . . . . . . . . . . . . . 36

2.5.2 Do alternative asset classes add value for long-term investors? 39

2.6 Conclusions . . . . . . . . . . . . . . . . . . . 42

2.7 Appendix: Risk and return at various horizons $\ldots \ldots \ldots \ldots$

$\begin{array}{lll}3 & \text { Strategic asset allocation for long-term investors } & 47\end{array}$

3.1 Introduction . . . . . . . . . . . . . . . . 47

3.2 Bayesian modeling framework . . . . . . . . . . . . . . 51

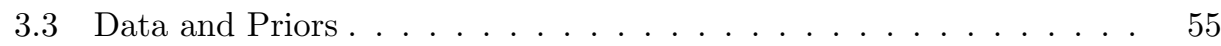


3.4 Empirical results . . . . . . . . . . . . . . . . . . . . 59

3.4 .1 Estimation results . . . . . . . . . . . . . . . . 59

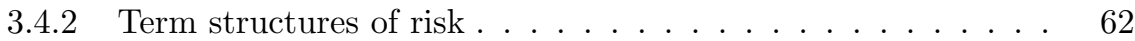

3.5 Optimal portfolio choice . . . . . . . . . . . . . . . . 69

3.6 Multiple Priors and Expected Loss _ . . . . . . . . . . . . . 77

3.7 Conclusion . . . . . . . . . . . . . . . . . . . . 80

3.8 Appendix: Properties of Posteriors . . . . . . . . . . . . . 82

4 Long-term investing with short-term constraints $\quad 85$

4.1 Introduction . . . . . . . . . . . . . . . . 85

4.2 Model for risk and return dynamics . . . . . . . . . . . . . . 89

4.2.1 Pricing kernel and affine term structure of interest rates . . . 89

4.2 .2 Data and estimation results . . . . . . . . . . . . 92

4.3 Value-based ALM and embedded options . . . . . . . . . . . . 94

4.4 Long-term investing with short-term constraints . . . . . . . . . 98

4.4.1 ALM framework . . . . . . . . . . . . . . . . 98

4.4 .2 Calendar rebalancing . . . . . . . . . . . . . . . . 103

4.4.3 Dynamic immunization of nominal liabilities . . . . . . . . 104

4.4 .4 Dynamic asset mix . . . . . . . . . . . . . . . . 106

4.4 .5 Dynamic swap-overlay . . . . . . . . . . . . . . . . 107

4.5 Conclusion . . . . . . . . . . . . . . . . . . . 110

5 Value-based ALM and intergenerational transfers 111

5.1 Introduction . . . . . . . . . . . . . . . . . . . . . 111

5.2 Generational accounting under uncertainty . . . . . . . . . 115

5.3 Asset Liability Management . . . . . . . . . . . . . . . . . . . 116

5.3 .1 Classical ALM . . . . . . . . . . . . . . . 116

5.3 .2 Value-based ALM . . . . . . . . . . . . . . . . 117

5.4 Pension fund in embedded generational options . . . . . . . . . . . 118

5.4.1 Pension fund characteristics . . . . . . . . . . . . . . . 118

5.4.2 Generational accounts as embedded options . . . . . . . . . 119

5.4 .3 Pricing embedded options . . . . . . . . . . . . . . . 122

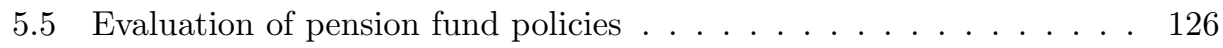

5.5 .1 Pension plan design $\ldots \ldots \ldots \ldots \ldots$

5.5.2 Investment policy in the hybrid plan . . . . . . . . . . . 136

5.5.3 Base contribution rate in the hybrid plan . . . . . . . . . 139

5.6 Evaluation of recent Dutch pension reforms . . . . . . . . . . . . . 141

5.7 Other applications . . . . . . . . . . . . . . . . . . . 144

5.7 .1 Public Finance . . . . . . . . . . . . . . . . . . . . . . . . 144 
5.7 .2 Social security reform . . . . . . . . . . . . . . 144

5.8 Conclusions . . . . . . . . . . . . . . . . . 145

5.9 Appendix: affine real term structure of interest rates . . . . . . . . . 146

6 Summary and conclusions $\quad 149$

$\begin{array}{lr}\text { Bibliography } & 157\end{array}$

$\begin{array}{lr}\text { Nederlandse samenvatting } & 169\end{array}$

$\begin{array}{lr}\text { Curriculum vitae } & 179\end{array}$ 



\section{Chapter 1}

\section{Introduction}

Institutional investors around the world invest trillions of Euros on behalf of many people who save money for the long run. In the Netherlands for example, pension funds hold more than 600 billion Euros of retirement income. One of the most critical decisions for such long-term investors is the selection of asset classes and their strategic weights. This becomes more of a challenge as the menu of investment choices has grown rapidly beyond traditional assets like stocks, government bonds and T-bills. Commodities, hedge funds, real estate, credits and other asset classes are common investment options these days. Besides the prominent question about how much long-term investors should allocate to stocks, bonds, T-bills and the alternative asset classes, institutional investors face other complex issues. For instance, the decision-making process depends on the governance structure of the institution, and some institutions invest on behalf of multiple clients with different objectives. They also must comply with regulatory frameworks, and there can be a variety of legal and investment constraints.

The recent interest in the area of strategic asset allocation for long-term investors emanates from falling stock returns and declining interest rates at the beginning of this century. The deterioration of the financial position of many pension funds led regulatory bodies to reconsider and adapt existing monitoring frameworks. Updated regulations in the Netherlands, Denmark, Sweden and the UK illustrate this. Minimum funding requirements and short-term solvency constraints now have a dominant role. Another well-known example is the shift towards fair valuation of both assets and liabilities. As a consequence, interest rate and inflation risk have become key elements in pension fund investments which has led to the investment industry focusing much more on liability driven investments.

On top of that, pension beneficiaries are demanding more transparency with 
regard to the exact nature of their pension arrangement. The sustainability of traditional defined benefit and defined contribution schemes is openly questioned. Discussions on pension reform build on issues like intergenerational risk sharing, life cycle approaches and governance structures. Understanding the relationship between the various stakeholders by identifying the value transfers embedded in the pension deal seems critically important for long-term sustainability and continuity. Therefore the valuation of the pension contract including all embedded options seems a major challenge for policy makers. For a further discussion of the current pension revolution we refer to Ambachtsheer (2007), and we refer to Clark, Munnell and Orszag (2006) for a broad discussion about the many diverse aspects of pensions and retirement income.

\subsection{Strategic asset allocation and asset liability man- agement}

This thesis is about strategic asset allocation for long-term investors and asset liability management (ALM) for pension funds. Asset liability management addresses the integral management of the assets and liabilities on the future balance sheet. It accounts for future uncertainties, multiple stakeholders, multiple objectives and the available policy instruments in an integral fashion. This thesis contributes to two areas of ALM: strategic asset allocation and embedded options in the pension deal (value-based ALM).

Concerning the area of strategic investment decisions for long-term asset-liability investors this thesis is related to three themes. The first is about the risk properties of asset categories at different investment horizons. Campbell and Viceira (2002) have clearly demonstrated the importance of time-varying risks for long-term investors. For instance, T-bills and other money market instruments are relatively safe for short-term investors, but not for long-term investors due to reinvestment risk of rolling T-bills at uncertain future rates. Long-term nominal bonds do not hedge inflation risk, but share the same attractive features as inflation-indexed bonds when inflation risk is low. Long-term inflation-indexed bonds are the risk free asset for long-term investors. Furthermore, a growing body of empirical research has documented predictability of asset returns. Excess stock returns appear related to valuation ratios like the dividend yield and price-earnings ratio, and also inflation and interest rates (see Campbell and Shiller (1987), Campbell (1987), Brandt and Santa-Clara (2006)). Similarly, the term spread is a well-known predictor of excess 
bond returns (Dai and Singleton (2002)). Fama and French (1989) link such macro economic variables to the business cycle. They can be interpreted as risk premia which are low in expansions and high in contraction periods. The persistency of for instance the dividend yield and the term spread is in line with the slow adjustment of these variables along the business cycle. As an insightful exploratory tool, Campbell and Viceira (2005) introduce the term structure of risk for stocks, bonds and T-bills. This term structure demonstrates the implications of time variation of various assets for their risks at different investment horizons. Mean reversion in stock and bond returns creates positive intertemporal hedging demands for these assets.

This thesis contributes to this literature by estimating and exploring the intertemporal covariance structure of an augmented asset universe and liabilities. This is important because liabilities are a predetermined component in the portfolio of many institutional investors, and the investment choices for investors have grown rapidly in the last years. Besides time and risk diversification, we focus on two relevant risk factors of pension liabilities: inflation hedge and real interest rate hedge features of assets at various investment horizons. Since the asset menu of most pension funds contains alternative asset classes, we extend the literature by specifically focusing on the risk properties of credits, commodities, hedge funds and listed real estate. We examine which alternatives have volatilities, risk diversification properties, inflation hedge and real interest rate hedge qualities that are markedly different from those of stocks and bonds. In addition, we investigate the robustness of the term structures of risk to parameter uncertainty in the estimation process using a bayesian framework. We also examine the impact on the term structures of prior information about the future level of asset returns, interest rates, inflation and macro economic variables. We show that imposing such prior information about the future distribution of the state variables can change the term structures of risk. This is particularly the case for long investment horizons due to the dominant role of mean uncertainty at long horizons.

The second theme is optimal portfolio choice. How much should an investor allocate to stocks, bonds, T-bills and alternatives? Since a number of years, there is a revived interest in asset allocation (Binsbergen and Brandt (2007), Campbel and Viceira (2002), Campbell, Chan and Viceira (2003)). The optimal mean-variance portfolio choice has two components that correspond to two possible motives. The speculative component is proportional to the Sharpe ratio and thus depends on the return expectations of the assets. The hedge component corresponds to risk management and aims at minimizing total portfolio volatility. Merton $(1969,1971)$ and Samuelson (1971) already showed that under changing investment opportunities optimal 
portfolio choices for long-term investors differ from those of short-term investors. In that case risk properties are horizon dependent and long-term investors can not only benefit from risk diversification between assets, but also from time diversification within an asset class. One of our contributions to this literature is that we find differences in strategic asset allocations for asset-only and asset-liability investors due to differences in the hedge component. The best liability hedging portfolio corresponds to minimizing the mismatch risk between returns on assets and liabilities instead of the stand-alone risk of the asset mix. We analytically decompose the economic loss for an asset-liability investor of suboptimal portfolio choice into missed return enhancement, liability hedge potential and stand-alone risk of the asset mix. We also compare horizon effects in the strategic asset allocation decision for the asset-liability and the asset-only investors.

Furthermore, it is well-documented that the speculative part of mean-variance portfolio choice is extremely sensitive to small changes in the expected return assumptions (see Kan and Zhou (2006) and DeMiguel, Garlappi and Uppal (2006)). To control erratic portfolio choices Pastor and Stambaugh (2000), Black and Litterman (1992) and Jorion (1986) have suggested priors that shrink portfolio weights to an asset pricing model. We contribute to this literature by developing a bayesian framework that shrinks the mean of the future distribution towards prior beliefs, and at the same time incorporates time-varying risk opportunities. Just as Brennan (1998), Barberis (2000) and Wachter and Warusawitharana (2007) the modeling framework also accounts for parameter uncertainty. In addition, we derive a robust portfolio choice which minimizes the expected utility loss when multiple experts have different prior beliefs about the expected returns, interest rates and macro economic variables.

The third theme is long-term investing with short-term solvency constraints. This has become an important topic in the last years as solvency constraints and minimum funding requirements have an eminent role in updated regulatory frameworks. Pension funds now explicitly face the challenge of balancing between short-term solvency risk, inflation compensation, and long-term continuity and sustainability. As a consequence, the investment industry explores dynamic investment strategies that are oriented at mitigating short-term solvency risk. Obviously, the menu of dynamic investment strategies is large, and a lot of the popular liability driven investment advices are related to the literature on portfolio insurance (Leland (1980) and Brennan and Solanki (1981)). Many applications like constant proportion portfolio insurance (Black and Perold (1992) and Black and Jones (1988)) and option based portfolio insurance (Perold and Sharpe (1988)) are discussed in the literature, but the basic 
idea is that a proportion of the difference between wealth and a prespecified floor is invested in risky assets. The remainder is invested in the risk free asset, or an asset that closely tracks the liabilities.

In this thesis we explore three different dynamic strategies that are representative for a variety of dynamic asset allocation strategies implemented in the pension industry. We investigate the attractiveness of such popular investment strategies for a realistic pension fund by a thorough ALM examination. The investment strategies under consideration include the immunization of the pension liabilities without inflation compensation, a dynamic mix conditional on solvency risk, and a constant mix with a dynamic interest rate swap-overlay. We demonstrate several important merits and pitfalls for pension funds in practice. We conclude that the attractiveness of dynamic asset allocation strategies for pension funds critically depends on a number of factors such as the return requirements for the risky assets, the downside risk attitude of the investor and the market environment.

Value-based ALM is the second area that is discussed in this thesis. The request for transparency and insights into the embedded value transfers between the various stakeholders of a pension plan has a prominent role in the current pension revolution. Understanding the relationships between the different groups of beneficiaries is critically important in pension reforms. We argue that the identification and valuation of embedded options in the pension deal can provide insights into the hidden value transfers between stakeholders. These embedded options emerge from conditionalities in an explicit and well-defined pension contract. The claims of stakeholders on the enormous surpluses during the eighties and nineties are a good example. Beneficiaries were afforded bonus indexation, contribution holidays and early retirement. Another example is the increase of pensions by inflation. Some DB plans provide inflation compensation rules conditional on the financial position of the fund. Others accommodate bonus indexation in an adhoc manner.

Although such arrangements make the solvency position more robust towards financial downturns, risks are implicitly reallocated among stakeholders. Therefore conditionalities can be interpreted as financial options. In financial markets, the noarbitrage principle guarantees that the market-based compensation for risk taken is fair, such that risk-taking is compensated by an appropriate reward. Unlike option holders in the financial markets the participants in DB schemes are not necessarily compensated for such implicit risks. Participants are often not automatically compensated for additional downside or indexation risks due to a change of the pension deal. It is not hard to imagine that specific policy changes will harm some groups of beneficiaries and will be beneficial for others. Such embedded value transfers endan- 
ger the long-term sustainability of pension schemes whenever the risk bearing parties are not properly compensated. In the current ageing society younger participants demand more transparency in the implicit risks they are exposed to.

The contribution of this thesis is that we propose and apply value-based ALM, and in particular value-based generational accounting, as a relevant extension to the ALM literature (a few references in this large literature include Leibowitz (1987), Sharpe and Tint (1990), Boender (1997), Ziemba and Mulvey (1998), Hoevenaars, Molenaar, Steenkamp (2003), Zenios and Ziemba (2006), Martellini (2006), Bauer, Hoevenaars, Steenkamp (2006) and Boender, Dert, Heemskerk, Hoek (2007)). As a first step, we identify embedded options by rewriting the balance sheet. Sharpe (1976) already identified embedded options in DB pension plans, and Steenkamp (1998) applies contingent claims analysis to corporate pension plans. Recently, the pension fund revolution led to a revived interest in embedded options in pension contracts in Kortleve, Nijman and Ponds (2006) and Kocken (2006), and in insurance contracts in Schrager (2007). We define an indexation option, surplus and deficit options and also embedded generational options. Changes in the option values reveal value transfers between participants. In the second step, we develop a consistent valuation framework which at the same time captures time-varying risk opportunities for the long-term investment decisions. Our framework is based on a vector autoregression with an affine term structure of interest rates and a pricing kernel specification. It is related to Ang, Piazzesi and Wei (2006), Cochrane and Piazzesi (2005) and Ang, Bekaert and Wei (2007). As a consequence, the pricing of the embedded options is based on how risks are priced in the market. Similar to financial options, we apply option valuation techniques as a market consistent method to value the embedded options in the pension contract. We show how the value-based ALM concept adds an extra dimension to the traditional ALM output. As an application, we illustrate how the embedded options help in the exploration of dynamic asset allocation strategies. In another chapter, we focus on the intergenerational value transfers from several policy changes or pension reforms like a shift from a traditional DB to a hybrid pension system. We demonstrate that policy changes in collective pension schemes will inevitably lead to value transfers between generations.

\subsection{Outline}

This thesis is organized as follows. Chapter 2 studies the strategic asset allocation for an investor with risky liabilities which are subject to inflation and real interest rate risk and who invests in stocks, government bonds, corporate bonds, T-bills, 
listed real estate, commodities and hedge funds. Following the asset allocation literature (Barberis (2002), Campbell and Viceira (2002), Campbell, Chan and Viceira (2003), Brandt and Santa-Clara (2006)) we use a vector autoregressive (VAR) modeling framework. We extend the VAR such that it can handle many assets for which we have short time-series. Using the VAR for returns, liabilities and macro-economic state variables the chapter explores the intertemporal covariance structure of assets and liabilities. We find horizon effects in time diversification, risk diversification, inflation hedge and real interest rate qualities. The covariance structure gives insights into which alternatives add value for long-term investors as they have a term structure of risk that is different from that of stocks and bonds. Differences in strategic portfolios for asset-only and asset-liability investors are due to differences in the global minimum variance and liability hedge portfolio. We find that the benefits of long-term investing are larger when there are liabilities.

In chapter 3 we consider the strategic asset allocation of long-term investors who account for prior information about expected returns and parameter uncertainty in a bayesian framework. We use the vector autoregressive model of Campbell and Viceira (2002) in a bayesian framework where different investors have conflicting prior views on long-term expected returns. We distinguish two types of prior information: (i) direct views on the long-term mean of the equity and bond premium, and (ii) prior views on the long-term mean of macro-economic variables like the dividend yield and the nominal interest rate. Both priors have a pronounced effect on optimal portfolios. Even weak prior information on the unconditional mean of highly persistent time series like dividend yield and the nominal interest rate changes the estimated persistence of shocks and the predictability of excess returns. For longterm investors we find that a portfolio that is optimal given one prior, often entails large utility costs when evaluated under an alternative prior distribution. The optimal portfolio for an optimistic investor is very costly (sub-optimal) in the eyes of an investor with a more negative prior view. We define a robust portfolio as the portfolio of an investor with a prior that has minimal costs among all priors that we consider. Such a robust portfolio coincides with the optimal portfolio of a moderately optimistic investor. It contains a large proportion of equity, but far less than would be implied under both more optimistic as well as very diffuse priors.

Chapter 4 is devoted to dynamic investment strategies for DB-like pension plans which are driven by the fair value of the liabilities in a realistic integral ALM framework. We consider three different dynamic strategies which are popular in the pension industry these days. The investment strategies include the immunization of pension liabilities without inflation compensation, dynamic asset allocation conditional on solvency risk, and a dynamic swap-overlay strategy mitigating interest 
rate risk. We compare these dynamic strategies to a more traditional investment strategy based on calendar rebalancing to a fixed asset mix. For the evaluation we focus on the financial solvency position and the inflation-linked ambition. Besides asset-liability and asset-only risks, we also value implicit claims on the excess and indexation agreements in the pension deal as embedded options. Our modeling framework is again based on a VAR, but now we follow Ang, Piazzessi and Wei (2006), Cochrane and Piazzesi (2005), and Ang, Bekaert and Wei (2007) and use the pricing kernel to derive the term structure of nominal interest rates. We derive timevarying risk opportunities for long-term investing, and accordingly use the scenarios for the construction of a term structure of interest rates. Liability driven portfolio insurance strategies are not necessarily in line with the inflation-linked ambition of DB pension plans. Dynamic asset allocation strategies based on short-term solvency risks should take care of the solvency-trap. The success of these portfolio insurance strategies critically depends upon the return potential of the risky component.

Chapter 5 applies contingent claim analysis to value embedded options in pension contracts for real-life collective pension plans with intergenerational risk sharing and offering DB-like benefits. We rewrite the balance sheet of such a pension fund as an aggregate of embedded generational options. This implies that a pension fund is a zero-sum game in value terms, so any policy change inevitably leads to value transfers between generations. We explore intergenerational value transfers that may arise from a plan redesign or from changes in funding policy and risk sharing rules. We extend the stochastic framework of chapter four by deriving a real term structure of interest rates. Again the modeling framework consistently accounts for time-varying investment opportunities, and at the same time can be used for valuing the embedded generational options. Changes in the values of the generational options enable us to evaluate the impact of policy modifications in the pension contract with respect to intergenerational transfers and redistribution. We find that a switch to a less risky asset mix is beneficial to elderly members at the expense of younger members who lose value. A reallocation of risk bearing from a plan with flexible contributions and fixed benefits to a plan with fixed contributions and flexible benefits leads to value redistribution from older plan members to younger ones.

Chapter 6 summarizes, concludes and gives directions for future research. It also gives ten recommendations for long-term investors, and we discuss the practical application of the investment insights of this thesis. 


\section{Chapter 2}

\section{Strategic asset allocation with liabilities: beyond stocks and bonds ${ }^{1}$}

\subsection{Introduction}

In making their strategic portfolio decisions, pension funds are restricted by their liabilities. At the same time pension funds and other institutional investors can choose from a large menu of alternative asset classes that goes beyond the traditional $\mathrm{T}$ bills, bonds and stocks. In this chapter we extend the existing models for strategic asset allocation to an asset and liability portfolio framework and expand the investment universe to include assets that are nowadays part of pension fund investment portfolios. This chapter studies the strategic asset allocation for an investor with risky liabilities that are subject to inflation and interest rate risk, who invests in stocks, government bonds, corporate bonds, T-bills, listed real estate, commodities and hedge funds.

Liabilities are a predetermined component in the institutional investor's portfolio with a return that is subject to real interest rate risk and inflation risk. The optimal portfolio for an institutional investor may therefore be different from the portfolio of an individual investor, since assets that hedge against long-term liabilities risk are valuable for an institutional investor. The hedge demand for alternative asset classes

\footnotetext{
1 This chapter is based on Hoevenaars, R.P.M.M., R.D.J. Molenaar, P.C. Schotman, and T.B.M. Steenkamp (2007), Strategic Asset Allocation with Liabilities: Beyond Stocks and Bonds, forthcoming Journal of Economic Dynamics and Control.
} 
like credits, commodities, hedge funds and real estate will depend on the covariance between assets and liabilities at different horizons.

Our main contributions are the estimation and exploration of the rich intertemporal covariance structure of assets and liabilities. Our interest is in three questions: (i) What do the time series properties of returns on assets and liabilities imply for the covariances at different investment horizons? (ii) Do the alternative asset classes add value for long-term investors? (iii) What do these covariances imply for the difference between the strategic portfolio of asset-only and asset-liability investors? We examine time and risk diversification properties and also the inflation hedge and real interest rate hedge qualities of the different assets. We investigate how the investment horizon influences the importance of the liabilities, and in particular whether the benefits from long-term investing are higher when there are liabilities.

To answer the first and second questions, we derive the covariance structure of assets and liabilities by constructing a discrete-time vector-autoregressive (VAR) model for asset returns, liabilities and other state variables. We look at the large dimension of the model and the problem of handling asset classes for which we have a short time series of returns. Both problems are addressed using the approach suggested by Stambaugh (1997). The "term structure of risk", introduced by Campbell and Viceira (2005), is a convenient tool for demonstrating the implications of asset price dynamics for investors at different investment horizons. This term structure shows the evolution of the annualized covariance matrix of assets as a function of the investment horizon. It can be computed using the estimated VAR coefficients.

We find that the covariance structure exhibits horizon effects regarding the inflation hedge and interest hedge qualities of the various assets. For example, stocks are a better inflation hedge in the long run than in the short run. In particular, the covariance structures reveal which alternative asset classes have a term structure of risk that is markedly different from that of stocks and bonds. Commodities help in hedging inflation risk, as they move closely with inflation in the short and long run. Since in addition commodities have little correlation with stocks and bonds, they have the best risk diversifying properties among the assets in our universe. Hedge funds have good inflation hedge qualities in the long run, but a high exposure to stocks and bonds. Term structure properties of listed real estate are, however, already captured by traditional asset classes such as stocks and bonds. The term structures of credits mimic those of bonds. Inflation hedge qualities of both credits and bonds are good in the long run, but poor in the short run. Both asset classes also have good real interest rate hedge qualities. In summary, alternative asset classes are important for a long-term investor with liabilities - more so than for an asset-only investor. 
For the third question, we consider the portfolio problem of an investor with a long-term horizon whose preferences are defined on the funding ratio. We derive the strategic hedging demands of the investor using the log-linear approximations of Campbell and Viceira $(2002,2005)$. Empirically, the main difference between the asset-only and asset-liability perspective is the attractiveness of short-term T-bills. Asset-only investors have strong demand for short-term instruments due to their low risk. Asset-liability investors shun T-bills due to the duration mismatch with the liabilities. T-bills do not provide a hedge against the long real interest rate risk in the liabilities. Nevertheless T-bills remain a good risk diversifier in a portfolio of stocks and bonds and are a good inflation hedge. We also find that the horizon effects are stronger for the asset-liability investor than for the asset-only investor. Therefore the benefits from long-term investing are greater when there are liabilities.

This chapter contributes to three strands of the literature: strategic asset allocation, asset liability management, and the behavior of alternative asset classes. In the literature on strategic asset allocation many studies have shown long-term decisions differ markedly from short-term portfolio rules if the investment opportunity set varies over time and the state variables that predict returns have strong autocorrelations. Brennan and Xia (2002), Detemple, Garcia and Rindisbacher (2003), Lioui and Poncet (2001), Bajeux-Besnainou, Jordan and Portait (2003), Barberis (2000), Wachter (2002), Campbell, Chacko, Rodriquez and Viceira (2004), Campbell, Chan and Viceira (2003), Guidolin and Timmermann (2007) are a few examples of studies that consider the long-term investor problem in different settings using variations in the preferences and return dynamics. These applications consider the asset-only investor and an asset menu consisting of T-bills, bonds and stocks. Similarly, Campbell and Viceira (2005) determine the term structure of risk in an assetonly context. This chapter explores the impact of time-varying expected returns of the alternative assets. Furthermore we investigate what the time-varying investment opportunities imply for the difference between the strategic portfolio of asset-only and asset-liability investors.

Until recently, almost all regulatory frameworks and accounting standards did not require fair valuation of pension liabilities. As a consequence, strategic asset allocation decisions were commonly considered in an asset-only context. The recent shift towards fair valuation of pension liabilities has led to a revived interest in ways to deal with interest and inflation risk in an optimal portfolio choice.

In an asset-liability model Leibowitz (1987) and Sharpe and Tint (1990) introduce a single-period surplus optimization framework when there are pension liabilities. In a long-horizon model Sundaresan and Zapatero (1997) solve the asset allocation of a pension plan and relate it to the marginal productivity of workers in the firm. They 
consider constant investment opportunities in a risky and riskless asset. Closest to this chapter is Binsbergen and Brandt (2006) who allow for time-varying investment opportunities in stocks, bonds and T-bills in a stylized asset liability management problem. They explicitly model the tradeoff between the long-term objective of maximizing the funding ratio and satisfying short-term risk constraints. This chapter differs in two ways. First, our emphasis is on the alternative asset classes. Second, our liabilities are like a real bond, whereas Binsbergen and Brandt (2006) treat the liabilities as a nominal bond.

In the literature on portfolio choice problems the portfolio composition is restricted to (index-linked) bonds, equities and cash. Other studies analyze the relation between investment horizon and risk and return for specific assets. For example Gorton and Rouwenhorst (2006) produce stylized facts about commodity futures. Froot (1995) argues listed real estate does not add much value in an already well-diversified portfolio. Fugazza, Guidolin and Nicodano (2007) find a considerable role for European listed real estate in a strategic portfolio with stocks, bonds and cash. Many authors focus on the heterogeneity of hedge fund performance, risk characteristics and biases (Fung and Hsieh (1997), Ackermann, McEnally and Ravenscraft (1999), Agarwal and Naik (2000), Fung and Hsieh (2000)). Literature on corporate bonds examines and explains credit spreads (Elton, Gruber, Agrawal and Mann (2001) and De Jong and Driessen (2005)). In this chapter we focus on the added value of these alternative asset classes in a portfolio with stocks, bonds and T-bills.

The structure of the chapter is as follows. Section 2.2 defines the portfolio choice problem. Section 2.3 describes the return dynamics and presents the estimation method and results of the VAR. Section 2.4 explores the covariance structure of the assets, liabilities and inflation at different horizons. Section 2.5 examines the implications of the covariances for the difference between the strategic portfolio of asset-only and asset-liability investors. This section also investigates the role of alternative asset classes in the strategic asset allocation. Section 2.6 gives the conclusions.

\subsection{Portfolio choice}

The asset allocation of an institutional investor is largely driven by long-run liabilities. A defined-benefit pension fund promises to pay benefits related to some function of lifetime earnings of participants. Liabilities depend on past and expected future earnings of participants, the term structure of interest rates, demographics and mortality rates. Markets are incomplete in the sense that the available asset classes can not fully hedge the liabilities. The main source of the incompleteness 
is the inflation dependence of the liabilities. ${ }^{2}$ The pension fund invests contributions by participants and the plan sponsor. In order to meet the liabilities in the long-run, the fund needs to take risk and attempts to earn a risk premium. We extend the usual asset menu of the traditional categories of bills, bonds and stocks to include the alternative assets classes (listed) real estate, hedge funds, commodities and corporate bonds.

Following Leibowitz, Kogelman and Bader (1994) we approach asset liability management from a funding ratio return perspective. The funding ratio $(F)$ is defined as the ratio of assets $(A)$ to liabilities $(L)$. The funding ratio log-return $r_{F}$ is then defined as the return of the assets minus the return on the liabilities,

$$
r_{F, t}=r_{A, t}-r_{L, t},
$$

where $r_{A, t}$ is the return of the asset portfolio and $r_{L, t}$ the return on the liabilities. All returns are defined in real terms, in excess of realized inflation $\pi_{t} \cdot{ }^{3}$ Logarithmic returns for asset class $i$ are denoted by $r_{i t}$ and excess returns are defined relative to the real return on T-bills $\left(r_{t b, t}\right)$ as $x_{i t}=r_{i t}-r_{t b, t}$. The logarithmic excess return on the liabilities are denoted $x_{L, t}=r_{L, t}-r_{t b, t}$. All excess returns are collected in the vector,

$$
x_{t}=\left(\begin{array}{c}
x_{A, t} \\
x_{L, t}
\end{array}\right) .
$$

In the next section we model the predictable component of the excess returns in detail. To evaluate the mean and variance of the $\tau$-period returns we define the annualized expected returns

$$
\mu_{t}^{(\tau)}=\frac{1}{\tau} \mathrm{E}_{t}\left[x_{t+\tau}^{(\tau)}\right]=\left(\begin{array}{c}
\mu_{A, t}^{(\tau)} \\
\mu_{L, t}^{(\tau)}
\end{array}\right),
$$

and the annualized covariance matrix

$$
\Sigma^{(\tau)}=\frac{1}{\tau} \mathrm{V}_{t}\left[x_{t+\tau}^{(\tau)}\right]=\left(\begin{array}{cc}
\Sigma_{A A}^{(\tau)} & \sigma_{A L}^{(\tau)} \\
\sigma_{A L}^{(\tau)^{\prime}} & \sigma_{L}^{(\tau) 2}
\end{array}\right)
$$

where the notation $x_{t+\tau}^{(\tau)}$ denotes the cumulative excess return $\tau$ periods. This relation between $\tau$ and $\Sigma^{(\tau)}$ is the term structure of risk introduced by Campbell and Viceira (2005), here extended to include the liabilities and alternative asset classes.

\footnotetext{
2 The best hedge against the inflation risk would be index-linked bonds. Since the market for inflation indexed bonds is small relative to the size of the pension liabilities, we exclude them from the analysis. So implicitly we assume an incomplete market with respect to inflation, which could be realistic in the case of pension liabilities.

${ }^{3}$ For the definition of the funding ratio return it does not matter whether the returns $r_{A}$ and $r_{L}$ are nominal or real. We use real returns for consistency in notation throughout the chapter.
} 
Estimating $\Sigma^{(\tau)}$ will be the main purpose of the econometric time series analysis of the returns.

One of the main results of the strategic asset allocation literature is the mean reversion of equity and long-term bond returns, implying that these assets have lower risk over long horizons. For this reason these asset classes become more important than short-term bills in the portfolio of a long-term investor. Our interest in this chapter is in the term structure of risk of the alternative assets and in the covariance $\sigma_{A L}^{(\tau)}$ of assets and liabilities. The latter determines the hedge potential of different asset classes at different horizons.

The term structure of risk provides many insights in the relative importance of different assets for an institutional investor. To obtain portfolio weights, we need a few more steps. The investor chooses a portfolio $\alpha_{t}$ of the risky assets and invests the remainder fraction of wealth $1-\iota^{\prime} \alpha_{t}$ in the T-bills. Campbell and Viceira (2002, 2005) provide the following log-linear approximation to the portfolio return,

$$
r_{A, t+1}=r_{t b, t+1}+\alpha_{t}^{\prime}\left(x_{A, t+1}+\frac{1}{2} \sigma_{A}^{2}\right)-\frac{1}{2} \alpha_{t}^{\prime} \Sigma_{A A} \alpha_{t},
$$

where $\sigma_{A}^{2}$ is the vector with the diagonal elements of $\Sigma_{A A}$.

As Van Binsbergen and Brandt (2006) we assume CRRA preferences on the funding ratio at some future date $T=t+\tau$,

$$
V_{t}^{(\tau)}=\max _{\left\{\alpha_{t}, \ldots, \alpha_{T-1}\right\}} \mathrm{E}_{t}\left[\frac{F_{T}^{1-\gamma}}{1-\gamma}\right]
$$

Van Binsbergen and Brandt (2006) proceed by numerically solving the dynamic programming problem (2.5). Applying the dynamic programming approach is, however, not without problems in our setting with a large number of asset classes. This is already a problem for single period problems, but it becomes much worse in longhorizon portfolio choice.

It has been widely documented that portfolio choice models produce erratic outcomes the larger the number of assets included. With more than a few assets optimized portfolios overestimate the investment opportunities and portfolio weights become very sensitive to minor estimation errors in expected returns. ${ }^{4}$ In our case we have seven asset classes plus the liabilities portfolio. With this expanded asset space the danger of error-maximization is large. ${ }^{5}$

\footnotetext{
${ }^{4}$ See Kan and Zhou (2006) for recent analytical results. DeMiguel, Garlappi and Uppal (2006) empirically establish that optimized portfolios do not outperform a naive equally weighted portfolio out-of-sample. Litterman $(2003$, ch 9, 10) illustrates the problem in an ALM setting and proposes to replace the estimated expected returns from a return model based on historical data by more plausible expected returns that do not imply extreme portfolio weights.

5 The phrase 'error maximization' has been coined by Michaud (1989) to describe the extreme sensitivity of portfolio weights to estimation errors in expected returns.
} 
Many suggestions have been made to solve the erratic portfolio choice. Most common are restrictions on portfolio weights and informative Bayesian priors. In the cross-sectional portfolio choice literature, Black and Litterman (1992), Pastor and Stambaugh (2000), Jorion (1986) and many others have suggested priors that shrink the portfolio weights towards an asset pricing model, the market portfolio or the global minimum variance portfolio. Likewise, Wachter and Warusawitharana (2006), for example, explore Bayesian priors on the predictability of equity returns. They conclude that informative priors improve out-of-sample performance of myopic market timing.

We also stabilise the portfolio weights by assuming that the investor plans to hold constant proportions of his wealth in each of the asset classes for $\tau$ periods. Fixed portfolio weights also appear more closely connected to the industry practice. Pension funds are not such extreme market timers and commonly plan their strategic portfolio on a constant mix basis. The typical strategic investment plan of an institutional investor is only reviewed once every three to five years. After performing an ALM study the fund defines a strategic mix over asset classes, while allowing various tactical bets depending on short term market views.

One way of implementing this assumption is to set the expected returns $\mu_{A, t}^{(\tau)}$ and $\mu_{L, t}^{(\tau)}$ constant over the investment horizon. Under this assumption maximization of (2.5) implies mean-variance portfolios as in Campbell and Viceira (2005). ${ }^{6}$ Substituting (2.4) in (2.1),

$$
r_{F, t+1}=\alpha_{t}^{\prime}\left(x_{A, t+1}+\frac{1}{2} \sigma_{A}^{2}\right)-x_{L, t+1}-\frac{1}{2} \alpha_{t}^{\prime} \Sigma_{A A} \alpha_{t}
$$

One-period portfolio returns are aggregated assuming that the investor rebalances to the initial weights at the end of each period. Starting from the one-period log return (2.6), aggregation to the $\tau$-period return with fixed, horizons specific, portfolio weight $\alpha_{t}^{(\tau)}$ gives

$$
\begin{aligned}
r_{F, t+\tau}^{(\tau)} & =\sum_{j=1}^{\tau} r_{F, t+j} \\
& =\alpha_{t}^{(\tau)^{\prime}}\left(x_{A, t+\tau}^{(\tau)}+\frac{\tau}{2} \sigma_{A}^{2}\right)-\frac{\tau}{2} \alpha_{t}^{(\tau)^{\prime}} \Sigma_{A A} \alpha_{t}^{(\tau)}-x_{L, t+\tau}^{(\tau)} .
\end{aligned}
$$

\footnotetext{
6 With constant expected returns the dynamic programming solution of (2.5) is still different from the static mean-variance solution. Under the maintained assumption that $\Sigma^{(\tau)}$ depends on the investment horizon, the investor still wants to adjust her portfolio as the horizon shrinks. In presenting the static portfolio weights we ignore this element, which is tantamount to assuming that the horizon $\tau$ remains constant and the terminal date $T$ shifts forward every period. This also seems more in line with an actual pension fund which does not have a fixed terminal date $\tau$.
} 
Evaluating the mean and variance of the $\tau$-period returns we find

$$
\begin{aligned}
& \mathrm{E}_{t}\left[r_{F, t+\tau}^{(\tau)}\right]=\tau\left(\alpha_{t}^{(\tau)^{\prime}}\left(\mu_{A, t}^{(\tau)}+\frac{1}{2} \sigma_{A}^{2}\right)-\frac{1}{2} \alpha_{t}^{(\tau)^{\prime}} \Sigma_{A A} \alpha_{t}^{(\tau)}-\mu_{L, t}^{(\tau)}\right) \\
& \mathrm{V}_{t}\left[r_{F, t+\tau}^{(\tau)}\right]=\tau\left(\sigma_{L}^{(\tau) 2}-2 \alpha_{t}^{(\tau)^{\prime}} \sigma_{A L}^{(\tau)}+\alpha_{t}^{(\tau)^{\prime}} \Sigma_{A A}^{(\tau)} \alpha_{t}^{(\tau)}\right) .
\end{aligned}
$$

We refer to the volatility of the funding ratio return as the mismatch risk. Assuming normality of the excess returns, the optimization problem (2.5) reduces to

$$
\max _{\alpha_{t}^{(\tau)}} \mathrm{E}_{t}\left[r_{F, t+\tau}^{(\tau)}\right]+\frac{1}{2}(1-\gamma) \mathrm{V}_{t}\left[r_{F, t+\tau}^{(\tau)}\right]
$$

implying that the asset-liability investor follows a mean-variance optimal investment strategy. Differentiating (2.10) we obtain the optimal portfolio as

$$
\alpha_{t}^{(\tau)}=\frac{1}{\gamma}\left(\left(1-\frac{1}{\gamma}\right) \Sigma_{A A}^{(\tau)}+\frac{1}{\gamma} \Sigma_{A A}\right)^{-1}\left(\mu_{t}^{(\tau)}+\frac{1}{2} \sigma_{A}^{2}-(1-\gamma) \sigma_{A L}^{(\tau)}\right)
$$

The portfolio has two components: the speculative portfolio

$$
\alpha_{S, t}^{(\tau)}=\frac{1}{\gamma}\left(\left(1-\frac{1}{\gamma}\right) \Sigma_{A A}^{(\tau)}+\frac{1}{\gamma} \Sigma_{A A}\right)^{-1}\left(\mu_{A, t}^{(\tau)}+\frac{1}{2} \sigma_{A}^{2}\right)
$$

and the hedge demand

$$
\alpha_{H}^{(\tau)}=\left(1-\frac{1}{\gamma}\right)\left(\left(1-\frac{1}{\gamma}\right) \Sigma_{A A}^{(\tau)}+\frac{1}{\gamma} \Sigma_{A A}\right)^{-1} \sigma_{A L}^{(\tau)}
$$

Under the assumption that the strategic portfolio is held constant over the entire investment horizon, the hedging demands do not depend on time. They are horizon dependent through the term structure of covariances of asset and liability returns. For large $\gamma$ the only demand will be the hedge demand. Taking the limit as $\gamma \rightarrow \infty$, the hedging demand reduces to

$$
\alpha_{H}^{(\tau)}=\left(\Sigma_{A A}^{(\tau)}\right)^{-1} \sigma_{A L}^{(\tau)}
$$

which is the portfolio that minimizes the mismatch risk (2.9). The quantities $\alpha_{H}^{(\tau)}$, and its building blocks $\Sigma_{A A}^{(\tau)}$ and $\sigma_{A L}^{(\tau)}$ that will be our main focus in the remainder of the chapter.

We also consider the costs of suboptimal portfolios and whether these costs are associated with expected returns or the liability hedge potential. We use the certainty equivalent to evaluate the economic loss of deviating from the optimal strategic asset allocation. We define the economic loss of holding some sub-optimal portfolio $a$ by computing the percentage riskfree return the investor requires to be compensated for holding the sub-optimal portfolio instead of the optimal portfolio $\alpha^{(\tau)}$ in (2.11). It is 
computed as the difference between the mean-variance utility of the two portfolios. Let $\hat{q}_{t}^{(\tau)}$ be the optimal value of the mean-variance function $(2.10)$, and let $q_{t}^{(\tau)}$ be the mean-variance utility for the arbitrary portfolio $a$. Subtracting the two utility values and expressing the result in an annualized percentage gives

$$
\begin{aligned}
f_{t}^{(\tau)}= & \frac{1}{\tau}\left(\hat{q}_{t}^{(\tau)}-q_{t}^{(\tau)}\right) \\
= & \left(\alpha^{(\tau)}-a\right)^{\prime}\left(\mu_{t}^{(\tau)}+\frac{1}{2} \sigma_{A}^{2}\right)-(1-\gamma)\left(\alpha^{(\tau)}-a\right)^{\prime} \sigma_{A L}^{(\tau)}+ \\
& \quad+\frac{1}{2} \gamma\left(a^{\prime} \Sigma_{A A}^{(\tau)} a-\alpha^{\left.(\tau)^{\prime} \Sigma_{A A}^{(\tau)} \alpha^{(\tau)}\right)+\eta^{(\tau)}}\right.
\end{aligned}
$$

The first two components on the right hand side attribute the certainty equivalent to compensations for return enhancement and for the liability hedge potential. The first term in the last line is the difference in the long-run variance of the two portfolios. The final component

$$
\eta^{(\tau)}=\frac{1}{2}\left(a^{\prime}\left(\Sigma_{A A}-\Sigma_{A A}^{(\tau)}\right) a-\alpha^{(\tau)^{\prime}}\left(\Sigma_{A A}-\Sigma_{A A}^{(\tau)}\right) \alpha^{(\tau)}\right)
$$

is a small remainder term due to the differences in the Jensen inequality corrections in aggregating the asset returns over time. All components in (2.15) are horizon dependent. The relative weight of the three main components depends on the level of risk aversion. For highly risk averse investors the costs of poor matching and diversification will dominate and portfolios that deviate from the portfolio with minimum mismatch risk will be costly.

Contrary to most of the literature on long-term asset allocation, we consider an institutional investor with liabilities on the balance sheet. Instead, most studies take the asset-only perspective of an individual investor. For an asset-only investor the mean-variance optimization (2.10) is equivalent to a second order approximation of maximizing expected utility. Assuming constant relative risk aversion over final period wealth, the asset-only investor maximizes

$$
V_{t}^{(\tau)}=\max \mathrm{E}_{t}\left[\frac{W_{t+\tau}^{1-\gamma}}{1-\gamma}\right]
$$

From the formulation (2.16) and the definition of $r_{A, t+j}$ in (2.4) it follows that the optimal portfolio of the asset-only investor is given by

$$
\alpha_{A O}^{(\tau)}=\frac{1}{\gamma}\left(\left(1-\frac{1}{\gamma}\right) \Sigma_{A A}^{(\tau)}+\frac{1}{\gamma} \Sigma_{A A}\right)^{-1}\left(\mu_{t}^{(\tau)}+\frac{1}{2} \sigma_{A}^{2}+(1-\gamma) \sigma_{A r}^{(\tau)}\right)
$$

where $\sigma_{A r}^{(\tau)}$ is the vector of covariances between excess returns and the benchmark T-bill return over an horizon of $\tau$ periods. The speculative component of the assetliability investor is the same as for the asset-only investor. The difference is in the 
hedging component of the portfolio. The mean-variance asset-only portfolio differs from the asset-liability portfolio in (2.11) only by the term $\sigma_{A r}^{(\tau)}$ which for the assetliability investor equals $-\sigma_{A L}^{(\tau)}$. The best liability hedging portfolio correspond to minimizing the mismatch risk (2.14) instead of the stand-alone risk of the asset mix. The difference in sign between (2.17) and (2.11) is due to the short position in the liabilities instead of the long position in the T-bill. Liabilities are not an investable asset themselves. The asset-liability investor invests in the risky assets, but cannot invest in the risky benchmark.

\subsection{Return dynamics}

This section describes a vector autoregression for the return dynamics. The return dynamics extend Campbell and Viceira (2005) and Campbell, Chan and Viceira (2003) in two ways. First, we include more asset classes. Campbell, Chan and Viceira (2003) include real returns on stocks, bonds and bill. We augment this set with credits and alternatives (i.e. listed real estate, commodities and hedge funds). We also add the credit spread as an additional state variable driving expected returns. Second, we introduce risky liabilities to the VAR. These liabilities are compensated for price inflation during the holding period (they are comparable to real coupon bonds (e.g. Treasury Inflation Protected Securities (TIPS))). The return on risky liabilities follows the return of long-term (in our case 17 years constant maturity) real bonds. Below we will first describe the model, then the data, and finally estimation results.

\subsubsection{Model}

We describe the dynamics of assets and liabilities by a first-order VAR for quarterly data. Specifically, let

$$
z_{t}=\left(\begin{array}{c}
r_{t b, t} \\
s_{t} \\
x_{t}
\end{array}\right),
$$

where $r_{t b, t}$ and $x_{t}$ have been defined in section 2.2 and $s_{t}$ is a vector of other state variables that predict $r_{t b}$ and elements of $x_{t}$. The vector with state variables $s_{t}$ contains four predictive variables: the nominal 3 -months interest rate $\left(r_{n o m}\right)$, the dividend-price ratio $(d p)$, the term spread $(s p r)$ and the credit spread $(c s)$. Altogether the VAR contains $1+4+7=12$ variables.

For most time series, data are available quarterly for the period 1952:II to 2005:IV. The exceptions are many of the alternative asset classes, for which the 
historical data are available for a much shorter period. Because of the large dimension of the VAR, and due to the missing data for the early part of the sample, we cannot obtain reliable estimates with an unrestricted VAR. We deal with this problem in two ways: $(i)$ by imposing a number of restrictions and $(i i)$ by making optimal use of the data information for estimating the dynamics of the series with shorter histories. For this purpose the vector of excess returns is split in two parts,

$$
x_{t}=\left(\begin{array}{c}
x_{1, t} \\
x_{2, t}
\end{array}\right),
$$

where $x_{1}$ contains the quarterly excess returns on stocks $\left(x_{s}\right)$ and bonds $\left(x_{b}\right)$, and $x_{2}$ contains the excess returns on credits $\left(x_{c r}\right)$, commodities $\left(x_{c m}\right)$, hedge funds $\left(x_{h}\right)$, listed real estate $\left(x_{r e}\right)$, and the liabilities $\left(x_{L}\right)$. The variables in $x_{1}$ are the assets that are also included in the model of Campbell, Chan and Viceira (2003). The variables in $x_{2}$ are the additional asset classes.

The restrictions on the VAR concern the vector $x_{2}$. The additional assets are assumed to provide no dynamic feedback to the basic assets and state variables. For the subset of variables,

$$
y_{t}=\left(\begin{array}{c}
r_{t b, t} \\
s_{t} \\
x_{1, t}
\end{array}\right)
$$

we specify the subsystem unrestricted VAR

$$
y_{t+1}=a+B y_{t}+\epsilon_{t+1},
$$

where $\epsilon_{t+1}$ has mean zero and covariance matrix $\Sigma_{\epsilon \epsilon}$. For the variables in $x_{2}$ we use the model

$$
x_{2, t+1}=c+D_{0} y_{t+1}+D_{1} y_{t}+H x_{2, t}+\eta_{t+1},
$$

where $D_{0}$ and $D_{1}$ are unrestricted $(4 \times 8)$ matrices, and $H=\operatorname{diag}\left(h_{1}, \ldots, h_{4}\right)$ is a diagonal matrix. The diagonal form of $H$ implies that $x_{2 i, t}$ only affects the expected return of itself, but not of the other additional assets. The shocks $\eta_{t}$ have zero mean and a diagonal covariance matrix $\Omega$. Contemporaneous covariances are captured by $D_{0}$. Without loss of generality we can therefore set the covariance of $\eta_{t}$ and $\epsilon_{t}$ equal to zero.

Combining (2.18) and (2.19) the complete VAR can be written as

$$
z_{t+1}=\boldsymbol{\Phi}_{0}+\boldsymbol{\Phi}_{1} z_{t}+u_{t+1}
$$

where

$$
\mathbf{\Phi}_{0}=\left(\begin{array}{c}
a \\
c+D_{0} a
\end{array}\right), \quad \mathbf{\Phi}_{1}=\left(\begin{array}{cc}
B & \mathbf{0} \\
D_{1}+D_{0} B & H
\end{array}\right)
$$


and $u_{t}$ has covariance matrix

$$
\boldsymbol{\Sigma}=\left(\begin{array}{cc}
\Sigma_{\epsilon \epsilon} & \Sigma_{\epsilon \epsilon} D_{0}^{\prime} \\
D_{0} \Sigma_{\epsilon \epsilon} & \Omega+D_{0} \Sigma_{\epsilon \epsilon} D_{0}^{\prime}
\end{array}\right)
$$

The form of (2.19), with the contemporaneous $y_{t+1}$ among the regressors, facilitates efficient estimation of the covariances between shocks in $y_{t}$ and $x_{2 t}$ when the number of observations in $x_{2 t}$ is smaller than in $y_{t}$. The full sample can be used for estimation of the core VAR (2.18), while each of the elements in $x_{2}$ is estimated using the available observations of the returns for that time series. This approach is based on Stambaugh (1997) and makes optimal use of all information in both the long and short time series. Furthermore it ensures that the estimate of $\boldsymbol{\Sigma}$ is positive semi-definite. As in Campbell and Viceira (2005) we assume that the errors are homoskedastic.

The system (2.18) and (2.19) imposes restrictions on the VAR parameters $\boldsymbol{\Phi}_{1}$. These restrictions can be tested for the subsample where all data series are available.

Since some of the state variables are very persistent, they might well have a unit root. As in the models of Brennan, Schwartz and Lagnado (1997), Campbell and Viceira (2002) and Campbell, Chan and Viceira (2003) we do not adjust the estimates of the VAR for possible small sample biases related to near non-stationarity of some series (see, for example, Stambaugh (1999), Bekaert and Hodrick (2001) and Campbell and Yogo (2004)).

\subsubsection{Data}

Our empirical analysis is based on quarterly US data. Most data series start in 1952:II; all series end in 2005:IV. However, data for commodities, hedge funds and listed real estate are only available for a shorter history. Commodities start in 1970:I, hedge funds start in 1990:II, listed real estate starts in 1972:II.

The 90-days T-bill, the 20-years constant maturity yield and the credit yield (i.e. Moody's Seasoned Baa Corporate Bond Yield) are from the FRED website. ${ }^{7}$ In order to generate the yield and credit spread we obtain the zero yield data up to 1996:III from Campbell and Viceira (2002, ch3). We have extended the series using data from the federal reserve. ${ }^{8}$ For inflation we use the seasonally adjusted consumer price index for all urban consumers and all items also from the FRED website. Data on stock returns and the dividend-price ratio are based on the S\&P Composite and are from the "Irrational Exuberance" data of Shiller. ${ }^{9}$ Credit returns are based on

\footnotetext{
7 http://research.stlouisfed.org/fred $2 /$

8 http://www.federalreserve.gov/pubs/feds/2006/

9 http://aida.econ.yale.edu/ shiller/data.htm
} 
the Salomon Brothers long-term high-grade corporate bond index, and are obtained from Ibbotson (until 1994:IV) and Datastream. Hedge fund returns are based on the HFRI fund of funds conservative index return series. This equally-weighted net-offees return index is broadly diversified across different style sectors. Fung and Hsieh (1997) and Ackermann, McEnally, Ravenscraft (1999) demonstrate that these hedge fund styles each exhibit different risk and return properties. Rather than accounting for this heterogeneity in investment styles, we focus on an index which represents the whole industry because we address hedge funds as an asset class. In the same way, commodities are represented as an asset class by the GSCI index. It is a composite index of all world-production weighted commodity sector returns. This total return index represents an unleveraged, long-only investment in fully collateralized nearby commodity futures with full reinvestment. The NAREIT North America return index represents listed real estate returns. This indirect market capitalization index represents total return behavior of publicly traded property companies on NYSE, AMEX, NASDAQ and Toronto stock exchange. Total returns include both price and dividend returns.

All return series are logarithmic. We construct the gross bond return series $r_{n, t+1}$ from 20 year constant maturity yields on US bonds using the approach described by Campbell and Viciera (2002), using

$$
r_{n, t+1}=\frac{1}{4} y_{n-1, t+1}-D_{n, t}\left(y_{n-1, t+1}-y_{n, t}\right)
$$

where $n$ is the bond maturity, $y_{n, t}=\ln \left(1+Y_{n, t}\right)$ is the yield on the $n$-period maturity bond at time $t$ and $D_{n, t}$ is the duration which is approximated by

$$
D_{n, t}=\frac{1-\left(1+Y_{n, t}\right)^{-n}}{1-\left(1+Y_{n, t}\right)^{-1}}
$$

We approximate $y_{n-1, t+1}$ by $y_{n, t+1}$. Excess returns are constructed in excess of the logarithm of the 90-day T-bill return, $x_{b, t}=r_{n, t}-r_{t b, t}$.

The liability return series is also based on the loglinear transformation (2.21),

$$
r_{L, t+1}=\frac{1}{4} r r_{n-1, t+1}-D_{n, t}\left(r r_{n-1, t+1}-r r_{n, t}\right)+\pi_{t+1}
$$

We assume that the pension fund unconditionally pays full indexation, therefore the liabilities should be discounted by the real interest rate. The $n$-period real yield, $r r_{n, t+1}$, is the 10- year US real interest rate. ${ }^{10}$ The liabilities are indexed by the price inflation $\pi_{t+1}$ of the corresponding quarter; the duration is assumed to be 17 years $\left(D_{n, t}=17\right)$, which is the average duration of pension fund liabilities.

\footnotetext{
10 The series used is based on proprietary Bridgewater's simulated data.
} 
To describe the liabilities of a pension fund as a constant maturity (index-linked) bond we need to assume that the fund is in a stationary state. A sufficient condition for this to be true is that the distribution of the age cohorts and the built-up pension rights per cohort are constant through time. Furthermore, we assume that the inflow from (cost-effective) contributions equals the net present value of the new liabilities and that it equals the current payments. We ignore taxation issues as described in Black (1980) and Tepper (1981).

The first two terms (i.e. $\left.\frac{1}{4} r r_{n-1, t+1}-D_{n, t}\left(r r_{n-1, t+1}-r r_{n, t}\right)\right)$ in $(2.22)$ reflect the real interest risk, whereas the third term reflects the inflation risk (i.e. $\pi_{t+1}$ ). By definition TIPS would be the risk-free asset (although the returns of TIPS are based on the lagged inflation, $\pi_{t}$ ). However, we have not included TIPS in the analysis due to their brief existence and because the size of the market is not large enough to allow investors to hedge all their liabilities with them.

Pension liabilities are also exposed to other risk factors which we do not account for in this chapter. These include not only actuarial risks such as longevity risk and ageing, but also changes in the characteristics of the participants and demographics. In particular there is a revived interest in longevity risk. Blake, Cairns and Dowd (2006) address longevity risk and discuss ways to manage this risk exposure. Expected pensions have to paid out for a longer period when participants who start receiving their pensions live longer. This will directly affect the funding status of the fund. Macro longevity risk refers to changes in survival probabilities due for instance to improvements in habits, health care, or external factors. Macro longevity risk might be hedged in the developing financial market of longevity bonds and swaps. In this chapter we assume inflation and interest rate risk are the only relevant risk factors for the pension fund under consideration. In particular the contribution rate adapts to changes in mortality rates, because we assume the inflow from contributions equals the net present value of new liabilities. For other risks we assume that they are either hedged away in the market or not material.

Return series of illiquid assets are often characterized by their high returns, low volatility and low correlation with other series. Hedge funds are a good example in this context. Hedge funds often hold illiquid or over-the-counter investment products for which no publicly available trade prices exist. As a consequence fund managers have the possibility to use the last available trade price as a proxy for the current price (stale pricing). Hedge fund managers can also intentionally smooth profits and losses in a particular month by spreading them over several months, hereby reducing the volatilities and correlations (managed pricing). Underestimation of volatility can make a return class more attractive in asset allocation than it actually is in reality. Geltner (1991, 1993) discusses methodologies to unsmooth return series to make 
them comparable with the more liquid assets. He proposes the autocorrelation in returns as a measure of illiquidity. Geltner (1991, 1993) suggests constructing unsmoothed return series as

$$
r_{t}^{*}=\frac{r_{t}-\rho r_{t-1}}{1-\rho}
$$

where $r_{t}$ is the original smoothed return series, $\rho$ is the first order autocorrelation coefficient and $r_{t}^{*}$ is the unsmoothed return series which will be used in the VAR ( $\rho=0.28$ for HFR). For the long-term analysis the unsmoothing is not necessary as the VAR takes the autocorrelation into account. On the other hand, if we were to include the smoothed series, this would seriously underestimate the short-term volatility. Unsmoothing produces more representative short-term volatilities. Note that the unsmoothed series have the same mean as the smoothed series.

Biases can arise when using a portfolio of hedge funds in a database. ${ }^{11}$ In order to correct particularly for backfill bias, we have corrected the returns of the hedge fund series by subtracting an annual $2.15 \%$ percent from the published returns. ${ }^{12}$ Such an adjustment only affects the average returns, but does not influence risk properties.

Apart from the return series, we include four other variables that drive longterm risks. The real T-bill return is defined as the difference between the nominal T-bill return and the price inflation. The log of the dividend-price ratio of the S\&P Composite is used. The yield spread is computed as the difference between the log 10 -year zeros yield and the log 90-day T-bill. In addition, the difference between the $\log$ BAA yield and the log 10-years zero is included as the credit spread.

These state variables are common in the literature. Campbell and Shiller (1988, 1991) are early references for the dividend-price ratio, the nominal short term interest rate and the yield spread as predictive variables for stock returns. Brandt and SantaClara (2006) use the dividend yield, term spread, credit spread and the nominal T-bill rate. Campbell, Chan and Viceira (2003) and Campbell and Viceira (2005) include the short-term nominal interest rate, yield spread and dividend-price ratio in the VAR. Cochrane and Piazzesi (2005) find that a linear combination of forward rates predicts bond returns. Furthermore, Campbell, Chan and Viceira (2003) find that shocks in the nominal short rate are strongly correlated with shocks in excess bond returns. In addition the yield spread is helpful in predicting future excess bond returns.

\footnotetext{
${ }^{11}$ Fung and Hsieh (2000) and Ackermann, McEnally and Ravenscraft (1999) provide an overview on survivorship, termination, self-selection, liquidation, backfill and multiperiod sampling biases.

12 We adjust the Sharpe ratio of hedge funds in the same way as Posthuma and Van der Sluis (2003) who show that the reported historical returns of hedge funds are on an annual basis too high.
} 
Furthermore, Fama and French (1989) link state variables including the dividend yield, credit spread and yield spread to the business cycle. They argue that the risk premia for investing in bonds and corporate bonds are high in contraction periods and low in expansion periods, and that these risk premia are related to the yield spread and credit spread respectively. The opposite applies to the dividend-price ratio, which is high in expansion periods and low in contraction periods. Since both the dividend yield and the credit spread adjust very slowly over time, they describe long run business cycles. The yield spread, on the other hand, is less persistent and describes shorter business cycles. Moreover, Cochrane (2005) shows that the explanatory power of the price-dividend ratio with regard to stock returns is substantial for longer horizon returns. He considers stocks returns on a 1-year to 5-year horizon.

Apart from the four state variables we include, many others have also been suggested. Lettau and Ludvigson (2001), for example, find that fluctuations in the consumption-wealth ratio are strong predictors of stock returns. Jurek and Viceira (2006) use the price earnings ratio, which has similar predictive effects as the dividend-price ratio. Poterba (2001) and Goyal (2004) investigate the relationship between population age structure and stock returns. ${ }^{13}$

Table 2.1 reports summary statistics from the data. Due to the different starting dates, the statistics must be interpreted with some care. Credits have a higher return than bonds. This is due to positive credit spreads and reflected in the higher Sharpe ratio (0.21 versus 0.15). Elton, Gruber, Agrawal and Mann (2001) explain credit spreads as being positive for three reasons: a compensation for expected default loss; a tax premium which should be paid on corporate bonds but not on government bonds; and a risk premium for systematic risk. De Jong and Driessen (2005) also identify a liquidity risk premium in credit spreads. The average return on commodities is higher than that on stocks, but the higher volatility $(18.94 \%$ vs. $14.39 \%$ ) results in a lower Sharpe ratio. Although listed real estate is often seen as equivalent to equity (see e.g. Froot (1995)) it has a lower return and higher volatility than stocks, which results in a lower Sharpe ratio of 0.29. Just like stocks, listed real estate returns have negative skewness.

\subsubsection{Estimation results}

Table 2.2 reports the parameter estimates of the subsystem VAR in (2.18) on the quarterly data 1952:II-2005:IV. Correlations and standard deviations of the innovations are given in Table 2.3. Quarterly standard deviations are on the diagonal.

\footnotetext{
13 The evidence on predictability is not uncontroversial. See Goyal and Welch (2003), Cochrane (2006) and Campbell and Thompson (2007) for opposing views on the issue.
} 
Table 2.1: Summary Statistics

\begin{tabular}{|c|c|c|c|c|c|c|c|c|}
\hline & Mean & Stdev & Sharpe & Min & Max & Skew & $X K$ & Start \\
\hline \multicolumn{9}{|l|}{ Excess returns } \\
\hline Stocks $\left(x_{s}\right)$ & 6.74 & 14.39 & 0.47 & -28.72 & 21.66 & -1.02 & 2.56 & 1952:II \\
\hline Bonds $\left(x_{b}\right)$ & 1.50 & 9.69 & 0.15 & -18.58 & 18.78 & 0.32 & 2.37 & 1952:II \\
\hline Credits $\left(x_{c r}\right)$ & 1.80 & 8.73 & 0.21 & -17.07 & 18.15 & 0.07 & 2.67 & 1952:II \\
\hline Commodities $\left(x_{c m}\right)$ & 7.52 & 18.94 & 0.40 & -23.86 & 42.03 & 0.29 & 1.79 & 1970:I \\
\hline Real Estate $\left(x_{r e}\right)$ & 5.54 & 16.86 & 0.33 & -30.58 & 28.98 & -0.37 & 1.75 & 1972:II \\
\hline Hedge Funds $\left(x_{h}\right)$ & 2.07 & 5.29 & 0.39 & -10.01 & 8.62 & -0.88 & 3.58 & 1990:II \\
\hline Liabilities $\left(x_{0}\right)$ & 2.82 & 6.82 & 0.41 & -9.41 & 13.52 & 0.17 & 1.30 & 1970:II \\
\hline \multicolumn{9}{|l|}{ State variables } \\
\hline Real rate $\left(r_{t b}\right)$ & 1.26 & 1.28 & & -1.64 & 2.37 & 0.10 & 1.14 & 1952:II \\
\hline Dividend-Price $(d p)$ & -3.46 & 0.40 & & -4.50 & -2.78 & -0.74 & 0.08 & 1952:II \\
\hline Nominal rate $\left(r_{\text {nom }}\right)$ & 5.01 & 1.36 & & 0.15 & 3.55 & 0.95 & 1.13 & 1952:II \\
\hline Term Spread (spr) & 1.24 & 0.59 & & -0.71 & 0.98 & -0.10 & 0.36 & 1952:II \\
\hline Credit Spread $(c s)$ & 1.55 & 0.32 & & 0.08 & 0.86 & 0.37 & -0.39 & 1952:II \\
\hline
\end{tabular}

The nominal interest rate, dividend-price ratio and credit spread have significant predictive power for excess stock returns. The negative correlation of shocks in the dividend-price ratio and credit spread with shocks in stocks returns imply that a positive innovation in the credit spread or dividend-price ratio has a negative effect on contemporaneous stock returns. The significant positive coefficients, however, predict that next period stock returns rise. In this way, both the credit spread and the dividend-price ratio imply mean reversion in stocks returns.

The yield spread is a strong predictor for bond returns. Although less significant, the nominal interest rate and stock returns also capture some dynamics in expected bond returns. The nominal interest rate is a mean-reversion mechanism in bond returns, whereas the covariance structure of the term spread leads to a mean aversion component. The $R^{2}$ of $9 \%$ implies that bond returns are difficult to explain, even more difficult than stocks which have an $R^{2}$ of $12 \%$. Nevertheless, a low $R^{2}$ on a quarterly basis implies a higher $R^{2}$ on an annual basis. Moreover, Campbell and Thompson (2007) show that even a very small $R^{2}$ can be economically meaningful because it can lead to large improvements in portfolio performance.

The state variables serve as predictor variables. The coefficients of both the nominal interest rate (1.03) and the dividend-price ratio (0.95) on their own lags 
Table 2.2: VAR of core variables: Parameter estimates

\begin{tabular}{|c|c|c|c|c|c|c|c|c|}
\hline & $r_{t b, t}$ & $x_{b, t}$ & $x_{s, t}$ & $d p_{t}$ & $r_{n o m, t}$ & $s p r_{t}$ & $c s_{t}$ & $R^{2} / p$ \\
\hline$r_{t b, t+1}$ & $\begin{array}{c}0.44 \\
(6.50)\end{array}$ & $\begin{array}{c}0.00 \\
(0.18)\end{array}$ & $\begin{array}{c}0.00 \\
(0.80)\end{array}$ & $\begin{array}{l}-0.07 \\
(0.70)\end{array}$ & $\begin{array}{c}0.27 \\
(3.10)\end{array}$ & $\begin{array}{c}0.23 \\
(1.37)\end{array}$ & $\begin{array}{l}-0.23 \\
(0.69)\end{array}$ & $\begin{array}{c}0.31 \\
(0.00)\end{array}$ \\
\hline$x_{b, t+1}$ & $\begin{array}{c}0.43 \\
(0.72)\end{array}$ & $\begin{array}{l}-0.12 \\
(1.39)\end{array}$ & $\begin{array}{l}-0.08 \\
(1.62)\end{array}$ & $\begin{array}{l}-0.44 \\
(0.47)\end{array}$ & $\begin{array}{c}0.83 \\
(1.09)\end{array}$ & $\begin{array}{c}4.83 \\
(3.29)\end{array}$ & $\begin{array}{l}-0.80 \\
(0.27)\end{array}$ & $\begin{array}{c}0.09 \\
(0.01)\end{array}$ \\
\hline$x_{s, t+1}$ & $\begin{array}{c}0.93 \\
(1.07)\end{array}$ & $\begin{array}{c}0.07 \\
(0.62)\end{array}$ & $\begin{array}{c}0.08 \\
(1.11)\end{array}$ & $\begin{array}{c}4.83 \\
(3.56)\end{array}$ & $\begin{array}{l}-3.50 \\
(3.15)\end{array}$ & $\begin{array}{l}-1.37 \\
(0.64)\end{array}$ & $\begin{array}{l}10.28 \\
(2.40)\end{array}$ & $\begin{array}{c}0.12 \\
(0.00)\end{array}$ \\
\hline$d p_{t+1}$ & $\begin{array}{l}-0.01 \\
(1.64)\end{array}$ & $\begin{array}{l}-0.00 \\
(0.30)\end{array}$ & $\begin{array}{l}-0.00 \\
(0.69)\end{array}$ & $\begin{array}{c}0.95 \\
(68.58)\end{array}$ & $\begin{array}{c}0.03 \\
(3.01)\end{array}$ & $\begin{array}{c}0.02 \\
(1.04)\end{array}$ & $\begin{array}{l}-0.13 \\
(3.06)\end{array}$ & $\begin{array}{c}0.97 \\
(0.00)\end{array}$ \\
\hline$r_{n o m, t+1}$ & $\begin{array}{l}-0.04 \\
(1.31)\end{array}$ & $\begin{array}{c}0.01 \\
(1.90)\end{array}$ & $\begin{array}{c}0.00 \\
(2.00)\end{array}$ & $\begin{array}{l}-0.02 \\
(0.41)\end{array}$ & $\begin{array}{c}1.03 \\
(28.84)\end{array}$ & $\begin{array}{c}0.20 \\
(2.88)\end{array}$ & $\begin{array}{l}-0.43 \\
(3.09)\end{array}$ & $\begin{array}{c}0.90 \\
(0.00)\end{array}$ \\
\hline$s p r_{t+1}$ & $\begin{array}{c}0.02 \\
(1.08)\end{array}$ & $\begin{array}{l}-0.01 \\
(2.00)\end{array}$ & $\begin{array}{l}-0.00 \\
(1.27)\end{array}$ & $\begin{array}{c}0.03 \\
(1.01)\end{array}$ & $\begin{array}{l}-0.06 \\
(2.38)\end{array}$ & $\begin{array}{c}0.69 \\
(13.17)\end{array}$ & $\begin{array}{c}0.51 \\
(4.85)\end{array}$ & $\begin{array}{c}0.69 \\
(0.00)\end{array}$ \\
\hline$c s_{t+1}$ & $\begin{array}{l}-0.01 \\
(0.77)\end{array}$ & $\begin{array}{l}-0.00 \\
(1.92)\end{array}$ & $\begin{array}{l}-0.00 \\
(2.23)\end{array}$ & $\begin{array}{l}-0.03 \\
(2.31)\end{array}$ & $\begin{array}{c}0.05 \\
(4.04)\end{array}$ & $\begin{array}{c}0.05 \\
(2.38)\end{array}$ & $\begin{array}{c}0.79 \\
(17.34)\end{array}$ & $\begin{array}{c}0.79 \\
(0.00)\end{array}$ \\
\hline
\end{tabular}

indicate that these series are very persistent. The maximal eigenvalue of the coefficient matrix equals 0.977 . The system is stable, but close to being integrated of order one. Although the credit spread is less persistent than the dividend-price ratio, its autocorrelation coefficient (0.79) is higher than that of the yield spread (0.69). The regression results suggest both nominal interest rate and credit spread have a significant explanatory power for all four macro- economic state variables.

For the overlapping sample (1990:II-2005:IV) we have tested the exclusion restriction on $x_{2}$ in the core VAR. We cannot reject the null hypothesis of absence of Granger causality $(p=0.24)$.

Table 2.4 shows the estimation results for the alternatives in $x_{2}$. Credits are well explained by stocks and bonds, its own lagged return, and news about the credit spread and the change in the long yield. Credit returns decrease when yields rise or credit spreads widen. The results are consistent with the notion that corporate bonds are a hybrid between default-free bonds and the firm's equity. De Jong and Driessen (2005) mention that corporate bond returns are related both to government 
Table 2.3: VAR of core variables: Error correlation matrix

\begin{tabular}{|c|c|c|c|c|c|c|c|}
\hline \multicolumn{8}{|c|}{$\begin{array}{l}\text { The table reports the error covariance matrix } \Sigma_{\epsilon \epsilon} \text { of the VAR } \\
y_{t+1}=a+B y_{t}+\epsilon_{t+1} \text { with variables: 3-month T-bill, } 20 \text {-years bonds, } \\
\text { stocks, dividend yield, nominal 3-month T-bill, yield spread, and credit } \\
\text { spread. Diagonal entries are standard deviations; off-diagonal entries } \\
\text { are correlations. }\end{array}$} \\
\hline & $r_{t b}$ & $x_{b}$ & $x_{s}$ & $d p$ & $r_{n o m}$ & spr & $c s$ \\
\hline$r_{t b}$ & 0.53 & - & - & - & - & - & - \\
\hline$x_{b}$ & 0.37 & 4.64 & - & - & - & - & - \\
\hline$x_{s}$ & 0.23 & 0.12 & 6.76 & - & - & - & - \\
\hline$d p$ & -0.26 & -0.13 & -0.98 & 0.07 & - & - & - \\
\hline$r_{n o m}$ & -0.36 & -0.63 & -0.06 & 0.07 & 0.22 & - & - \\
\hline spr & 0.21 & 0.12 & -0.01 & 0.01 & -0.82 & 0.17 & - \\
\hline$c s$ & 0.07 & 0.57 & -0.16 & 0.14 & -0.28 & -0.12 & 0.07 \\
\hline
\end{tabular}

bonds and stocks because of the exposure to liquidity shocks in both markets.

The primary assets can hardly explain commodity returns. Commodities have as much predictability as stocks and bonds $\left(R^{2}=0.14\right)$; the negative exposure to stocks confirms the findings of Gorton and Rouwenhorst (2006) that stocks and commodities behave differently across the business cycle. Returns are negatively related to an increase in the real T-bill because it leads to a loss on cash collateral. The real estate series are rather well explained $\left(R^{2}=49 \%\right)$ by contemporaneous bonds, stocks and term spreads. Hedge funds are only explained by their equity exposure $\left(R^{2}=22 \%\right)$. Finally, liabilities are mainly driven by real T-bills, bonds and the change in the long yield. The exposure to the change in the long yield reflects the high duration of liabilities.

\subsection{Term structures of assets and liabilities}

This section discusses the long-run covariance structure of assets and liabilities implied which follows from the return dynamics implied by the VAR model (see Appendix A). This is the term structure of risk introduced by Campbell and Viceira (2005). We discuss the results in four subsections. We first look at the volatilities. Next we consider all covariances with stocks, bonds, inflation and liabilities. 
Table 2.4: Excess return regressions The table reports parameter estimates for the excess returns of the assets in the subset $x_{2}:$ credits $\left(x_{c r}\right)$, commodi-
ties $\left(x_{c m}\right)$, listed real estate $\left(x_{r e}\right)$, hedge funds $\left(x_{h}\right)$ and liabilities $\left(x_{L}\right)$. For each asset we report the regression results after setting to zero all insignificant coefficients in the general specification

$$
x_{2, t+1}=c+D_{0} y_{t+1}+D_{1} y_{t}+H x_{2, t}+\eta_{t+1}
$$

and after reparameterization. Reparameterization involves the first differences of the variables $y^{10}=s p r+r_{n o m}$ and $c s$. Explanatory variables in $y_{t}$ are the nominal T-bill rate $\left(r_{n o m}\right)$, the term spread $(s p r)$, the default spread $(c s)$, and the dividend-price ratio $(d p)$. The last column reports the regression $R^{2}$ and the $p$-value of the F-statistic of the zero restrictions with respect to the general model.

\begin{tabular}{|c|c|c|c|c|c|c|c|c|c|c|}
\hline & \multicolumn{6}{|c|}{ Contemporaneous } & \multicolumn{3}{|c|}{ Lagged } & \multirow[b]{2}{*}{$R^{2} / p$} \\
\hline & $r_{t b, t+1}$ & $x_{b, t+1}$ & $x_{s, t+1}$ & $s p r_{t+1}$ & $\Delta y_{t+1}^{10}$ & $\Delta c s_{t+1}$ & $r_{t b, t}$ & $x_{b, t}$ & own $n_{t}$ & \\
\hline \multirow[t]{2}{*}{$x_{c r, t+1}$} & - & 0.40 & 0.04 & - & -20.50 & -10.43 & - & 0.10 & -0.15 & 0.90 \\
\hline & - & $(6.52)$ & $(2.94)$ & - & $(8.16)$ & $(5.88)$ & - & $(1.90)$ & $(2.60)$ & 0.10 \\
\hline \multirow[t]{2}{*}{$x_{c m, t+1}$} & -4.55 & - & -0.23 & - & - & - & 2.62 & - & - & 0.14 \\
\hline & $(3.59)$ & - & $(2.33)$ & - & - & - & $(2.09)$ & - & - & 0.45 \\
\hline \multirow[t]{2}{*}{$x_{r e, t+1}$} & - & 0.32 & 0.65 & 4.48 & - & - & - & - & - & 0.49 \\
\hline & - & $(3.35)$ & $(9.27)$ & $(2.80)$ & - & - & - & - & - & 0.47 \\
\hline \multirow[t]{2}{*}{$x_{h, t+1}$} & - & - & 0.19 & - & - & - & - & - & - & 0.22 \\
\hline & - & - & $(4.09)$ & - & - & - & - & - & - & 0.87 \\
\hline \multirow[t]{2}{*}{$x_{0, t+1}$} & -1.97 & 0.19 & -0.07 & - & -15.86 & -3.89 & - & - & -0.12 & 0.78 \\
\hline & $(9.48)$ & $(2.22)$ & $(3.23)$ & - & $(4.79)$ & (1.83) & - & - & $(2.37)$ & 0.27 \\
\hline
\end{tabular}

\subsubsection{Term structure of risk}

The first set of implications of the VAR model concerns time diversification properties within an asset class. Figure 2.1 shows the annualized conditional standard deviation of cumulative real holding period returns of all asset classes for investment horizons (in quarters) up to 25 years. We compare the term structure from the perspective of an asset-only and an asset-liability investor. For the asset-only investor returns are in deviation of inflation; for the asset-liability investor returns are in excess of the liabilities.

Results for stocks, bonds and T-bills confirm findings in Campbell and Viceira (2005). Stocks are less risky in the long run: the standard deviation falls from $14 \%$ in the first quarter to $10.5 \%$ after 10 years and $8 \%$ after 25 years. This strong decrease is caused by mean reversion in stock returns. This mean reverting behavior of stocks is normally attributed to the dividend yield. In our model this effect is reinforced by the credit spread.

Returns on a constant 20-year maturity rolling bond portfolio also exhibit mean reversion, but less so since they are subject to two offsetting effects. A negative 
shock in the short rate induces a positive shock in bond returns, and subsequently predicts that next-period bond returns will decrease. In contrast, shocks in the term spread variable are positively correlated with both current and future bond returns. As the short rate is more persistent than the spread, the mean reverting effect of the short rate dominates. Risks of a constant 20-year maturity bond portfolio decline from $10 \%$ after one quarter to $6 \%$ after 25 years.

Investing in the 90-day T-bill is more risky in the long run due to the reinvestment risk due to persistent variation in real interest rates. At longer investment horizons the risk of reinvesting in the 90-day T-bill approaches the risk of a rolling investment in 20 year bonds. We also observe persistence in the inflation process, meaning that inflation is a long-term risk factor.

Investment-grade credit returns show time diversification as well. Mean reversion is the result of the predictability of the returns from the credit spread. It also inherits some of the mean reversion of bonds due to the strong correlation between the two returns. Coefficient estimates of the VAR are significant and positive, while shocks are negatively correlated. Credit returns decline when credit spreads widen or bond yields rise. The volatility of credits is below that of bonds, which is due to the negative correlation between changes in credit spreads and yields.

The term structure of listed real estate shows a hump-shaped pattern. For investment horizons up to four years listed real estate exhibits mean aversion due to persistency of interest rates which is captured in our model by the yield spread. Furthermore the drivers for mean reversion in stock and bond returns also influence the term structure of listed real estate. Mean reversion dominates in the long run. Nevertheless listed real estate exhibits less mean reversion than stocks and the term structure lies above the one of stocks.

No time diversification is observed in commodities. Commodity returns are described in the VAR by contemporaneous stock returns and real T-bill. Since stocks are mean-reverting and the T-bill exhibits mean-aversion, their combined effect results in a flat term structure of risk.

Hedge fund returns also have a flat term structure of volatility. At short horizons the term structure is affected by the unsmoothing filter applied to hedge fund returns. Using smooth return series with a non-zero first order autocorrelation would result in a rising term structure with lower volatility for short investment horizons.

Liability risk scarcely exhibits horizon effects, because two effects offset each other. Liabilities are the sum of long-term real bond returns plus inflation. The real bond returns exhibit mean reversion, whereas inflation has a mean averting character. The total effect is a modestly downward-sloping term structure of risk. 
Figure 2.1: Time diversification

Annualized volatilities (y-axis) across different investment horizons (in quarters on $\mathrm{x}$-axis). Solid lines represent real asset returns. Dashed lines represent real asset returns relative to the liabilities.
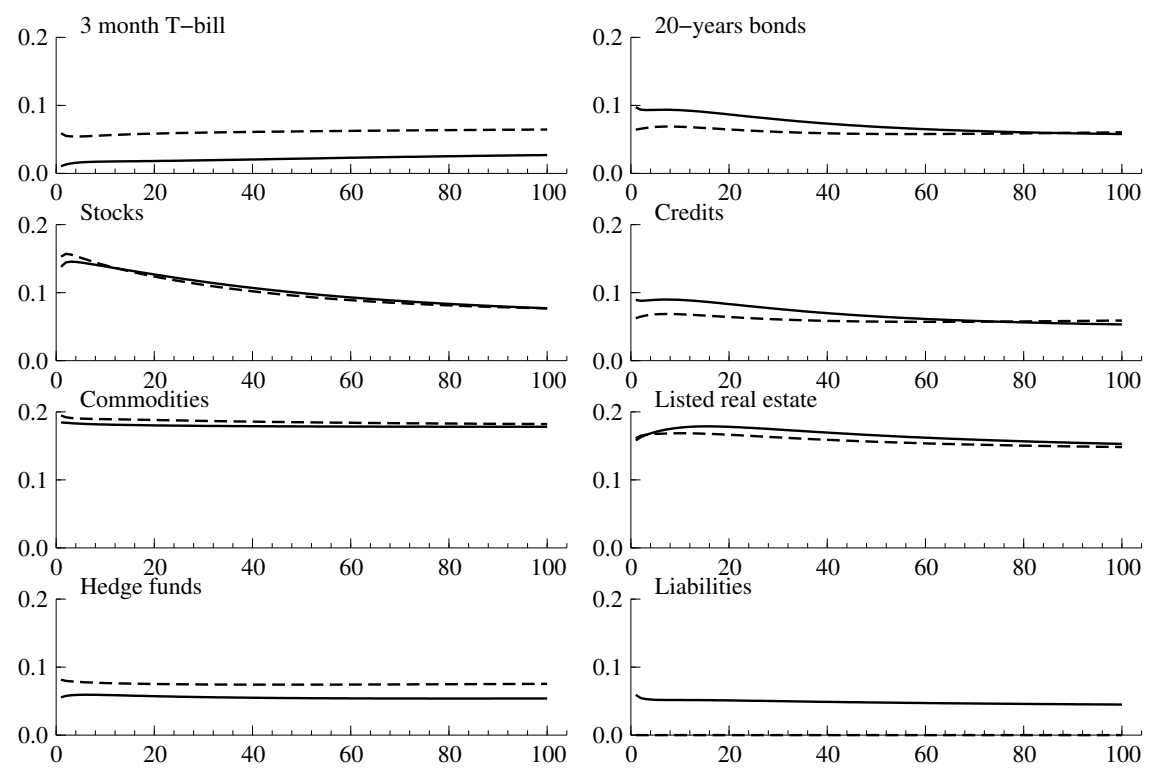

Term structures relative to liabilities are markedly different for T-bills and bonds. For an asset-liability investor T-bills are about three times as risky as for an assetonly investor (5.4\% versus $1.6 \%$ for an annual horizon). The duration mismatch of T-bills makes them as risky as bonds. The risk of bonds and credits is substantially lower in the short and medium term when there are liabilities (the difference is $2.5 \%$ points for bonds for an annual horizon). In the long run, differences are smaller because cumulative inflation risk dominates the term structures. Since stocks, commodities and listed real estate have high stand-alone risk and a low correlation with liabilities, the term structures do not change greatly relative to liabilities.

\subsubsection{Risk diversification}

We now turn to the diversification possibilities between asset classes at different horizons. We discuss the correlations of real returns on stocks and bonds with other asset classes (Figure 2.2). 
The correlation between stocks and bonds changes drastically along the investment horizon. The correlation is lowest in the very short run (around 25\%) and in the long run (47\% for a 25 -year horizon). For investors with a medium-term investment horizon, risk diversification possibilities are worse since the correlation can be up to $64 \%$. Movements in interest rates explain these horizon effects. Bond returns immediately decline when interest rates increase, but rise next period after rolling the bond portfolio. Stock returns, however, react more slowly. They also decline next period before they can rise again in the intermediate term.

The correlation between stocks and credits is similar to the correlation between stocks and bonds. The correlation is slightly higher, ranging from $27 \%$ at a quarterly horizon to $67 \%$ at a 10 -year horizon and $52 \%$ for a 25 -year horizon. An explanation is that credit returns vary systematically with the same factors that affect stock returns (see Elton, Gruber, Agrawal and Mann (2001)). Default loss moves with equity prices. If stock prices decline, default risk goes up and vice versa. Furthermore, the compensation for risk required in the market changes over time and affects stocks and corporate bonds in the same way. Obviously bonds are highly correlated with credits at all horizons: correlation is always more than $90 \%$.

T-bills are a good diversifier in a portfolio with stocks or long-term bonds. The correlation of bonds with the T-bill has a U-shape. It starts high for short horizons at $45 \%$, comes down to $8 \%$ for the medium term and rises again to $22 \%$ at longer horizons. The low correlation is due to duration mismatch. Returns on T-bills rise rather quickly when interest rates rise, whereas bonds with a longer maturity are more sensitive to interest rate changes. The correlation between stocks and the T-bill is high for short horizons (45\%) but this comes down to $-10 \%$ after 25 years.

Listed real estate is often seen as similar to equity. This is supported by the high correlation $(65 \%)$ between stocks and listed real estate at short investment horizons. This correlation diminishes with the investment horizon. Indirect real estate indices are based on publicly traded property companies listed on major stock exchanges. Froot (1995) explains that similar factors (e.g. productivity of capital and labor) drive both stocks and real estate and that lots of corporate assets are invested in real estate. As a consequence listed indices tend to have a high correlation with publicly traded stocks and bonds indices. In this sense real estate does not seem like a very different asset class. ${ }^{14}$

Horizon effects are much weaker in the correlation between stocks and hedge funds. The correlation moves from $56 \%$ for short horizons towards $23 \%$ in the long run. The magnitude of the short-term correlation implies a large exposure to

\footnotetext{
14 The conclusion might be different for direct real estate. Since direct real estate is not listed on publicly traded financial markets, this could imply lower correlations with stocks and bonds.
} 
Figure 2.2: Correlations with stocks and bonds

Correlations of real stock returns (solid lines) and real bond returns (dashed lines) with other real asset returns (y-axis) across different investment horizons (in quarters on $\mathrm{x}$-axis).
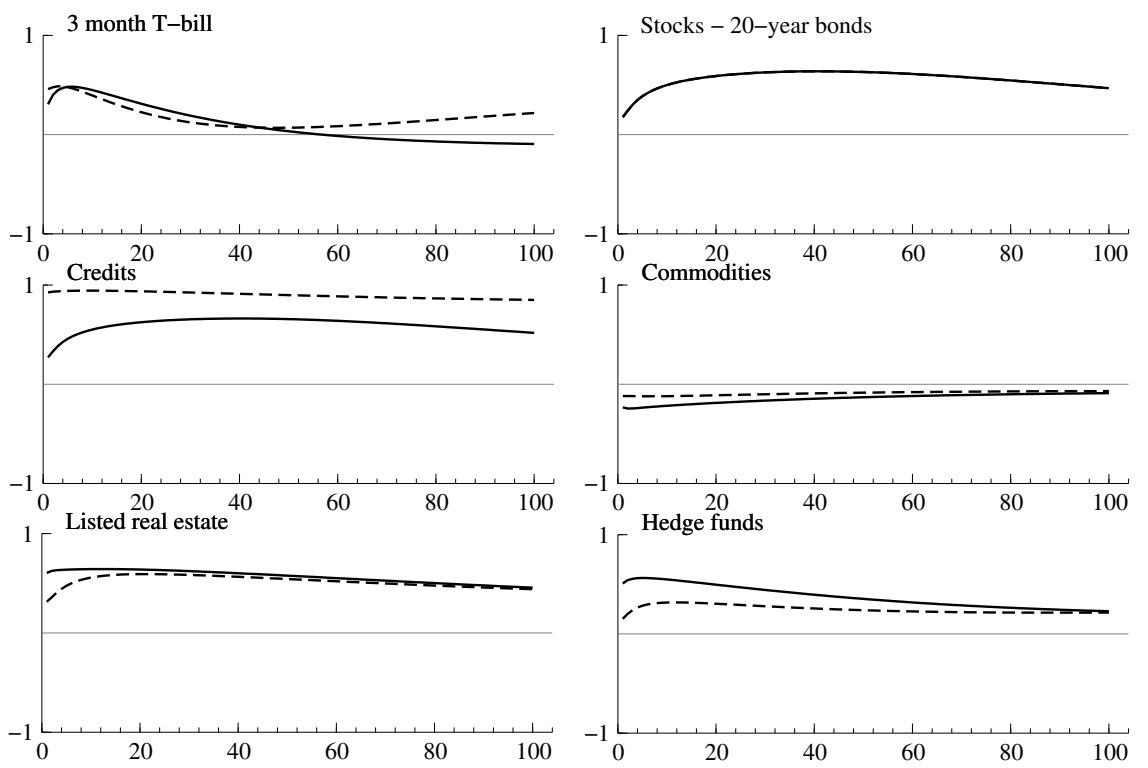

the stock market which reduces in the long run. Bond exposure is less than equity exposure and has a lagged effect. Like the correlation between stocks and bonds, the correlation between hedge funds and bonds initially increases with the investment horizon before decreasing for horizons beyond three years.

Since commodities are negatively correlated with both stocks and bonds at all horizons they have the best risk diversifying properties. Commodity returns behave differently, since unlike stocks and bonds, commodities are not claims on long-lived corporations and they do not provide resources for firms to invest. Rather commodity futures are derivatives and provide insurance for future values of inputs or outputs. Investors receive compensation for fluctuations around the future expected spot price, return on collateral and a risk premium for providing insurance (backwardation). The negative correlations are in line with Gorton and Rouwenhorst (2006) who also find negative correlations for quarterly, annual and 5-year returns. They explain the negative correlation in two ways. First, commodities perform better in periods of unexpected inflation when stocks and bonds disappoint. Second, commodities behave differently over the business cycle. Commodity futures perform 
well in the early stages of a recession, because generally speaking oil and energyrelated prices increase. Stocks and bonds generally disappoint in the early stages of a recession. In late stages of a recession, returns are the other way round.

\subsubsection{Inflation hedging qualities}

This section examines the potential of stocks, bonds and the alternatives as a hedge against inflation for different investment horizons. Since inflation is not explicitly included in the VAR, we construct its properties from the difference between the real T-bill return and the lagged nominal interest rate (i.e. $\pi_{t}=r_{n o m, t-1}-r_{t b, t}$ ). Figure 2.3 shows the correlation of nominal asset returns with inflation across investment horizons. The correlation with inflation changes substantially with the horizon for all asset classes. All asset classes are a better hedge against inflation in the long run than in the short run. There are also marked differences among asset classes.

The T-bill quickly catches up with inflation changes, and therefore seems the best inflation hedge at all horizons. The high correlation with inflation is due to rolling over 3-months T-bills, which ensures that the lagged inflation is incorporated.

Inflation-hedging qualities of bonds and credits are good in the long run (correlation after 25 years is 0.61 and 0.65 respectively), but poor in the short run due to the inverse relationship between yield changes and bond prices. The positive long-term correlations are mainly due to the use of constant-maturity bonds, whereas Campbell and Viceira (2005) show that holding bonds to maturity is akin to accumulating inflation risk. The negative short-term hedging qualities of credits are also related to the negative relationships between inflation and real economic growth. Therefore the credit spread widens in business cycles downturns, which leads to a negative return.

Stocks also turn out to be a good inflation hedge in the long run and a poor one in the short run, consistent with the extensive existing literature on this relation (see for instance Schotman and Schweitzer (2000)). Fama (1981) argues that inflation, acting as a proxy for real activity, leads to the negative short-term correlation. Increasing inflation would lead to lower real economic activity and this leads to lower stock returns. In particular, unexpected inflation is related to negative output shocks, which generally lead to falling stock prices. The positive inflation hedge potential in the long run could be explained by a present-value calculation of real stock prices. Campbell and Shiller (1988) distinguish two offsetting effects. First, inflation increases the discount rate, which lowers stock prices. Second, inflation increases future dividends, which boosts stock prices. They argue that due to price 
rigidities in the short run, the net effect will be negative in the short run, but positive in the long run.

Commodity prices move along with inflation in the short and the long term, which makes them very attractive from an inflation hedge perspective. Bodie (1983) showed that the risk-return trade-off of a portfolio in an inflationary environment can be improved by the addition of commodity futures to a portfolio consisting of stocks and bonds. Gorton and Rouwenhorst (2006) argue that as futures prices include information about expected trends in commodity prices, they rise and fall with unexpected inflation. We find commodity futures have very stable inflation hedge qualities (correlation above 0.30 for investment horizons longer than 3 years).

Listed real estate behaves like stocks in the short run from an inflation hedge perspective, although stocks are a slightly better inflation hedge in the long run. This is again in line with the observation that listed real estate behaves like stocks.

Hedge funds are better inflation hedges in the short run than most assets, but they still have a negative inflation hedge potential. As hedge fund returns are often seen as Libor plus an alpha component, the inflation hedge qualities may come from the Libor part of the return which moves with the lagged inflation, which results in a positive long-term correlation.

\subsubsection{Real interest rate hedging qualities}

This section studies the potential of stocks, bonds and alternatives (in real terms) as a hedge against real interest rate risk at different investment horizons. The liabilities of pension funds are the present value of future obligations, discounted at a real interest rate. Liability risk is associated with both the future obligations as well as the discount factor. Both inflation, affecting the future obligations, as well as the discount rate, lead to liability risk. Our time series of liability returns combines both types of risks (see (2.22)).

Figure 2.3 shows that the real interest rate hedge potentials of the asset classes change substantially with the investment horizon. Bonds and credits provide the best real interest rate hedge. Bonds have a correlation of around $70 \%$ at an annual investment horizon. Due to cumulative inflation, the correlation reduces to $35 \%$ in the long run. The hedging qualities of credits are slightly lower owing to the lower duration and the credit exposure. The mismatch between the quarterly inflation compensation of the liabilities and the expected long-term inflation implicitly in the long yields underlying the investment strategies becomes more severe at longer horizons. As a consequence, cumulative unexpected inflation shocks lead to a reduction of liability hedging potential along the investment horizon. 
Figure 2.3: Inflation hedge and real interest rate hedge properties

Solid lines represent correlations between inflation and nominal asset returns. Dashed lines represent correlations between real returns on liabilities and real asset returns. Correlations are on the $\mathrm{y}$-axis across different investment horizons (in quarters on $\mathrm{x}$-axis).
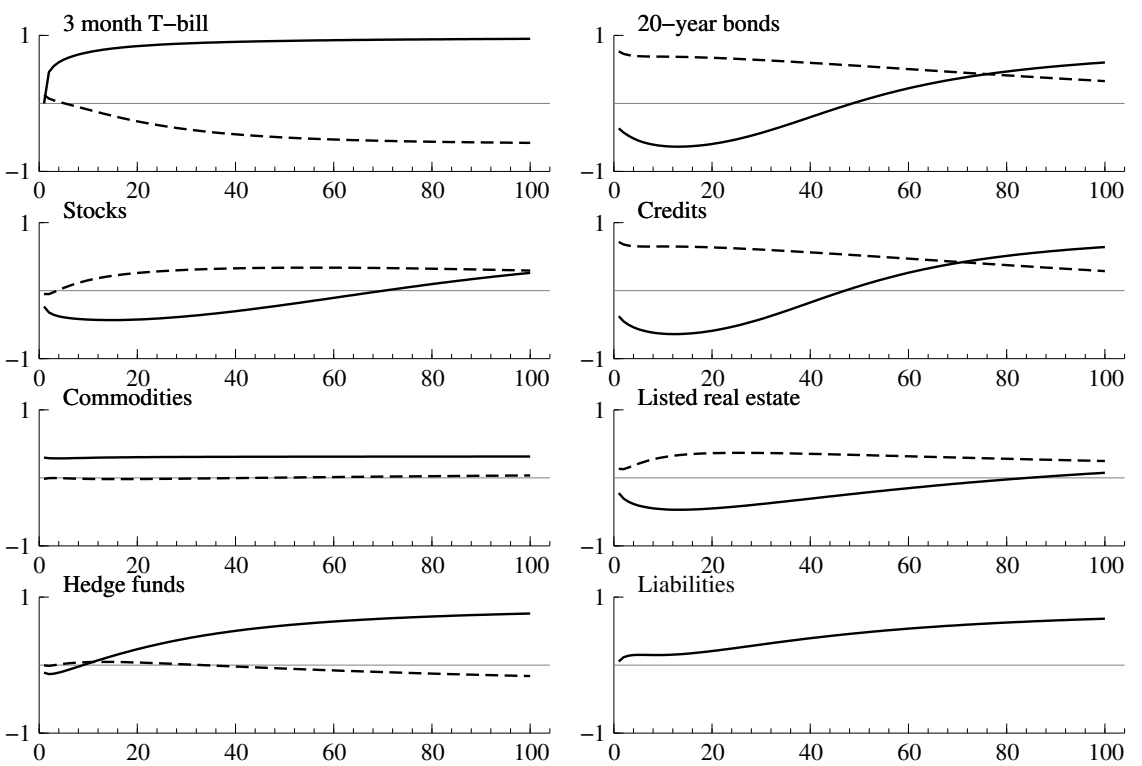

The real interest rate hedge potential of stocks and listed real estate are comparable, although the latter one provides a slightly better hedge due to the exposure to spreads and bonds. Both term structures of risk are hump-shaped. In the short run the correlation of listed real estate is around 14\%; it reaches a maximum at the seven year horizon with a correlation of $37 \%$; it then falls to $25 \%$ at a 25 year horizon. Stocks reach its maximum of $34 \%$ at around 15 years.

Commodities and hedge funds are scarcely correlated at all with the liabilities across all horizons. T-bills have the worst liability hedging qualities among the assets in our universe. Alongside duration mismatch with long-dated liabilities, cumulative unexpected inflation risk leads to a declining correlation. The correlation between real T-bills and liabilities converges to $-57 \%$ in the long run. Combining the inflation and the real interest rate hedge qualities of T-bills and long-dated bonds (in Figure 2.3) reveals pitfalls of nominal swap-overlay strategies which are often considered by asset-liability investors for liability matching by duration extension. The long receiver rate is a better liability hedge, while the short payer rate exposes the investor to substantial inflation risk. 


\subsection{Strategic asset liability management}

We now turn to the portfolio implications. We compare the optimal mean-variance portfolio for the asset-liability investor in (2.11) with the asset-only portfolio (2.17). The speculative part of portfolio choice is the same for an asset-only and assetliability investor. As a consequence, differences in strategic asset allocation are due to the global minimum variance (GMV) and the liability hedge (LHP) portfolios. These two portfolios are obtained by letting $\gamma \rightarrow \infty$. We discuss these hedge portfolio for investment horizons of $1,5,10$ and 25 years in section 2.5.1. In section 2.5.2 we add the speculative portfolio for risk version parameters $\gamma=5,10,20$.

\subsubsection{Hedge portfolios}

Table 2.5 shows the GMV and LHP portfolios at different investment horizons. At the 1-year horizon the GMV portfolio is entirely invested in T-bills, exactly as in Campbell and Viceira (2005). At longer horizons much of the weight shifts to longterm bonds and stocks, showing that these assets have good long-run risk diversification properties. At the 25-year horizon, 6\% of the GMV consists of alternatives. If we compare the hedge portfolios with portfolios which are restricted to T-bills, bonds and stocks only, we find that the alternatives drive bonds and T-bills out of the hedge portfolios in favor of credits and commodities.

The liability hedge portfolio is very different. At the 1-year horizon, the weight of T-bills is much lower than in the GMV. The asset-liability investor chooses primarily bonds $(34 \%)$ and credits $(12 \%)$. Bonds are the best hedge against real interest rate risk, and therefore have a large weight in the LHP. Credits have a substantial weight (12\%-21\%) in the LHP, because they are the second-best real rate hedge. They replace bonds to some degree, as they offer some risk diversification benefits, despite their somewhat lower hedge potential. Even though T-bills (62\%) are a bad liability hedge, they still have a substantial allocation in the portfolio. T-bills remain attractive for their low risks at short horizons. At longer horizons they are in the portfolio for their diversification properties with stocks and bonds and for their good inflation hedge qualities. At short horizons stocks are less attractive due to their limited liability hedge qualities. At the 25 years horizon, however, stocks obtain more weight in the LHP than in the GMV.

At a 25-year horizon, $23 \%$ of the LHP is allocated to the alternative assets. Most of the weight comes from the credits. Commodities also have a positive weight simply because they are a good risk diversifier to the other asset classes and a good inflation hedge. Moreover, their weight increases with the investment horizon The LHP allocates $1 \%$ to listed real estate and does not include in hedge funds. 
Figure 2.4: Hedging demands in GMV for long-term asset-only investors

Hedging demands in the global minimum variance portfolio compared to the single-period portfolio (in percentage points on $y$-axis) for different investment horizons (in quarters on x-axis).

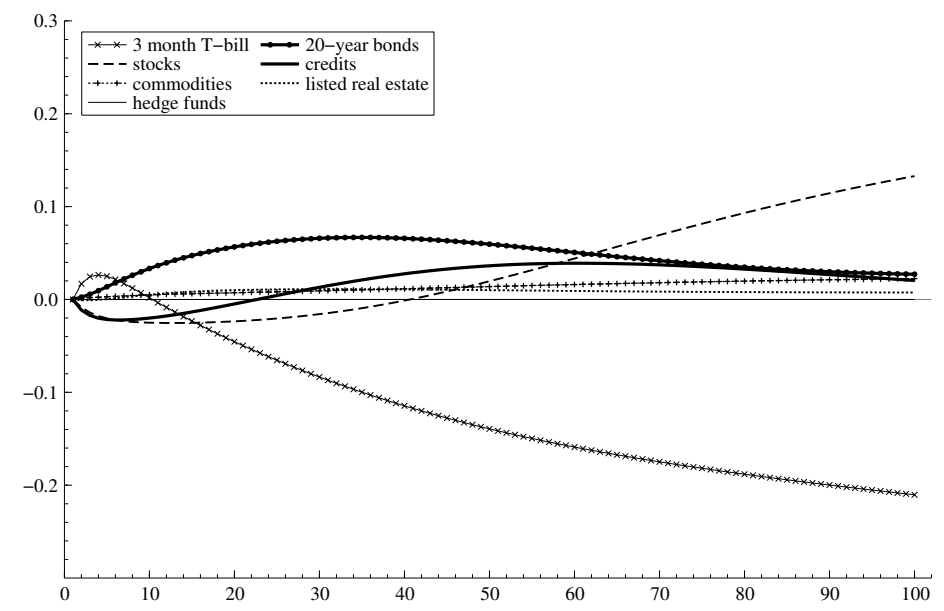

Figure 2.5: Hedging demands in LHP for long-term asset-liability investors

Hedging demands in the liability hedge portfolio compared to the single-period portfolio (y-axis) for different investment horizons (in quarters on $\mathrm{x}$-axis).

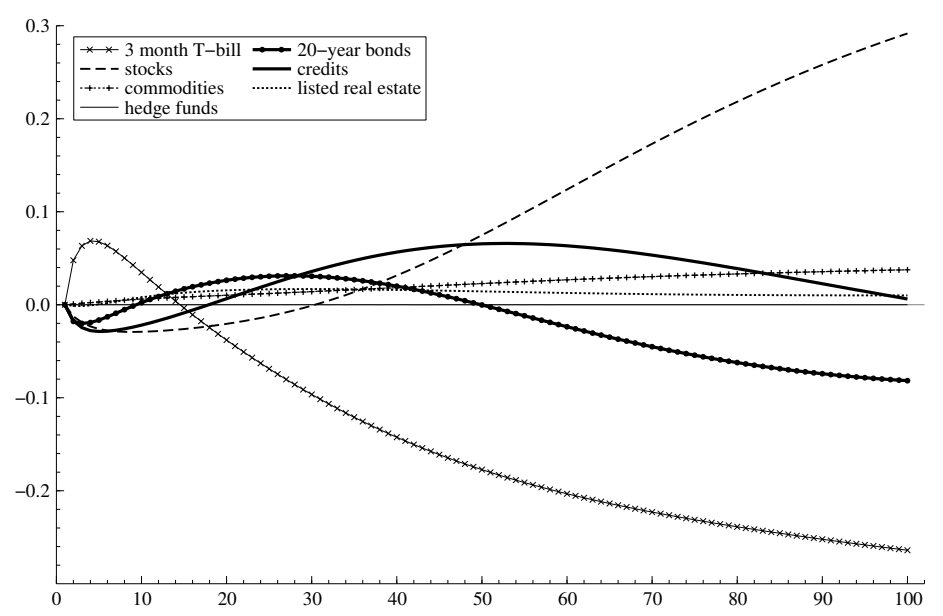


Table 2.5: Global minimum variance and liability hedge portfolios

The left panel shows the global minimum variance portfolio for the asset-only problem for different investment horizons. The right panel shows the liability hedge portfolio for the asset-liability problem. Weights may not add up to one due to rounding. Panel A consider the full menu of all seven asset classes. Panel B excludes the alternatives.

\begin{tabular}{|c|c|c|c|c|c|c|c|c|}
\hline \multirow[b]{2}{*}{ Horizon (years) } & \multicolumn{4}{|c|}{ Global Minimum Variance } & \multicolumn{4}{|c|}{ Liability Hedge } \\
\hline & 1 & 5 & 10 & 25 & 1 & 5 & 10 & 25 \\
\hline \multicolumn{9}{|c|}{ A) Unrestricted portfolios } \\
\hline T-bills $\left(r_{t b}\right)$ & 1.06 & 0.99 & 0.92 & 0.83 & 0.62 & 0.52 & 0.41 & 0.29 \\
\hline Bonds $\left(x_{b}\right)$ & -0.01 & 0.03 & 0.04 & 0.01 & 0.34 & 0.39 & 0.38 & 0.28 \\
\hline Stocks $\left(x_{s}\right)$ & -0.03 & -0.03 & -0.01 & 0.12 & -0.11 & -0.11 & -0.06 & 0.20 \\
\hline Credits $\left(x_{c r}\right)$ & -0.03 & -0.02 & 0.01 & 0.01 & 0.12 & 0.16 & 0.21 & 0.16 \\
\hline Commodities $\left(x_{c m}\right)$ & 0.02 & 0.02 & 0.02 & 0.04 & 0.03 & 0.04 & 0.04 & 0.06 \\
\hline Real estate $\left(x_{r e}\right)$ & 0.00 & 0.01 & 0.01 & 0.01 & 0.00 & 0.01 & 0.01 & 0.01 \\
\hline Hedge funds $\left(x_{h}\right)$ & 0.00 & 0.00 & 0.00 & 0.00 & 0.00 & 0.00 & 0.00 & 0.00 \\
\hline \multicolumn{9}{|c|}{ B) Restricted portfolios } \\
\hline T-bills $\left(r_{t b}\right)$ & 1.08 & 1.01 & 0.94 & 0.86 & 0.67 & 0.57 & 0.48 & 0.37 \\
\hline Bonds $\left(x_{b}\right)$ & -0.05 & 0.02 & 0.06 & 0.01 & 0.44 & 0.53 & 0.56 & 0.39 \\
\hline Stocks $\left(x_{s}\right)$ & -0.03 & -0.03 & -0.01 & 0.13 & -0.11 & -0.10 & -0.04 & 0.23 \\
\hline
\end{tabular}

The duration of the fixed-income portfolio in the LHP (around 8) is below that of the liabilities (which is equal to 17). This duration follows from the allocation to T-bills, long bonds and credits. We offer several explanations as to why the fixedincome portfolio has a shorter duration than the liabilities. With respect to the short-term vs. long-term tradeoff, short-dated bonds are a good risk diversifier in a portfolio of long-dated bonds (see also Brennan and Xia (2002)). Furthermore, in order to tradeoff nominal inflation risk and real interest rate risk long-dated bonds are a better long real rate hedge, but short-dated bonds provide a better hedge against cumulative inflation. Finally, stocks also have positive real rate hedge qualities at longer horizons. As a result of the intertemporal covariance structures the duration of the fixed-income portfolio is horizon dependent. It rises from 7 for a 1-year horizon to 9 for a 25-year horizon.

Figures 2.4 and 2.5 summarize the horizon effects in the GMV and LHP. For each investment horizon the figures show the difference in portfolio weights compared to the one-quarter GMV or LHP portfolio weight. For both the asset-only as the assetliability investor, long-term portfolio demands are most different from the single period portfolio for stocks and T-bills. Stocks obtain a much larger weight at longer horizons; T-bills a much lower weight. The effect is strongest for the asset-liability investor, because he needs to hedge against both reinvestment risk and duration 
mismatch with liabilities.

\subsubsection{Do alternative asset classes add value for long-term in- vestors?}

In this section we investigate the role of alternatives when the investor deviates from the LHP or GMV portfolios. For the expected returns we use the unconditional full sample means. In Table 2.6 we show the strategic asset allocation for an assetliability and an asset-only investor for different degrees of risk aversion.

An asset-liability investor with a 1-year horizon holds a well-diversified portfolio. Hedge funds are in the optimal portfolio for their return enhancement qualities, at the expense of stocks and real estate. Bonds and credits are in the portfolio for their liability-hedge qualities and their low correlation with all other assets. Credits are a substitute for bonds for investors with lower risk aversion. Commodities are particularly interesting as a risk diversifier. Combined with the high Sharpe ratio of commodities, this explains the substantial positive weighting of this asset class. When risk aversion increases, the portfolio contains more bonds and T-bills, and less of the other asset classes.

Risk diversification is a dominant investment motive for long-term investing. The mean reverting character of stocks results in increasing weights at longer horizons. In addition, credits replace bonds to some extent. The flat term structure of commodities explains why their portfolio weight is stable over the investment horizon. Listed real estate does not seem to add much in portfolio context, either in relation to liability hedging qualities or to risk diversification. The allocation to hedge funds exhibits even less horizon effects than commodities and real estate. Their weight only changes due to changes in risk attitude.

What is the added value of alternatives and credits? And what are the benefits of explicitly taking an asset-liability perspective? Is it associated with expected returns, risk diversification or liability-hedge potential? We use the certainty equivalent to estimate the costs of three alternative portfolios.

First we consider an investor who is restricted to T-bills, bonds and stocks (Table 2.7). The alternatives drive T-bills and bonds further out of the portfolios in favor of the alternatives with higher expected returns like hedge funds, commodities and credits. Figure 2.6 indicates that the alternative asset classes add value for longterm investors. At the 1-year horizon a risk averse $(\gamma=20)$ asset-liability investor requires a lump sum of 1.2 dollars for each 100 dollars of initial investment to be compensated for ignoring the four alternative asset classes. The cost can be attribute to three components. The largest component is the considerable expected return 
Table 2.6: Optimal portfolio choice

\begin{abstract}
The table shows the fixed-weights optimal portfolio holdings for two types of investor (asset-only versus asset-liability) who plan to invest constant proportions of wealth in each of the asset classes for four investment horizons $(1,5,10$, and 25 years) and for three levels of risk aversion $(\gamma=5,10,20)$. Weights may not add up to one due to rounding.
\end{abstract}

\begin{tabular}{|c|c|c|c|c|c|c|c|c|c|}
\hline \multirow[b]{2}{*}{$\gamma$} & \multirow[b]{2}{*}{ Horizon (years) } & \multicolumn{4}{|c|}{ Asset-only } & \multicolumn{4}{|c|}{ Asset-Liability } \\
\hline & & 1 & 5 & 10 & 25 & 1 & 5 & 10 & 25 \\
\hline \multirow[t]{7}{*}{5} & T-bills $\left(r_{t b}\right)$ & -1.27 & -1.11 & -1.18 & -1.64 & -1.61 & -1.48 & -1.56 & -2.00 \\
\hline & Bonds $\left(x_{b}\right)$ & -0.08 & -0.42 & -0.51 & -0.30 & 0.17 & -0.19 & -0.30 & -0.13 \\
\hline & Stocks $\left(x_{s}\right)$ & 0.65 & 0.90 & 1.14 & 1.42 & 0.58 & 0.87 & 1.15 & 1.50 \\
\hline & Credits $\left(x_{c r}\right)$ & 0.27 & 0.27 & 0.24 & 0.24 & 0.40 & 0.41 & 0.36 & 0.30 \\
\hline & Commodities $\left(x_{c m}\right)$ & 0.61 & 0.59 & 0.57 & 0.52 & 0.62 & 0.61 & 0.59 & 0.55 \\
\hline & Real estate $\left(x_{r e}\right)$ & 0.06 & 0.00 & -0.02 & 0.00 & 0.06 & 0.02 & 0.00 & 0.01 \\
\hline & Hedge funds $\left(x_{h}\right)$ & 0.76 & 0.76 & 0.76 & 0.76 & 0.76 & 0.76 & 0.76 & 0.76 \\
\hline \multirow[t]{7}{*}{10} & T-bills $\left(r_{t b}\right)$ & -0.10 & -0.03 & -0.09 & -0.39 & -0.49 & -0.45 & -0.53 & -0.83 \\
\hline & Bonds $\left(x_{b}\right)$ & -0.06 & -0.26 & -0.34 & -0.23 & 0.24 & 0.03 & -0.08 & -0.01 \\
\hline & Stocks $\left(x_{s}\right)$ & 0.31 & 0.47 & 0.65 & 0.90 & 0.24 & 0.42 & 0.64 & 0.98 \\
\hline & Credits $\left(x_{c r}\right)$ & 0.12 & 0.13 & 0.10 & 0.07 & 0.27 & 0.29 & 0.26 & 0.17 \\
\hline & Commodities $\left(x_{c m}\right)$ & 0.31 & 0.31 & 0.30 & 0.27 & 0.33 & 0.32 & 0.32 & 0.30 \\
\hline & Real estate $\left(x_{r e}\right)$ & 0.03 & 0.01 & -0.00 & 0.00 & 0.03 & 0.02 & 0.01 & 0.01 \\
\hline & Hedge funds $\left(x_{h}\right)$ & 0.38 & 0.38 & 0.38 & 0.38 & 0.38 & 0.38 & 0.38 & 0.38 \\
\hline \multirow[t]{7}{*}{20} & T-bills $\left(r_{t b}\right)$ & 0.49 & 0.49 & 0.43 & 0.23 & 0.07 & 0.04 & -0.04 & -0.25 \\
\hline & Bonds $\left(x_{b}\right)$ & -0.04 & -0.13 & -0.18 & -0.14 & 0.29 & 0.19 & 0.11 & 0.10 \\
\hline & Stocks $\left(x_{s}\right)$ & 0.14 & 0.23 & 0.35 & 0.56 & 0.06 & 0.17 & 0.32 & 0.64 \\
\hline & Credits $\left(x_{c r}\right)$ & 0.04 & 0.06 & 0.05 & 0.02 & 0.20 & 0.22 & 0.22 & 0.14 \\
\hline & Commodities $\left(x_{c m}\right)$ & 0.17 & 0.16 & 0.16 & 0.15 & 0.18 & 0.18 & 0.18 & 0.18 \\
\hline & Real estate $\left(x_{r e}\right)$ & 0.01 & 0.01 & 0.00 & 0.00 & 0.01 & 0.02 & 0.01 & 0.01 \\
\hline & Hedge funds $\left(x_{h}\right)$ & 0.19 & 0.19 & 0.19 & 0.19 & 0.19 & 0.19 & 0.19 & 0.19 \\
\hline
\end{tabular}

advantage from alternatives. Alternatives are thus not solely interesting for their liability hedging qualities. The liability hedge potential also contributes positively to the certainty equivalence cost. Alternatives have good liability hedge properties at all investment horizons and these become more important for long-term investing. The third component is negative: the variance of the unrestricted portfolio is higher than that of the restricted portfolio. Even though the optimal allocation to alternatives is preferred from an asset-liability perspective, it can lead to more stand-alone risk of the asset mix compared with a restrictive asset universe.

We do a second certainty equivalence calculation to determine the economic loss from choosing the strategic asset allocation in an asset-only context when the 
Table 2.7: Restricted Portfolios

\begin{tabular}{|c|c|c|c|c|c|c|c|c|c|}
\hline \multirow[b]{2}{*}{$\gamma$} & \multirow[b]{2}{*}{ Horizon (years) } & \multicolumn{4}{|c|}{ Asset-only } & \multicolumn{4}{|c|}{ Asset-Liability } \\
\hline & & 1 & 5 & 10 & 25 & 1 & 5 & 10 & 25 \\
\hline \multirow[t]{3}{*}{20} & T-bills $\left(r_{t b}\right)$ & 0.88 & 0.85 & 0.77 & 0.53 & 0.50 & 0.44 & 0.34 & 0.10 \\
\hline & Bonds $\left(x_{b}\right)$ & -0.02 & -0.07 & -0.12 & -0.12 & 0.44 & 0.39 & 0.32 & 0.21 \\
\hline & Stocks $\left(x_{s}\right)$ & 0.13 & 0.22 & 0.35 & 0.59 & 0.06 & 0.17 & 0.34 & 0.69 \\
\hline
\end{tabular}

relevant criterion would be the asset-liability perspective. Figure 2.6 shows that the annualized costs decrease with the investment horizon (solid line). Obviously the costs are positively related to risk aversion. A more risk averse investor puts more emphasis on the liability hedging qualities. An investor with a 10-year horizon requires $1.1 \%$ extra return per year if his risk aversion is 20 , but he requires only $0.18 \%$ per year if his risk aversion is 5 .

Figure 2.6 also provides insights into the sources of the required compensation: return enhancement, liability hedge or risk diversification. The compensation for missed liability hedge opportunities is substantial at all horizons and dominates the certainty equivalent. At medium and longer horizons, the attribution to the return enhancement component becomes important as well. In the asset-liability framework, the investor explicitly maximizes the return of the asset mix in excess of the liabilities, rather than the return in excess to T-bills. The required compensation for lost return and liability hedge is partly undone by the lower risk of the asset-only portfolio. The asset-liability investor is worse off in terms of the stand-alone risk of the asset mix due to the longer duration. As a result, a portfolio which is preferred in mismatch risk terms is not necessarily optimal from an asset-only perspective.

Finally, we compare the gains from the long-horizon portfolios compared to the one-period portfolios. Figure 2.7 shows gains from choosing the asset allocation in a strategic way instead of single-period portfolio choice for both an asset-only and an asset-liability investor. For horizons shorter than five years, gains are modest and equally large for asset-only as for asset-liability investors. For longer horizons the gains increase for both types of investors. They increase much more steeply, however, for the asset-liability investor. At the 25 years horizon, the gains for the asset-liability investor are almost double the gains of the asset-only investor. Due to long maturities of accrued pension obligations, pension funds do have such long 
Figure 2.6: Certainty equivalents

The log of the certainty equivalent (in percentages on $\mathrm{y}$-axis) is based on (2.15) and given for several investment horizons (in quarters on x-axis). It represents the annualized required monetary compensation for suboptimal investing of each invested dollar. The log certainty equivalent (solid line) is attributed to three components: return compensation (dashed line), liability hedge compensation (solid circled line) and risk diversification compensation (solid crossed line). This graph is based on a strategic investor with risky liabilities and risk aversion 20. Panel (a) shows the added value of credits, commodities, real estate and hedge funds: the investor chooses an optimal portfolio in an asset-liability context and an investment universe which is restricted to stocks and bonds. Panel (b) shows the certainty equivalent when the investor chooses the optimal portfolio in an asset-only context, instead of in an asset-liability context.
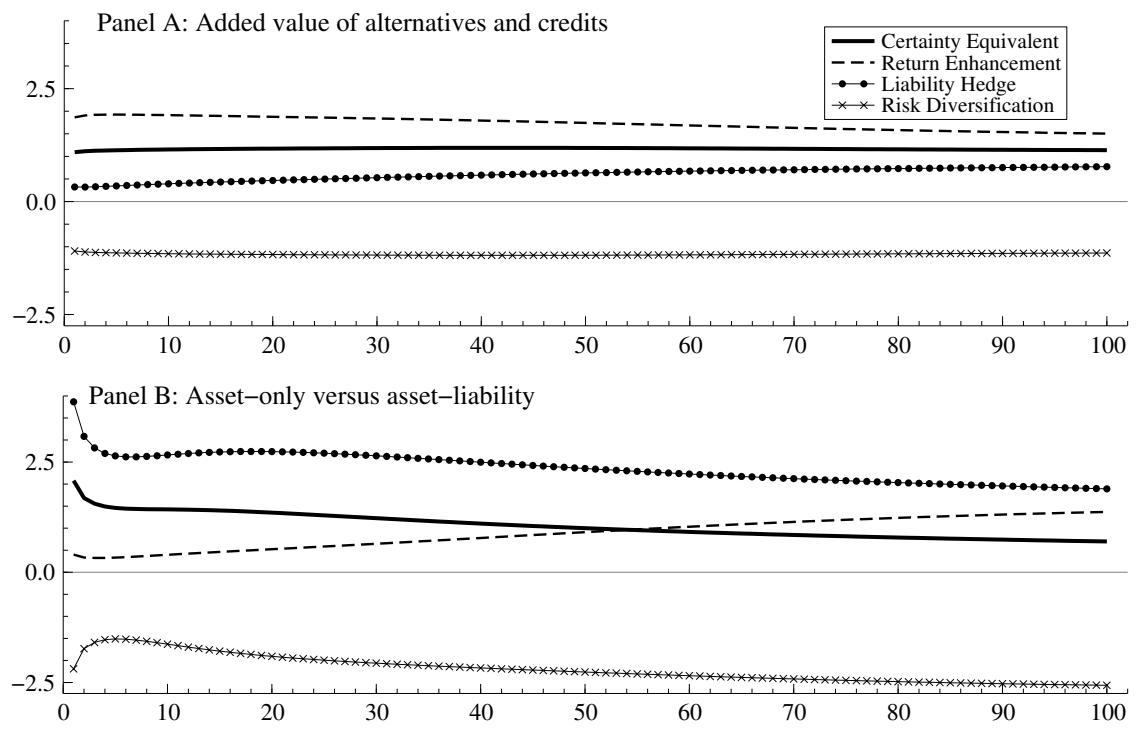

planning horizons. We thus find that it is more important to be strategic when there are liabilities.

\subsection{Conclusions}

This chapter has explored the intertemporal covariance structure of assets and liabilities. The covariance structures give insights into which alternative asset classes have a term structure of risk that is markedly different from that of stocks and bonds. Alternative asset classes add value for long-term investors. Commodities help in hedging inflation risk, since their returns move closely with inflation in the short and long run. Among the assets in our universe, commodities have the best 
Figure 2.7: Short-term versus long-term portfolio choice

The figure shows the benefits from long-term investing for an asset-liability (solid line) and an asset-only (dashed line) investor. Benefits are expressed as a certainty equivalent in simple terms (in percentages on $\mathrm{y}$-axis) for different investment horizons (in quarters on $\mathrm{x}$-axis). They represent the annualized percentage gains from being strategic $\left(\alpha^{(\tau)}\right)$ instead of choosing the asset allocation in a single-period context $\left(\alpha^{(1)}\right)$. The risk aversion parameter $\gamma=20$. The certainty equivalent is based on (2.15).

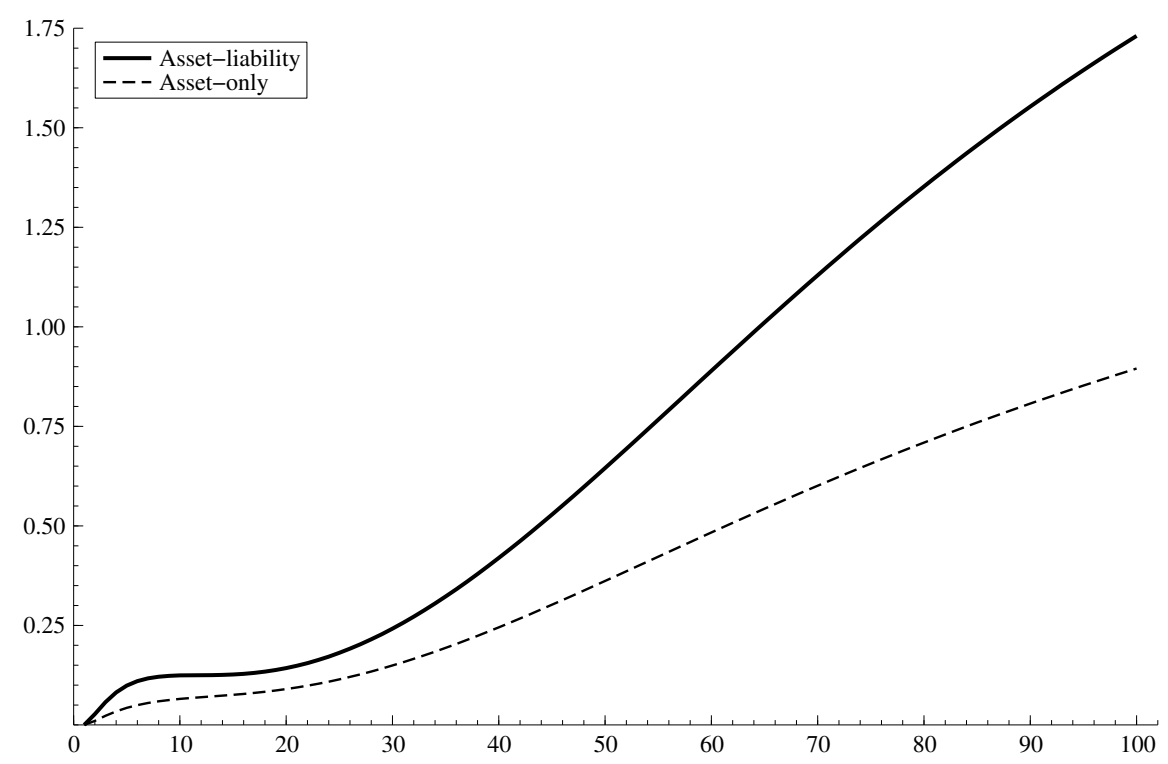

risk diversifying properties relative to stocks and bonds. Term structure properties of listed real estate seem to a large extent captured by traditional asset classes such as stocks and bonds. The term structures of credits mimic those of bonds. The correlation between stocks and credits is slightly higher than for bonds. Just like bonds, the inflation hedge qualities of credits are good in the long run, but poor in the short run due to the inverse relationship between yield changes and bond prices. Hedge funds have good inflation hedge qualities in the long run, but a high exposure to stocks and bonds.

Differences in strategic portfolios for asset-only and asset-liability investors are due to differences in the global minimum variance and liability hedge portfolio. The main difference between the asset-only and asset-liability perspective shows up in the attractiveness of short-term T-bills and long-maturity bonds. Asset-only investors have a large demand for short-term instruments due to their strong positive correlation with inflation at longer horizons. Although T-bills are a bad liability hedge, 
they still have a substantial allocation in the portfolio. T-bills remain attractive for their low risks at short horizons and good diversification properties with stocks and bonds at longer horizons. Bonds and credits are the best real rate hedge, and therefore have a high weight in the LHP. Commodities are in the LHP for their risk diversifying qualities. The LHP allocates a small amount to listed real estate and does not invest in hedge funds.

We find that the benefits of long-term investing are larger when there are liabilities. For investment horizons beyond five years, asset-liability investors gain more from strategic asset allocation than asset-only investors. Apart from a different single-period portfolio, the asset-liability investor has different hedging demands for changes in the investment opportunities at various horizons. In particular, assetliability investors focus much more on interest rate risk and fixed-income products than asset-only investors. The diminishing correlation at longer horizons between stocks and bonds creates positive hedging demand for stocks in the liability hedge portfolio. The increasing correlation at short and medium term horizons results in more negative hedging demand for stocks once there are liabilities. In addition, asset-liability investors not only need to deal with reinvestment risks of T-bills, but also with duration mismatch risk with respect to the liabilities.

Whereas this chapter considered the drivers of the intertemporal covariances between assets and liabilities, many issues that are relevant for portfolio choice are not addressed. Among these, the form of the utility function of a multiple-member and multiple-objective pension plan deserves examination. Different dynamic portfolio choice frameworks could exploit the covariance structure differently. Also the implications of the intertemporal covariances in a broader asset liability management context that adapts contributions, indexation, mortality risk and shortfall constraints deserves more scrutiny.

Similarly, this chapter has only considered the statistical properties of alternative investments. Investors sometimes do not invest in alternatives due to implementation issues or for reasons of liquidity, reputation risk or legal constraints. Implementation issues include advanced risk management and legal issues with different requirements than for stocks and bonds, high entrance costs or high manager selection skills. Liquidity forms a restriction whenever the desired allocation to an asset class is not available in the market at realistic transaction costs. Reputation risk comes in as most institutional investors are evaluated and compared to their peers and competitors, while legal constraints could follow from rules which restrict investments to specific classes (e.g. no hedge funds allowed). Moreover, an investor could be reluctant to invest in alternatives if its peers only invest in more traditional assets like stocks and bonds. 


\subsection{Appendix: Risk and return at various horizons}

With $z_{t}$ defined by the first order VAR in (2.20), we can forward substitute to obtain $z_{t+j}$ as

$$
z_{t+j}=\left(\sum_{i=0}^{j-1} \boldsymbol{\Phi}_{1}^{i}\right) \boldsymbol{\Phi}_{0}+\boldsymbol{\Phi}_{1}^{j} z_{t}+\sum_{i=0}^{j-1} \boldsymbol{\Phi}_{1}^{i} u_{t+j-i}
$$

Therefore the $j$-period ahead forecast is

$$
\hat{z}_{t+j \mid t}=\sum_{i=0}^{j-1} \boldsymbol{\Phi}_{1}^{i} \boldsymbol{\Phi}_{0}+\boldsymbol{\Phi}_{1}^{j} z_{t}
$$

For cumulative returns over $\tau$ periods we need $Z_{t+\tau}^{(\tau)}=\sum_{j=1}^{\tau} z_{t+j}$, which has expectation

$$
\hat{Z}_{t}^{(\tau)}=\sum_{j=1}^{\tau}\left(\sum_{i=0}^{j-1} \boldsymbol{\Phi}_{1}^{i} \boldsymbol{\Phi}_{0}+\boldsymbol{\Phi}_{1}^{j} z_{t}\right)
$$

and forecast error

$$
Z_{t+\tau}^{(\tau)}-\hat{Z}_{t}^{(\tau)}=\sum_{j=1}^{\tau} \sum_{i=0}^{j-1} \boldsymbol{\Phi}_{1}^{i} u_{t+j-i}
$$

The covariance matrix of the $\tau$-period errors follows as

$$
\Sigma^{(\tau)}=\sum_{j=1}^{\tau}\left(\left(\sum_{i=0}^{j-1} \boldsymbol{\Phi}_{1}^{i}\right) \Sigma\left(\sum_{i=0}^{j-1} \boldsymbol{\Phi}_{1}^{i}\right)^{\prime}\right)
$$

The matrix $\Sigma^{(\tau)}$ contains all information on the (co-)variances of real asset returns and returns in deviation of the liabilities. 



\section{Chapter 3}

\section{Strategic asset allocation for}

\section{long-term investors:}

\section{parameter uncertainty and prior information ${ }^{1}$}

\subsection{Introduction}

The optimal behavior of long-run investors differs from myopic investors if asset returns are predictable. The revived interest in strategic asset allocation and the well-documented predictability in stocks and bonds indicates that optimal portfolio choice is horizon dependent. ${ }^{2,3}$ Merton $(1969,1971)$ showed that under changing investment opportunities optimal portfolio decisions of long-term investors differ from those of short-term investors. Long-term investors can not only benefit from risk diversification between assets, but also from time diversification within an asset class.

\footnotetext{
1 This chapter is based on Hoevenaars, R.P.M.M., R.D.J. Molenaar, P.C. Schotman, and T.B.M. Steenkamp (2007),Strategic Asset Allocation for Long-Term Investors: Parameter Uncertainty and Prior Information, Working Paper, Maastricht University.

2 The predictability of asset returns is often described to be captured by valuation ratios as the dividend yield, price-earnings ratio, and also by inflation, interest rates and the term spread. A few references to this large literature are Barberis (2000) for work on the dividend yield, Campbell and Shiller (1988) for the price-earnings ratio, Lettau and Ludvigson (2001) for the consumption-wealth ratio, and see for example the enormous amount of evidence against the expectations model of the term structure reviewed in Dai and Singleton (2002, 2003). As the evidence is not uncontroversial we also refer to Goyal and Welch (2003) for a dissenting view.

3 We refer to Campbell and Viceira (2005), Detemple, Garcia and Rindisbacher (2005), Brandt and Santa-Clara (2006), Hoevenaars, Molenaar, Schotman and Steenkamp (2007).
} 
The optimal portfolio contains a speculative component and a hedge component. The hedge component depends on the covariance properties of returns, whereas the speculative demand depends on expected excess returns in the next period. How robust are the horizon dependent risk properties of stocks, bonds and T-bills to parameter uncertainty? How robust are these term structures of risk to prior views about the future level of predictor variables as the dividend yield?

This chapter uses bayesian methods to consider the strategic asset allocation of long-term investors. The investor adapts parameter uncertainty and prior information about the level of expected asset returns in optimal portfolio choice. His investment universe consists of stocks, bonds and T-bills. First, we consider an investor who has a prior belief that the future level of expected asset returns, inflation and macro economic variables as the dividend yield and interest rates differs from the historical unconditional mean in the data. Wachter and Warusawitharana (2007), Avramov (2004) and Pastor (2000) suggest that allowing informative beliefs in the portfolio choice decision can be superior to using data alone. Furthermore, the speculative part of optimal portfolio choice in a mean variance or power utility buy-and-hold setting is extremely sensitive to small changes in the expected return assumptions (See Kan and Zhou (2006) and DeMiguel, Garlappi and Uppal (2006)). Pastor and Stambaugh (2000) and Jorion (1986) and many others have suggested priors that shrink the portfolio weights towards an asset pricing model. In this chapter informative priors shrink the mean of the future return distribution to the prior beliefs. This makes it possible to control the speculative part of the portfolio choice.

Another motivation for such a prior stems from the sensitivity of historical average returns to the choice of the sample period (unlike volatilities and correlations). Therefore investors can have good reasons to base their future return expectations not only on historical data, but also on other criteria. It is common practice for long-term investors to use historical data to estimate volatilities and correlations of the long-term future return distribution, and use economic theory and current market circumstances to form their view about the long-term mean of the future return distribution. We consider a robust portfolio which minimizes the expected utility loss when there are multiple experts with competing beliefs. In our case the robust portfolio is based on an informative prior which is rather conservative about stocks, a little optimistic about bonds and includes parameter uncertainty.

Furthermore, the persistence in the dividend yield, interest rates and yield spreads makes it hard to estimate the long-term mean of these state variables. If it turns out that the true long-term mean of the dividend yield is far above or below the mean in the sample period, the autocorrelation parameter of the dividend yield is 
underestimated. More persistency of the dividend yield has a direct effect on the term structures of risk of for instance stock returns. The informative prior on the future level of the state variables can therefore influence the hedge part of optimal portfolio choice. We find that imposing prior information about the mean of the future distribution of the state variables can change the term structures of risk.

Second, we account for parameter uncertainty in a bayesian setting as an additional source of uncertainty in optimal portfolio choice. We also study the robustness of the term structures to parameter uncertainty. We find that predictability dominates parameter uncertainty most of the times. Nevertheless, time diversification properties within asset classes in terms of volatilities weaken if parameter uncertainty is incorporated. The risk properties in the cross section are much more stable than the ones in the time dimension. Risk diversification properties between asset classes in terms of correlations seem robust against parameter uncertainty. Apparently, the impact of parameter uncertainty on the covariance is proportional to the impact on the variance. As a consequence the effect of parameter uncertainty cancels out to a large degree in terms of correlation.

This chapter builds on previous research that applies bayesian methods in asset allocation $^{4}$. Brennan (1998) considers the role of learning about the mean return on risky assets on dynamic portfolio choice when there are constant investment opportunities. In this chapter we adapt informative priors about mean returns in the presence of time varying investment opportunities and parameter uncertainty. We also derive a robust portfolio when there are competing experts with different prior beliefs. Unlike Brennan (1998), Xia (2001) and Brandt, Goyal, Santa-Clara and Stroud (2005), we ignore learning in the optimal portfolio choice. Learning induces the optimal asset allocation to be less sensitive to predictability, which reduces horizon effects.

Kandel and Stambaugh (1996) find that weak predictability of stock returns can still have large impact on the optimal portfolio choice. They use the sample evidence to update prior beliefs about regression coefficients. Wachter and Warusawitharana (2007) examine optimal portfolio choice for an investor who is skeptical about the predictability in the data. They model an informative prior on the regression coefficients as the expected improvement in the maximum Sharpe ratio from conditioning portfolio choice on the predictor variable. We specify an informative prior on the level of future asset returns and state variables, rather than on the amount of predictability as in Wachter and Warusawitharana (2007), Shanken and

\footnotetext{
4 A growing number of studies uses bayesian methods in finance. Apart from the references in the text we refer to Pastor and Stambaugh (1999), Lewellen and Shanken (2002), Stambaugh (1999), Pastor (2000), Avramov (2002), Cremers (2002), Kadiyala and Karlsson (1997), Hollifield, Koop and Li (2003), Fugazza, Guidolin, and Nicodano (2007).
} 
Tamayo (2005), Avramov (2004), Xia (2001), Kandel and Stambaugh (1996) and many others. We also focus on a long-term investor who accounts for time varying investment opportunities.

Since the early work by Klein and Bawa (1976) and Brown (1979) many studies account for parameter uncertainty in portfolio choice problems. Barberis (2000) analyzes optimal asset allocation for two asset categories: stocks and cash. $\mathrm{He}$ shows that incorporating parameter uncertainty can substantially reduce the horizon effect. We extend Barberis' work in a number of ways. Our investment universe includes stocks, bonds and T-bills. We do not only focus on time diversification, but particularly on risk diversification. Furthermore, we describe the return dynamics by a vector autoregression for asset returns and macro-economic state variables.

Black and Litterman (1992) develop a bayesian framework in which the optimal portfolio is the scaled market equilibrium portfolio plus a weighted sum of portfolio's representing prior views. The Black-Litterman approach is widely used for (global) tactical asset allocation. The approach in this chapter focuses on the long-term strategic asset allocation. It deals with parameter uncertainty, asset return predictability, and incorporates time varying investment opportunities. Furthermore, the return dynamics are based on a vector autoregression, and portfolio constraints are easily implemented. This chapter also derives the robust portfolio which minimizes the expected utility loss when multiple experts have different prior beliefs about expected returns, interest rates and macro economic variables.

The remainder of this chapter is organized as follows. Section 3.2 describes the modeling framework for the return dynamics. We consider a vector autoregression for returns and macro-economic state variables and we use bayesian methods to incorporate parameter uncertainty and prior information about the level of future returns and state variables. Section 3.3 describes the used data and elaborates on the prior information about the level of the future mean. Section 3.4 discusses the empirical results. We discuss the estimation results, and we show the robustness of the term structures to parameter uncertainty and prior information. In section 3.5 we show the impact of parameter uncertainty and prior information on optimal portfolio choice for a buy-and-hold investor. Section 3.6 defines a robust portfolio as the portfolio of an investor with a prior that has minimal costs among all priors that we consider. Finally, section 3.7 concludes. 


\subsection{Bayesian modeling framework}

Following Campbell and Viceira (2005), among others, we describe the return dynamics by a first-order vector autoregression (VAR) model. Specifically, let

$$
y_{t}=\left(\begin{array}{c}
r_{t} \\
x_{t} \\
s_{t}
\end{array}\right)
$$

where $r_{t}$ is the real return on the three month T-Bill, $x_{t}$ contains excess returns on stocks $\left(x_{s}\right)$ and bonds $\left(x_{b}\right)$, and $s_{t}$ is a vector of other state variables that capture important dynamics in the data. In the empirical model $s_{t}$ will have three elements: the nominal return on a 3-month T-bill, dividend yield and yield spread. Risk and return dynamics follow the first order VAR,

$$
y_{t+1}=c+B y_{t}+\epsilon_{t+1}
$$

where $\epsilon_{t}$ is normally distributed with zero mean and covariance matrix $\Sigma$.

The main purpose of the analysis is the effects of parameter and model uncertainty. Parameter uncertainty is accounted for by a bayesian analysis of the VAR. Model uncertainty is represented by a series of alternative priors on the unconditional mean of the asset returns and state variables.

Our first prior is uniform prior on $c$ and $B$ and an invariant prior for $\Sigma$,

$$
p(c, B, \Sigma) \propto|\Sigma|^{-(n+1) / 2} I(B)
$$

The indicator function $I(B)$ restricts the domain of the VAR to the stationary region $\mathcal{C} \subset R^{n \times n}$ such that the maximum eigenvalue of $B$ is less than one. We include this prior as a benchmark for comparison with the informative priors to be specified below. The posterior mode of the flat prior coincides with the least squares estimates of the VAR. It is also a benchmark in the sense that the flat prior has previously been used by Barberis (2000) in his analysis of the effects of parameter uncertainty on long-term portfolio decisions between the riskfree asset and equity.

In order to impose prior views on the unconditional mean of asset returns and state variables, we rewrite the VAR model (3.1) as

$$
y_{t+1}=\mu+B\left(x_{t}-\mu\right)+\epsilon_{t+1}
$$

where $\mu$ is the vector of unconditional means of all elements in the VAR. Our informative prior on $\mu$ is specified as a normal distribution with mean $\mu_{0}$ and covariance matrix $\Omega_{0} / \kappa$. Both $\mu_{0}$ and $\Omega_{0}$ are exogenously specified. The scalar parameter $\kappa$ 
is a shrinkage factor. It represents the investors degree of confidence in his prior information. A shrinkage factor close to zero corresponds to a dispersed prior on $\mu$. A large shrinkage factor gives much weight to the prior information and a precision factor equal to infinity imposes the mean. For a clear interpretation of $\kappa$ we set $\Omega_{0}$ equal to the long-run sample covariance matrix of the time series,

$$
\Omega_{0}=\frac{1}{T^{2}} \sum_{\ell=-L}^{L}\left(1-\frac{|\ell|}{L+1}\right) \sum_{t}\left(y_{t}-\bar{y}\right)\left(y_{t}-\bar{y}\right)^{\prime}
$$

With this choice of $\Omega_{0}$ a precision factor equal to one gives equal weight to the prior information and the data in the likelihood. We vary $\kappa$ to increase or decrease the precison of the prior while keeping $\Omega_{0}$ fixed.

Apart from the informative prior on $\mu$, the priors on $B$ and $\Sigma$ are as in the benchmark prior. We thus obtain the joint prior

$$
p(\mu, B, \Sigma) \propto I(B)|\Sigma|^{-(n+1) / 2} \exp \left(-\frac{1}{2} \kappa\left(\mu-\mu_{0}\right)^{\prime} \Omega_{0}^{-1}\left(\mu-\mu_{0}\right)\right),
$$

The non-linearity in the parameters, $c=(I-B) \mu$, makes this setting different from a uniform prior on all coefficients including the constant term $c$. The prior on the mean $\mu$ can be transformed back to a prior on the constant term $c$ in the reduced form parameterization (3.2). Define $A=I-B$. The transformation $c=A \mu$ gives a Jacobian $|A|^{-1}$, leading to the implied joint density of $c$ and $B$

$$
p(c, B) \propto|A|^{-1} \exp \left(-\frac{1}{2} \kappa\left(c-A \mu_{0}\right)^{\prime}\left(A \Omega_{0} A^{\prime}\right)^{-1}\left(c-A \mu_{0}\right)\right)
$$

Since the matrix $A$ is singular at points where $B$ has a unit root, the prior forces a singularity on the constant terms $c$ when the dynamics of the system move towards the unit root. Prior independence of $\mu$ and $B$ is thus very different from prior independence of $c$ and $B$. This prior correlation between $c$ and $B$ will have a strong effect on the posterior for $B$. Conditional on a small constant term, in the sense that $c-A \mu_{0}$ is small, the prior induces a large weight on one or more unit roots in the system. Relative to the uniform prior (3.2) the specification of an independent prior directly on the unconditional mean will shift the posterior towards the unit root. From the results in Schotman (1994) we infer that the posterior of $B$ will be proper with well-defined first and second moments if the prior on $\mu$ is proper in the sense that $\kappa>0$.

As an illustration of the prior, figure 3.1 shows the marginal prior distribution of $c$ in the univariate $\operatorname{AR}(1)$ case when $\mu$ is normally distributed with mean $\mu_{0}=2$ and variance $\Omega_{0}=2$, while the first order autocorrelation coefficient, the single element in $B$, has a uniform distribution. The density has a distinct spike at $c=0$. Even 
more telling are the conditional densities $p(B \mid c)$ for alternative values of $c$. For the same prior, figure 3.2 shows the conditional densities of $B$ for $c=0$ and $c=0.25$. Conditional on $c=0$ the density is highly concentrated on the unit root, whereas for $c=0.25$, the density drops to zero for $B>0.98$. Inference on the autocorrelation is strongly correlated with inference on the constant term in the model.

Collect all parameters in $\theta=(\mu, \operatorname{vec}(B), \operatorname{vech}(\Sigma))$. Our posterior inference combines the prior with the conditional likelihood function

$$
L(\mathbf{Y} \mid \theta)=\prod_{t=1}^{T} L\left(y_{t} \mid y_{t-1}, \theta\right)
$$

which takes the initial condition $y_{0}$ as given. Inference on the parameters proceeds through a simple Gibbs sampler. Technical details are provided in the appendix.

Uhlig (1994) and Wachter and Warusawitharana (2007) derive the unconditional likelihood by combining the likelihood of the first observation with the conditional likelihood of the other observations in (3.7). The first observation is then a draw from the unconditional distribution of $y_{t}$, which has mean $\mu$ and covariance matrix $\Psi$ satisfying

$$
\operatorname{vec}(\Psi)=(I-B \otimes B)^{-1} \operatorname{vec}(\Sigma)
$$

This only leads to a tractable posterior in the univariate case. In that case the conditional posteriors of $B, c$ and $\mu$, given all other parameters, remain normal, thus enabling a simple Gibbs sampler for the posterior analysis. In our six-dimensional VAR the term $(I-B \otimes B)^{-1}$ induces such a strong deviation from conditional normality close to the unit root that a Gibbs sampler or Metropolis-Hastings algorithm are more difficult to implement. 


\section{Figure 3.1: Marginal Prior on $c$}

The figure shows the implied marginal prior on $c=\mu(1-b)$ with a flat prior on $b \in[0,1]$ and $\mu \sim N\left(\mu_{0}, \omega_{0}^{2}\right)$.

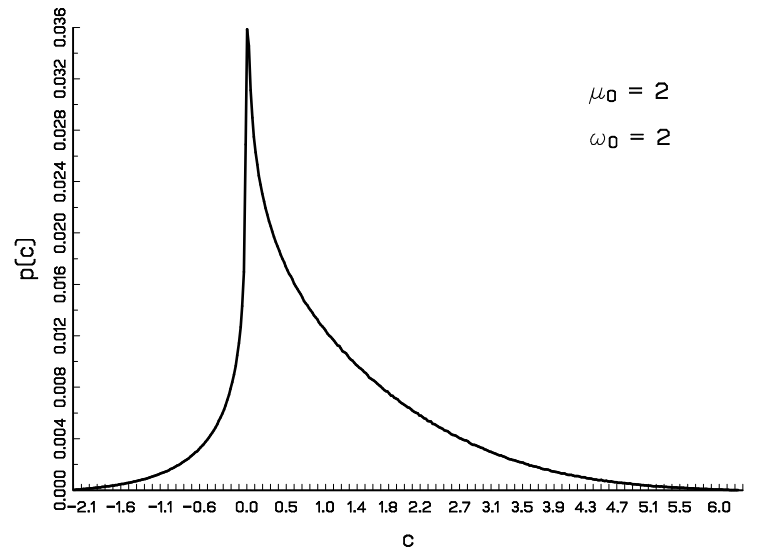

Figure 3.2: Conditional Prior on $b$

The figure shows the conditional prior on $b$ given $c=(1-b) \mu$ with a flat marginal prior on $b \in[0,1]$ and $\mu \sim N\left(\mu_{0}, \omega_{0}^{2}\right)$.

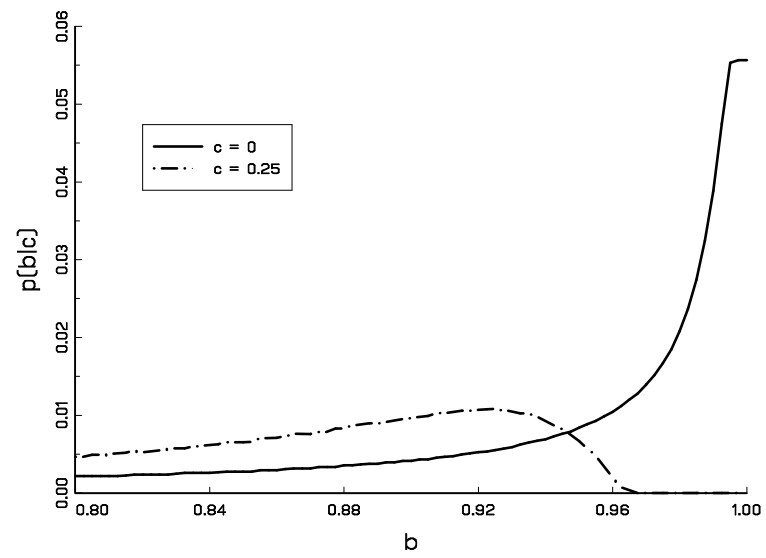




\subsection{Data and Priors}

We consider three asset classes (stocks, bonds and T-Bills) and three state variables that help predict asset returns (inflation, dividend yield and term spread).

For our empirical analysis we use quarterly US data. All series start in 1952:I; and end in 2003:IV. The 90-days T-bill and the 10-years constant maturity yield are from the FRED website. ${ }^{5}$ In order to generate the yield spread we obtain the zero yield data from Duffee (2002). ${ }^{6}$ As these data are only available until 1998:IV, we have extended the series using a similar approach for the data after 1998:IV. For inflation we use the non-seasonally adjusted consumer price index for all urban consumers and all items also from the FRED website. Data on stock returns and the dividend price ratio are based on the S\&P Composite and are from the "Irrational Exuberance" data of Shiller. ${ }^{7}$ We construct the gross bond return series from 10 year constant maturity yields on US bonds using a log-linear approximation approach as in Campbell, Lo and MacKinlay (1997).

Table 3.1 provides summary statistics. The sample equity premium of more than $7 \%$ is much larger than most recent studies on the prospective equity premium suggest. For example, Claus and Thomas (2001) suggest a forward looking equity premium of about $3.5 \%$. Since our post-second-world-war sample period is rather short, the sample means of the equity and bond premia might be very poor estimates of the long-run expected returns. But even with data over very long horizons, investors can form very different opinions about these risk premia. Dimson, Marsh and Staunton (2002) compare bond and equity premia of sixteen countries over various long horizons. Based on their evidence long-run equity and bond premia show huge cross sectional variation.

Our approach in this chapter is to use multiple priors for the expected returns and the other state variables. Among these priors we implement both optimistic outlooks and more negative views on the future. We also distinguish between very confident views and highly dispersed priors on the long run expected returns. In specifying a prior for the equity premium we take into account the other variables in the system in order to define coherent long-term means. As a particular way of implementing such priors we split the historical data in two parts: NBER expansion periods and NBER contraction periods. Averages in the expansion periods represent a positive outlook, whereas the contraction period averages define a pessimistic outlook for long-term means.

\footnotetext{
5 http://research.stlouisfed.org/fred $2 /$

6 http://faculty.haas.berkeley.edu/duffee/affine.htm

7 http://aida.econ.yale.edu/ shiller/data.htm
} 
Table 3.1: Summary Statistics

\begin{tabular}{|c|c|c|c|c|c|c|}
\hline \multicolumn{7}{|c|}{$\begin{array}{l}\text { Annualized means, standard deviations, autocorrelations and Sharpe } \\
\text { ratios for the entire sample (1952:II - 2003:IV) and two subsamples: } \\
\text { NBER contraction periods and NBER expansion periods. The mean log } \\
\text { returns are adjusted by one-half their variance so that they reflect mean } \\
\text { gross returns. Standard errors of the mean ("se") are computed using } \\
\text { the Newey-West estimate of the long-run variance. Variables are real } \\
\text { 3-months T-Bill return }(r) \text {, excess stock returns }\left(x_{s}\right) \text {, excess bond returns } \\
\left(x_{b}\right) \text {, nominal Treasury Bill return }\left(r_{n o m}\right) \text {, dividend yield }\left(d_{p}\right) \text { and term } \\
\text { spread }(S) \text {. }\end{array}$} \\
\hline & $r$ & $x_{s}$ & $x_{b}$ & $r_{n o m}$ & $d_{p}$ & $S$ \\
\hline \multicolumn{7}{|c|}{ 1952:II - 2003:IV } \\
\hline Average & 1.21 & 7.04 & 1.46 & 5.10 & -3.43 & 1.21 \\
\hline Std.Dev. & 1.34 & 15.89 & 9.58 & 1.36 & 0.39 & 0.59 \\
\hline se & 0.23 & 1.05 & 0.68 & 0.32 & 0.19 & 0.10 \\
\hline $\operatorname{AR}(1)$ & 0.43 & 0.08 & -0.04 & 0.93 & 0.97 & 0.79 \\
\hline Sharpe & & 0.44 & 0.15 & & & \\
\hline \multicolumn{7}{|c|}{ NBER Contraction (33 observations) } \\
\hline Average & 1.47 & 4.75 & 6.50 & 5.74 & -3.20 & 1.22 \\
\hline Std.Dev. & 1.96 & 23.00 & 13.65 & 1.90 & 0.40 & 0.60 \\
\hline Sharpe & & 0.21 & 0.48 & & & \\
\hline \multicolumn{7}{|c|}{ NBER Expansion (175 observations) } \\
\hline Average & 1.33 & 7.47 & 0.50 & 4.98 & -3.47 & 1.21 \\
\hline Std.Dev. & 1.19 & 14.12 & 8.52 & 1.22 & 0.38 & 0.59 \\
\hline Sharpe & & 0.53 & 0.06 & & & \\
\hline
\end{tabular}

The prior on the unconditional means affects both the expected returns directly as well as the other state variables. Their effect on the results is very different. The speculative part of optimal portfolio choice is extremely sensitive to small changes in the expected returns. Chopra and Ziemba (1993) argue that the primary emphasis in portfolio choice should be on obtaining superior estimates for means. Although historical data can provide robust estimates of future volatility and correlation, historical average returns are very sensitive to the choice of the data period. Investors therefore have good reasons to base their future return expectations not only on historical data, but also on other criteria. A prior on the level of future returns is already in place for some time in global tactical asset allocation at many institutional 
investors and asset managers (see Black and Litterman (1992)). In practice, prior information is not only used for tactical asset allocation, but also for strategic asset allocation. It is common practice for long-term investors to use historical data to estimate volatilities and correlations of the long-term future return distribution, but use economic theory and current market circumstances to form their view about the long-term mean. An informative prior on the mean of the future return distribution makes it possible to control the speculative part of the portfolio choice.

The persistence in the dividend yield, interest rates and yield spread makes it hard to estimate the long-term mean of these state variables. If it turns out that the true long-term mean of the dividend yield is far above or below the mean in the sample period, the autocorrelation parameter of the dividend yield is underestimated. More persistence of the dividend yield has a direct effect on the term structures of risk of for instance stock returns. As a result this influences the hedge part of optimal portfolio choice.

In this chapter we relate our prior information about the mean of the future distribution to business cycles. We use the NBER classification for business cycle expansion and contraction periods. The NBER Business Cycle Dating Committee chooses turning points in the economy. Their decisions are based on economic activity which is visible in macro economic variables as real (personal) income, real GDP, industrial production and employment. There is no fixed rule about the weights of various indicators or about what other measures contribute to the process. We assign each observation in our 1952:I - 2003:IV sample period to either contraction or expansion (see Figure 3.3). A contraction starts at the peak of a business cycle and ends at the trough, and the expansion vice versa. Nine contraction periods exist in our data sample, which have a duration between two and six quarters. Ten expansion periods exist in our sample period with a duration ranging from four to 40 quarters. Contractions appear to be much shorter than expansion, and consequently 175 out of the 208 observations are assigned to expansions, and the remaining 33 observations are contractions. We choose the closest quarter to end the contraction or expansion whenever a through occurs during a quarter. The second and third blocks in Table 3.1 give the summary statistics for the NBER contraction and expansion periods. The Sharpe ratios clearly reflect the different risk-return trade-offs between the periods. Bonds seem less attractive than stocks during expansion (Sharpe ratio of 0.16 versus 0.53 , respectively), whereas they seem more attractive during contractions (Sharpe ratio of 0.48 versus 0.21 , respectively). The difference in Sharpe ratios indicates the wide range of reasonable expectations. This range is much wider than the "good deal bounds" in Cochrane and Saa-Requejo (2000). Also the averages of state variables as the short interest rate, dividend yield, and term spread differ 
Figure 3.3: NBER expansion and contraction periods

NBER expansion periods and contraction periods in our sample are assigned 1 and 0 respectively.

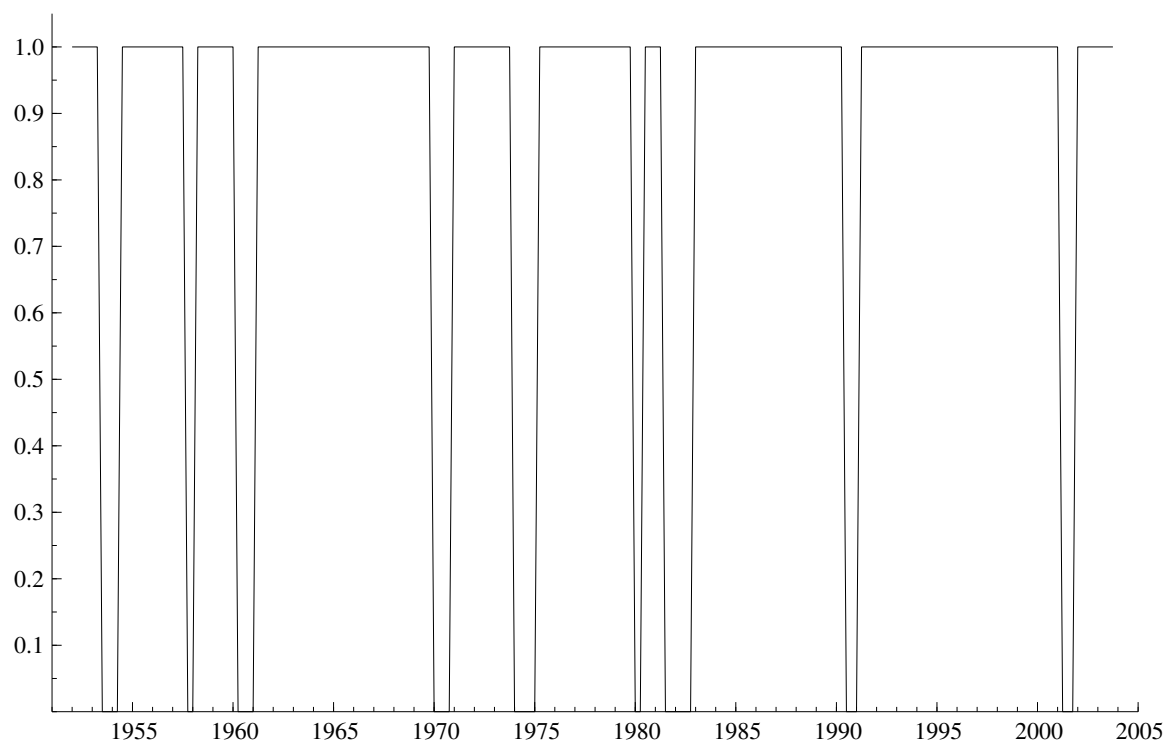

between the two periods. Fama and French (1989) link the dividend yield and yield spread to the business cycle. They argue that the risk premia are high in contraction periods and low in expansion periods. The opposite applies to the dividend price ratio which is high in expansion periods and low in contraction periods. Since the dividend yield adjusts very slowly over time, it describes long run business cycles. The yield spread, on the other hand, is less persistent and describes shorter business cycles. The level of the informative prior on the mean is set at either the averages over the contraction periods, or the averages over the expansion periods.

The choice of the prior information is always a debatable issue in bayesian statistics. Investors can have good reasons to base their future return expectations not only on historical data, but also on current market circumstances (e.g. forward rates can be interpreted as the view of the market about interest rates), economic theory (see Fama and French (2002) who use dividends and earnings growth to measure the expected rate of capital gains) and human judgement (see Welch (2001) who provides a consensus forecast for the one-year equity premium). Alternatively, future expected returns could be based on a equilibrium approach as in Black and 
Litterman (1992). The market portfolio (or benchmark of the investor) can be seen as the optimal portfolio when investors have no explicit views regarding the expected returns and risks of the assets in his investment universe. Once the suitable benchmark or market portfolio is identified and the corresponding volatilities and correlations are defined, implied returns can be derived from for instance a (International) Capital Asset Pricing Model ((I)CAPM). These implied returns can be interpreted as equilibrium returns, and subsequently as prior information for strategic asset allocation.

\subsection{Empirical results}

\subsubsection{Estimation results}

The VAR system is estimated on the entire sample. Tables 3.2 and 3.3 summarize the OLS parameter estimates together with the correlations and standard deviations of the residuals. We highlight the most important results. First, the three state variables (nominal interest rate, dividend yield, term spread) are almost univariate $\mathrm{AR}(1)$ processes. The maximum eigenvalue of the coefficient matrix of 0.982 indicates that the estimated VAR is stationary. Second, the nominal interest rate and the dividend price ratio predict excess stocks returns. As in Campbell and Viceira (2005) the combination of a negative correlation of shocks to the dividend price ratio and stocks, and the positive predictive coefficient of the dividend price ratio imply mean reversion in stocks returns. The excess return on bonds is related to the yield spread, the nominal interest rate and stock returns. Third, bond returns are also mean-reverting. The nominal interest rate is a predictor of excess bond returns, which has the required opposite signs of the predictive coefficient and residual correlation. The term spread leads to a mean aversion part. The low $R^{2}$ of both stocks and bond returns of $8 \%$ implies that a large degree of the return variation remains unexplained. However, even a low degree of explanatory power on a quarterly basis can be economically meaningful at longer horizons (see Campbell and Thompson (2007)).

The priors influence the predictability of stock and bond returns, and the persistence of state variables. Tables 3.4 and 3.5 indicate that the priors substantially influence the posterior means and standard deviations of the VAR coefficients. The predictability coefficient of the dividend price ratio to stocks varies between 4.304 for the flat prior and 2.68 for the pessimist. The tables also shows that a flat prior has different implications on the posteriors than a dispersed prior on $\mu$. If both $c$ and $B$ are approximately normal distributed the posterior density of $\mu=(I-B)^{-1} c$ 
Table 3.2: Parameter estimates

The table reports full sample (1952:II - 2003:IV) OLS parameter estimates of the VAR $y_{t+1}=c+B y_{t}+\epsilon_{t+1}$ with variables: real 3-months T-Bill return $(r)$, excess stock returns $\left(x_{s}\right)$, excess bond returns $\left(x_{b}\right)$, nominal Treasury Bill return $\left(r_{n o m}\right)$, dividend yield $\left(d_{p}\right)$ and term spread $(S)$. Standard errors are in parentheses. The last column contains the $R^{2}$.

\begin{tabular}{lccccccc}
\hline & $r_{n o m, t}$ & $r_{t}$ & $d_{p, t}$ & $S_{t}$ & $x_{s, t}$ & $x_{b, t}$ & $R^{2}$ \\
\hline$r_{n o m, t+1}$ & 0.96 & 0.00 & 0.03 & 0.08 & 0.00 & 0.00 & 0.89 \\
& $(0.03)$ & $(0.03)$ & $(0.04)$ & $(0.06)$ & $(0.00)$ & $(0.00)$ & $\cdot$ \\
$r_{t+1}$ & 0.25 & 0.36 & -0.10 & 0.30 & 0.00 & 0.01 & 0.24 \\
& $(0.07)$ & $(0.07)$ & $(0.11)$ & $(0.16)$ & $(0.01)$ & $(0.01)$ & $\cdot$ \\
$d_{p, t+1}$ & 0.01 & 0.00 & 0.97 & -0.02 & 0.00 & 0.00 & 0.96 \\
& $(0.01)$ & $(0.01)$ & $(0.02)$ & $(0.02)$ & $(0.00)$ & $(0.00)$ &. \\
$S_{t+1}$ & 0.02 & 0.00 & -0.03 & 0.82 & 0.00 & 0.00 & 0.64 \\
& $(0.02)$ & $(0.02)$ & $(0.03)$ & $(0.05)$ & $(0.00)$ & $(0.00)$ & $\cdot$ \\
$x_{s, t+1}$ & -1.81 & 0.34 & 4.08 & 2.03 & 0.04 & 0.17 & 0.08 \\
& $(0.97)$ & $(0.93)$ & $(1.48)$ & $(2.10)$ & $(0.07)$ & $(0.13)$ &. \\
$x_{b, t+1}$ & 0.90 & -0.13 & -0.36 & 4.71 & -0.07 & -0.06 & 0.08 \\
& $(0.58)$ & $(0.56)$ & $(0.89)$ & $(1.26)$ & $(0.04)$ & $(0.08)$ &. \\
\hline
\end{tabular}

Table 3.3: Residual correlation matrix

The table reports the residual correlation matrix $\Sigma$ of the VAR $y_{t+1}=c+B y_{t}+\epsilon_{t+1}$. Diagonal entries are standard deviations; off-diagonal entries are correlations.

\begin{tabular}{lrrrrrr}
\hline & $r_{n o m, t}$ & $r_{t}$ & $d_{p, t}$ & $S_{t}$ & $x_{s, t}$ & $x_{b, t}$ \\
\hline$r_{n o m, t}$ & 0.23 & - & - & - & - & - \\
$r_{t}$ & -0.31 & 0.60 & - & - & - & - \\
$d_{p, t}$ & 0.17 & -0.26 & 0.08 & - & - & - \\
$S_{t}$ & -0.83 & 0.12 & -0.09 & 0.18 & - & - \\
$x_{s, t}$ & -0.10 & 0.25 & -0.95 & 0.02 & 7.77 & - \\
$x_{b, t}$ & -0.64 & 0.40 & -0.23 & 0.12 & 0.20 & 4.67 \\
\hline \hline
\end{tabular}

has fat tails such that the posterior mean and standard deviation in table 3.4 do not exist. 
Table 3.4: Posterior means of VAR parameters

This table shows the effect of different priors on selected important VAR parameters. Entries denote posterior means. Posterior standard deviations are in parentheses.

\begin{tabular}{lcccccc}
\hline VAR coefficients & OLS & Flat & P01 & P100 & O01 & O100 \\
\hline$r_{n o m, t+1}, r_{n o m, t}$ & 0.96 & 0.95 & 0.96 & 0.96 & 0.96 & 0.95 \\
& $(0.03)$ & $(0.03)$ & $(0.03)$ & $(0.03)$ & $(0.03)$ & $(0.03)$ \\
$d_{p, t+1}, d_{p, t}$ & 0.97 & 0.97 & 0.97 & 0.98 & 0.97 & 0.97 \\
& $(0.02)$ & $(0.01)$ & $(0.01)$ & $(0.01)$ & $(0.01)$ & $(0.01)$ \\
$x_{s, t+1}, d_{p, t}$ & 4.08 & 4.30 & 3.92 & 2.68 & 3.91 & 4.17 \\
& $(1.48)$ & $(1.41)$ & $(1.38)$ & $(1.20)$ & $(1.37)$ & $(1.42)$ \\
$x_{b, t+1}, r_{n o m, t}$ & 0.90 & 0.96 & 0.79 & 1.08 & 0.80 & 0.97 \\
& $(0.58)$ & $(0.56)$ & $(0.55)$ & $(0.58)$ & $(0.56)$ & $(0.56)$ \\
$x_{b, t+1}, S_{t}$ & 4.71 & 4.75 & 4.53 & 4.97 & 4.54 & 4.76 \\
& $(1.26)$ & $(1.26)$ & $(1.27)$ & $(1.29)$ & $(1.27)$ & $(1.27)$ \\
\hline \hline
\end{tabular}

The posterior distributions for a few selected parameters are shown in Figures 3.4 and 3.5. The figures summarize the differences between the optimist and pessimist priors and the effect of the precision factor. As the precision factor rises (from 0.01 to 1 to 100 ), the posterior distributions of the means become denser and move towards the prior means. This pattern is very evident for stocks and bonds. A high degree of prior confidence $(\kappa=100)$ drives the posterior distribution of bond returns far to the right under the pessimist view. Since the mean of bond returns is lower in the optimist view than in the data, a high precision factor shifts the posterior distribution to the left. The opposite pattern is observed for stocks. The figures also show that the impact of the precision factor is larger for more persistent series. The posterior densities of the mean of the dividend yield and nominal interest rate become extremely tight for high precision factors, whereas the densities of posterior mean stock and bond returns are less dense. Furthermore, the maximum Eigenvalue of the posterior coefficient matrix depends on the prior. This affects the restrictiveness of the non-stationarity condition. For the uninformative prior $22 \%$ of the draws are discarded, because the condition is violated.

Figure 3.6 illustrates the effect for the mean of the nominal interest rate. The location of the posterior densities clearly reflect that the pessimist mean (5.74 on an annualized basis) is far above the mean in the data (5.10) and the mean in the 
Table 3.5: Posterior means of unconditional means

\begin{tabular}{lcccc}
\hline \hline \multicolumn{6}{l}{$\begin{array}{l}\text { This table shows the effect of different priors on the uncon- } \\
\text { ditional means. Entries denote posterior means. } \\
\text { standard deviations are in parentheses. }\end{array}$} & & \\
\hline Unconditional Mean & P01 & P100 & O01 & O100 \\
\hline Nominal rate & 1.3 & 1.4 & 1.1 & 1.2 \\
& $(0.8)$ & $(0.0)$ & $(0.7)$ & $(0.0)$ \\
Real T-Bill & 0.4 & 0.4 & 0.3 & 0.3 \\
& $(0.2)$ & $(0.0)$ & $(0.2)$ & $(0.0)$ \\
Dividend Yield & -3.5 & -3.2 & -3.7 & -3.5 \\
& $(0.5)$ & $(0.0)$ & $(0.4)$ & $(0.0)$ \\
Term Spread & 0.3 & 0.3 & 0.3 & 0.3 \\
& $(0.1)$ & $(0.0)$ & $(0.1)$ & $(0.0)$ \\
Equity premium & 0.7 & 0.5 & 0.7 & 1.6 \\
& $(0.5)$ & $(0.1)$ & $(0.5)$ & $(0.1)$ \\
Bond Premium & 0.3 & 1.3 & 0.4 & 0.1 \\
& $(0.2)$ & $(0.0)$ & $(0.2)$ & $(0.0)$ \\
\hline \hline
\end{tabular}

optimist view (4.98). Even $\kappa=1$ has an enormous impact on the centrality of the distribution. $\kappa=100$ reduces almost all uncertainty about the mean. $\kappa=0.01$ shows that the data do not provide a lot of information about the location of the mean nominal interest rate. The posterior distribution is extremely flat in this case.

Figure 3.7 demonstrates that the priors also influence the persistence of state variables. The pessimist view leads to more persistency in the dividend yield process. Since the pessimist mean $(-3.20)$ is above the data mean (-3.43), it takes longer to mean revert so that the posterior density of the autocorrelation coefficient shifts to the right. The effect is already observed for $\kappa=1$. However, the centrality around the posterior mean is hardly influenced by the confidence in the prior mean of the dividend yield.

\subsubsection{Term structures of risk}

How robust are the term structures of risk to parameter uncertainty and prior information? As an extension of Barberis (2000) we do not restrict ourselves to the time dimension, but also investigate risk properties in the cross-section.

We find that mean reversion is stocks and bonds dominates parameter uncertainty. The impact of parameter uncertainty is horizon dependent. It increases 
Figure 3.4: Posterior distributions for the pessimist prior

Posterior distributions of means, autocorrelation coefficients and maximum Eigenvalues of simulated covariance matrices and coefficient matrices of the joint posterior distribition in the Gibbs sampler under the pessimist prior. (20000 simulations). $\kappa=0.01$ : solid, $\kappa=1$ : bold solid, $\kappa=100$ : dashed
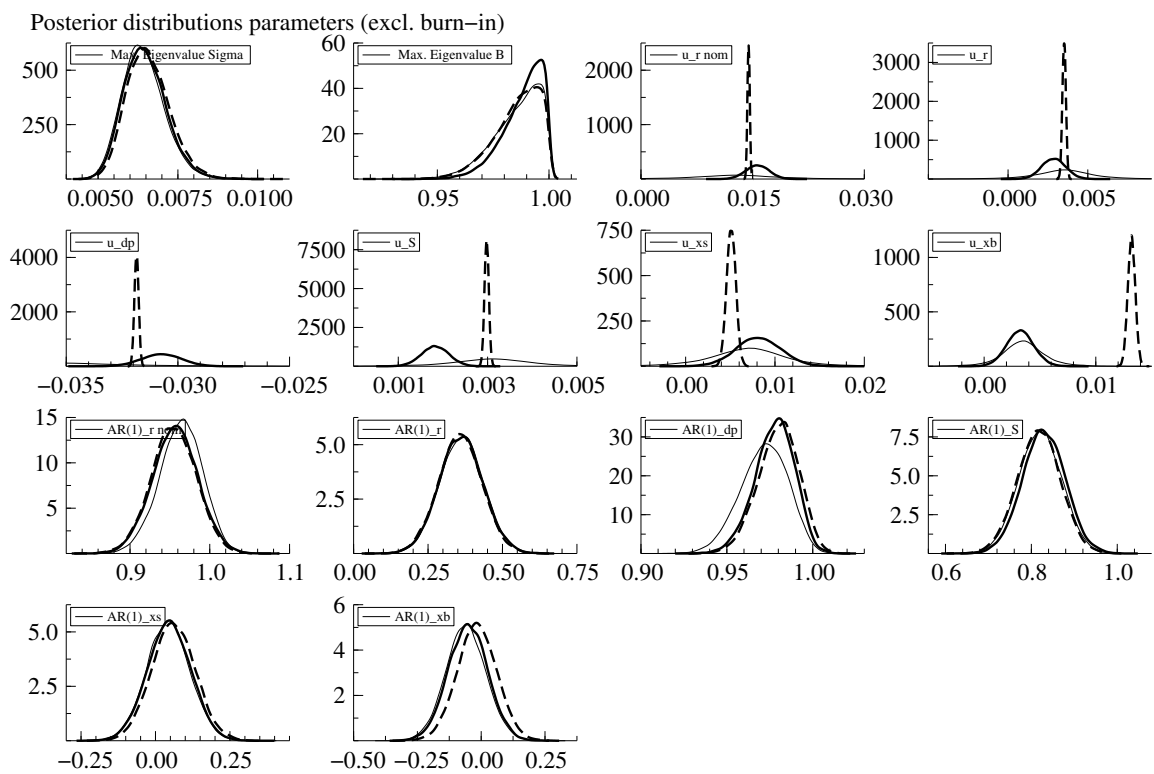

with the investment horizon. Mean uncertainty leads to a rise in annualized stock and bond volatility for investment horizons longer than 25 years. Furthermore, a pessimist prior reduces mean reversion in stock returns. In contrast to volatilities, correlations are robust against parameter uncertainty. As a consequence risk diversification between assets are much more stable than time diversification within an asset class.

Figure 3.8 shows the annualized standard deviation of real holding period returns on stocks, bonds and T-bills for investment horizons up to 50 years (in quarters). The solid lines represent the results without parameter uncertainty, which are in line with the results of Campbell and Viceira (2005). The impact of parameter uncertainty is reflected by the dashed lines. Obviously, the parameter uncertainty spread" should be positive. Parameter uncertainty increases the variance of risky asset categories over the investment horizon. This effect can be explained by the bayesian framework that updates prior probabilities of parameters. Following periods of high returns investors update their expectations for the following years upwards. The other way 
Figure 3.5: Posterior distributions for the optimist prior

Posterior distributions of means, autocorrelation coefficients and maximum Eigenvalues of simulated covariance matrices and coefficient matrices of the joint posterior distribition in the Gibbs sampler under the optimist prior, (20000 simulations). $\kappa=0.01$ : solid, $\kappa=1$ : bold solid, $\kappa=100$ : dashed
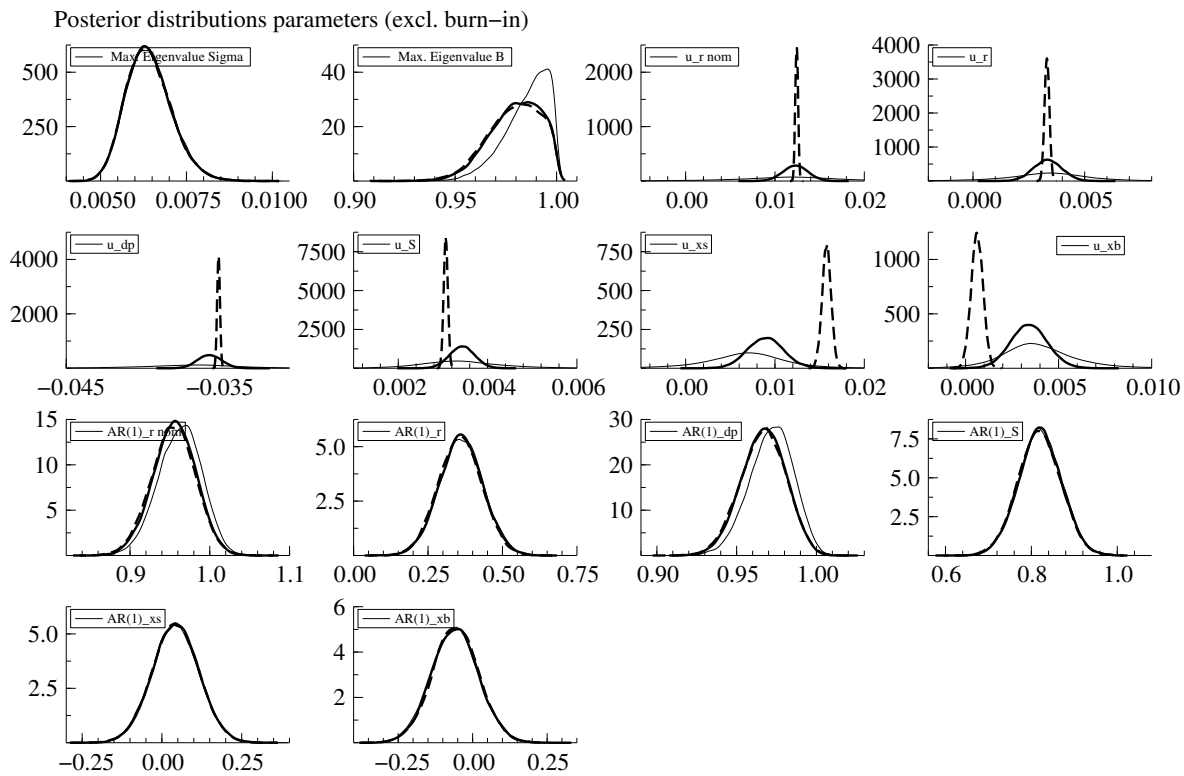

around, investors adjust their expectations downwards after a period of low returns. The resulting positive autocorrelation in returns causes the multi-period variance to increase, whereas the predictability reduces the multi period volatility. The graphs indicate that generally predictability dominates parameter uncertainty.

Ignoring parameter uncertainty leads to an underestimation of the annualized stock volatility by $0.5 \%, 1.5 \%, 2 \%$ and $3.75 \%$-points at a 1, 5, 10 and 25-year horizon, respectively. The rise in annualized volatilities for investment horizons longer than 25 years indicates that parameter uncertainty dominates the mean reverting dynamics that are captured by the dividend yield in the long run. This is due to the uncertainty about the expected return.

This effect is also strong for bonds. The weight of parameter uncertainty in the total risk is almost the same for bonds as for stocks. This suggests that incorporating parameter uncertainty has a similar effect on the attractiveness of bonds as it has on the attractiveness of stocks. The VAR estimates suggest that mean reversion in bonds is captured by the nominal T-bill, while the term spread captures mean 
Figure 3.6: Mean nominal interest rate

Posterior distributions of the mean of the nominal interest rate for the optimist and pessimist priors and for three precision factors $\kappa=0.01$ : solid, $\kappa=1$ : bold solid, $\kappa=100$ : dashed (20000 simulations).

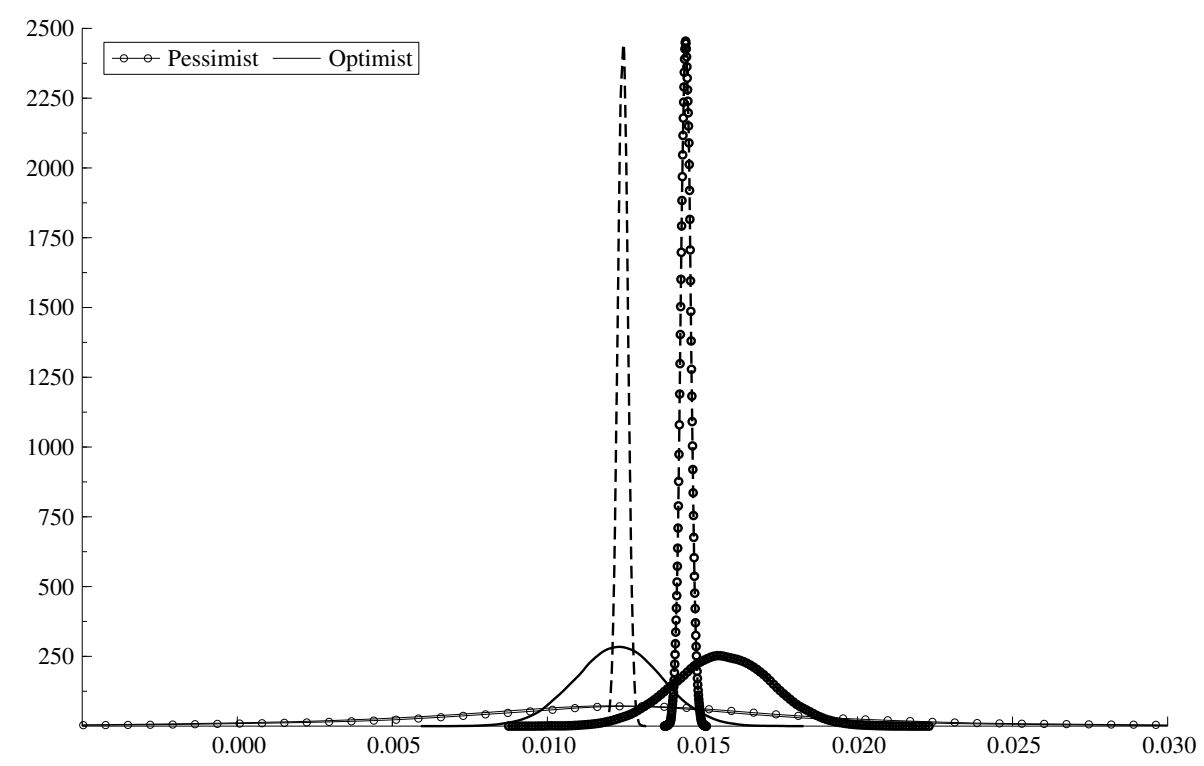

aversion in treasury returns. The first factor dominates in the case without parameter uncertainty for investment horizons up to 25 years. The latter one becomes much more important if this additional source of uncertainty is accounted for, and even dominates in the long run. The "parameter uncertainty spread", rises with the investment horizon and is for bonds around $0.5 \%, 1 \%, 1.5 \%$ and $2.5 \%$-points at a 1 , 5, 10 and 25-year horizon, respectively.

The unexpected cumulative inflation in the real T-bill and the uncertainty around the coefficient estimates of the underlying inflation process cause the mean averting pattern of the real T-bill to strengthen once parameter uncertainty is accounted for.

Prior information on the mean influences the term structures of annualized volatility. Figure 3.9 summarizes the annualized volatility for different priors. The solid circled line represents the term structure of risk for real stock returns according to the OLS approach thus based on fixed parameter estimates. The solid line with the plus gives the term structure according to the flat prior. The grey lines correspond to the pessimist and the black lines correspond to the optimist. The dashed lines represent a high $(\kappa=100)$ and the solid lines a low $(\kappa=0.01)$ degree 
Figure 3.7: Persistency of dividend yield

Posterior distributions of the autocorrelation coefficient of the dividend yield for the optimist and pessimist priors and for three precision factors $\kappa=0.01$ : solid, $\kappa=1$ : bold solid, $\kappa=100$ : dashed (20000 simulations).

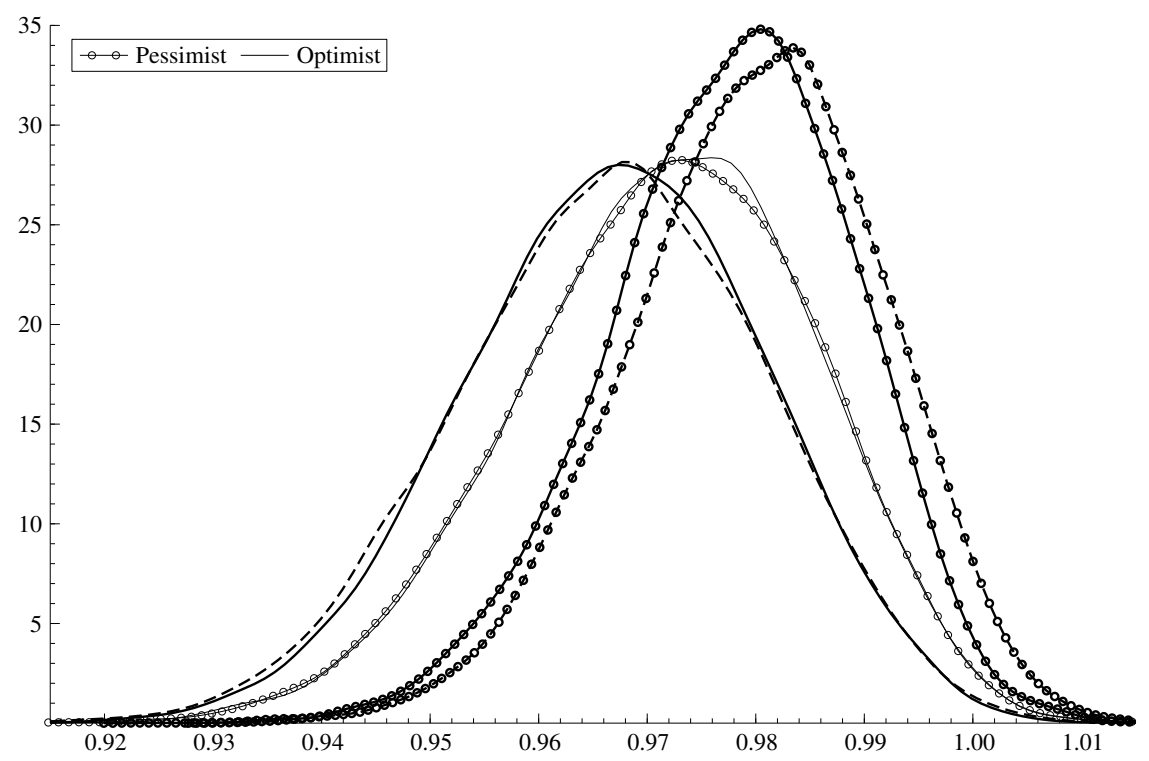

of confidence in the prior information.

The location of the prior mean determines whether the annualized stock volatility increases or decreases compared to a flat prior. A pessimist prior leads to a higher equity risk. This is in line with earlier findings in this case about the more persistent dividend yield process (Figure 3.7) and the lower predictability of the dividend yield to stock returns (Table 3.4). The opposite occurs for an optimist prior. Compared to a flat prior, it leads to a downward shift of the term structure. These features are exhibited at all investment horizons, and can lead to a higher or lower equity risk of about 1.5 percentage point. Obviously, the location of the prior mean has less impact for lower precision factors. $\kappa=0.01$ and a flat prior result result in a comparable term structures.

What explains the mean averting pattern of equity risk at investment horizons beyond 25 years? Figures 3.9 and 3.10 indicate that the uncertainty about the mean is crucial for this. Mean uncertainty is a mean averting mechanism in the holding period volatility. On the other hand, the conditional variance is the mean reverting mechanism in the unconditional volatility at almost all horizons. In order to verify 
Figure 3.8: Annualized volatilities and parameter uncertainty

This graph shows the effect of parameter uncertainty on the annualized holding period volatilities of real returns on equities, bonds and the real T-bill (40000 simulations).

OLS: solid, Parameter uncertainty: dashed
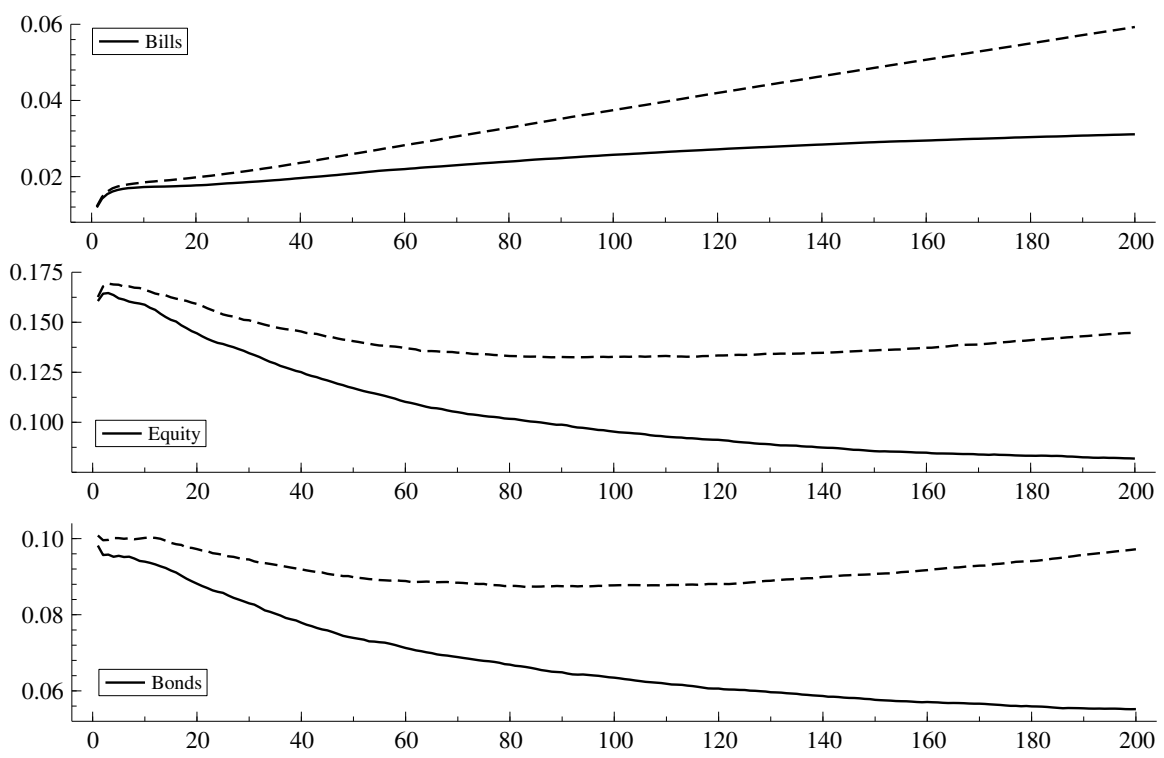

this Figure 3.10 decomposes the annualized unconditional volatility (solid line) into two factors: the average conditional volatility (dashed line) and the volatility of the conditional mean (solid circle line). ${ }^{8}$ The spread between the OLS volatility (solid plus line) and the average conditional volatility reflects parameter uncertainty. The distance between the average conditional volatility and the unconditional volatility represents mean uncertainty. The latter factor dominates the square root formula at longer horizons. However, the uncertainty about the mean plays a very small role in the total variance for short investment horizons.

Figure 3.11 demonstrates the impact on the risk diversification properties in the cross section. Risk properties between assets are much more stable than time diversification within an asset class. This can have important implications for optimal portfolio management. Apparently, the impact of parameter uncertainty on the covariance is proportional to the impact on the variance. As a result the effect of parameter uncertainty cancels out to a large degree in terms of correlation. The

\footnotetext{
8 Note that the unconditional variance is the sum of mean conditional variance and the variance of the conditional mean.
} 
Figure 3.9: Annualized volatilities: parameter uncertainty and prior information

This graph shows the effect of different priors on the annualized holding period volatilities of real equity returns (40000 simulations). Two precision factors are chosen for either the optimist or pessimist prior: $\kappa=0.01$ : solid, $\kappa=100$ : dashed, OLS: solid circle

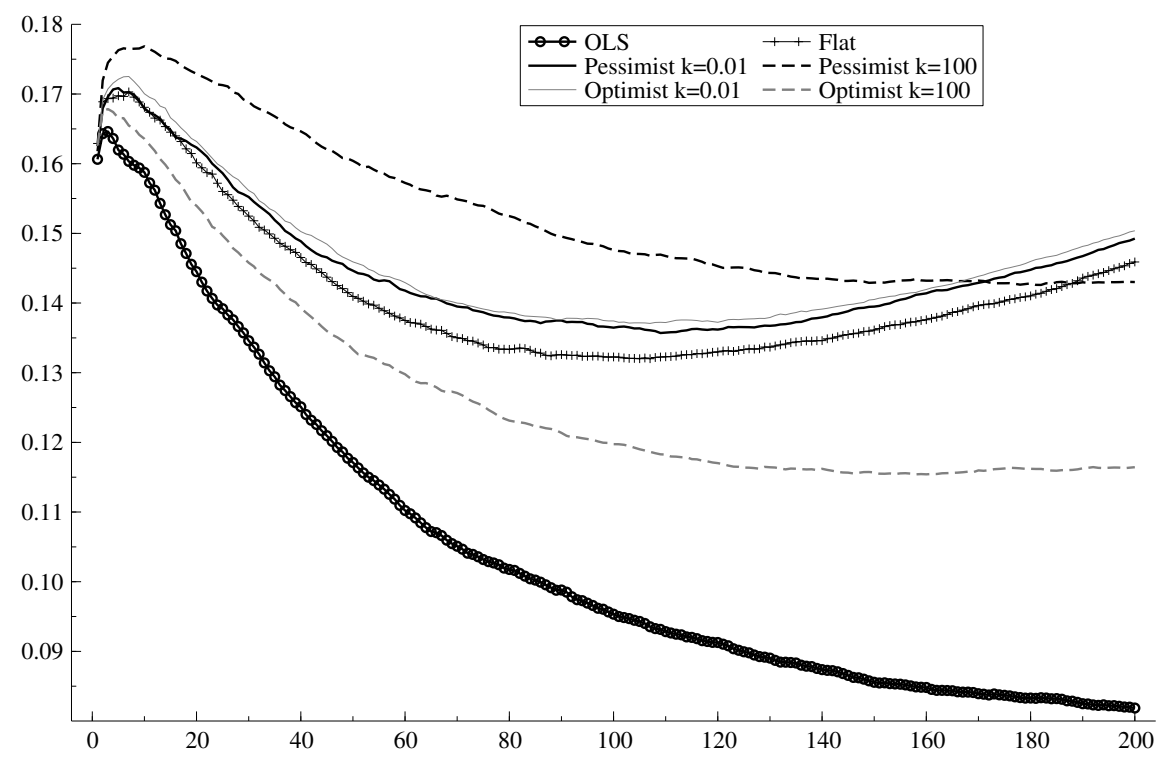

correlation between T-bills and bonds becomes marginally lower for horizons longer than five years, and the correlation between stocks and T-bills reduces somewhat in the very long run.

The inflation hedge qualities of (nominal) returns on T-bills, stocks and a constant maturity treasury portfolio are also robust to incorporating parameter uncertainty. Seemingly, the effect of parameter uncertainty on the covariance between these (nominal) asset returns and inflation is proportional to the effect on the corresponding variances. The inflation hedge properties in Figure 3.12 are in line with the ones found in Hoevenaars, Molenaar, Schotman and Steenkamp (2007) for fixed parameter estimates. Rolling over 3-month T-bills ensures that the lagged inflation is incorporated, and consequently the T-bill is the best inflation hedge among the asset classes we consider at all investment horizons. At long horizons constant maturity bonds are a good inflation hedge as well. However, due to the inverse relationship between yield changes and bond prices, the short-term inflation hedging properties are poor, before the hedging qualities improve in the long run. Stocks also seem a better inflation hedge in the long run than at short horizons, consistent with the 
Figure 3.10: Mean uncertainty vs. parameter uncertainty

This graph decomposes the annualised unconditional volatility of equities (solid) ( $\kappa=0.01$ ) into two factors: the average conditional volatility (dashed) and the volatility of the conditional mean (solid circle). The OLS volatility is added as a reference (solid plus).

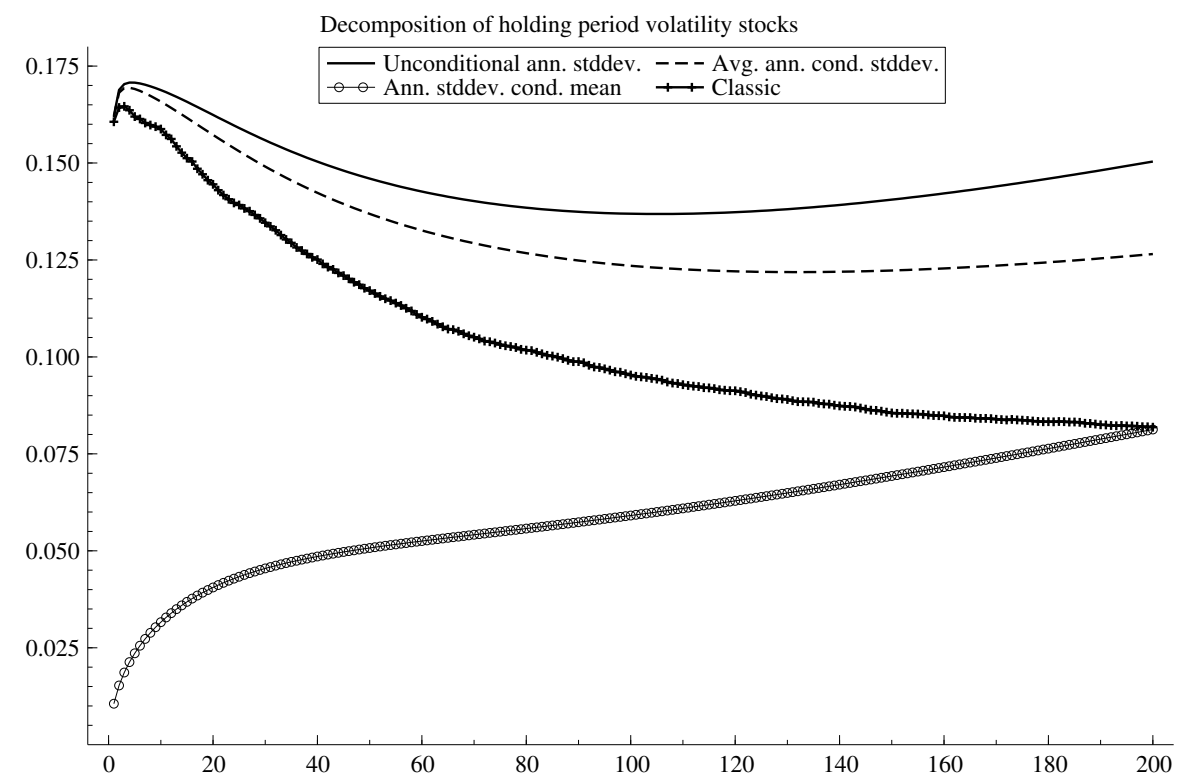

large literature on this relationship.

\subsection{Optimal portfolio choice}

We derive the optimal portfolio for a buy-and-hold investor who maximizes the utility of end-of-period wealth. At time $t$ the investor allocates wealth to real T-bills, stocks and bonds with portfolio weights $w=\left(w_{r}, w_{s}, w_{b}\right)$ and holds the portfolio until time $t+k$ without rebalancing. Assuming power utility with risk aversion $\gamma$, the investor solves

$$
\max _{w} \mathrm{E}_{t}\left[U\left(W_{t+k}\right)\right]=\max _{w} \mathrm{E}_{t}\left[\frac{W_{t+k}^{1-\gamma}}{1-\gamma}\right]
$$

where wealth at $t+k$ is defined as

$$
W_{t+k}=\sum w_{i} \exp \left(r_{i, t+k}^{(k)}\right),
$$


Figure 3.11: Correlations and parameter uncertainty

This graph shows the effect of parameter uncertainty on the correlations of real holding period returns between equities and T-bill, bonds and equities, and the T-bill and bonds (40000 simulations). OLS: solid, Parameter uncertainty: dashed
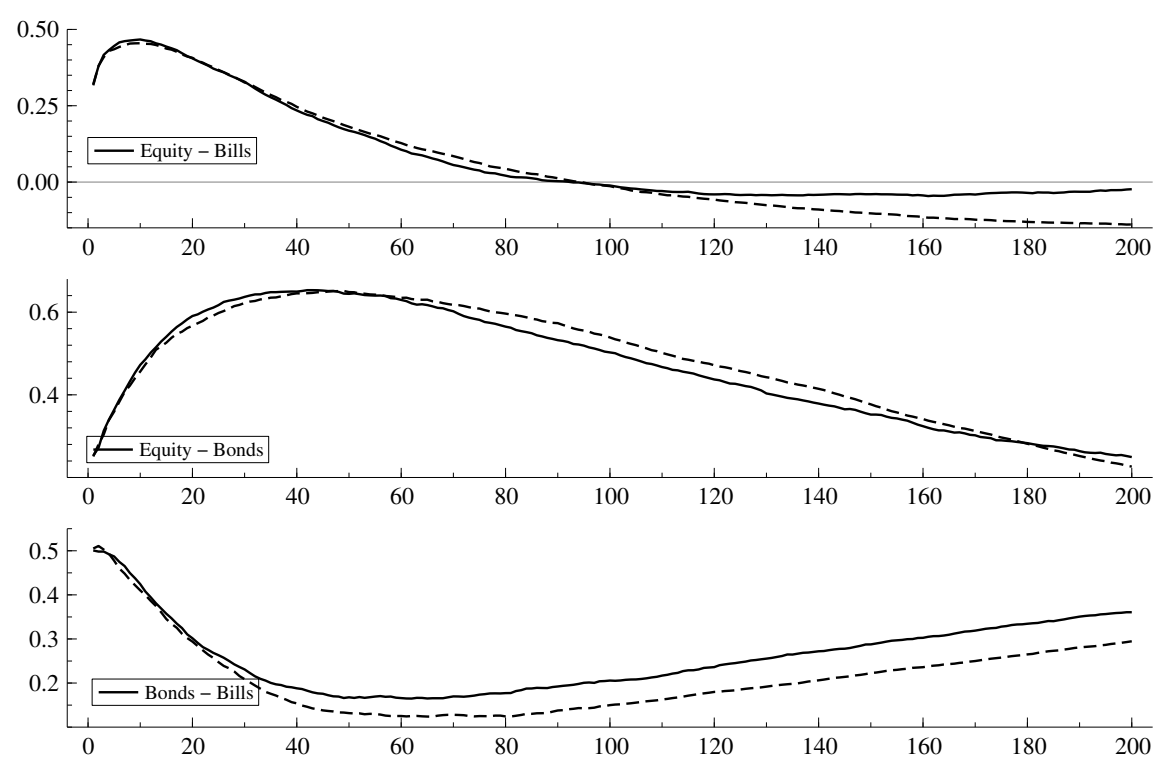

normalizing initial wealth at $W_{t}=1$, and returns are defined as the real cumulative logarithmic return from $t$ to $t+k$,

$$
r_{i, t+k}^{(k)}=\sum_{s=1}^{k} r_{i, t+s}
$$

We assume that short-sell restrictions restrict the weights to be non-negative, and that the weights sum to one. In the numerical optimization we use a fixed grid for the weights with stepsize 0.01. Consequently, the feasible portfolios have weights $w_{i}=0,0.01, \ldots, 0.99(i=b, s), w_{r}=1-w_{b}-w_{s}$, and $w_{r}>0$.

In order to numerically calculate the maximum expected utility in (3.8) we need the distribution of future asset returns. This is either based on the OLS or bayesian approach. In the OLS case, the parameter estimates of the VAR are used to simulate the model conditional on the parameter estimates. In the bayesian case we first draw a set of parameters from the posterior distribution, and conditional on these parameters we simulate a scenario from the VAR. In both cases the unconditional sample means are chosen as the starting values to create the future scenarios. 
Figure 3.12: Inflation hedge qualities and parameter uncertainty

This graph shows the effect of parameter uncertainty on the inflation hedge qualities of nominal holding period returns of equities, bonds, and the T-bill (40000 simulations). OLS: solid, Parameter uncertainty: dashed
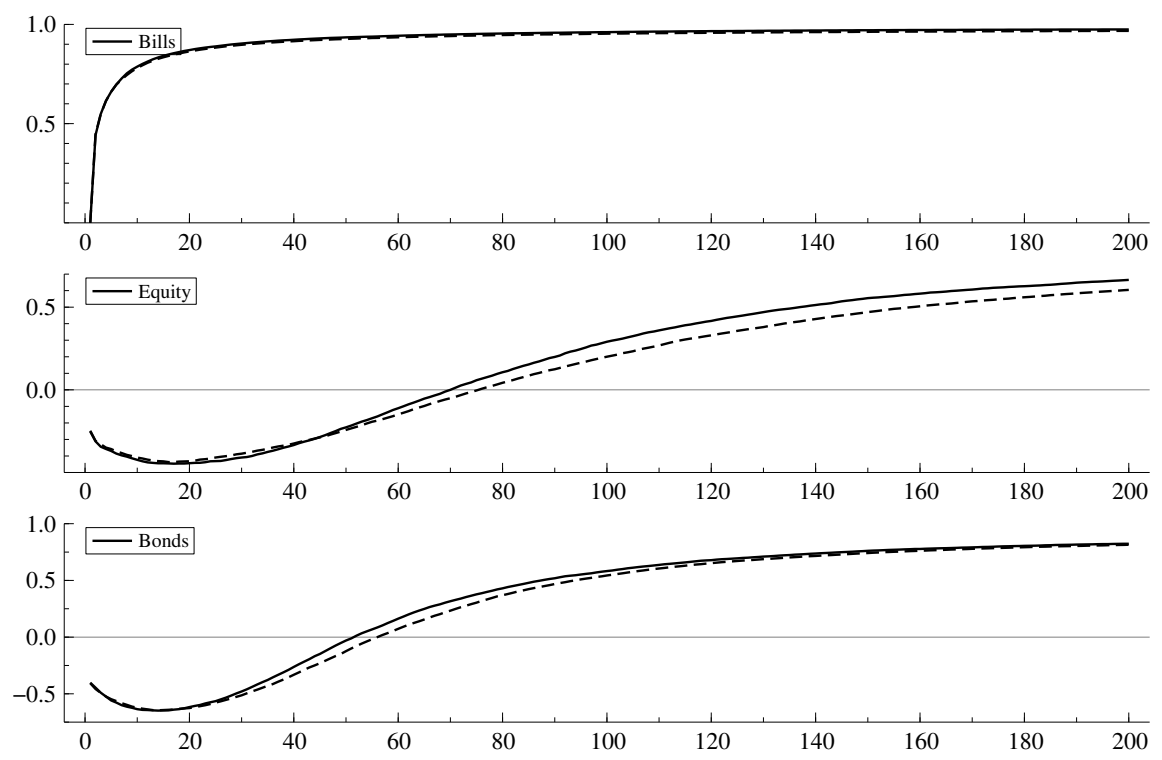

The optimal portfolio is the one that corresponds to the maximum expected utility. In order to determine this asset allocation we begin calculating the real returns of all possible asset mix combinations in each simulation. Next, the wealth can be computed in each simulation and the expected utility is estimated as the average over all scenarios. Finally, the optimal strategic asset allocation is selected.

For $\gamma>1$ the expectation in (3.8) will not always exist. Although we assume that the innovations in the VAR are normally distributed conditional on the parameters, the predictive densities,

$$
f\left(y_{t} \mid y_{t-1}\right)=\int_{\theta} f\left(y_{t} \mid y_{t-1}, \theta\right) \times p(\theta \mid \mathbf{Y}) \mathrm{d} \theta,
$$

will have fatter tails than the normal distribution. If a random variable $X$ has a fat-tailed distribution, the expected value $\mathrm{E}\left[e^{X}\right]$ does not exist. For the expected utility problem (3.8) this implies that expected utility will be negative infinity for portfolios of assets that have fat left (negative) tails. We can guarantee that at least some portfolios have finite utility if we assume that the riskfree asset is bounded in the sense that its return is always above a lower limit $r_{\text {min }}$. In simulating paths 
Table 3.6: Optimal portfolio choice: OLS and flat prior

Optimal portfolio choice under power utility for a $k$-period buy and hold investor with risk aversion 5 and for different investment horizons: 1, 5, 10, 15, 25, 40, 50 years (based on 40000 simulations).

\begin{tabular}{lrrrrrr}
\hline & \multicolumn{3}{c}{ OLS } & \multicolumn{3}{c}{ Parameter Uncertainty } \\
Horizon & Bills & Equity & Bonds & Bills & Equity & Bonds \\
\hline 1 & 0.41 & 0.53 & 0.06 & 0.45 & 0.50 & 0.05 \\
5 & 0.32 & 0.68 & 0.00 & 0.44 & 0.56 & 0.00 \\
10 & 0.12 & 0.88 & 0.00 & 0.38 & 0.62 & 0.00 \\
15 & 0.01 & 0.99 & 0.00 & 0.37 & 0.63 & 0.00 \\
25 & 0.01 & 0.99 & 0.00 & 0.43 & 0.57 & 0.00 \\
40 & 0.01 & 0.99 & 0.00 & 0.57 & 0.43 & 0.00 \\
50 & 0.01 & 0.99 & 0.00 & 0.56 & 0.43 & 0.01 \\
\hline \hline
\end{tabular}

of asset returns we reject draws that would violate the constraint $r_{t}>r_{\text {min }}$. We have set the lower bound to $-15.80 \%$, which is ten times the minimum observed in the sample. The probability that the T-bill reaches the boundary is almost zero. If the T-bill has a positive weight in the portfolio, wealth will never go to zero and expected utility is bounded away from minus infinity. This approach ensures that the maximization problem (3.8) is well-defined.

Table 3.6 compares the optimal portfolios of an investor who ignores parameter uncertainty with an investor who accounts for parameter uncertainty using the flat prior for $\tilde{B}$. The risk aversion parameter $\gamma=5$. The OLS portfolio exhibits the standard result that the weight of stocks increases with the investment horizon. For horizons longer than 15 years the investor would prefer to be fully invested in stocks. T-bills have a high weight for short investment horizons, but this reduces quickly for longer horizons. Reinvestment risk makes them less attractive for longer horizons. The combination of the high Sharpe ratio of stocks and their mean reverting pattern makes them more attractive for long-term investors. Due to the low bond premium in the data sample (Sharpe ratio is 0.15 versus 0.44 for stocks) Treasuries are not in the optimal portfolio.

Introducing parameter uncertainty influences the long-term asset allocation substantially. However, parameter uncertainty seems not to influence the optimal asset allocation for very short investment horizons. The right part of Table 3.6 shows that the asset allocation for a one-year horizon hardly changes when the investor incorporates parameter uncertainty through the uninformative prior. Since correlations 
between assets are much more robust against parameter uncertainty than volatilities of assets, we find that risk diversification becomes much more emphasized after incorporating parameter uncertainty, typically at longer horizons. Besides stocks the optimal asset allocation also consists of T-bills, which are a good risk diversifier due to the very low correlation with stocks especially at longer horizons (see Figure 3.11). Bonds are not in the optimal portfolio, because their risk rises in the same proportion as the risk of stocks, while the bond premium is much lower. Although ignoring parameter uncertainty leads to an overallocation of stocks at all horizons, the investor should still benefit from mean reversion in stocks by increasing their weight for investment horizons up to 20 years. On the other hand, stock holdings decrease for investment horizons beyond 25 years due to the uncertainty in the expected returns, which dominates the holding period volatility at these horizons. Consequently, ignoring parameter uncertainty can lead to an underallocation of T-bills and risk diversification.

Obviously, the optimal asset allocation varies substantially with the view and confidence the investor has about the level of the future asset returns, which is included in the future distribution through the informative prior. Table 3.7 shows the impact on the asset allocation for the pessimist view while accounting for parameter uncertainty. Regardless of the precision factor, risk diversification remains an obvious characteristic in the optimal portfolio typically at longer investment horizons. The strong diversification in the portfolio composition reflects the stable correlations (see Figure 3.8), which indicates that risk diversification remains particularly important.

The prior mean gets more weight in the posterior mean for higher precision factors. Bonds become more important in the portfolio choice when the precision factor rises, which clearly reflects the higher Sharpe ratio of bonds than stocks in the pessimist view. At a precision factor $\kappa=100$ the investor allocates his wealth almost entirely to bonds. However, at horizons longer than 25 years the optimal portfolio becomes more diversified, and stocks and T-bills are also in the optimal asset allocation. So even an investor who is skeptical about stocks, includes them for hedging purposes. On the contrary, the investor hardly invests in bonds at a precision factor $\kappa=0.01$. Only for very long investment horizons the optimal portfolio is diversified with bonds. A precision factor $\kappa=1$ gives equal weight to the data and prior information. In the data sample stocks have a higher Sharpe ratio (0.44) than bonds (0.15), whereas in the pessimist view stocks have a lower Sharpe ratio $(0.21)$ than bonds (0.48). As a consequence, the optimal asset allocation is diversified at all investment horizons. T-bills, stocks and bonds all have a substantial weight in the optimal portfolio choice. 
Table 3.7: Optimal portfolio choice: pessimist prior

\begin{tabular}{|c|c|c|c|c|c|c|c|c|c|}
\hline \multirow[b]{2}{*}{ Horizon } & \multicolumn{3}{|c|}{$\kappa=0.01$} & \multicolumn{3}{|c|}{$\kappa=1$} & \multicolumn{3}{|c|}{$\kappa=100$} \\
\hline & Bills & Equity & Bonds & Bills & Equity & Bonds & Bills & Equity & Bonds \\
\hline 1 & 0.49 & 0.42 & 0.09 & 0.43 & 0.19 & 0.38 & 0.04 & 0.04 & 0.92 \\
\hline 5 & 0.57 & 0.43 & 0.00 & 0.56 & 0.11 & 0.33 & 0.01 & 0.00 & 0.99 \\
\hline 10 & 0.55 & 0.45 & 0.00 & 0.52 & 0.10 & 0.38 & 0.01 & 0.00 & 0.99 \\
\hline 15 & 0.54 & 0.46 & 0.00 & 0.51 & 0.12 & 0.37 & 0.01 & 0.02 & 0.97 \\
\hline 25 & 0.49 & 0.42 & 0.09 & 0.53 & 0.19 & 0.28 & 0.05 & 0.15 & 0.80 \\
\hline 40 & 0.46 & 0.36 & 0.18 & 0.61 & 0.23 & 0.16 & 0.06 & 0.31 & 0.63 \\
\hline 50 & 0.40 & 0.35 & 0.25 & 0.64 & 0.27 & 0.09 & 0.60 & 0.18 & 0.22 \\
\hline
\end{tabular}

Table 3.8: Optimal portfolio choice: optimist prior

Optimal portfolio choice under power utility for a k-period buy and hold investor with risk aversion 5 for different investment horizons: 1, 5, 10, 15, 25, 40, 50 years and for different precision factors under the optimist prior. (based on 40000 simulations).

\begin{tabular}{lrrrrrrrrrr}
\hline & \multicolumn{3}{c}{$\kappa=0.01$} & \multicolumn{3}{c}{$\kappa=1$} & & \multicolumn{3}{c}{$\kappa=100$} \\
Horizon & Bills & Equity & Bonds & Bills & Equity & Bonds & Bills & Equity & Bonds \\
\hline 1 & 0.47 & 0.44 & 0.09 & 0.53 & 0.43 & 0.04 & 0.40 & 0.60 & 0.00 \\
5 & 0.55 & 0.45 & 0.00 & 0.51 & 0.49 & 0.00 & 0.33 & 0.67 & 0.00 \\
10 & 0.52 & 0.48 & 0.00 & 0.44 & 0.56 & 0.00 & 0.29 & 0.71 & 0.00 \\
15 & 0.51 & 0.49 & 0.00 & 0.41 & 0.59 & 0.00 & 0.34 & 0.66 & 0.00 \\
25 & 0.45 & 0.44 & 0.11 & 0.41 & 0.59 & 0.00 & 0.41 & 0.59 & 0.00 \\
40 & 0.39 & 0.45 & 0.16 & 0.37 & 0.49 & 0.14 & 0.53 & 0.47 & 0.00 \\
50 & 0.26 & 0.56 & 0.18 & 0.37 & 0.43 & 0.20 & 0.60 & 0.40 & 0.00 \\
\hline \hline
\end{tabular}

The large weight of T-bills reflects their low correlation with stocks and bonds, which make them an interesting risk diversifier at long horizons. The low volatility of T-bills makes them attractive especially at short horizons. Other features remain observed as well. Mean reversion in stock returns still makes stocks more attractive for long-term investors. However, this effect is mitigated in the very long-term due to its rising annualized volatility.

Table 3.8 clearly shows that the impact on portfolio choice of the informative prior mean is much less once the investor has an optimistic view. This can be explained by the fact that the means in the optimist view differ much less from the 
sample mean than means in the pessimist view. The weight of stocks is positively related to $\kappa$. Just as before the weight in stocks first rises with the investment horizon, but eventually decreases for horizons longer than 25 years. Bonds only have a substantial weight in the asset allocation once there is less prior information $(\kappa=0.01)$ and typically at longer horizons. For $\kappa=1$ or $\kappa=100$ bonds play not a significant role. T-bills have a substantial weight in optimal portfolio choice for all horizons and for all precision factors. In contrast to the pessimist prior in Table 3.7, T-bills are still in the optimal portfolio even when the investor is extremely certain $(\kappa=100)$ about the prior information. This reflects the strong risk diversification properties of T-bills in a portfolio of stocks. T-bills are demanded in a portfolio with a lot of stocks for risk reduction. So even an investor who is very optimistic about stocks, invests a large part of his assets in T-bills for hedging purposes.

Figure 3.13 demonstrates how the impact on optimal portfolio choice of different prior information is influenced by the risk aversion of an investor. The optimal portfolios are given for a 10-year investment horizon versus the risk attitude of an investor. The pessimist prior is analyzed for three different precision factors $(\kappa=0.01,1,100)$. We determined the optimal asset allocations for five grid points of the risk attitude $1 / \gamma: 0.15,0.2,0.3,0.4$ and 0.5 .

In general, the optimal weight of stocks is negatively related to the risk aversion $\gamma$ : if the risk aversion decreases, the optimal weight in stocks increases. Compared to the OLS approach (the solid circled line) the weight in stocks reduces whenever the degree of confidence in the prior mean increases. This effect is independent of the risk attitude, and is explained by the lower Sharpe ratio of stocks than bonds in the pessimist view. However, observe that the weight in stocks reduces considerably due to parameter uncertainty even when there is little prior information about the location of the mean (which corresponds to $\kappa=0.01$ ).

The weight in bonds solely depends on the degree of confidence in the higher bond return in the future distribution, and seems negatively related to the risk attitude of the investor. Under a very strong optimistic view $(\kappa=100)$ the investor allocates his entire wealth to bonds.

Ignoring parameter uncertainty leads to an underallocation of T-bills even when prior information about the mean is incorporated. In contrast to stocks, T-bills are positively related to the riskaversion $\gamma$. T-bills become particularly interesting at higher risk aversions for diversification purposes. For higher risk aversions the optimal asset allocation is more balanced and diversified when there is less prior information.

Figure 3.14 shows how the risk attitude of the investor influences optimal portfolio choice under an optimist prior. Just as before the allocation to stocks is negatively 
Figure 3.13: Buy-and-Hold asset allocation versus risk aversion

Optimal portfolio weights under power utility for a buy and hold investor with a 10-year investment horizon versus ( 1 /risk aversion) (we choose $0.15,0.2,0.3,0.4$, and 0.5 as grid for 1 /risk aversion) and for different precision factors under the pessimist prior (based on 40000 simulations). $\kappa=0.01$ : solid, $\kappa=1$ : bold solid, $\kappa=100$ : dashed, OLS: solid circle

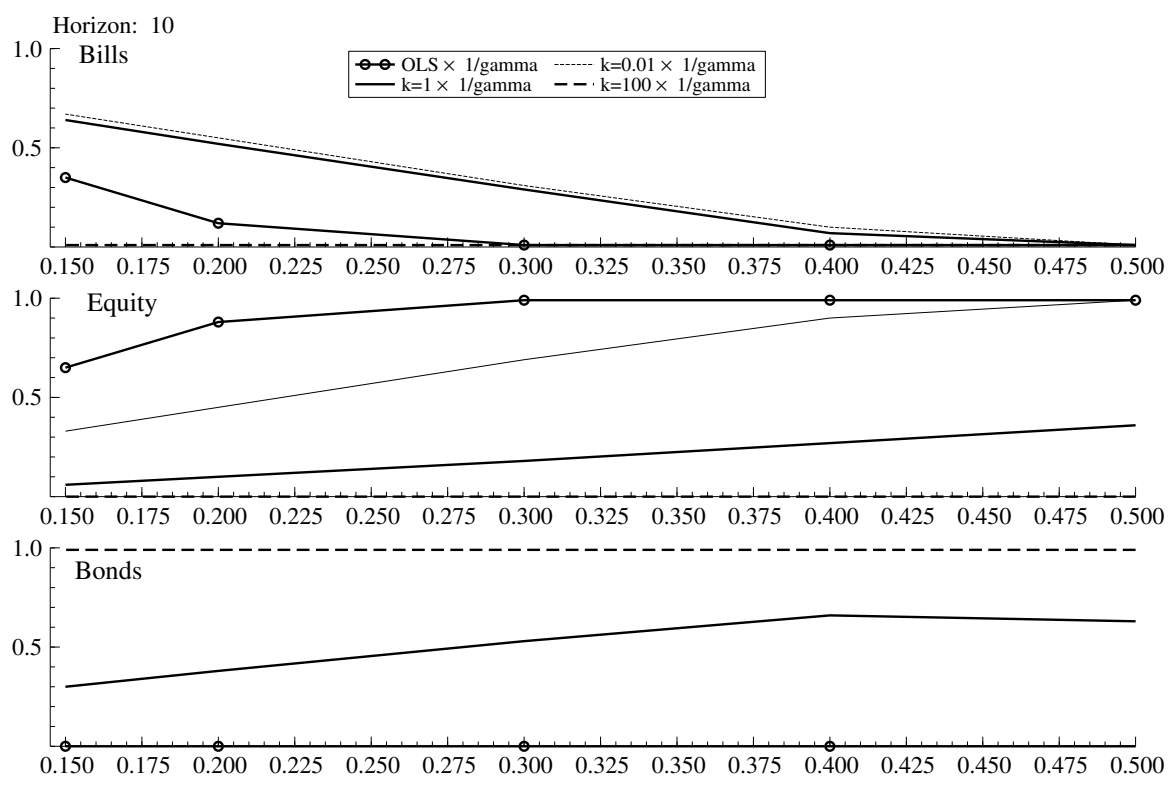

related with the risk aversion $(\gamma)$. The weight of stocks increases for higher precision factors. However, even if the investor is extremely sure about the prior information $(\kappa=100)$ the allocation to stocks is still considerable below the OLS case for higher risk aversions. This reflects some conservatism for parameter uncertainty. For this case the weight of T-bills is higher than the OLS weight. The low volatility of T-bills and the low and stable correlation with stocks at a 10-year horizon makes them an important risk diversifier. This is even more emphasized at higher risk aversions and for less prior information. The allocation to T-bills increases in these cases. The weight of bonds is negligible, regardless of the risk attitude. The lower Sharpe ratio of bonds compared to stocks in the sample data (0.15 versus 0.44$)$, and an even lower Sharpe ratio in the optimist view (0.53 versus 0.06$)$ explains this. 
Figure 3.14: Buy-and-Hold asset allocation versus risk aversion

Optimal portfolio weights under power utility for a buy and hold investor with a 10-year investment horizon versus ( 1 /risk aversion) (we choose $0.15,0.2,0.3,0.4$, and 0.5 as grid for 1 /risk aversion) and for different precision factors under the optimist prior (based on 40000 simulations). $\kappa=0.01$ : solid, $\kappa=1$ : bold solid, $\kappa=100$ : dashed, OLS: solid circle

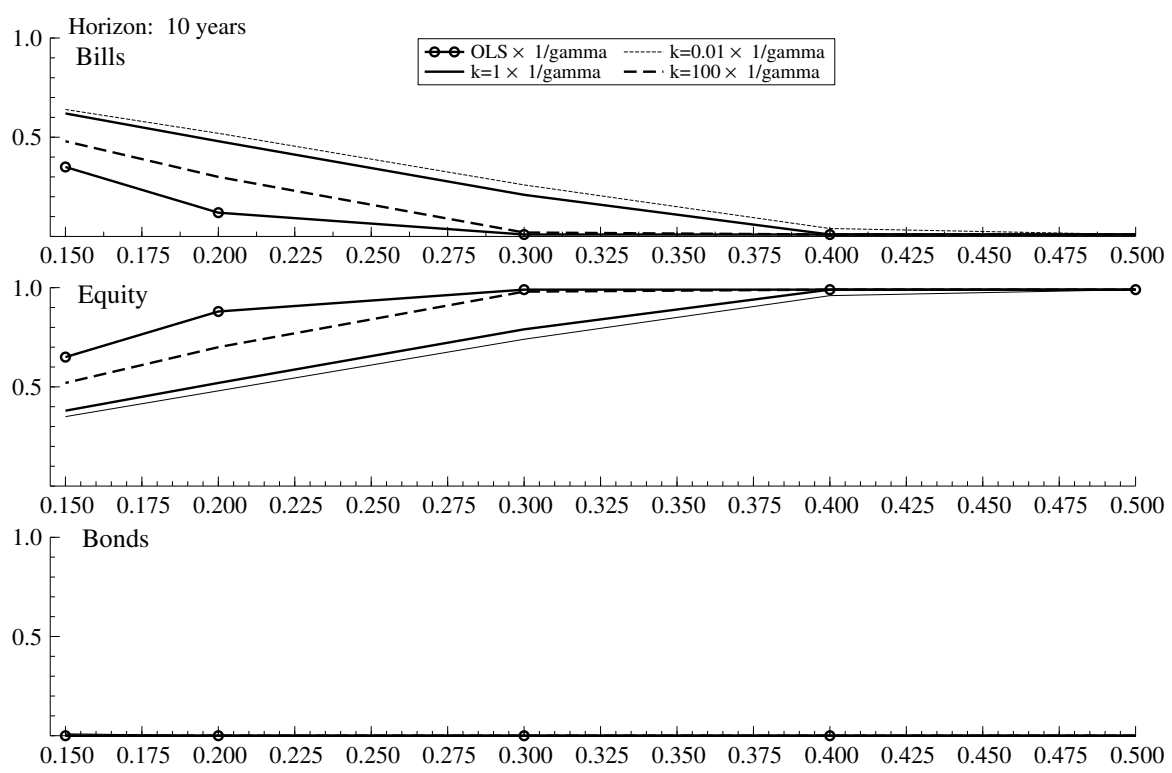

\subsection{Multiple Priors and Expected Loss}

Let $Q_{i}(w)$ be the utility of investor $i$, who uses a prior $p_{i}(\theta)$, when investing in portfolio $w$,

$$
Q_{i}(w)=\mathrm{E}_{i t}\left[U\left(W_{t+k}(w)\right)\right]
$$

The expectation operator has the additional subscript $i$ to indicate that the expectation is taken relative to the predictive distribution of returns based on the prior of investor $i$. Also future wealth is explicitly expressed as a random variable that is a function of the portfolio $w$. The investor combines his prior $p_{i}(\theta)$ with the common likelihood $L(\mathbf{Y} \mid \theta)$ to form his posterior $p_{i}(\theta \mid \mathbf{Y})$ and predictive distribution

$$
f_{i}\left(y_{t+1} \mid \mathbf{Y}\right)=\int_{\theta} f\left(y_{t+1} \mid y_{t}, \theta\right) \times p_{i}(\theta \mid \mathbf{Y}) \mathrm{d} \theta
$$

which differs from (3.11) by the subscript $i$. Consequently, the expectation in (3.12) is taken with respect to (3.13). 
According to investor $j$, who has prior views $p_{j}(\theta)$, the expected utility of the same portfolio is

$$
Q_{j}(w)=\mathrm{E}_{j t}\left[U\left(W_{t+k}(w)\right)\right]
$$

The optimal portfolio according to investor $i$ need not be optimal in the eyes of investor $j$. Let $w_{i}^{*}$ and $w_{j}^{*}$ be the optimal portfolios of investors $i$ and $j$, respectively. Define the expected loss of the optimal portfolio of investor $i$ relative to the views of investors $j$ as

$$
\ell_{j}\left(w_{i}^{*}\right)=Q_{j}\left(w_{j}^{*}\right)-Q_{j}\left(w_{i}^{*}\right)
$$

Conversely, the optimal portfolio of investor $j$ will be evaluated as sub-optimal by investor $i$ and ental the cost $\ell_{i}\left(w_{j}^{*}\right)$.

For a meaningful quantitative comparison of the expected loss, we express it in terms of a certainty equivalent. The economic loss can be interpreted as an opportunity cost. It is defined as the percentage with which the initial asset value must increase to compensate the investor for suboptimal investing. We define the economic loss $C_{i j}$ as the percentage risk free return investor $i$ would need to be compensated for being forced to choose asset allocation $w_{j}^{*}$. It is computed as

$$
C_{i j}=\left(\frac{\mathrm{E}_{i t}\left[W_{t+k}\left(w_{j}^{*}\right)^{1-\gamma}\right]}{\mathrm{E}_{i t}\left[W_{t+k}\left(w_{i}^{*}\right)^{1-\gamma}\right]}\right)^{\frac{1}{1-\gamma}}
$$

This way we construct the entire matrix $C$ with elements giving the costs of portfolio $w_{j}^{*}$ under prior $i$.

Since all priors are assumed reasonable, we assume it is impossible to put a probability on the validity of each prior. This also leads to the impossibility to define an overall weighted average prior and weighted average predictive density to evaluate the utility and costs of all portfolios as in Avramov (2002). There will thus remain some ambiguity in how to define the optimal portfolio. This situation with multiple priors has been analyzed in a variety of recent papers. ${ }^{9}$ A robust portfolio is defined as the best worst case or minimax solution. For each portfolio the prior that gives the lowest utility is selected. The robust portfolio is the best among all these worst case evaluations.

With our limited set of portfolios and limited set of priors, the robust portfolio is selected as the minimax solution within the matrix $C$. As each column of $C$ represents a portfolio, we select the worst case of portfolio $w_{i}^{*}$ as the maximum element in column $i$. The portfolio with the lowest maximum is the minimax portfolio.

The results are summarized in Table 3.9. The asset allocation that is used for the asset allocation decision is in the columns. The prior is listed in the rows. Clearly,

\footnotetext{
9 See for example Uppal and Wang (2003) and Goldfarb and Iyengar (2003).
} 
Table 3.9: Certainty equivalent and robust portfolio choice

\begin{tabular}{|c|c|c|c|c|c|c|c|c|}
\hline \multirow[b]{2}{*}{ Prior } & \multicolumn{8}{|c|}{ Portfolio } \\
\hline & OLS & Flat & $\mathrm{P} 01$ & $\mathrm{P} 1$ & P100 & O01 & $\mathrm{O} 1$ & O100 \\
\hline & \multicolumn{8}{|c|}{ Horizon $k=1$ year } \\
\hline OLS & 0.0 & 0.0 & 0.1 & 0.7 & 2.2 & 0.1 & 0.1 & 0.0 \\
\hline Flat & 0.0 & 0.0 & 0.0 & 0.6 & 2.2 & 0.0 & 0.0 & 0.1 \\
\hline Pessimist $(\kappa=0.01)$ & 0.1 & 0.0 & 0.0 & 0.4 & 1.9 & 0.0 & 0.0 & 0.2 \\
\hline Pessimist $(\kappa=1)$ & 0.8 & 0.7 & 0.4 & 0.0 & 0.6 & 0.5 & 0.5 & 1.2 \\
\hline Pessimist $(\kappa=100)$ & 2.9 & 2.8 & 2.2 & 0.7 & 0.0 & 2.3 & 2.4 & 3.6 \\
\hline Optimist $(\kappa=0.01)$ & 0.1 & 0.0 & 0.0 & 0.5 & 1.9 & 0.0 & 0.0 & 0.2 \\
\hline Optimist $(\kappa=1)$ & 0.1 & 0.0 & 0.0 & 0.5 & 2.0 & 0.0 & 0.0 & 0.2 \\
\hline \multirow[t]{2}{*}{ Optimist $(\kappa=100)$} & 0.1 & 0.1 & 0.3 & 1.3 & 3.4 & 0.2 & 0.2 & 0.0 \\
\hline & \multicolumn{8}{|c|}{ Horizon $k=10$ years } \\
\hline OLS & 0.0 & 2.1 & 5.7 & 21.0 & 33.8 & 4.9 & 3.1 & 0.9 \\
\hline Flat & 4.8 & 0.0 & 1.4 & 14.0 & 32.8 & 1.0 & 0.2 & 0.4 \\
\hline Pessimist $(\kappa=0.01)$ & 12.3 & 1.4 & 0.0 & 4.6 & 18.6 & 0.0 & 0.6 & 3.4 \\
\hline Pessimist $(\kappa=1)$ & 33.4 & 10.4 & 4.5 & 0.0 & 7.5 & 5.3 & 7.9 & 15.5 \\
\hline Pessimist $(\kappa=100)$ & 79.1 & 49.6 & 40.9 & 15.0 & 0.0 & 42.1 & 45.9 & 56.7 \\
\hline Optimist $(\kappa=0.01)$ & 9.7 & 0.9 & 0.0 & 5.3 & 18.5 & 0.0 & 0.3 & 2.7 \\
\hline Optimist $(\kappa=1)$ & 5.1 & 0.2 & 0.5 & 7.4 & 18.7 & 0.3 & 0.0 & 1.0 \\
\hline \multirow[t]{2}{*}{ Optimist $(\kappa=100)$} & 2.3 & 0.4 & 3.5 & 23.3 & 48.5 & 2.7 & 1.2 & 0.0 \\
\hline & \multicolumn{8}{|c|}{ Horizon $k=25$ years } \\
\hline OLS & 0.0 & 23.7 & 38.5 & 76.0 & 87.8 & 36.1 & 22.1 & 22.1 \\
\hline Flat & 347.7 & 0.0 & 4.6 & 23.2 & 76.9 & 4.4 & 0.1 & 0.1 \\
\hline Pessimist $(\kappa=0.01)$ & 134.0 & 1.7 & 0.0 & 3.9 & 29.1 & 0.1 & 2.2 & 2.2 \\
\hline Pessimist $(\kappa=1)$ & 1160. & 11.1 & 3.9 & 0.0 & 26.2 & 4.6 & 12.4 & 12.4 \\
\hline Pessimist $(\kappa=100)$ & 1092. & 116.3 & 66.7 & 32.6 & 0.0 & 61.6 & 118.7 & 118.7 \\
\hline Optimist $(\kappa=0.01)$ & 177.8 & 1.2 & 0.1 & 4.7 & 31.0 & 0.0 & 1.6 & 1.6 \\
\hline Optimist $(\kappa=1)$ & 133.3 & 0.0 & 1.9 & 11.2 & 27.3 & 1.4 & 0.0 & 0.0 \\
\hline Optimist $(\kappa=100)$ & 115.7 & 0.1 & 7.2 & 34.7 & 82.0 & 6.9 & 0.0 & 0.0 \\
\hline
\end{tabular}

the zero diagonal reflects that the costs of portfolio $w_{i}^{*}$ under prior $i$ equals zero. Table 3.9 shows that the opportunity costs of alternative priors are economically meaningful and increase with the investment horizon. The OLS results, ignoring parameter uncertainty, are included in the table as well.

At the one year horizon all costs are low. The largest entries show the contrast between the confident optimistic view and the confident pessimistic view. The op- 
timal portfolio for the confident optimistic view performs poorly in the eyes of the confident pessimistic investor and vice versa. The minimax solution would be the optimal portfolio according to the reasonably pessimistic view. This portfolio has the low costs for all priors. The maximum cost is $1.3 \%$ in the eyes of of the confident optimistic investor. This maximum is the lowest over all columns for the one-year horizons and is therefore the minimax solution.

An important result from table 3.9 is that parameter uncertainty seems not to be economically relevant on an annual investment horizon. The OLS portfolio performs reasonably well. Ignoring the parameter uncertainty does not entail economic losses except under the confident pessimistic prior.

In contrast, using the OLS approach for longer investment horizons is far from optimal for all prior views. The opportunity costs are economically significant, and are even extraordinary high at a 25-year horizon (with opportunity costs sometimes above $1000 \%$ ). The OLS approach leads to a portfolio that is fully invested in equity, whereas all other portfolios have less equity. The reduction of the equity holdings is just the result of accounting for parameter uncertainty. Whatever the prior, even a very confident optimistic investor attaches a high price to being forced to hold that much equity.

An investor who is extremely skeptical about stocks and very optimistic about bonds (Pessimist $(\kappa=100)$ in the table) has very low valuations of the optimal portfolios implied by all other priors. Vice versa, the optimal portfolio of the confident pessimistic investor is very costly to all other investors. The minimax strategy is to invest according to the dispersed $(\kappa=0.01)$ optimistic prior.

\subsection{Conclusion}

This chapter considered the strategic asset allocation of long-term investors who account for parameter uncertainty and prior information about the level of expected asset returns and state variables in optimal portfolio choice, and who can invest in stocks, bonds and T-bills. We use bayesian methods and a vector autoregression for returns and macro-economic state variables for the empirical examination. We study both the impact of parameter uncertainty as well as the impact of prior information about the means on optimal portfolio choices.

We find that mean reversion in stocks and bonds dominates parameter uncertainty. The impact of parameter uncertainty is horizon dependent. It increases with the investment horizon. As a consequence, time diversification properties within asset classes in terms of volatilities are much weaker if parameter uncertainty is incorporated. Equities still exhibit mean reversion at short and medium investment 
horizons, but mean reversion is mitigated at longer horizons. The same effect also holds for bonds. Parameter uncertainty contributes as much to the risk of bonds as it does to stocks.

Priors views on the long-run mean of predictor variables influence the predictability of stock and bond returns, and the persistency of state variables. Even weak prior information on the unconditional mean of highly persistent time series like dividend yield and the nominal interest rate changes the estimated persistence of shocks and the predictability of excess returns. This has also implications for the term structures of annualized volatility. The location of the prior mean determines whether the annualized stock volatility increases or decreases compared to a flat prior. A pessimist prior for instance leads to a higher equity risk. Mean uncertainty is a mean averting mechanism in the holding period volatility. It explains the mean averting pattern of equity risk at investment horizons beyond 25 years.

Risk properties between assets are much more stable than time diversification within an asset class. Apparently, the impact of parameter uncertainty on the covariance is proportional to the impact on the variance. In the same line of reasoning inflation hedge qualities of (nominal) returns on T-bills, stocks and a constant maturity treasury portfolio are also robust to incorporating parameter uncertainty.

Parameter uncertainty alters the optimal portfolio choice. Since correlations between assets are much more robust against parameter uncertainty than volatilities of assets, we find that risk diversification becomes much more emphasized after incorporating parameter uncertainty, typically at longer horizons. Ignoring parameter uncertainty leads to an overallocation of stocks and an underallocation of T-bills and risk diversification at all horizons. On the other hand, the investor can still benefit from mean reversion in stocks by increasing their weight for longer investment horizons. However, he should take care about the rise of the annualized volatility at horizons beyond 25 years.

Optimal asset allocation varies substantially with the prior information that the investor has about long-run means. Risk diversification becomes much more important once there is less prior information, and particularly for longer investment horizons. In these cases stocks, bonds and T-bills all have a substantial weight in optimal portfolio choice. Regardless of the prior precision, T-bills are an important risk diversifier in a portfolio with stocks, which results in a substantial portfolio weight for T-bills for all horizons.

We find that an investor who is very optimistic about stocks should also invest a substantial part of his assets in T-bills for hedging purposes, regardless of the investment horizon. An investor who is skeptical about stocks still includes them in his optimal portfolio for hedging purposes, particularly for longer investment 
horizons. On the other hand, our findings suggest that an investor who is extremely positive about bonds invests entirely in bonds, and only includes T-bills and stocks for risk diversification at very long investment horizons.

For short (1-year) investment horizons it is justifiable to base the strategic asset allocation decision on the OLS approach that ignores parameter uncertainty. The opportunity costs are small for short horizons. In contrast, the results indicate that it is recommendable to account for parameter uncertainty for long-term strategic asset allocation. The opportunity costs are economically significant whenever the asset allocation is based on a OLS approach.

The optimal portfolio for an optimistic investor is very costly (sub-optimal) in eyes of an investor with a more negative prior view. We define a robust portfolio as the portfolio of an investor with a prior that has minimal costs among all priors that we consider. Such a robust portfolio coincides with the optimal portfolio of a moderately optimistic investor. It contains a large proportion of equity, but far less than would be implied under both more optimistic as well as very diffuse priors.

\subsection{Appendix: Properties of Posteriors}

We derive the posterior for the different prior specifications in the text.

\section{Reduced form uniform prior}

The first prior is the uniform flat prior on the parameters of the VAR system in reduced from (3.1). Stacking observations, the model can be written in matrix notation as

$$
Y=\tilde{X} \tilde{B}^{\prime}+E
$$

where $Y$ is the $(T \times n)$ matrix of observations on $y_{t}, X$ the $(T \times n)$ matrix of observations $y_{t-1}, \tilde{X}=(\iota X)$ and $\tilde{B}=(c B)$. Using the standard conditional likelihood,

$$
p(Y \mid \tilde{B}, \Sigma, X) \propto|\Sigma|^{-T / 2} \exp \left(-\frac{1}{2} \operatorname{tr}\left(\Sigma^{-1} E^{\prime} E\right)\right),
$$

and the prior (3.2) the joint posterior is given by

$$
p(\tilde{B}, \Sigma \mid Y, X) \propto I(B)|\Sigma|^{-(T+n+1) / 2} \exp \left(-\frac{1}{2} \operatorname{tr}\left(\Sigma^{-1} E^{\prime} E\right)\right) .
$$

The conditional posterior of $\Sigma$ is the inverted Wishart,

$$
p(\Sigma \mid \tilde{B}, Y, X) \sim i W\left(E^{\prime} E, T\right)
$$

The stationarity restriction implies that exact analytical integration over $B$ is not possible, so that the marginal posterior for $\Sigma$ cannot be derived analytically. An 
obvious simulation algorithm is available, since the conditional posterior of $\tilde{B}$ will be truncated normal and therefore easily sampled from. Using standard algebra, see Zellner (1971), we rewrite the term in the trace in (3.19) as

$$
\begin{aligned}
E^{\prime} E & =\left(Y-\tilde{X} \tilde{B}^{\prime}\right)^{\prime}\left(Y-\tilde{X} \tilde{B}^{\prime}\right) \\
& =Y^{\prime} \tilde{M} Y+(\tilde{B}-\hat{\tilde{B}}) \tilde{X}^{\prime} \tilde{X}(\tilde{B}-\hat{\tilde{B}})^{\prime}
\end{aligned}
$$

where

$$
\begin{aligned}
\tilde{M} & =I-\tilde{X}\left(\tilde{X}^{\prime} \tilde{X}\right)^{-1} \tilde{X}^{\prime} \\
\hat{\tilde{B}} & =Y^{\prime} \tilde{X}\left(\tilde{X}^{\prime} \tilde{X}\right)^{-1}
\end{aligned}
$$

Therefore the conditional posterior of $\tilde{B}$ is

$$
p\left(\operatorname{vec}\left(\tilde{B}^{\prime}\right) \mid \Sigma, Y, X\right) \sim N^{*}\left(\operatorname{vec}\left(\hat{\tilde{B}}^{\prime}\right), \Sigma \otimes\left(\tilde{X}^{\prime} \tilde{X}\right)^{-1}\right),
$$

where the superscript * denotes truncation to the stationary region. We use a Gibbs sampler to draw from the joint posterior by alternating draws for $\Sigma$ from (3.20) and $\tilde{B}$ from (3.22), where we reject draws from the latter if $B$ is outside the stationary range.

\section{Structural form prior on $\mu$}

For the prior on $\mu$ we rewrite the structural VAR model (3.3) in matrix notation as

$$
Y=\iota \mu^{\prime}+\left(X-\iota \mu^{\prime}\right) B^{\prime}+E
$$

The joint prior on $\mu, B$ and $\Sigma$ is

$$
p(\mu, B, \Sigma) \propto I(B)|\Sigma|^{-(n+1) / 2} \exp \left(-\frac{1}{2} \kappa\left(\mu-\mu_{0}\right)^{\prime} \Omega_{0}^{-1}\left(\mu-\mu_{0}\right)\right)
$$

Multiplication of prior and likelihood gives the joint posterior $p(\mu, B, \Sigma \mid Y, X) \propto I(B)|\Sigma|^{-(T+n+1) / 2} \exp \left(-\frac{1}{2}\left(\kappa\left(\mu-\mu_{0}\right)^{\prime} \Omega_{0}^{-1}\left(\mu-\mu_{0}\right)+\operatorname{tr}\left(\Sigma^{-1} E^{\prime} E\right)\right)\right)$

As before, the conditional posterior of $\Sigma$ in this case is

$$
p(\Sigma \mid Y, X, \mu, B) \sim i W\left(E^{\prime} E, T\right)
$$

To derive the conditional posterior of $\mu$ conditional on $(B, \Sigma)$ we rewrite the terms in the exponent of (3.25) as quadratic forms in $\mu$. Let $\tilde{e}=\operatorname{vec}\left(Y-X B^{\prime}\right)$, let $A=I-B$, and use

$$
\begin{aligned}
\operatorname{tr}\left(\Sigma^{-1} E^{\prime} E\right) & =\operatorname{vec}(E)^{\prime}\left(\Sigma \otimes I_{T}\right)^{-1} \operatorname{vec}(E) \\
& =(\tilde{e}-(A \otimes \iota) \mu)^{\prime}\left(\Sigma \otimes I_{T}\right)^{-1}(\tilde{e}-(A \otimes \iota) \mu) \\
& =\tilde{e}^{\prime}\left(\Sigma^{-1} \otimes I_{T}\right) \tilde{e}+T \mu^{\prime} A^{\prime} \Sigma^{-1} A \mu-2 \tilde{e}^{\prime}\left(\Sigma^{-1} A \otimes \iota\right) \mu
\end{aligned}
$$


Combining the trace term in (3.27) with the quadratic form in the prior (3.24) gives

$$
\kappa\left(\mu-\mu_{0}\right)^{\prime} \Omega_{0}^{-1}\left(\mu-\mu_{0}\right)+\operatorname{tr}\left(\Sigma^{-1} E^{\prime} E\right)=Q+(\mu-\hat{\mu})^{\prime} V^{-1}(\mu-\hat{\mu})
$$

where

$$
\begin{aligned}
V & =\left(T A^{\prime} \Sigma^{-1} A+\kappa \Omega_{0}^{-1}\right)^{-1} \\
\hat{\mu} & =V\left(\left(\Sigma^{-1} A \otimes \iota\right)^{\prime} \tilde{e}+\kappa \Omega_{0}^{-1} \mu_{0}\right),
\end{aligned}
$$

and $Q$ a constant independent of $\mu$. Thus the full conditional posterior of $\mu$ is

$$
p(\mu \mid Y, X, B, \Sigma) \sim N(\hat{\mu}, V)
$$

As $B$ only appears in $E$, the conditional posterior of $B$ can be derived directly from the term $\operatorname{tr}\left(\Sigma^{-1} E^{\prime} E\right)$, which for this purpose is now decomposed as a quadratic function of $B$. Let $\bar{Y}=Y-\iota \mu^{\prime}, \bar{X}=X-\iota \mu^{\prime}$, and use

$$
\begin{aligned}
E^{\prime} E & =\left(\bar{Y}-\bar{X} B^{\prime}\right)^{\prime}\left(\bar{Y}-\bar{X} B^{\prime}\right) \\
& =\bar{Y}^{\prime} \bar{M} \bar{Y}+(B-\hat{B}) \bar{X}^{\prime} \bar{X}(B-\hat{B})^{\prime}
\end{aligned}
$$

where

$$
\begin{aligned}
\bar{M} & =I-\bar{X}\left(\bar{X}^{\prime} \bar{X}\right)^{-1} \bar{X}^{\prime} \\
\hat{B} & =\bar{Y}^{\prime} \bar{X}\left(\bar{X}^{\prime} \bar{X}\right)^{-1}
\end{aligned}
$$

The conditional posterior of $B$ follows directly as

$$
p\left(\operatorname{vec}\left(B^{\prime}\right) \mid Y, X, \mu, \Sigma\right) \sim N^{*}\left(\operatorname{vec}\left(\hat{B}^{\prime}\right), \Sigma \otimes\left(\bar{X}^{\prime} \bar{X}\right)^{-1}\right)
$$

Again the The bayesian analysis is numerical and based on Gibbs sampling. We use the full conditional posteriors to simulate from the joint posterior by iterating over the sequence (3.26), (3.29) and (3.31).

For the initialization of the Gibbs sampler we use the OLS estimates. We discard the first 2500 draws such that we end with a sample of 20,000 parameter estimates. Conditional on a draw for the parameters $\theta=\left(\mu^{\prime}, \operatorname{vec}\left(B^{\prime}\right), \operatorname{vech}(\Sigma)\right)$ we simulate two antithetic scenarios of future returns. In this way we create 40,000 scenarios of future returns for 50 years into the future.

The burn-in phase is chosen by visual inspection of the posterior draws and supported by the convergence tool of $\mathrm{Yu}$ and Mykland (1998). We use a standardized version of their cumsum statistic as suggested by Bauwens, Lubrano and Richard (2003). For all priors the plot of the standardized version of the cumsum statistic converges smoothly and quickly to zero, especially after the burn-in phase, which indicates the convergence of the Monte Carlo chain. Sufficient conditions for convergence of the Gibbs sampler are given in Geweke (1996). Plots of the autocorrelation function suggest that the draws do not suffer from serious autocorrelation. 


\section{Chapter 4}

\section{Long-term investing with short-term constraints}

\subsection{Introduction}

Many institutional investors like pension funds face the challenge of implementing an investment strategy that is oriented to the liabilities. A revived interest in this area emanated from falling stock returns and low interest rates at the beginning of this century. Deterioration of the financial position of many pension funds also led regulatory bodies to evaluate and adapt existing monitoring frameworks. An example is the shift in the Netherlands, Denmark, Sweden and UK towards fair valuation of liabilities aligned to the yield curve in the market. In addition, the regulator in the Netherlands introduced solvency requirements. The probability that pension fund assets are less than scheme liabilities after one year has to be less than $2.5 \%$. On top of that, pension fund beneficiaries are increasingly demanding more transparency with regard to implicit arrangements in the pension deal. Defined benefit schemes are reconsidered and pension reforms seem unavoidable.

These recent industry developments have emphasized interest rate and inflation risk in Asset Liability Management (ALM) studies. Typically traditional ALM adapts a static calendar rebalancing to a fixed asset allocation. Recently, the investment industry reconsiders dynamic investment strategies as a way to mitigate the volatility of the solvency position. Propagated liability driven investment approaches often take one of three routes. Match strategies involve a match between cash flows from assets and pension obligations (see Fabozzi, Martellini, Priaulet (2005), Fabozzi and Christensen (2001), Fong and Tang (1988), Fong and Vasicek 
(1984)). A higher allocation to fixed income securities and a long duration are required. Apart from implementation issues and the fact that it is hardly possible to find a perfect inflation-linked match, the cash-flow matching approach might not be optimal in the risk/return space. React strategies depend on the development of the funding ratio. Portfolio insurance strategies have better downside protection and maintain upside potential (see Leland (1980) and Brennan and Solanki (1981)). They sell risky assets as markets fall, and buy risky assets as markets rise. Hedge strategies hedge (tail) risk with equity options, swaptions or structured products (see Engel, Kat and Kocken (2005)).

The models of the previous chapters cannot directly be applied to investigate the attractiveness of such popular dynamic asset allocation strategies for a realistic pension fund. One of the reasons is that there is more than just one utility function. In practice the process of decision-making in a multiple member and multiple objective pension plan is most of the time not based on a well-defined utility function. Among others it also depends on the pension fund governance, the financial position of the fund and the risk attitude. In addition, there is more than just the funding ratio approach of chapter 2. Besides a healthy financial position, stakeholders prefer low contribution rates, high indexation and they demand insights into the intergenerational value transfers in collective schemes. Furthermore, there is not just one single investment horizon, but there are many. Pension payments, inflation compensation and solvency positions are considered at many points in time. Another reason is that regulatory frameworks often adapt requirements about short-term solvency and the long-term continuity.

In order to provide a thorough ALM examination about the merits and pitfalls of dynamic asset allocation strategies for pension funds, this chapter extend the models of the previous chapters in two directions. First, we provide a realistic ALM framework. As in Boender (1997) and Hoevenaars, Molenaar, Steenkamp (2003) we use a simulation approach to asset liability management. We develop an integral ALM framework with a realistic description of the policy instruments for the board of a pension fund in terms of investments, indexation and contribution rates. Rather than solving an explicit utility function we present the variants in the same way as ALM studies are commonly presented to the board of a pension fund. We consider many evaluation criteria and focus on probability distribution of the financial solvency position and the goal of full indexation in each of the next ten years. We also incorporate regulatory restrictions like the probability of underfunding.

We extend the traditional ALM toolkit based on probability distributions by identifying embedded options in the pension deal. We rewrite changes in the bal- 
ance sheet in terms of embedded surplus, deficit and indexation options. Conducting such a value-based ALM analysis reveals value transfers between stakeholders. For instance, a high deficit option value in ten years from now and a high indexation option for the coming years indicates that current beneficiaries receive high indexation benefits at the expense of future beneficiaries who face large downside risks. The literature on embedded options in DB pension plans starts with Sharpe (1976). He defines the so-called pension put, because US pension plans are insured through the Pension Benefit Guarantee Corporation. Steenkamp (1998) applies contingent claim analysis to value the pension liabilities and surpluses of corporate pension funds. Ponds (2003) and Hoevenaars and Ponds (2006) explore embedded options for different generations in order to examine intergenerational value transfers in DB pension deals. Kortleve and Ponds (2006) apply value-based ALM and verify who gain and loose from changing the pension deal. Kocken (2006) identifies the employer guarantee, the option to default and the inflation indexation option on the balance sheet of DB schemes. In this chapter we focus on the embedded surplus, deficit and indexation options.

Second, we extend the vector autoregression for the joint dynamics of stock returns, interest rates, inflation and macro economic variables by an affine term structure of interest rates, because interest rate risk is one of the most important risk factors in a fair value world (see Hoevenaars, Steenbeek, Sleijpen (2005)). As in Campbell and Viceira (2001), Cochrane and Piazzesi (2005) and Ang, Bekaert and Wei (2007) the term structure is derived via the pricing kernel. Identification is based on the absence of arbitrage. Bond yields are affine in the state variables of the VAR and arbitrage opportunities are ruled out to the included bonds. The affine specification takes care of both the cross section of yields and the time dimension. ${ }^{1}$ The model also captures time-varying risk premia which are important for the time variation in bond premia (see Dai and Singleton (2002)). In this way we construct an economic environment that incorporates the time-varying risk opportunities of the previous chapters and also models a term structure of interest rates via a pricing kernel specification.

This chapter applies the extended modeling framework to explore the tradeoffs when a pension fund would choose for a dynamic asset allocation strategy which is driven by the fair value of scheme liabilities. Obviously, the menu of dynamic investment strategies is large. In order to illustrate the merits and pitfalls we analyze three different dynamic strategies which are representative for a variety of dynamic asset allocation strategies implemented in the pension industry. First, immunization of nominal pension liabilities guarantees that the investment return is at least as high

\footnotetext{
1 See Duffie and Kan (1996) for a characterization of models with affine bond yields.
} 
as the growth of the nominal liabilities. The remaining risk budget is invested in risky assets whose return can be used for inflation compensation. The second strategy is based on a dynamic mix conditional on nominal solvency risks. At the beginning of each year the fund considers a constant equity-bond mix but shifts more into an asset that closely tracks the liabilities whenever the probability of underfunding exceeds $2.5 \%$. The third alternative is a constant equity-bond mix with a dynamic interest rate swap-overlay. Each year the notional of the swap is determined such that the probability of underfunding is below $2.5 \%$.

These liability-driven investment strategies are related to the portfolio insurance literature where less risk is taken in bad financial situations and more risk in good financial situations (see Perold and Sharpe (1988), Black and Jones (1988) and Black and Perold (1992)). A proportion of the difference between wealth and a prespecified floor is invested in risky assets. The remainder is invested in a riskless asset or an asset that closely tracks the liabilities. In contrast to a constant mix, portfolio insurance strategies generally perform best in trending upward or downward markets, while they perform bad in trendless but volatile (mean reverting) markets. We demonstrate that portfolio insurance strategies based on short-term solvency risks should take care of a solvency-trap. Short-term risk protection comes at the expense of upward indexation potential for future beneficiaries. In our example the dynamic swap-overlay strategy seems to create a much better balance between short-term risks and long-term inflation compensation, but there are some serious concerns. We conclude that the challenge for dynamic asset allocation strategies is to balance between nominal and real pensions, and between the short-term and the long-term.

This chapter is organized as follows. Section 4.2 describes the model for the risk and return dynamics. We elaborate on the VAR model, pricing kernel and affine term structure model of interest rates. Section 4.3 rewrites the balance sheet in terms of embedded options and explains value-based ALM. Section 4.4 discusses the impact of the dynamic asset allocations on the ALM variables. It also describes the characteristics of the pension fund under consideration. Finally, section 4.5 gives conclusions. 


\subsection{Model for risk and return dynamics}

The return dynamics is based on a vector autoregressive (VAR) model. ${ }^{2}$ An attractive property of a VAR is that it enables us to distinguish long-term and short-term risk properties of asset classes (see Campbell and Viceira (2002)). Along the lines of Cochrane and Piazessi (2005) we extend the VAR system with the pricing kernel to derive an affine term structure of interest rates. In such a way we construct a consistent economic environment applicable to strategic asset allocation and fair value ALM.

\subsubsection{Pricing kernel and affine term structure of interest rates}

Specifically, we model the return dynamics by a first-order VAR,

$$
z_{t+1}=c+B z_{t}+\Sigma \zeta_{t+1}
$$

where $\zeta_{t+1} \sim N(0, I)$ and $z_{t}$ is a $(n \times 1)$ vector of state variables including the 1month interest rate, 10-year zero coupon rate, price inflation, stock returns in excess of the 1-month interest rate and the corresponding dividend yield. As in the previous chapters we include the dividend yield to capture dynamics in the data.

In order to develop the affine term structure model we use the no-arbitrage assumption, and we follow Cochrane and Piazzesi (2005) in relating the pricing kernel to the state variables as

$$
-m_{t+1}=\delta_{0}+\delta_{1} z_{t}+\frac{1}{2} \lambda_{t}^{\prime} \lambda_{t}+\lambda_{t}^{\prime} \zeta_{t+1}
$$

where $-m_{t+1}=-\ln M_{t+1} . M_{t+1}$ is the stochastic discount factor, and $\delta_{0}+\delta_{1} z_{t}$ is the short rate which is assumed to be affine in the state variables of the VAR. As we use monthly data we use the observable 1-month yield as the short rate, such that $y_{t}^{(1)}=\delta_{0}+\delta_{1} z_{t}$. To achieve consistency between the VAR and the short rate dynamics we let $\delta_{0}=0$ and $\delta_{1}^{\prime}=(1,0,0,0,0)$. $\lambda_{t}$ is a $(n \times 1)$ vector with time-varying market prices of risk which are affine in the state variables:

$$
\lambda_{t}=\lambda_{0}+\Lambda_{1} z_{t}
$$

${ }^{2}$ There are many ways to generate economic scenarios. A traditional method is to generate one central future scenario and some limited stress scenarios, most often based on both qualitative and quantitative input. In most ALM studies a very large number of scenarios is generated with the help of a stochastic model. These stochastic models can be of a widely varying nature. For instance, an unconditional correlation matrix can be used to impose relationships on return drawings from a multivariate standard normal distribution. Furthermore, Wilkie (1987, 1995) suggests the cascade approach, whereas Mulvey $(1994,2000)$ proposes a stochastic differential equation approach for generating these scenarios. Steehouwer (2005) suggests a frequency domain approach (with filtering techniques and spectral analysis) for scenario generation. All approaches have their merits and pitfalls as described in Hoevenaars, Molenaar and Steenkamp (2003). 
The $(n \times n)$ matrix $\Lambda_{1}$ accounts for time-variation in the risk premia and conditional heteroskedasticity in the pricing kernel in (4.2). The stochastic discount factor $\left(M_{t+1}\right)$ varies with the random variables in the VAR. The first component $\left(\delta_{0}+\delta_{1} z_{t}\right)$ is the short rate $\left(y_{t}^{(1)}\right)$ which is also included in the VAR. The other component $\left(\frac{1}{2} \lambda_{t}^{\prime} \lambda_{t}+\lambda_{t}^{\prime} \zeta_{t+1}\right)$ relates shocks in the state variables to the pricing kernel. A positive market price of risk $\lambda_{t}$ leads in (4.2) to low values for the stochastic discount factor in states of the world where the values of the innovations are high. These effects are mitigated for lower market prices of risk.

Asset pricing theory states that the price of an asset $\left(P_{t}\right)$ is

$$
P_{t}=\mathrm{E}_{t}\left(M_{t+1} X_{t+1}\right)
$$

where $M_{t+1}$ is the stochastic discount factor and $X_{t+1}$ the asset payoff (see Cochrane (2001)). This holds for any asset, and specifically the price $P_{t}^{(n)}$ of an $n$-period nominal bond at time $t$ can be written as

$$
P_{t}^{(n)}=\mathrm{E}_{t}\left(M_{t+1} P_{t+1}^{(n-1)}\right)
$$

At the same time, the affine class of term structure models expresses log bond prices as an affine function of the state variables. We can therefore write the log bond prices as a linear function of the state variables in the VAR.

$$
p_{t}^{(n)}=A_{n}+B_{n}^{\prime} z_{t}
$$

The scalar $A_{n}$ and $(n \times 1)$ vector $B_{n}$ are defined under the no-arbitrage condition, and $A_{0}=B_{0}=0$ as $p_{t}^{(0)}=0$. Under these assumptions $A_{n}$ and $B_{n}$ can be solved recursively. The no-arbitrage assumption implies that for an n-period bond

$$
\begin{aligned}
A_{n}+B_{n}^{\prime} z_{t}=\mathrm{E}_{t}\left[m_{t+1}\right] & +\mathrm{E}_{t}\left[p_{t+1}^{(n-1)}\right]+\frac{1}{2} \operatorname{Var}_{t}\left[m_{t+1}\right] \\
& +\frac{1}{2} \operatorname{Var}_{t}\left[p_{t+1}^{(n-1)}\right]+\operatorname{Cov}_{t}\left(m_{t+1}, p_{t+1}^{(n-1)}\right),
\end{aligned}
$$

using (4.2) and (4.5) this equation can be rewritten as

$$
\begin{gathered}
A_{n}+B_{n}^{\prime} z_{t}=-\delta_{0}-\delta_{1}^{\prime} z_{t}+\mathrm{E}_{t}\left[A_{n-1}+B_{n-1}^{\prime} z_{t+1}\right]+\frac{1}{2} \operatorname{Var}_{t}\left[A_{n-1}+B_{n-1}^{\prime} z_{t+1}\right] \\
+\operatorname{Cov}_{t}\left[m_{t+1}, A_{n-1}+B_{n-1}^{\prime} z_{t+1}\right] .
\end{gathered}
$$

Substituting the VAR equation (4.1) results in

$$
A_{n}+B_{n}^{\prime} z_{t}=-\delta_{0}+A_{n-1}+B_{n-1}^{\prime} c+B_{n-1}^{\prime} B z_{t}-\delta_{1}^{\prime} z_{t}+\frac{1}{2} B_{n-1}^{\prime} \Sigma \Sigma^{\prime} B_{n-1}-B_{n-1}^{\prime} \Sigma \lambda_{t}
$$


Matching coefficients and rearranging obtains the recursive formulas for $A_{n}$ and $B_{n}$

$$
\begin{aligned}
& A_{n}=-\delta_{0}+A_{n-1}+B_{n-1}^{\prime}\left(c-\Sigma \lambda_{0}\right)+\frac{1}{2} B_{n-1}^{\prime} \Sigma \Sigma^{\prime} B_{n-1} \\
& B_{n}=-\delta_{1}+\left(B-\Sigma \lambda_{1}\right)^{\prime} B_{n-1} .
\end{aligned}
$$

Log bond yields are also linear in the state variables due to the inverse relationship between bond prices and yields $p_{t}^{(n)}=-n y_{t}^{(n)}$, such that

$$
y_{t}^{(n)}=-\frac{A_{n}}{n}-\frac{B_{n}^{\prime}}{n} z_{t} .
$$

This equation describes the whole term structure of nominal interest rates. The constant part of the risk premia $\lambda_{0}$ influences $A_{n}$, and the time-varying component $\Lambda_{1}$ influences $B_{n}$. As a consequence, $\lambda_{0}$ only affects the average level of the term structure of interest rates and the term spread. $\Lambda_{1}$ introduces time-variation in the term structure and term spreads. This modeling framework ensures that the term structure model in (4.9) and the VAR in (4.1) have identical implications for the 1-month interest rate and the 10-year zero coupon rate. The return dynamics of the VAR are reflected in and consistent with the modeled term structure of interest rates.

In line with Ang, Piazzesi and Wei (2006) we conduct a two-step estimation process. The VAR parameters $(c, B$, and $\Sigma)$ in (4.1) are estimated by maximum likelihood. Next, we estimate the other parameters (i.e. $\lambda_{0}, \Lambda_{1}$ ) conditional on the VAR parameters. This is done by minimizing the sum of the squared differences between the fitted yields of the term structure model in (4.9) and historical zero coupon yields. Besides the 10-year interest rate, we calibrate the model on 2, 3 and 5 -years zero yields. In order to generate a self-consistent model we ensure that the expected equity return implied by the VAR is the same as the one implied by the asset pricing equation (4.3). Since the dividend yield is a non-tradable assets we assume that the risk premium on the dividend yield is zero. Furthermore, following Ang, Bekaert, Wei (2007) we assume that the inflation risk premium is zero. ${ }^{3}$

We generate 25,000 future scenarios for economic variables by forward iterating the VAR in (4.1). Since the historical inflation (2.91\%) is well above the current long-term inflation target of the European Central Bank (2\%), we transform the constant term of the VAR $(c)$ for the scenario generation as described in Hoevenaars, Molenaar, Steenkamp (2003). In addition, we calibrate the level of term structure of nominal interest rates $A_{n}$ such that the expected value of the future spot interest rate $k$ periods from now equals the current implied forward rate. The average of the future interest rate scenarios is thus in line with current market expectations.

\footnotetext{
${ }^{3}$ In the next chapter we relate this restriction to the affine real term structure of interest rates.
} 
The average equity risk premium and dividend yield in the scenarios is pinned down at the historical averages. Stock returns and inflation scenarios follow immediately from the VAR system. Interest rates are constructed by the affine term structure model in (4.9). Returns on a rolling 10-year constant maturity zero coupon bond portfolio are calculated from the underlying bond prices (as $\left.p_{t+1}^{(n-1)}-p_{t}^{(n)}\right) . M_{t+1}$ can be used as the stochastic discount factor for valuation of embedded options in the pension deal. ${ }^{4}$

\subsubsection{Data and estimation results}

For our empirical analysis we use monthly European data. All data start in 1973:01 and end in 2005:12. German zero coupon yields are from the Deutsche Bundesbank, and the price inflation (non-seasonally adjusted) is from Datastream. MSCI world stock returns (in Euros and dollar hedged) and the corresponding dividend yield are from Factset. Summary statistics are provided in panel (a) of Table 4.1. The equity risk premium of $4.26 \%$ implies a Sharpe ratio of 0.29 .

Parameter estimates of the VAR are also summarized in Table 4.1. Stock returns are explained by the dividend yield, the 10-year yield, lagged stock returns and inflation. In particular the dividend yield captures mean reversion in stock returns. Dividend yields rise if stock prices decline. A higher dividend yield predicts an increase of stock returns next period. The higher $R^{2}$ of inflation (0.17) reveals that this series is better explained than stock returns $\left(R^{2}=0.06\right)$. Besides its own lag, inflation is explained by 1-month interest rates and the dividend yield. Furthermore inflation is an important driver for the other variables in our system. An increase in inflation predicts an increase in interest rates and dividend yield. On the contrary inflation is negatively related to next period stock returns.

Figure 4.1 demonstrates how the 10-year yield drives horizon effects in risk diversification properties between stocks and bonds. The correlation between stocks and bonds increases at short horizons and reaches its maximum of 0.53 at an investment horizon of 5.5 years. Both the correlation between stocks and bonds and the impulse response functions (in the lower graph) are derived numerically by simulation. The impulse response functions are insightful for explaining the term structure of correlations. They represent the cumulative effect of a one-standard deviation shock in the 10-year nominal interest rate for stock and bond returns after several periods (in quarters on the x-axis). To identify the impulse response functions numerically,

\footnotetext{
4 Alternatively, option values can be computed in a risk-neutral economy by changing the numeraire. In the empirical part we find that in our model setup with time-varying risk opportunities less scenarios are required for a high degree of accuracy in the risk neutral Q-world, than in the $\mathrm{P}$-world. In order to relax the computational burden we numerically compute the option values in the Q-world.
} 
Table 4.1: Summary statistics and VAR estimation results

Panel (a) provides summary statistics of the data. Annualized means and standard deviations are provided for the entire sample (1973:01-2005:12). Variables are 1-month euribor $\left(y^{1}\right)$, 10-year zero coupon yield $\left(y^{120}\right)$, price inflation $(\pi)$, MSCI world stock returns in excess of 1-month euribor $\left(x_{s}\right)$ and dividend yield $(d y)$. Panel (b) contains parameter estimates $(B)$ of the VAR with tvalues between parentheses. Panel (c) contains cross-correlations of the innovations with monthly standard deviations on the diagonal $\left(\Sigma^{\prime} \Sigma\right)$.

\begin{tabular}{lrrrrrr}
\hline a) Summary statistics & $\left(y^{1}\right)$ & $(\pi)$ & $\left(y^{120}\right)$ & $\left(x_{s}\right)$ & $(d y)$ & \\
$\mu$ & 5.43 & 2.91 & 6.72 & 4.26 & 3.05 & \\
$\sigma$ & 2.60 & 1.14 & 1.66 & 14.65 & 1.19 & \\
\hline b) VAR estimates $(B)$ & $\left(y_{t}^{1}\right)$ & $\left(\pi_{t}\right)$ & $\left(y_{t}^{120}\right)$ & $\left(x_{s, t}\right)$ & $\left(d y_{t}\right)$ & $\left(R^{2} / p\right)$ \\
$y_{t+1}^{1}$ & 0.95 & 0.02 & 0.05 & -0.00 & -0.01 & 0.96 \\
& $(58.77)$ & $(2.53)$ & $(1.59)$ & $(-0.91)$ & $(-1.13)$ & $(0.00)$ \\
$\pi_{t+1}$ & 0.46 & 0.11 & -0.02 & 0.01 & 0.10 & 0.17 \\
& $(3.99)$ & $(2.16)$ & $(-0.11)$ & $(1.48)$ & $(1.69)$ & $(0.00)$ \\
$y_{t+1}^{120}$ & 0.01 & 0.01 & 0.97 & 0.00 & -0.00 & 0.97 \\
& $(1.55)$ & $(1.86)$ & $(67.51)$ & $(0.69)$ & $(-0.20)$ & $(0.00)$ \\
$x_{s, t+1}$ & -0.72 & -1.30 & -6.62 & 0.10 & 2.79 & 0.06 \\
& $(-0.46)$ & $(-1.87)$ & $(-2.18)$ & $(2.05)$ & $(3.61)$ & $(0.00)$ \\
$d y_{t+1}$ & -0.00 & 0.02 & 0.06 & -0.00 & 0.98 & 0.99 \\
& $(-0.16)$ & $(2.12)$ & $(1.78)$ & $(-1.34)$ & $(122.43)$ & $(0.00)$ \\
\hline c) VAR estimates $\left(\Sigma^{\prime} \Sigma\right)$ & $\left(y^{1}\right)$ & $(\pi)$ & $\left(y^{120}\right)$ & $\left(x_{s}\right)$ & $(d y)$ & \\
$y^{1}$ & 0.04 & & & & & \\
$\pi$ & -0.04 & 0.30 & & & & \\
$y^{120}$ & 0.19 & 0.12 & 0.02 & & & \\
$x_{s}$ & -0.05 & 0.03 & -0.12 & 4.10 & & \\
$d y$ & 0.07 & -0.01 & 0.14 & -0.91 & 0.04 & \\
\hline \hline
\end{tabular}

we changed the ordering of the variables for the choleski decomposition such that a shock in the 10-year interest rate affects the other variables in the VAR system. If interest rates rise, bond returns decline immediately. Stock returns decrease as well, but initially at a lower degree. The negative correlation between the innovations of stock returns and the 10-year yield is -0.12 . This initial decrease is reinforced for next period stock returns by the negative coefficient of the 10-year yield (-6.62). At investment horizons beyond 5.5 years the impulse response function turns around which leads to a reduction of the correlation at longer investment horizons.

Figure 4.2 indicates that the term structure model in (4.9) fits the historical interest rates good in the cross section and in the time dimension. It provides a good fit in periods of high yields like the beginning of the eighties and nineties, and in periods of low yields as in recent years. Panel (a) of Table 4.2 summarizes the 
Figure 4.1: Impulse response analysis and correlation

The first panel gives the correlation (on the y-axis) of returns on stocks and a 10 year zero-coupon bond portfolio across various investment horizons (in quarters on the $\mathrm{x}$-axis). Impulse response functions in the second panel illustrate how a shock in 10 year zero-coupon rates affects returns on stocks and bonds (percentage points on the y-axis, investment horizon in quarters on the x-axis).
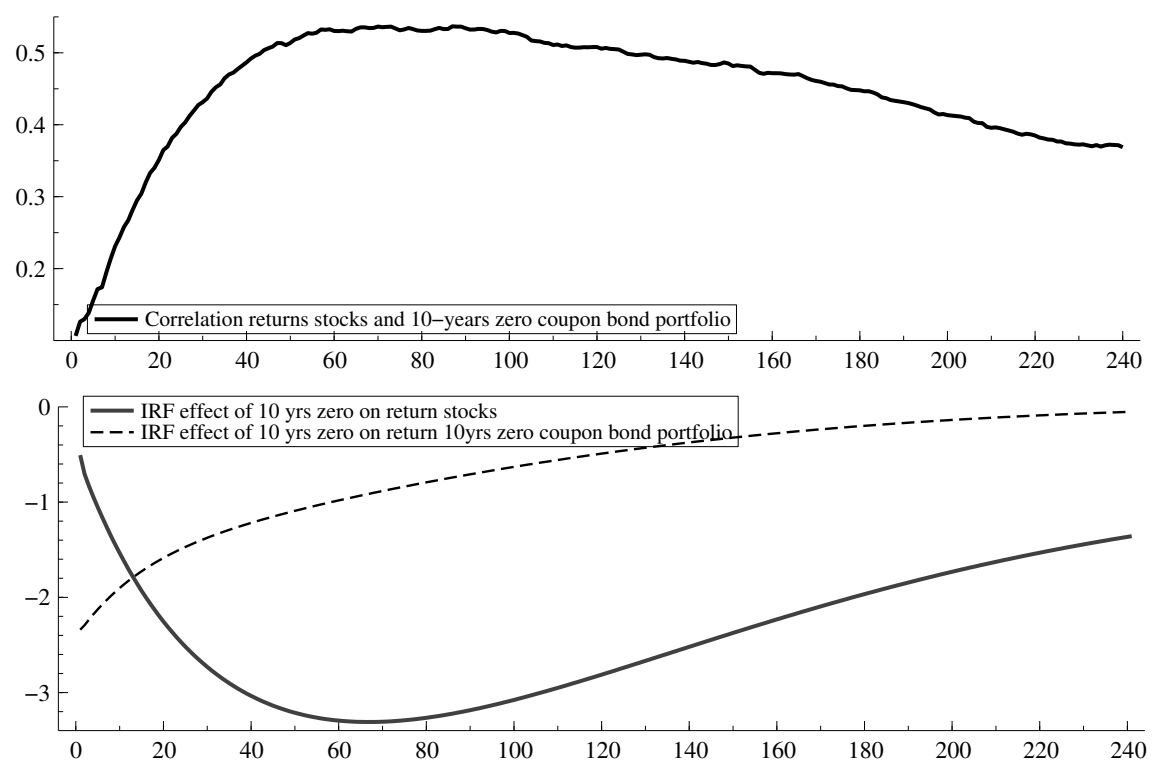

historical mispricing of the fitted term structure of interest rates. The fit is relatively worse at the short end of the curve. The 1-year yield is on average overestimated by 16 basis points. Panel (b) shows the estimated risk premia $\Sigma \lambda_{0}$ and $\Sigma \Lambda_{1}$. The estimates for $\Sigma \Lambda_{1}$ indicate that risk premia for stocks and bonds are time-varying. Risk premia for stocks are identical to the VAR coefficients. This ensures the consistency between the VAR model and the term structure of interest rates. The risk premia on the dividend yield and the one-period inflation risk premium are assumed to be zero.

\subsection{Value-based ALM and embedded options}

This section identifies embedded options on the balance sheet of a funded collective pension scheme. To that purpose we rewrite the balance sheet such that it reveals the implicit payoffs and claims to the stakeholders. The current price or present value of the future payoffs can be calculated with the asset pricing equation (4.3). 
Figure 4.2: Fit historical nominal term structures of interest rates

Historical fit of the affine term structure model in equation 4.9 for five points on the term structure: 1-month $(y 1), 2$ year $(y 24), 3$ year $(y 36), 5$ year $(y 60)$ and 10 year $(y 120)$ zero coupon interest rates. Solid lines represent the actual series. Dashed lines denote the fitted series.
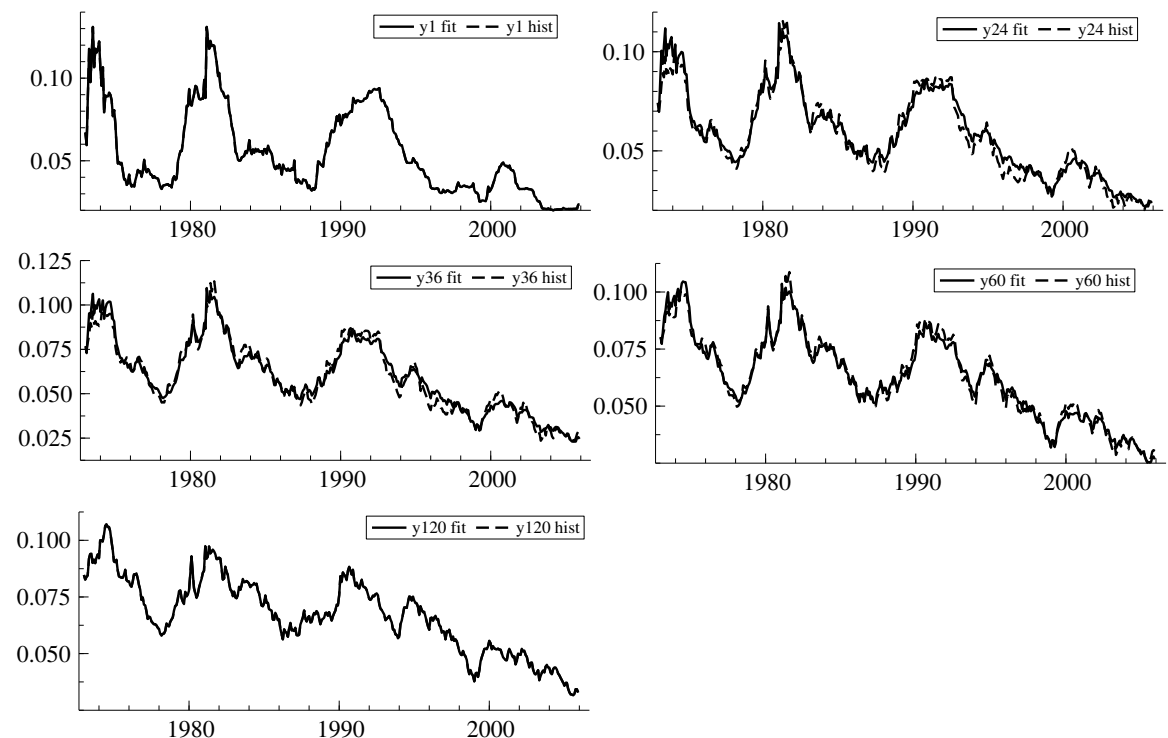

Table 4.2: Estimation results term structure model

Panel (a) shows risk premia $\left(\Sigma \lambda_{0}\right.$ and $\left.\Sigma \Lambda_{1}\right)$ and panel (b) gives the annualized means and standard deviations of historical mispricing of the nominal term structure of interest rates.

\begin{tabular}{lrrrrrr} 
a) Risk premia & $\left(y^{1}\right)$ & $(\pi)$ & $\left(y^{120}\right)$ & $\left(x_{s}\right)$ & $(d y)$ & $\left(\lambda_{0}\right)$ \\
$y^{1}$ & 0.01 & 0.02 & -0.02 & 0.00 & -0.01 & 0.00 \\
$\pi$ & 0.00 & 0.00 & 0.00 & 0.00 & 0.00 & 0.00 \\
$y^{120}$ & 0.02 & 0.01 & -0.04 & 0.00 & 0.00 & 0.00 \\
$x_{s}$ & -0.72 & -1.30 & -6.62 & 0.10 & 2.79 & 0.15 \\
$d y$ & 0.00 & 0.00 & 0.00 & 0.00 & 0.00 & 0.00 \\
\hline b) Mispricing term structure & $\left(y^{12}\right)$ & $\left(y^{24}\right)$ & $\left(y^{36}\right)$ & $\left(y^{48}\right)$ & $\left(y^{60}\right)$ & $\left(y^{120}\right)$ \\
$\mu$ & 0.16 & 0.11 & 0.04 & 0.00 & 0.03 & 0.00 \\
$\sigma$ & 0.45 & 0.42 & 0.38 & 0.32 & 0.26 & 0.00 \\
\hline \hline
\end{tabular}

We show how changes in the present value of future payoffs due to for instance a pension reform represent embedded value transfers. 
We define the excess on the balance sheet $\left(E_{t}\right)$ as the market value of the assets $\left(A_{t}\right)$ minus the market value of the liabilities $\left(L_{t}\right): E_{t}=A_{t}-L_{t}$. During a year the asset side changes due to pension payments $\left(P_{t}\right)$, inflow from contributions $\left(C_{t}\right)$ and investment returns $\left(R_{t}\right)$. Changes on the liability side result from new accrued pension claims $\left(N_{t}\right)$, pension payments and indexation $\left(I_{t}\right)$. In other words,

$$
\begin{aligned}
A_{t} & =A_{t-1}\left(1+R_{t}\right)+C_{t}-P_{t} \\
L_{t} & =L_{t-1}+N_{t}+I_{t}-P_{t}
\end{aligned}
$$

Equation (4.3) implies that in an arbitrage-free world the present value of future investment returns equals one. If we then use equations (4.10) and (4.11) the present value of the excess at $t+\tau$ can be written as

$$
\begin{aligned}
V_{t}\left(E_{t+\tau}\right) & =\mathrm{E}_{t}\left(M_{t+\tau}^{*} E_{t+\tau}\right) \\
& =A_{t}-L_{t}-V_{t}\left(\triangle I_{t, t+\tau}\right)-V_{t}\left(\triangle N_{t, t+\tau}+\triangle P_{t, t+\tau}-\triangle C_{t, t+\tau}\right)
\end{aligned}
$$

where $M_{t+\tau}^{*}=M_{t+1} \cdots M_{t+\tau}$ is the corresponding stochastic discount factor for payoffs in period $t+\tau$. In general, high values of the stochastic discount rates are assigned to bad scenarios, and low values are assigned to good scenarios. As a consequence payoffs during bad times are more valuable than payoffs during good times. This Monte Carlo approach to option valuation accommodates complex real-world path-dependent policy decisions and investment strategies. $V_{t}\left(\triangle I_{t, t+\tau}\right)$, $V_{t}\left(\triangle N_{t, t+\tau}\right), V_{t}\left(\triangle P_{t, t+\tau}\right)$, and $V_{t}\left(\triangle C_{t, t+\tau}\right)$ represent the present value of the indexation, new accrued pension claims, pension payments and contributions during the time period $(t, t+\tau)$. Accordingly, the change in the balance sheet between $t$ and $t+\tau$ is

$$
V_{t}\left(\triangle I_{t, t+\tau}\right)+V_{t}\left(\triangle E_{t, t+\tau}\right)+V_{t}\left(\triangle N_{t, t+\tau}+\triangle P_{t, t+\tau}-\triangle C_{t, t+\tau}\right)=0 .
$$

Changes in the balance sheet can be attributed to three components: (i) the embedded indexation option, (ii) the embedded excess option and (iii) an embedded option that is related to the contribution policy and the actuarial characteristics of the beneficiaries. The zero-sum character in value terms reveals that policy changes lead to value transfers between the three components in equation (4.14), but do not create additional value. A comparison of the embedded option values of two different pension deals discloses the value transfers between current and future beneficiaries if the pension deal would be changed from one to the other. For instance, if a prearranged policy reform would lead to a higher increase in the deficit option than in the surplus option, the policy reform implies that future generations implicitly get more exposure to downside risks than upward potential. As such value-based 
ALM considers questions like who bears what kinds of risks? How does the pension deal implicitly redistribute risks between stake holders? The traditional ALM measures in terms of probability distributions are not able do deal with these issues. Value-based ALM uses the same scenarios as classical ALM, but makes it possible to detect value transfers. Option valuation techniques are the market consistent method to value uncertain future payoffs in accordance with how risks are shared in the market. Value-based ALM adds an extra dimension to the implications of the contribution, indexation and investment strategy, and therefore gives more insights into the attractiveness of a pension deal.

The value of $V_{t}\left(\triangle N_{t, t+\tau}+\triangle P_{t, t+\tau}-\triangle C_{t, t+\tau}\right)$ is zero when two conditions are satisfied. If the pension fund is in a stationary state newly built-up pension rights in a year are equal to the pension payments in that year such that $N_{t}=P_{t}$ in equation (4.11). In addition, the contribution rate should be actuarial fair in the sense that contribution payments in a particular year cover the new accrued pension rights in the corresponding year such that $C_{t}=P_{t}$ in equation (4.10). If the option value differs from zero, at least one of these two conditions does not hold.

The embedded indexation option discloses the future indexation potential. It depends on the indexation policy. Conditional indexation can be interpreted as a put option for the fund which is written by the participants. Whenever the financial position deteriorates such that full indexation is not longer sustainable, the put option becomes in-the-money and the fund can exercise the option. This leads to conditional indexation. Equivalently, the put-call parity implies that the conditional indexation option can also be interpreted as a call option for the participants written by the fund. From this perspective the policy ladder implies that participants implicitly have the right to claim indexation according to the indexation policy. We express the indexation option as a European call option because this is in accordance with (4.14). The embedded value of the indexation option with maturity $\tau\left(V_{t}\left(I_{t+\tau}\right)\right)$ is the present value of the uncertain future indexation payoffs $\left(L_{t+\tau}-L_{t+\tau}^{*}\right)$ over the period $(t, t+\tau)$.

$$
V_{t}\left(I_{t+\tau}\right)=\mathrm{E}_{t}\left[M_{t+\tau}\left(L_{t+\tau}-L_{t+\tau}^{*}\right)\right]
$$

where $L_{t}$ represents the accrued benefit obligations including (conditional) indexation, and $L_{t}^{*}$ represents the accrued benefit obligations without indexation.

Embedded excess options would have been insightful during the eighties and nineties. In these years enormous surpluses of several pension funds were claimed by stake holders who required for instance contribution holidays, bonus indexation and early retirement. Such an example indicates that participants demand a claim on the excess, which will be either a surplus or a deficit. Accordingly, the claims on the excess at the end of each year $\tau$ can be interpreted as an embedded excess option 
$\left(V_{t}\left(E_{t+\tau}\right)\right)$ for the stake holders, which consists of a surplus option $\left(V_{t}\left(S_{t+\tau}\right)\right)$ and a deficit option $\left(V_{t}\left(D_{t+\tau}\right)\right)$

$$
\begin{aligned}
V_{t}\left(E_{t+\tau}\right) & =\mathrm{E}_{t}\left[M_{t+\tau}\left(A_{t+\tau}-L_{t+\tau}\right)\right] \\
& =\mathrm{E}_{t}\left[M_{t+\tau} \max \left[0, A_{t+\tau}-L_{t+\tau}\right]\right]+\mathrm{E}_{t}\left[M_{t+\tau} \max \left[0, L_{t+\tau}-A_{t+\tau}\right]\right] \\
& =V_{t}\left(S_{t+\tau}\right)-V_{t}\left(D_{t+\tau}\right)
\end{aligned}
$$

Typically we focus on the change of the surplus and deficit options in (4.16) and we define $V_{t}\left(\triangle S_{t, t+\tau}\right)=V_{t}\left(S_{t+\tau}-S_{t}\right)$ and $V_{t}\left(\triangle D_{t, t+\tau}\right)=V_{t}\left(D_{t+\tau}-D_{t}\right)$.

The surplus option represents the upward potential for future beneficiaries. It is a European call option on the surplus written by the fund. A high value suggests that there is a large upward potential. In some circumstances it could be interesting from a welfare perspective to payout some of the surplus to the current beneficiaries in terms of contribution holidays or extra indexation. On the other hand, such a decision would harm the upward potential of future generations. A positive option value could also be desirable, because the surplus serves as a risk buffer or cushion in economic downturns.

The value of the deficit option indicates to what extent future generations or third parties like the plan-sponsor are exposed to downside risks. It is a European put option written by the beneficiaries. The embedded option value is the economic value of future deficits. The option value represents the value transfers from current to future beneficiaries because they are exposed to downside risks. The deficit option can also be interpreted as the reinsurance premium that the pension fund has to pay to an insurance company for the agreement that the insurance company deposits any deficits in case of under funding in a particular year. The difference between the values of the surplus option and the deficit option is an indicator for the balance of between upward potential and future risks.

\subsection{Long-term investing with short-term constraints}

\subsubsection{ALM framework}

Our ALM framework is representative for a stylized stand-alone funded collective defined benefit-like pension plan. It is an average-wage plan with the goal to fully index liabilities with price inflation. Workers acquire for each year of service $2 \%$ of their pensionable wage as new accrued pension rights. The financial position of the fund is represented by the funding ratio which is defined as the ratio of the market value of the assets to the present value of the pension liabilities. The discount rates for the latter one are nominal interest rates, because pension payments are 
guaranteed without inflation compensation. It is evident that the attractiveness of policy variants depends on the initial funding ratio. Many pension funds around the world have a deficit in real terms, but a surplus in nominal terms. For the empirical part we therefore set the initial nominal funding ratio at $115 \%$. Such a starting position clearly reveals the tradeoffs between the probability of a nominal deficit and the real inflation ambition later on in this chapter.

The value of pension liabilities on the balance sheet is calculated as the current (discounted) value of earned pension rights. Changes in this value can therefore be due to three factors: actuarial, (nominal or real) interest rates and indexation. Actuarial factors include the level and length of nominal cash flows of earned pension rights. Factors of this sort represent demographic trends, retirement age, job promotion, mortality rates and discharge. Actuarial factors are generally modeled as Markov processes where transition probabilities, for example, indicate the likelihood that someone lives next year. The ageing of the population is taken into account and current active, retired and sleeping participants are integrated as well. As the main focus in this chapter is on the analysis of investment strategies, we consider actuarial risks as exogenous risk factors which are either hedged away or not material. ${ }^{5}$

Changes in interest rates have a direct impact on the valuation of pension liabilities, because they serve as discount rates for future cash flows of nominal earned pension rights. ${ }^{6}$

The third variable influencing the value of liabilities is indexation. Since pensions are meant to provide a standard of living, pension funds generally aim to index pension payments by inflation. In our ALM framework the indexation of the liabilities with price inflation is conditional on the financial position of the fund. Whenever the nominal funding ratio is below $100 \%$ pension payments are no longer indexed by price inflation. Indexation is between $0 \%$ and $100 \%$ whenever the nominal fund-

\footnotetext{
${ }^{5}$ Recently, longevity risk is a hot topic in academic research. Blake, Cairns, Dowd (2006) address longevity risk and discuss ways to manage this risk exposure. Cairns, Blake, Dowd (2005) examine modeling mortality risks and price mortality-linked instruments. Nijman, Hari, De Waegenaere, Melenberg (2006) model survival probabilities and longevity risk. They also compute the market value of liabilities in case of macro longevity risk. Macro longevity risk refers to changes in survival probabilities due to for instance improvements in habits, health care, or external factors. Micro longevity risk refers to realized mortality of individual participants which differs from anticipated mortality.

${ }^{6}$ Most new regulatory frameworks require fair market valuation of liabilities. This can be interpreted as the value against which liabilities could be sold to a third party. Under the assumption that liabilities are only guaranteed in nominal terms, the appropriate discount rate is a term structure of nominal yields. These nominal yields could be government bond yields or swap rates and an additional risk premium reflecting the default probability of the pension fund. Similarly, when liabilities are guaranteed in real terms, hence full (wage or price) inflation compensation, a real term structure of interest rates is required. De Jong (2005) examines the valuation of pension liabilities in such incomplete markets. He concludes that incompleteness can be incorporated by lowering the real discount rate. Another perspective for fair valuation of liabilities is a cost-of-capital like approach similar to company valuation for a sale in corporate finance (see Waring (2004)).
} 
ing ratio is between $100 \%$ and $140 \% .^{7}$ Pensions are fully indexed by price inflation otherwise. Additionally, any foregone indexation of pension payments - the nominal funding ratio was less than $140 \%$ - is made up.

The other side of the balance sheet is influenced by pension payments (cash outflow), contributions (cash-inflow) and investment returns. Pension payments are considered to be reasonably predictable and determined by the same actuarial factors as mentioned before. Contribution levels are set in the contribution policy of the fund. Workers pay yearly contributions out of their wage income in order to fund newly accrued liabilities in that year. In the empirical part we assume that there is a uniform rate of $20 \%$ of the pensionable salary. Investment returns depend on the chosen investment strategy, and the investment universe consists of equities and bonds. $^{8}$

Our ALM model combines the asset and liability side of the balance sheet via a simulation approach. The risk and return dynamics of the scenarios are based on the VAR model of section 4.2. An attractive feature is that the simulation approach can easily deal with highly non-linear and company-specific decision rules in the investment-, contribution-, indexation- and pension policy. In order to analyze the relevant ALM output variables, the preferences of the various stakeholders and a probability distribution of the relevant decision variables are required. Determining the preferences of the beneficiaries of a pension fund is an extremely debatable issue as there are stakeholders with different interests. As it is tentative to assign different weights to the divers objectives of the stakeholders, we evaluate the output of the ALM study for each of these stakeholders. ${ }^{9}$ Therefore we consider the indexation quality, downside risks, the funding ratio, and several risk measures. We also identify the embedded options as additional evaluation criteria. Although our ALM model enables the board to decide on strategic issues as the strategic asset allocation, and the contribution, indexation and pension policies in an integral fashion, this chapter

7 In the next chapter we specify the the upperbound of the indexation ladder as the nominal funding ratio where the asset value equals the value of the real liabilities. In that case the real interest rate is used as a discount factor. However, this corresponds to a the nominal funding ratio around $140 \%$.

${ }^{8}$ Obviously the return on the assets can also be increased by raising contribution rates. However, large jumps in the contribution rates are not desired in practice and often restricted to a few percentage points per year. This makes the contribution rate a less effective steering instrument for mature funds if the investment returns are not as high as they should be. In all the variants of this ALM study we therefore fix the contribution rate at $20 \%$ of the pensionable salary and we focus on the impact of the investment strategies.

${ }^{9}$ Recall that we do not explicitly optimize a utility function as in Binsbergen and Brandt (2007) or stochastic programming approaches to ALM (see Carino et. al. (1994), Dert (1995, 1998), Kouwenberg (2001) and Ziemba (2003)). Neither do we confine ourselves to a surplus measure and surplus optimization as suggested in Sharpe and Tint (1990), Leibowitz, Kogelman and Bader (1994) and Waring (2004). 
particularly focuses on the investment strategy as a policy instrument of the board in order to get a better understanding of the underlying mechanics. ${ }^{10}$

\section{ALM evaluation criteria}

Probability distributions of the relevant decision variables and embedded options are used to evaluate the investment strategies. Table 4.3 summarizes the ALM output for each investment strategy in terms of expectations, downside risks and upward potential. We evaluate the impact of the investment strategies on the output variables in the short run (one year) and in the long run (ten years).

More specifically, we represent the probability density of the nominal funding ratio by the median (Fnom) and downside risks. The "within probability" $(P w(F n o m<100))$ provides the probability that the funding ratio is at least once below $100 \%$ within a period, instead of in a specific year $(P(F n o m<100))$. The conditional funding ratio at risk $\left(C F a R_{2.5 \%}\right)$ represents tail risk as the expected funding ratio in the $2.5 \%$ worst-case outcomes.

The indexation quality is summarized by the probability of full indexation $(P(F I))$, the indexation result $(I R)$ and pension result $(P R)$. The latter one incorporates both nominal liabilities and indexation. It is always between $0 \%$ and $100 \%$. A pension result of $90 \%$ means that participants who have 40 years of service receive $90 \%$ of the $80 \%$ average wage promise as a pension payment (therefore $72 \%$ of the average wage). On the contrary, the indexation result, which is also between 0 and $100 \%$, excludes the nominal liabilities. It focuses solely on the appointed indexation.

Value transfers between current and future generations due to changes in the investment strategy are indicated by the embedded option values in Table 4.4. We focus in the discussion on the embedded excess and indexation options in (4.14). It follows from the zero-sum nature of policy changes in (4.14) that the embedded option that is related to the contribution policy and actuarial characteristics of the beneficiaries changes accordingly. However, we refrain from a discussion of this option value because the contribution rate is not an active policy instrument in our ALM study, and actuarial factors are considered to be exogenous as well.

We also provide risk measures in terms of asset performance and with respect to the liabilities. The nominal mismatch risk $\left(\sigma_{F}\right)$ is the volatility of the nominal funding ratio return. Mismatch risk can serve as a measurable and manageable risk

\footnotetext{
10 To isolate the impact of the dynamic asset allocation strategies we refrain from adjustments of the other policy instruments of the board. Obviously, the initial funding ratio, the contribution rate and the indexation policy directly influence the output of the ALM study. Adjustments of the indexation policy, contribution policy and pension reforms are considered in the next chapter. Furthermore, we have tried to choose our settings such that they are representative for an average collective DB pension scheme.
} 
Table 4.3: ALM evaluation criteria: probability distributions

Summary statistics of probability distributions of the main decision variables for the board based on the ALM model with an initial funding ratio of $115 \%$. The ALM study is based on a simulation approach. We explore four different investment frameworks: (i) calendar rebalancing, (ii) immunization, (iii) dynamic mix, and $(i v)$ dynamic swap-overlay. The model incorporates a nonlinear indexation policy, the investment and contribution policies in an integral fashion. The selected output variables for the solvency position include the median of the nominal funding ratio (Fnom), probability of under funding in a year $(P(F n o m<100))$, probability of under funding within the next ten years $(P w(F n o m<100))$, the conditional funding ratio at risk in the $2.5 \%$ percentile $\left(\mathrm{CFaR}_{2.5 \%}\right)$, and the maximum drawdown (in percentage points) of the funding ratio in the next year $\left(\delta_{F}\right)$. The indexation quality is summarized by the median indexation result $(I R)$, the probability of an indexation result less than $80 \%(P(I R<80))$, the median pension result $(P R)$, and the probability on full indexation in a year $(P(F I))$. Other asset-only and asset-liability risk figures include the nominal asset-liability mismatch risk $\left(\sigma_{F}\right)$, the holding period nominal asset-liability mismatch risk $\left(\sigma_{F}^{(\tau)}\right)$, the correlation between the returns on assets and liabilities $\left(\rho_{A L}\right)$, and the stand-alone risk of the asset $\operatorname{mix}\left(\sigma_{R}\right)$.

\begin{tabular}{|c|c|c|c|c|}
\hline Solvency position & $(i)$ & $(i i)$ & $(i i i)$ & $(i v)$ \\
\hline Fnom $_{t+1}$ & 1.17 & 1.15 & 1.16 & 1.16 \\
\hline Fnom $_{t+10}$ & 1.29 & 1.14 & 1.07 & 1.28 \\
\hline$P\left(\right.$ Fnom $\left._{t+1}<100\right)$ & 0.05 & 0.00 & 0.01 & 0.01 \\
\hline$P\left(\right.$ Fnom $\left._{t+10}<100\right)$ & 0.01 & 0.01 & 0.12 & 0.02 \\
\hline$P w\left(\right.$ Fnom $\left._{t+10}<100\right)$ & 0.21 & 0.01 & 0.16 & 0.16 \\
\hline $\mathrm{CFaR}_{2.5 \%, t+1}$ & 0.94 & 1.08 & 1.00 & 1.00 \\
\hline$\delta_{F, t+1}$ & 0.34 & 0.13 & 0.23 & 0.25 \\
\hline \multicolumn{5}{|l|}{ Indexation quality } \\
\hline$I R_{t+1}$ & 0.37 & 0.31 & 0.34 & 0.34 \\
\hline$I R_{t+10}$ & 0.51 & 0.26 & 0.21 & 0.46 \\
\hline$P\left(I R_{t+1}<80\right)$ & 0.92 & 1.00 & 0.99 & 0.97 \\
\hline$P\left(I R_{t+10}<80\right)$ & 0.97 & 1.00 & 1.00 & 0.95 \\
\hline$P R_{t+10}$ & 0.88 & 0.81 & 0.81 & 0.87 \\
\hline$P\left(F I_{t+10}\right)$ & 0.26 & 0.00 & 0.03 & 0.26 \\
\hline \multicolumn{5}{|l|}{ Other risk measures } \\
\hline$\sigma_{F, t+1}$ & 0.09 & 0.03 & 0.06 & 0.07 \\
\hline$\sigma_{F}^{(t+10)}$ & 0.04 & 0.02 & 0.03 & 0.05 \\
\hline$\sigma_{R, t+1}$ & 0.09 & 0.11 & 0.09 & 0.15 \\
\hline$\rho_{A L, t+1}$ & 0.62 & 0.98 & 0.89 & 0.88 \\
\hline
\end{tabular}


Table 4.4: Value based ALM: embedded options

\begin{tabular}{|c|c|c|c|c|}
\hline \multicolumn{5}{|c|}{$\begin{array}{l}\text { Embedded options in the pension deal for four different in- } \\
\text { vestment frameworks: (i) calendar rebalancing, (ii) immuniza- } \\
\text { tion of nominal liabilities, (iii) dynamic mix, and (iv) dynamic } \\
\text { swap-overlay. The results are based on the ALM model with an } \\
\text { initial funding ratio of } 115 \% \text {. } V_{t} \triangle S_{t, t+10} \text { represents the em- } \\
\text { bedded surplus option value at } t+10 \text { relative to the current sur- } \\
\text { plus, } V_{t} \triangle D_{t, t+10} \text { represents the embedded deficit option value } \\
\text { at } t+10, V_{t} \triangle E_{t, t+10} \text { represents the embedded residue option } \\
\text { value at } t+10 \text { relative to the current residue, and } V_{t} \triangle I_{t, t+10} \\
\text { represents the embedded indexation option value based on the } \\
\text { indexation during }(t, t+10) \text {. }\end{array}$} \\
\hline & $(i)$ & $(i i)$ & $(i i i)$ & $(i v)$ \\
\hline$V_{t} \triangle S_{t, t+10}$ & +1 & -6 & -6 & -1 \\
\hline$V_{t} \triangle D_{t, t+10}$ & -14 & -4 & -5 & -11 \\
\hline$V_{t} \triangle E_{t, t+10}$ & -13 & -10 & -11 & -12 \\
\hline$V_{t} \triangle I_{t, t+10}$ & +12 & +8 & +9 & +10 \\
\hline
\end{tabular}

parameter. Risk budgeting and risk allocation for instance, often incorporate restrictions about the maximum mismatch risk and the required rate of return. The holding period mismatch risk $\left(\sigma_{F}^{(\tau)}\right)$ is the volatility of geometric funding ratio returns under the policy settings. Time diversification properties of the assets in our investment universe explain the mean reverting pattern in $\sigma_{F}^{(\tau)}$. The maximum drawdown measures the largest fall of the nominal funding ratio in the next year in percentage points $\left(\delta_{F}\right)$. Finally, we show the correlation between the returns on assets and liabilities $\left(\rho_{A, L}\right)$ and the volatility of the asset mix $\left(\sigma_{R}\right)$.

\subsubsection{Calendar rebalancing}

Traditionally, it has been common practice among long-term institutional investors to adapt a constant investment mix. Therefore we specify the reference strategy as a constant 50-50 equity-bond mix and think that this is representative for the average equity-bond allocation of (Dutch) pension funds. ${ }^{11}$ The duration of the bond allocation is around 8 years, and the duration of the liabilities is around 16 years. The expected return on this investment mix is $5.3 \%$ per year with $10 \%$ volatility. ${ }^{12}$

\footnotetext{
11 This is also in line with the investment portfolio of the stylized pension fund in "Financial Assessment Framework Consultation Document" available at www.dnb.nl.

12 In the scenarios for the next ten years the average stock and bond return are $7.7 \%$ and $3.4 \%$, respectively. Since the average growth of the nominal liabilities is $3.7 \%$ per year, the expected investment return is not high enough to fully index the pension payments with the annual price inflation (on average $2.95 \%$ ).
} 
Calendar rebalancing strategies exploit (short-term) mean reversion. Assets which have risen relative to other assets are sold at the end of the year, and vice versa. Calendar rebalancing strategies buy assets as markets have fallen, and sell assets as markets have risen. We use this reference strategy as a benchmark in the discussion of the three dynamic investment strategies.

The ALM output variables in Table 4.3 suggest that an increase of the nominal funding ratio is anticipated, but that there are also substantial downside risks. The $2.5 \%$ solvency requirement of the Dutch regulator would be violated, and there is an $21 \%$ probability that the fund will be underfunded within the next ten years. Drawdowns in the next year of the funding ratio could be up to $34 \%$, and the average funding ratio in the $2.5 \%$ worst-case scenarios is only $94 \%$. Furthermore, the ALM study indicates that under the return assumptions used there is only a $26 \%$ chance that pension payments can be fully indexed by price inflation in the long run. In the long run pension payments can on average be corrected for half of the price inflation. This is in accordance with a pension equal to $88 \%$ of the average wage. Apparently the $50 \%$ equity allocation is not sufficient under the return expectations used to pursue the long run goal of the pension fund.

The embedded options in Table 4.4 reveal that the value transfers from current to future beneficiaries are due to downside risks and indexation compensation. In the current pension deal beneficiaries are largely compensated for the exposure to downside risks (the deficit option is $-14 \%$ ) by the indexation policy (the indexation option is $+12 \%$ ) rather than by a high upward potential of the funding ratio (the surplus option is $+1 \%$ ). Furthermore, in ten years from now future generations at that point in time are much more exposed to downside risks than upward potential. A comparison of the surplus and deficit option values (1:14) to the probabilities of underfunding and overfunding unveils that bad financial outcomes are more heavily discounted than good financial outcomes. The large increase of the expected funding ratio in the next ten years by $14 \%$-points has only a low value in option terms $(+1 \%)$.

\subsubsection{Dynamic immunization of nominal liabilities}

The first alternative investment strategy is the immunization of nominal pension liabilities. Immunization is a so-called matching strategy. The idea behind this dynamic strategy is that the investment return in each year should be at least as high as the growth of the nominal liabilities. To this purpose a percentage of the assets equal to the reciprocal of the nominal funding ratio is allocated to a hedge portfolio that closely tracks the nominal liabilities. The hedge portfolio entails purchasing a bond that replicates the liabilities. As we construct a hypothetical bond with 
the same duration as the nominal liabilities (around 16 years) there may be some mismatch risk due to convexity effects. The remainder of the assets is allocated to a risky portfolio which in our case consists entirely of equities. ${ }^{13}$ In our example where the initial funding ratio is $115 \%$ this means that $87 \%$ of the assets $(=1 / 1.15)$ is invested in the hedge portfolio and $13 \%$ in an equity portfolio. The return on the asset mix is

$$
R_{t}=\left(1-\alpha_{t}^{(h)}\right) R_{t}^{r}+\alpha_{t}^{(h)} R_{t}^{h}
$$

where $R_{t}^{r}$ and $R_{t}^{h}$ are returns on the risky and the hedge portfolio respectively. The allocation to the hedge portfolio $\left(\alpha_{t}^{(h)}\right)$ is a dynamic function of the funding ratio $\left(f_{t}\right): \alpha_{t-1}^{(h)}=\min \left(1 / f_{t}, 1\right)$. By construction immunization focuses on total risk of the surplus relative to liabilities. Depending on the development of the funding ratio the remaining risk budget is invested in equities. Inevitably this implies that the expected return on the asset mix changes with the financial position. In contrast to the reference strategy, equities are bought when they have risen relative to the liabilities, and sold when they have declined. More money is allocated to the hedge portfolio if interest rates fall and vice versa. As risky assets are sold when the funding ratio approaches $100 \%$, there is high chance that the pension fund evolves in a "solvency trap". In such a case the return on the investment portfolio has little upside (indexation) potential because the fund tries to guarantee nominal pensions.

The ALM results in Table 4.3 indicate that downside risks in terms of underfunding improve substantially compared to the reference strategy. The $2.5 \%$ solvency requirements are met and the average funding ratio in the $2.5 \%$ worst-case scenarios is far above $100 \%$. The maximum drawdown of the funding ratio in the next year is projected to be $2 \%$-points less than the available surplus. Nevertheless, there is still a very small probability of underfunding, because the hedge portfolio does not completely match the underlying pension cash flows. On top of that, the duration extension aligns interest rate sensitivity of the assets with that of the liabilities, mismatch risks reduce substantially (it is still $3 \%$ due to equity risk and mismatch of the hedge portfolio) and the correlation between returns on asset and liabilities is very high (0.98). On the other hand, asset-only risks increase to $11 \%$ due to the duration extension. The alternative consideration is that indexation qualities deteriorate over time, also relative to the reference strategy. Once the funding ratio approaches $100 \%$, assets are shifted to the hedge portfolio such that there is less upward potential. Such a "solvency-trap" is not in line with the goal of inflation

13 The portfolio insurance literature commonly allows for leverage of the risky portfolio by introducing a multiplier term. We implicitly assume that the multiplier for the risky investment equals one. Although we think that this is a realistic assumption for pension funds, the return potential might be improved in many ways like a higher multiplier, structured derivative solutions and alternative investments. 
compensation. Obviously, its severeness does not only depend on the return potential of the risky portfolio, but also on characteristics of participants and ageing of the fund. In the long run pension payments are expected to be $81 \%$ of the average wage during the working life and there hardly is upward potential.

The embedded options in Table 4.4 suggest that switching from a constant mix to an immunization strategy would lead to value transfers from indexation in the long run to short-term downside risk protection. In addition the low surplus option of $-6 \%$ indicates that there will be a value transfer from future generations to the current ones. The protection against downside risks reduces the upside potential for beneficiaries in the long run. The embedded options illustrate how the 1\%-point decrease of the expected funding ratio in ten years from now should be compared to the $14 \%$-points increase of the expected funding ratio in case of the reference strategy. The latter has a lower value in terms of value-based ALM $(-6 \%$ vs $+1 \%)$. The surplus option is negative because in more than half of the scenarios the surplus at $t+10$ is below the initial surplus of $15 \%$. Deteriorations of the funding ratio are more heavily discounted in option value terms than improvements of the funding ratio. The low value of the excess option $(-10 \%)$ is also largely attributed to missed upward potential, whereas in case of a constant mix the low value of the excess option $(-13 \%)$ is entirely attributed to downside risks.

\subsubsection{Dynamic asset mix}

The second alternative investment strategy is a dynamic mix. The fund adapts the same constant 50-50 equity-bond constant mix as in the reference strategy, but now changes the asset allocation whenever the probability of underfunding within one year exceeds $2.5 \%$. This strategy reacts to downside risks, and adjusts them if they are unacceptable in the eyes of a regulatory framework. Just as with the immunization strategy the dynamic mix switches between a risky and a hedge portfolio, but now the allocation is based on an ex-ante risk measure. The return on the asset mix is again given by

$$
R_{t}=\left(1-\alpha_{t}^{(h)}\right) R_{t}^{r}+\alpha_{t}^{(h)} R_{t}^{h}
$$

where $R_{t}^{r}$ and $R_{t}^{h}$ are returns on the risky and the hedge portfolio respectively. The hedge portfolio is the same as in the immunization strategy, and thus closely tracks the growth of the nominal liabilities. In accordance with the reference strategy the risky portfolio is a 50-50 equity-bond mix. The allocation to the hedge portfolio $\left(\alpha_{t}^{(h)}\right)$ is determined numerically such that the probability of underfunding equals the risk constraint. In contrast to the reference strategy equities are sold and the duration is extended whenever equity markets or interest rates fall and the probabil- 
ity of underfunding exceeds $2.5 \%$. In that case there will be a lower return potential, and the duration extension will lead to losses if interest rates rise.

Relative to the reference strategy the dynamic mix leads to an improvement of the risk profile in the short run, but a worsening in the long run (see Table 4.3). In the short run the maximum drawdown $(23 \%)$ and the probability of underfunding in the next year (1\%) improve compared to the reference strategy, but in the long run the numbers are worse. The solvency trap affects the fund more extremely than with the immunization strategy. The reduction of the return potential inevitably leads to a decrease of the funding ratio towards $107 \%$ over ten years of time. Furthermore, this investment strategy has the worst indexation quality among the four investment strategies (the expected indexation result is $21 \%$ ). If the fund would switch from a constant mix to a dynamic mix Table 4.4 demonstrates that there would be similar value transfers as with a shift to an immunization strategy. Unlike the immunization strategy the downside risk protection does not hold in the long run. The upside potential for future generations in term of a healthy funding ratio and indexation in the long run would be given up for downside protection in the short run for the current generations.

\subsubsection{Dynamic swap-overlay}

In the last investment strategy we consider a dynamic swap-overlay. In this case the fund takes on the same constant 50-50 equity-bond mix, but now mitigates interest rate risk via a swap-overlay whenever the probability of underfunding exceeds $2.5 \%$. This reaction strategy thus extends the duration of the reference strategy conditional on the probability of underfunding. The notional of the swap is chosen such that the remaining downside risk reconciles the risk constraint, or at least hedges all the interest rate risk. If the solvency constraint is not binding the weight of the swap $\left(\alpha_{t}^{(s)}\right)$ equals zero, and the fund invests in the 50-50 equity bond mix. Instead, if the probability of underfunding in the next year exceeds the $2.5 \%$ threshold, $\alpha_{t}^{(s)}$ is numerically optimized such that the risk constraint is not binding anymore as long as $\alpha_{t}^{(s)} \leq 1$. Indeed, there could be cases that the interest rates risk is fully hedged, but that a downside risk above $2.5 \%$ is unavoidable due to equity risk. Hence, unlike the immunization and dynamic mix strategies, the dynamic swapoverlay solely reduces interest rate risk. The idea behind this is that interest rate risk is one of the dominant risk factors when pension liabilities are based on a fair value approach (see Hoevenaars, Steenbeek and Sleijpen (2005)). If $\alpha_{t}^{(s)}>0$ the fund receives a (fixed) long-term interest rate and pays (variable) short-term 
interest rates. The return on the investment mix can be written as

$$
R_{t}=R_{t}^{r}+\alpha_{t}^{(s)}\left(R_{t}^{h}-R_{t}^{(1)}\right) .
$$

where $R_{t}^{r}$ and $R_{t}^{h}$ are returns on the risky and the hedge portfolio respectively, which are the same as for the immunization and dynamic mix strategies. $R_{t}^{(1)}$ is the return on the short payer rate.

The strategy would for instance work as follows. The duration is extended whenever the funding ratio drops and downside risks exceed the threshold value due to a fall in interest rates or stock returns. The other way around, the duration is reduced whenever interest rates rise again. An attractive feature of the swap-overlay is that one of the major risk factors (interest rate risk) can be reduced while maintaining the return potential of the asset mix. We would even expect that the swap-overlay contributes to the expected funding ratio return, because the average yield curve has historically been upward sloping. For these reasons we expect beforehand that the solvency trap is less of an issue with this investment strategy. However, these benefits come at the expense of other downside risks. A situation of underfunding could evolve because the swap-overlay solely hedges interest rate risk, while other market risks are not hedged. Another reason could be that the market falls sharply before the fund has the opportunity to rebalance.

According to the ALM results in Table 4.3 the dynamic swap-overlay reduces downside risks while maintaining return potential. The results also indicate that the upward potential is somewhat lower than for the reference strategy. Apparently, losses from the duration extension in periods of rising interest rates dominate the yield pick-up effect in our scenarios. Without the swap-overlay a period of falling interest rates would lead ceteris paribus to a declining funding ratio and a higher probability of underfunding. To mitigate asset-liability risks the dynamic strategy extends the duration via the swap-overlay. However, mean reverting return dynamics in our scenarios eventually lead to rising interest rates again. As a result, the indexation quality worsens compared to the reference strategy. Pensions are now adjusted for $46 \%$ of the price inflation whereas this was $51 \%$ for the reference strategy. Relative to immunization and the dynamic mix, the indexation quality strongly improves when a dynamic swap-overlay is adapted. In addition, downside risk figures like the maximum drawdown (25\%), conditional funding ratio at risk (1.00), the probability of underfunding next year $(1 \%)$ and within ten years $(16 \%)$ improve compared to the reference strategy. Compared to the dynamic mix these risk figures are similar in the short run, but better in the long run. However, the duration extension leads to a much higher asset-only risk. 
Table 4.4 demonstrates that the value transfers from a dynamic swap strategy are somewhat lower than for the reference strategy, but that they are in the same direction. The embedded options also give more insights into the risk of a swap. Current generations are largely compensated for downside risks via the indexation option $(-11 \%$ versus $+10 \%)$. Furthermore, in ten years from now future generations at that point in time are much more exposed to downside risks than upward potential. The value of the deficit option reduces compared to calendar rebalancing, but is higher than in case of immunization and dynamic mix. Compared to the classical ALM results in Table 4.3 the embedded option values clearly demonstrate that downside risks are more severe in case of a swap-overlay than for the immunization and dynamic mix strategies. In contrast to those strategies, there are still substantial market risks that are not hedged via the interest rate swap. Furthermore, the upward potential of the funding ratio has a low option value (the surplus option is $-1 \%$ ) as the embedded surplus and indexation options decrease due to the losses on the duration extension when interest rates and/or inflation rise.

There are some serious considerations with a dynamic swap-overlay that might be understated based on the ALM analysis sofar. First, since the swap-overlay solely hedges interest rate risk, the scheme is still exposed to downside risks from the static 50\% equity allocation. This also explains why the mismatch risk is still $7 \%$. Obviously, we would need additional instruments to hedge such risks. Second, the investor needs to deal with reinvestment risk and risk diversification qualities of the short payer rate (see chapter 2). The low degree of mean reversion in mismatch risk can be explained by the mean averting pattern in the volatility of the short payer rate. On top of that, the correlation between T-bills and stocks (chapter 2) suggests that holding T-bills is a good risk diversifier in a portfolio with stocks, particularly for longer horizons. When the investor shorts the T-bill he does not benefit from this risk diversifying aspect at longer horizons. This explains why the holding period mismatch is the highest (5\%) among the investment strategies. Third, the higher interest rate sensitivity and equity allocation contribute to the highest asset-only risk among the strategies (15\%). Fourth, the swap-overlay is more exposed to inflation risk than immunization or dynamic mix due to leverage. The short payer rate of the swap increases rather quickly in a high inflation regime, whereas the return on the long receiver yield is negatively correlated with inflation in the short-term (see chapter 2). The horizon dependent covariances in chapter 2 demonstrated that a swap-overlay trades off inflation risk due to the short payer rate versus interest rate hedging via the long receiver rate. Hence, the suggestion that the dynamic swap-overlay creates a much better balance between short-term risks and long-term indexation ambition is only one side of the coin. 


\subsection{Conclusion}

Dynamic asset allocation strategies are not necessarily in line with the full inflationlinked goal of DB pension plans. Whether portfolio insurance strategies are preferred to calendar rebalancing depends on the market environment, the downside risk attitude of the investor and upward potential of the return portfolio. The integral value-based ALM framework identifies how portfolio insurance strategies balance between nominal risks, inflation compensation, long-term continuity and short-term solvency. The embedded options add an extra dimension to the traditional ALM output. They give insights into the value transfers between stakeholders and enable a comparison of probability distributions on the basis of how risks are shared. Option valuation techniques are the market consistent method for this.

Portfolio insurance strategies based on short-term solvency risks should take care of a "solvency-trap". Immunization of nominal liabilities might be attractive from a solvency risk perspective, but in conflict with the goal of full inflation compensation in the long-term. The downside risk protection for current beneficiaries comes at the expense of upward potential for future generations. Reducing the return potential by selling risky assets can lead to lower solvency buffers. Such buffers particularly adapt investment and mortality risks, but they can also be used for inflation compensation in the long-term. The value transfers from future to current beneficiaries are larger for a dynamic mix than for immunization. The dynamic swap-overlay mitigates interest rate risk and warrants upward indexation potential, but there may be serious considerations. The deficit option indicates that there is substantial equity risk left. A high duration is less attractive when interest rates rise, and the short payer rate introduces reinvestment risk. Another pitfall is that both the short payer rate and the long receiver introduce inflation risk (see chapter 2). In general we argue that the challenge for dynamic asset allocation strategies is to balance between nominal and real pensions, and between the short-term and the long-term tradeoffs.

Although this chapter provides insights about the merits and pitfalls of portfolio insurance strategies, several issues deserve scrutiny. Obviously, the initial funding ratio is an important determinant for the risk attitude and return requirement. It affects the balance between nominal risks, inflation compensation, long-term continuity and short-term solvency. Furthermore, the return potential is essential for the success of portfolio insurance strategies. It may be improved in many ways like other investment opportunities, structured derivative solutions, and alternative asset classes that focus on stable inflation-indexed returns. Finally, role of inflation swaps and other inflation-linked products, and the usefulness of derivatives such as swaptions or equity options for hedging downside risks deserve examination. 


\section{Chapter 5}

\section{Value-based ALM and intergenerational transfers ${ }^{1}$}

\subsection{Introduction}

The pension fund industry worldwide is in a turbulent period. Defined benefit (DB) plans are reconsidered. In the US and UK private sectors, DB plans have largely been replaced by individual defined contribution (DC) plans. Employer-sponsored DB plans also have been replaced by stand-alone pension funds with DB-like benefits, where risks are shared between the younger and older generations of plan members according to explicit rules (Boeri, Bovenberg, Coere, Roberts (2006)). Many pension funds in the Netherlands have recently taken this route (Ponds and Van Riel 2007). Also, sector-wide pension funds and public sector pension funds in countries such as Canada, the US and Finland have moved in the direction of stand-alone risksharing cooperatives (Ambachtsheer 2007). On top of that, the introduction of fair value principles in the pension fund industry has had a profound impact. The trend is to define more explicit and transparent pension contracts. An example is the compensation of pensions for inflation. Some DB plans provide inflation compensation rules conditional on the financial position of the fund.

\footnotetext{
${ }^{1}$ This chapter is based on Hoevenaars, R.P.M.M. and E.H.M. Ponds (2007b), Valuation of intergenerational transfers in funded collective pension schemes, forthcoming Insurance: Mathematics and Economics, Hoevenaars, R.P.M.M. and E.H.M. Ponds (2007a), Intergenerational Value Transfers within an Industry-Wide Pension Fund - a Value-Based ALM analysis, Springer, Costs and Benefits of Collective Pension Systems, Editors: O. Steenbeek and F. van der Lecq., and on Hoevenaars, R.P.M.M. and E.H.M. Ponds (2006), Waardeoverdrachten tussen generaties binnen een bedrijfstakpensioenfonds, Kluwer, Kosten en Baten van Collectieve Pensioensystemen, Editors: O. Steenbeek and F. van der Lecq.
} 
It is well-documented that collectively funded pension schemes with intergenerational risk sharing may be welfare-enhancing ${ }^{2}$. Current and future plan participants are able to share shocks in asset returns and labor income and thereby smooth these shocks over and even beyond the lifespan of any single generation (Cui, De Jong, Ponds (2006), Gollier (2006), Teulings and de Vries (2006)). Surpluses or deficits in the funding process are shared between younger and older generations and future generations by adjusting either contributions, benefit levels or a combination of these. Inevitable this leads to intergenerational transfers. Mandatory participation backed by appropriate government legislation makes this long run smoothing possible as future generations cannot opt out when they are confronted with a low initial level of funding. However, Cui, De Jong, Ponds (2006) show that even pension funds with deficits in their funding may be a welfare improvement for new young entrants.

The move to stand-alone risk-sharing cooperatives has been accompanied by a change in risk-bearing in order to create a more robust solvency position in financial downturns. An example of this type of reform is the compensation of pensions for inflation. Traditional DB plans always offered inflation indexation irrespective of the solvency position of the pension fund. Recently stand-alone risk-sharing plans have reconsidered indexation policy by introducing inflation compensation rules conditional on the financial position of the fund. For risk sharing cooperatives, a crucial question is what the impact is of pension reforms on different groups of participants. It is not hard to imagine that specific policy changes will harm some groups of beneficiaries but will be beneficial to others.

In financial markets, the no-arbitrage principle guarantees that the market-based compensation for risk taken is fair, such that risk-taking is compensated by an appropriate reward. Within pension funds, the rules of the pension contract define the risk and reward allocation among the members. Unlike option holders in the financial markets, it is not guaranteed that the participants in DB schemes are fairly compensated for their risk-taking. Embedded value transfers may occur when the risk bearing parties are not properly compensated. This can endanger the long-term sustainability of pension schemes. In the current ageing society, younger participants demand more transparency in the implicit risks they are exposed to. This paper focuses on the exploration of embedded value transfers induced by changes in the pension deal. The pricing of these embedded transfers should be based on how risks are priced in the market. Similar to financial options we therefore apply contingent

\footnotetext{
${ }^{2}$ For a general exposition on the welfare aspects of intergenerational risk sharing, see Gordon and Varian (1988), and Shiller (1999). Contributions to the extensive literature in the field of pensions can be divided into the categories of risk sharing via pay-as-you-go plans (see Merton (1983), Enders and Lapan (1982), Krueger and Kubler (2005)) and risk sharing via funded plans (see Cui, De Jong, Ponds (2006), Gollier (2006)).
} 
claims analysis as a market consistent method to value the embedded options in the pension contract.

The contribution of this paper is to value generational transfers as a result of a reform in real-existing collective pension plans. As a first step we identify embedded generational options by rewriting the balance sheet of a pension fund. Changes in the value of generational options enable us to evaluate the impact of policy switches in the pension contract with respect to intergenerational transfers and redistribution. In the second step we use a stochastic valuation framework which also captures timevarying investment opportunities for the valuation. We explore intergenerational value transfers that may result from a plan redesign or from changes in funding policy and risk sharing rules.

This paper innovates in combining three building blocks. The first building block is the field of generational accounting as developed in public finance. We use this method to frame a pension fund in terms of generational accounts. A generational account in a pension fund is defined as the difference between benefits to be received and contributions to be paid by a specific age cohort. The second building block is the valuation of these generational accounts as embedded options with the help of deflators. As the third building block, we employ an asset liability management (ALM) model. ALM has proved its usefulness in its ability to simulate, in a stochastic and integrated framework, the often complex real life cashflow patterns between a pension fund and its stakeholders. The output of the ALM model is used to value the various generational embedded options.

Generational accounting was developed by public finance economists to investigate intergenerational distributional effects of fiscal policy (Auerbach, Kotlikoff, Leibfritz (1999), Kotlikoff (2002)). Generational accounting reveals the zero-sum feature of government finance - what some generations receive as an increase in net lifetime income must be paid for by other generations, who will experience a decrease in net lifetime income. Generational accounting is also of relevance for collective pension plans with intergenerational risk sharing. These plans indeed can be framed as a zero-sum game as well, implying that changes in the funding strategy or an adjustment in risk allocation rules will lead to intergenerational redistribution (Ponds 2003).

Furthermore, this study is indebted to the literature on framing pension funds in terms of embedded options. Since the classic paper of Sharpe (1976), there has been a large number of applications of contingent claim analysis to real-life problems in the fields of pensions and insurance (Blake (1998), Steenkamp (1999), Chapman, Gordon, Speed (2001), Guillén, Jorgensen, Nielsen (2006), Kortleve and Ponds (2006), Kocken (2006)). Ponds (2003) was the initial contribution to combining generational 
accounting with embedded options in order to identify value transfers between generations within pension funds. Using a simple one-period binomial model, he shows that intergenerational value transfers occur when different generations in the pension fund do not get market-based compensation for the risks allocated to them. He calls this approach "value-based generational accounting." Cui, De Jong, Ponds (2006) apply this approach to a multi-period setting for the purpose of analyzing the welfare aspects of intergenerational risk sharing. They show intergenerational risk sharing within a pension fund is indeed a zero-sum game in value terms; however well-structured plans may be a positive-sum game in welfare terms compared with the optimal individual plan without risk sharing. The welfare analysis is performed from the perspective of a new worker aged 25 .

There is a broad literature on asset-liability modeling (see Zenios and Ziemba (2006) for an overview). As in Boender (1997), Bauer, Hoevenaars, Steenkamp (2006) and Boender, Dert, Heemskerk, Hoek (2007), we use a scenario approach to asset liability management. We develop an integral ALM framework with a realistic description of the policy tools available for pension funds in operation regarding asset allocation, indexation policy, and contribution rate setting. The ALM analysis incorporates term structures of risk as in Campbell and Viceira (2005). The accompanying time-varying investment opportunities are important for long-term institutional investors like pension funds (see Hoevenaars, Molenaar, Schotman, Steenkamp (2007)). The modeling framework adapts the pricing kernel and defines an affine term structure of interest rates as in Cochrane and Piazzesi (2005). We show how the value-based ALM concept adds an extra dimension to the traditional ALM output. As such it explores a different direction than a welfare analysis based on utility functions.

This paper is the first to apply the methodology of embedded generational options to real existing pension funds with intergenerational risk sharing. We explore intergenerational transfers that result from policy changes. These intergenerational value transfers are calculated as changes in the value of embedded generational options resulting from these policy adjustments. We find that any policy change inevitably will lead to value transfers. A switch to a less risky asset mix is beneficial to older plan participants at the expense of the younger members, who lose value. A reallocation of risk from flexible contributions with fixed benefits to fixed contributions with flexible benefits leads to value redistribution from older members to younger ones.

Reconsidering a pension deal in operation may be done for different reasons. This might be for example to meet new solvency requirements of the supervisor, to restrict the volatility in contribution adjustments or to arrive at more certainty around the 
final pension result for plan members. This put forward the issue of what the rules and procedures are in the process of decision-making regarding policy changes. This is an important topic as for a grouping of stakeholders with diverging interests, it is not guaranteed beforehand that the process of decision-making is in the best interest of all stakeholders. Good pension fund governance is crucial to evade that the pension plan in operation is beneficial to one or more of the dominant stakeholders at the expense of others. We refer to Clark (2004) and Ambachtsheer (2007) for indepth treatment of pension fund governance issues. This paper offers an analytical tool to improve pension fund governance. The method of embedded generational options is helpful to detect value transfers between the plan stakeholders, and so this method is a valuable instrument for good pension fund governance to evaluate policy changes regarding implied value redistribution between plan members

The set up of the chapter is as follows. The framework of generational accounting is introduced in section 2. Then we explain the method of value-based generational accounting. Section 3 highlights the relevance of value-based ALM. Section 4 describes the methodology of embedded generational options. Section 5 applies the methodology to a stylized pension fund which is representative for a real existing stand-alone multi-member plan. As an illustration we analyze some recent policy reforms in the Netherlands in section 6 . We close the chapter with a discussion of how the proposed method can be applied to other areas, like generational accounting in public finance and reforms in social security.

\subsection{Generational accounting under uncertainty}

Generational accounting is a method developed by public finance economists as a tool for investigating the intergenerational distributional effects of fiscal policy (Auerbach, Kotlikoff, Leibfritz (1999), Kotlikoff (2002)). Generational accounting is based on the government's intertemporal budget constraint, which requires that either current or future generations pay for government spending via taxation. The government's net wealth (including debt) plus the present value of the government's net receipts from all current and future generations, must be sufficient to pay for the present value of the government's current and future consumption. The generational accounting method can be employed for calculating the present value changes in net life-time income of both living and future generations that result from changes in fiscal policy. Generational accounting reveals the zero-sum feature of the intertemporal budget constraint of government finance - what some generations receive as an increase in net lifetime income must be paid for by other generations who will experience a decrease in net lifetime income. Planned increase or decrease in government 
debt can be used for tax smoothing over time in order to realize a sustainable fiscal policy (Auerbach, Kotlikoff, Leibfritz (1999), van Ewijk et al. (2000)).

Similarly, the method of generational accounting may be of use in evaluating the policy of pension funds to cover both current and future participants. Two similarities with public finance can be discerned. Pension funds also face an intertemporal budget constraint, as the promised benefits must be backed by current and future contributions and returns on paid contributions. Secondly, as the government uses the tax instrument to close the budget over time, adjustments in contribution and indexation rates are the instruments used by pension funds to square the balance over time.

Economists using the generational accounting framework for public finance issues find difficulty in dealing with uncertainty (Kotlikoff (2002)). Usually, a deterministic approach is followed. Uncertainty is studied using a sensitivity analysis for alternative assumptions for key variables, amongst them the discount factor. However a value-based approach is more appropriate to deal with uncertainty. We rewrite the pension fund in generational accounts and apply the value-based approach. The uncertain cashflows from and to the participating cohorts, in particular contributions and benefits, are treated as embedded generational options which can be valued with the help of stochastic discount factors (see section 5.2). Moreover the valuebased approach reveals the zero-sum character of the contract. At any given time, the total economic value to be distributed amongst the generations is equal to the value of pension fund assets. Alternative funding and risk-allocation rules have no impact on total economic value, however this may lead to transfers of value between generations.

The generational accounting approach as applied by public finance economists also has been criticized for the neglect of general equilibrium repercussions of changes in the budgetary policy of the government. Usually tax incidences are ignored as well as impact of policy changes on relative prices (Buiter (1997)). This critique may be of relevance for government studies, however not for this study as the pension fund in operation is sufficiently small to warrant a partial analysis.

\subsection{Asset Liability Management}

\subsubsection{Classical ALM}

Pension funds use ALM analysis to evaluate the pension contract in operation and to explore the performance of alternative pension deals. Essentially, a pension contract defines what is being promised, how the promises are funded (asset mix and 
contribution policy) and who is bearing the risks in the funding process (risk allocation rules). ALM is broadly seen as a cornerstone for the fund policy as it provides insight into the realism and the sustainability of the pension contract in operation over differing horizons. Typically an ALM study uses an economic model to produce stochastic simulations of returns on asset classes and other relevant economic data, like inflation. Subsequently a scenario analysis is performed that results in probability distributions for the key variables. Sensitivity analysis is usually carried out to explore specific policy variants in terms of asset mix, contribution policy and indexation rules. Policy variants are evaluated in terms of expected values and relevant risk measures for key variables - for example, the funding ratio, the contribution rate, the indexation rate, and so on. Moreover one can easily take care of specific constraints, like funding requirements of the supervisor (e.g., a minimum probability of underfunding) and a maximum level of contribution rate.

\subsubsection{Value-based ALM}

Despite its widespread popularity, one may feel uncomfortable with the classical ALM tool kit. Chapman, Gordon, Speed (2002) characterize ALM studies as producing merely "funnels of doubt", which serve only to demonstrate that taking more risk will imply more uncertainty about key outputs. Moreover, it is difficult to rank policy variants using solely the classical ALM output. Is a risky strategy with, on average, a high but volatile funding ratio to be preferred above a less risky strategy that will end up with, on average, a low funding ratio with little risk? Younger members in a plan with intergenerational risk sharing may prefer a risky strategy that could yield a high pay-out per unit contribution, whereas older members will prefer a liability-hedged investment strategy to safeguard pension fund assets in order to reduce benefit risk. Practitioners solve the ranking problem by discovering the policy setting that is most acceptable given the interests of all participants, taking into account all constraints. However in seeking this 'most acceptable' policy variant, the ALM professionals and/or the board of trustees do not usually consider whether the policy variant is fair in economic value terms for all members. In financial markets, the no-arbitrage principle guarantees that the market-based compensation for a taken risk is fair, so that risk taking is accompanied by an appropriate reward compensation. Within pension funds, the no arbitrage principle of financial markets is replaced by the rules of the pension contract defining the risk and reward allocation amongst the members.

Contingent claim analysis is fruitful to test for possible value transfers. Restating the highly stylized framework of Sharpe (1976) into a realistic setting results in what 
is now called value-based ALM (Kortleve and Ponds (2006)). Value-based ALM essentially uses the same output from scenario analysis as classical ALM, however the future outcomes are discounted back to the present with an appropriate risk adjusted discount rate. This is realized by making use of a pricing kernel specification (see section 5.2 for technical details). Value-based ALM enables us to detect possible transfers of value resulting from policy changes by examining changes in the value of the various embedded generational options.

\subsection{Pension fund in embedded generational options}

\subsubsection{Pension fund characteristics}

Before deriving generational accounts in a pension fund setting, it may be useful to describe the specific institutional characteristics of the pension fund. We study generational accounts for a real life pension fund with intergenerational risk sharing. All funding risks must be borne by current and future members of the pension plan. The content of the pension contract is decisive as to how surpluses and deficits in the funding process are allocated amongst participants. Essentially there are three ways to allocate the funding risks amongst the participants: (i) doing nothing by shifting forward in time a position of underfunding or overfunding, i.e. to future participants; (ii) adjusting the contribution rate; or (iii) adjusting the indexation rate.

The fund under study has the following features:

1. Pension Plan: The pension plan is an average-wage plan with indexed liabilities. Workers acquire for each year of service $2 \%$ of their pensionable wage as new accrued liabilities. The yearly indexation of benefits and accrued liabilities aims to follow the wage growth of the sector; however the actual indexation may be contingent on the financial position of the pension fund.

2. Liabilities: The real value of accrued liabilities is the value of liabilities when full indexation would always be granted as promised. Valuation is based on discounting future benefit cashflows following from the liability structure using the real interest yield curve net of real wage growth. The nominal value of accrued liabilities is the value of liabilities when no indexation would be given at all. The nominal value of accrued liabilities is derived by discounting the future benefit cashflows using the prevailing nominal yield curve. The duration of the indexed liabilities is 19 years (at a real rate of $2 \%$ ). Sixty percent of the participants consist of pensioners. The remaining $40 \%$ comprises the (current and future) active members. 
3. Funding ratio: The real funding ratio is defined as the ratio of assets over the value of real liabilities, the nominal funding ratio is assets over the value of nominal liabilities.

4. Pension fund residue: The difference between assets and nominal liabilities is called the pension fund residue.

5. Contribution rate: Workers pay yearly contributions out of their wage income in order to fund new accrued liabilities in that year. Total contributions must be equal to the present value of new rights. We make a distinction between two approaches in setting the level of the contribution rate. In line with many real existing pension funds, the pension fund under study makes use of the funding method. This method reflects the notion that in the long run the sum of contributions plus investment proceeds must match the stream of wage-indexed benefits. In this method, the present value of new liabilities is calculated with the expected rate of return on assets net of wage growth as the discount rate. The second method is called the fair value accounting approach which uses as the discount rate the nominal interest rate in the market minus wage growth ${ }^{3}$.

All workers pay the same uniform contribution rate as a percentage of pensionable wages. This implies that young workers pay more contributions than the present value of their new accrued liabilities, whereas older workers contribute less than their new accrued liabilities. Younger workers grow older so that at the end of their careers there will be a balance between the value of paid contributions and the value of accrued liabilities ${ }^{4}$. Apart from the base contribution rate, an additional contribution rate (positive or negative) may be asked in relation to the funding position of the pension fund.

6. Investment policy: We assume a constant mix rebalancing policy in which the investment manager rebalances to fixed asset weights at the end of each year. The investment universe consists of stocks and bonds only.

\subsubsection{Generational accounts as embedded options}

The value of pension fund assets $A_{t}$ is equal to the value of total pension fund nominal liabilities $L_{t}$ plus the pension fund residue $R_{t}$ :

$$
A_{t}=L_{t}+R_{t}
$$

3 The term "fair value accounting" reflects that the same discount rate is used as in the fair value reporting standards. In contrast, the funding approach chooses a stable discount factor in order to mitigate contribution rate volatility. This discount factor is used for funding purposes only, not for reporting.

${ }^{4}$ We refer to Hári, Koijen, Nijman (2006) for a general analysis of differences in money's worth of participation in a collective scheme due to differences in age, gender and education level. 
The balance sheet next period $(t+1)$ expressed in present value terms at $t$ is

$$
A_{t}+V_{t}\left[C_{t+1}\right]-V_{t}\left[P P_{t+1}\right]=V_{t}\left[L_{t+1}\right]+V_{t}\left[R_{t+1}\right]
$$

Inherent to the deflator approach is that the economic value of initial assets plus investments proceeds is equal to initial assets: $V_{t}\left[A_{t}\left(1+r_{t+1)}\right]=A_{t}\right.$ with $r_{t+1}$ as rate of return in $t+1$. The term $V_{t}\left[C_{t+1}\right]$ is the economic value at $t$ of contributions $C_{t+1}$ paid in $t+1$ and $V_{t}\left[P P_{t+1}\right]$ is the economic value at $t$ of pension payments $P P_{t+1}$ in $t+1$. The term $V_{t}\left[L_{t+1}\right]$ stands for the economic value of accrued liabilities at the end of period $t+1$, being the sum of the accrued liabilities at the end of period $t$, including indexation minus the liabilities written off in $t+1$, as they have been reserved for pension payments in $t+1$ plus the new accrued liabilities in $t+1$ attributable to one year of additional service of working members. The term $V_{t}\left[R_{t+1}\right]$ is the economic value at $t$ of the pension fund residue at the end of period $t+1, R_{t+1}$.

Using (1), we can rearrange (2) as:

$$
V_{t}\left[L_{t+1}\right]-L_{t}+V_{t}\left[P P_{t+1}\right]-V_{t}\left[C_{t+1}\right]+\left(V_{t}\left[R_{t+1}\right]-R_{t}\right)=0
$$

This expression says that the one year change in the value of liabilities is backed by contributions and by either an increase or a decrease in the pension fund residue. This reflects the zero-sum nature of a pension fund. However, the zero-sum feature does not hold necessarily for the different age cohorts. We can split up expression (3) by age cohort. This results in the expression below:

$$
\Delta G A_{t+1}^{x}=V_{t}\left[L_{t+1}^{x}\right]-L_{t}^{x}+V_{t}\left[P P_{t+1}^{x}\right]-V_{t}\left[C_{t+1}^{x}\right]+\left(V_{t}\left[R_{t+1}^{x}\right]-R_{t}^{x}\right)
$$

where $x$ refers to cohort $x$. We call the term $\Delta G A_{t+1}^{x}$ the generational account option of cohort $x$, that is defined as the economic value at $t$ of the change in the generational account of cohort $x$ during $t+1$.

We assume that the pension fund residue can be allocated amongst the cohorts at all times proportionately to each cohorts's stake of nominal liabilities ${ }^{5}$ :

$$
R_{t}^{x}=l_{t}^{x} R_{t}
$$

with

$$
l_{t}^{x}=\frac{L_{t}^{x}}{L_{t}}
$$

5 The claim on the residue is not just a fictive claim in accounting terms. In the Netherlands, the "system of value transfer" is operative. This system rules that when an employee switches to another pension fund because of a new job, the worker has the right to transfer wealth from the old to the new fund equal to the value of accrued liabilities, including indexation. 
Figure 5.1: Accrued pension obligations for different age cohort

Relative distribution of nominal liabilities in 2006 (y-axis) for various age cohorts with age at 2006 on $\mathrm{x}$-axis.

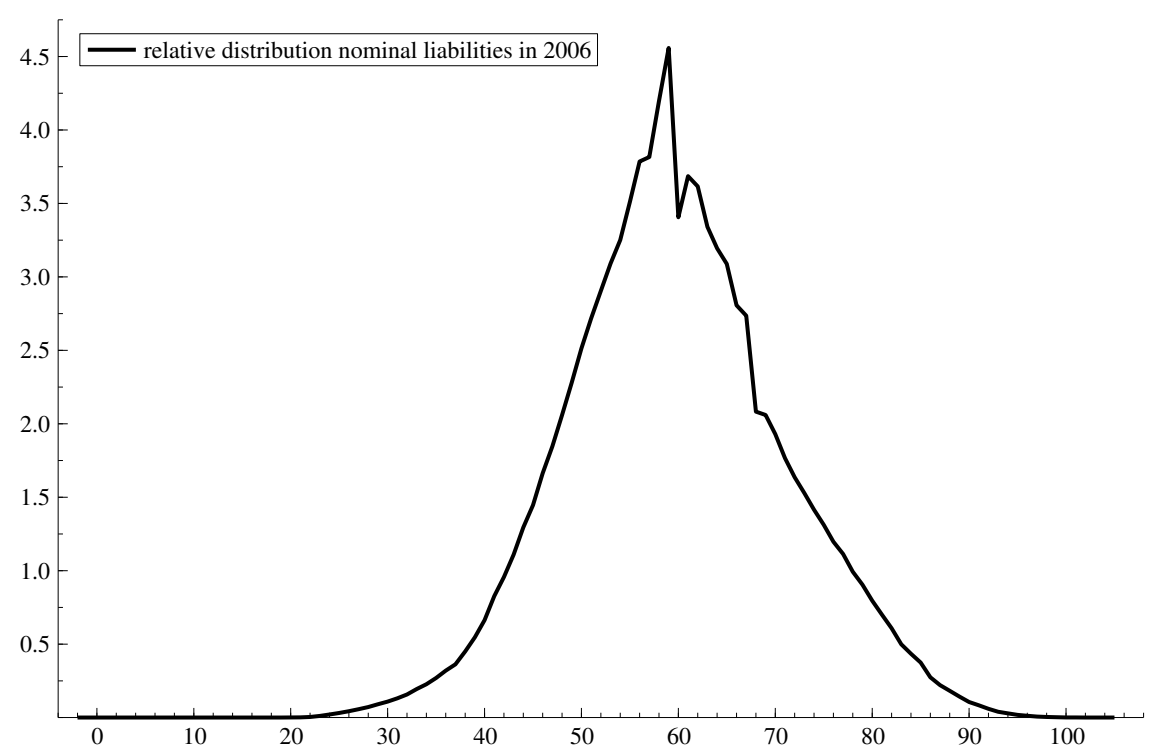

Figure 5.1 displays the relative distribution of nominal liabilities over the cohorts in 2006. The size of $l^{x}$ initially increases with age because cohorts have fulfilled more years of service, and have more accrued liabilities, and because the time value of accrued liabilities increases as the age of retirement nears. The size of $l_{t}^{x}$ will decline in retirement as liabilities gradually are written off with the planned pension payments.

The sum of all generational account options, $\sum_{x \in X} \Delta G A_{t+1}^{x}$, must be necessarily equal to 0 , reflecting that the pension fund is a zero-sum game in value terms:

$$
\sum_{x \in X} \Delta G A_{t+1}^{x}=0
$$

We can split up $\Delta G A^{x}$ into two parts: the so-called net benefit option $N B^{x}$ and the so-called residue option $\Delta R^{x}$ :

$$
\Delta G A_{t+1}^{x}=\underbrace{V_{t}\left[L_{t+1}^{x}\right]-L_{t}^{x}+V_{t}\left[P P_{t+1}^{x}\right]-V_{t}\left[C_{t+1}^{x}\right]}_{N B^{x}}+\underbrace{\left(V_{t}\left[R_{t+1}^{x}\right]-R_{t}^{x}\right)}_{\Delta R^{x}}
$$

The net benefit option consists of the change in the value of liabilities $V_{t}\left[L_{t+1}^{x}\right]-$ $L_{t}^{x}$ due to new nominal accruals and the writing off of planned nominal pension pay- 
ments, plus the value of actual pension payments $V_{t}\left[P P_{t+1}^{x}\right]$ including indexation, and the value of paid contributions $V_{t}\left[C_{t+1}^{x}\right]$.

The net residue option says that a cohort gives away the certain claim on the current residue $R_{t}^{x}$ by participating in the fund and it receives an uncertain claim on the residue at the end of the evaluation period $R_{t+1}^{x}$, with economic value equal to $V_{t}\left[R_{t+1}^{x}\right]$.

Below, we compare some alternative policy variants to study the impact on the generational accounts of cohorts. This comparison is based on the expression:

$\Delta G A_{\text {alternative }}^{x}-\Delta G A_{\text {basic }}^{x}=\left(N B_{\text {alternative }}^{x}-N B_{\text {basic }}^{x}\right)+\left(\Delta R_{\text {alternative }}^{x}-\Delta R_{\text {basic }}^{x}\right)$

Stepping over from the current pension contract to an alternative one may lead to a change of the generational account option of cohort $x$, and this can be split up into changes in the net benefit option and in the residue option held by cohort $x$.

\subsubsection{Pricing embedded options}

The ALM framework is based on a simulation study which projects the development of the pension fund in many future scenarios. The policy horizon is 20 years. ${ }^{6}$ As this chapter focuses on the method of value-based generational accounting, we have suppressed the degree of complexity of the ALM framework. The investment universe consists only of a MSCI world stock index and nominal bonds with a constant maturity of 10 years. Furthermore, we assume that wage inflation equals price inflation, so that real wage growth is zero. ${ }^{7}$

The valuation framework is based on the model in the previous chapter. In accordance with Campbell and Viceira (2002), we describe the return dynamics by a first-order vector autoregressive (VAR) model. The relevant economic factors $z_{t}$ in the model include the one-month interest rate, the 10-year zero coupon rate, price inflation, stock returns in excess of the one-month interest rate, and the corresponding dividend yield. Returns on a rolling 10-year constant maturity bond portfolio are constructed from the nominal term structure.

\footnotetext{
6 An infinite horizon for the pension contract and pension fund would be hard to justify. We choose to evaluate the fund position at a finite horizon. On the one hand, we aim for insights about the implications of a pension policy at various horizons. On the other hand, it makes no sense to simulate too far into the future, because we have only a limited amount of historical data to estimate the return dynamics. A 20 year horizon reveals implications for short, medium and long horizons.

7 The assumption of a real wage growth of zero avoids the problem of valuation in an incomplete market. As there are no wage-indexed assets, risk relating to real wage growth is not priced into the market. De Jong (2005) discusses several methods to value wage-indexed cashflows in an incomplete market.
} 
Formally, the VAR is written as:

$$
z_{t+1}=c+B z_{t}+\Sigma \zeta_{t+1}
$$

where $\zeta_{t+1} \sim N(0, I)$.

To derive an affine term structure of interest rates, we use the no-arbitrage assumptions, and we specify the pricing kernel as

$$
-\log M_{t+1}=\delta_{0}+\delta_{1} z_{t}+\frac{1}{2} \lambda_{t}^{\prime} \lambda_{t}+\lambda_{t}^{\prime} \zeta_{t+1}
$$

where $\lambda_{t}$ are time-varying prices of risk which are affine in the state variables. $M_{t+1}$ is the stochastic discount factor which can be used for the valuation of embedded options in the pension deal. The short rate $\left(\delta_{0}+\delta_{1} z_{t}\right)$ is assumed to be the observable 1 -month interest rate $\left(y_{t}^{(1)}\right)$ which is also included in the VAR such that $y_{t}^{(1)}=$ $\delta_{0}+\delta_{1} z_{t}$. To achieve consistency between the VAR and the short rate dynamics we let $\delta_{0}=0$ and $\delta_{1}^{\prime}=(1,0,0,0,0)$.

The affine class of term structure models states that (nominal) yields on an n-period zero coupon bond are linear in the state variables.

$$
y_{t}^{(n)}=-\frac{A_{n}}{n}-\frac{B_{n}^{\prime}}{n} z_{t}
$$

The scalar $A_{n}$ and $(n \times 1)$ vector $B_{n}$ are defined under the no-arbitrage condition and can be solved recursively when $A_{0}=B_{0}=0$ (see the previous chapter for the derivation), such that

$$
\begin{aligned}
& A_{n}=-\delta_{0}+A_{n-1}+B_{n-1}^{\prime}\left(c-\Sigma \lambda_{0}\right)+\frac{1}{2} B_{n-1}^{\prime} \Sigma \Sigma^{\prime} B_{n-1} \\
& B_{n}=-\delta_{1}+\left(B-\Sigma \lambda_{1}\right)^{\prime} B_{n-1} .
\end{aligned}
$$

We extend the model of the previous chapter by a real term structure of interest rates. The Fisher equation decomposes the nominal yield $\left(y_{t}^{(n)}\right)$ on a zero coupon bond of maturity $n$ into a real yield, an inflation expectation and an inflation risk premium. The nominal yields and the expected inflation are implied by the VAR, in contrast to the real yield and inflation risk premium. In line with Ang, Bekaert, Wei (2007) we obtain identification by restricting the one-period inflation risk premium to zero. Models with a positive one-period inflation risk premium imply lower real rates and a higher inflation risk premium. Ang, Bekaert, Wei (2007) mention that such models have a poorer fit with the data than their model which uses the zero restriction. In the appendix we show that the real yield $\left(\hat{y}_{t}^{(n)}\right)$ on a zero coupon bond of maturity $n$ is also affine in the state variables $z_{t}$.

$$
\hat{y}_{t}^{(n)}=-\frac{\hat{A}_{n}}{n}-\frac{\hat{B}_{n}^{\prime}}{n} z_{t}
$$


Figure 5.2: Fit historical nominal and real term structures of interest rates

Historical fit of the affine term structure model for nominal and real interest rates on zero coupon bonds for five points on the term structure of zeros: 1-month $(y 1), 2$ year (y24), 3 year (y36), 5 year (y60) and 10 year (y120). Bold lines represent the nominal series. Thin lines denote the real series.
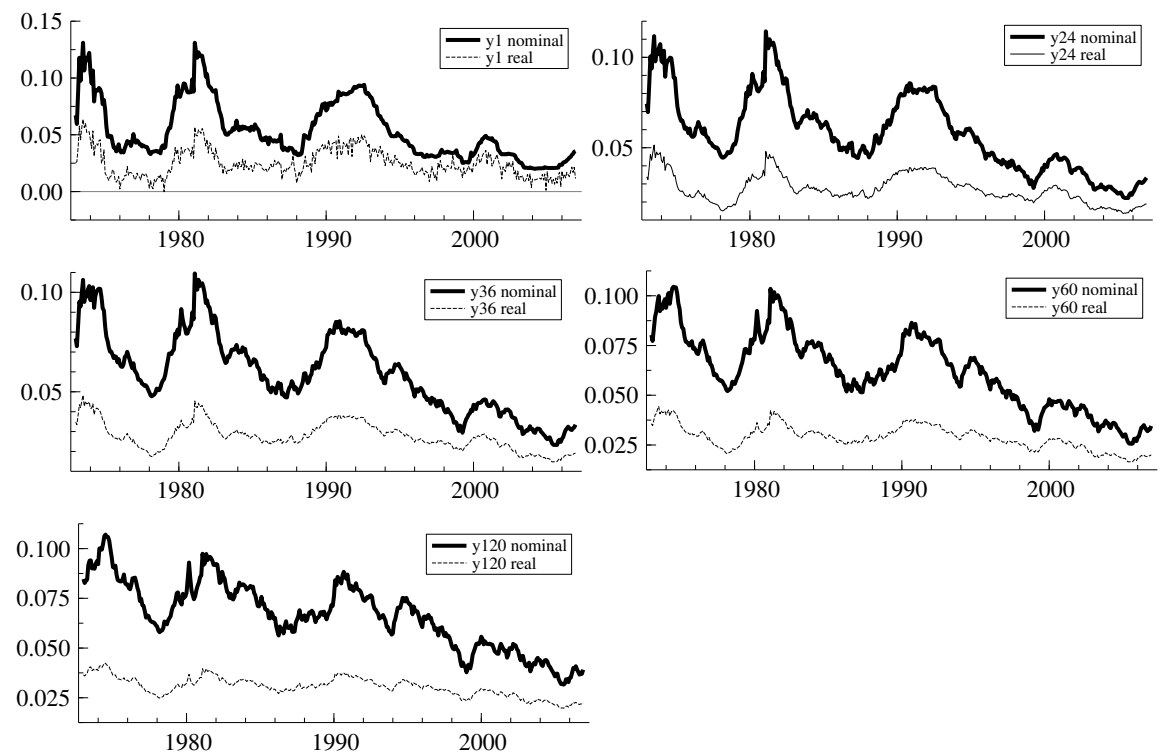

$k$ periods from now equals the current implied forward rate. ${ }^{8}$ The average of the future interest rate scenarios is thus in line with current market expectations. The average equity risk premium and dividend yield in the scenarios is pinned down at the historical averages. Asset returns are used to determine the returns on the asset mix. Interest rates are used to compute the present value of liabilities, and inflation scenarios are employed to index the liabilities. $M_{t+1}$ can be used as the stochastic discount factor for valuation of embedded options in the pension deal. ${ }^{9}$

Our ALM modeling process provides both classical as well as value-based outcomes. The classical results include a set of probability distributions for all relevant ALM output variables in each future year. Asset returns and the asset mix policy are

\footnotetext{
8 The forward rate is equal to the expected value of the future spot rate and a Jensen's inequality term.

9 Alternatively option values can be computed in a risk-neutral economy by changing the numeraire. In the empirical part we find that in our model setup with time-varying risk opportunities less scenarios are required for a high degree of accuracy in the risk neutral Q-world, than in the $\mathrm{P}$-world. In order to relax the computational burden we numerically compute the option values in the Q-world.
} 
used to determine returns on the asset mix. Real and nominal interest rates are used to compute the present value of liabilities in real and nominal terms, respectively. The inflation scenarios are employed to index the liabilities.

We value embedded options in the pension contract using the pricing kernel specification, which is arbitrage-free and consistent with the VAR return dynamics of the economic environment. In this way, scenario-dependent and thus stochastic discount factors (deflators) are assigned to the scenarios (see Nijman and Koijen (2006), and Brennan and Xia (2002)). Low discount rates are assigned to bad scenarios, whereas high discount rates are assigned to good scenarios. This reflects the prevailing risk aversion in the market which implies that payoffs during bad times are more valuable than payoffs during good times. Multiplication of the future payoffs $k$ periods from now $\left(P_{t+k}\right)$ by the corresponding stochastic discount factor $\left(M_{t+k}^{*}=M_{t+1} M_{t+2} \cdots M_{t+k}\right)$ and averaging over all scenarios gives the current economic value $V_{t}\left[P_{t+k}\right]$ (i.e., the option value) embedded in the pension contract:

$$
V_{t}\left[P_{t+k}\right]=\mathrm{E}_{t}\left[M_{t+k}^{*} P_{t+k}\right]
$$

\subsection{Evaluation of pension fund policies}

We apply the methodology of value-based generational accounting to analyze stylized examples of policy changes for a stand-alone pension fund with intergenerational risk sharing. Using value-based generational accounting, we demonstrate that changes in the pension contract may easily lead to sizeable intergenerational value transfers as the allocation of risk amongst stakeholders changes substantially. We evaluate three types of policy changes: pension plan design, investment policy and the setting of the contribution rate.

\subsubsection{Pension plan design}

Figure 5.3 provides four stylized examples of risk bearing in a funded collective scheme with intergenerational risk sharing. Diagram 1 in figure 5.3 reflects the case of a DB scheme with no risk allocation at all to current members. There is full indexation and a fixed contribution rate, irrespective of the financial position of the fund. Actually, funding risks are shifted forward in time and hence these risks must be borne by future participants. Diagram 2 is a stylized representation of risk allocation within a traditional DB plan structure, wherein benefits are guaranteed and funding risks are absorbed by flexible contributions. The third diagram reflects the risk-allocation policy in what we have called a hybrid plan. Contribution rate is fixed. All participants take part in bearing risk as this plan makes indexation of 
Figure 5.3: Different collective pension deals

Different collective pension deals (see section 5.5.1): pension deal 1 represents unconditional indexation and a fixed contribution rate; pension deal 2 is a traditional DB plan with unconditional indexation and a dynamic contribution rate; pension deal 3 is a hybrid plan with a dynamic indexation policy (with boundaries) and a fixed contribution rate; pension deal 4 is a collective DC with dynamic indexation and a fixed contribution rate.
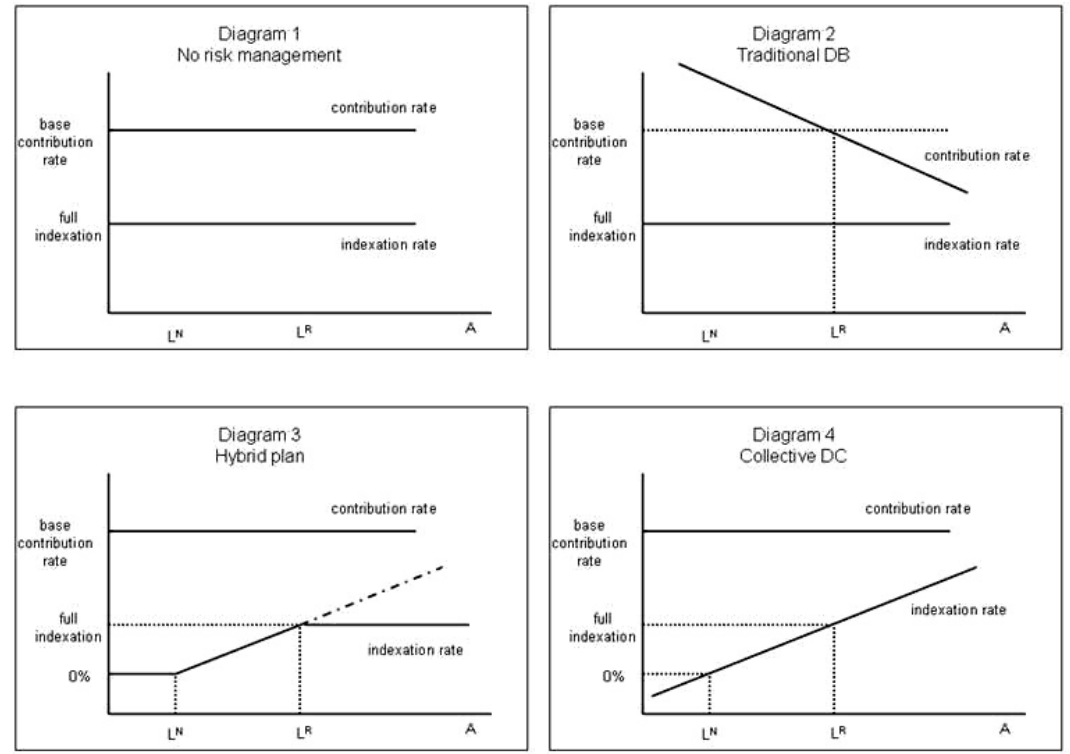

all accrued liabilities solvency contingent. This is also the case in the collective $D C$ plan shown in the fourth diagram; however, no cap or minimum is defined in the indexation of accrued benefits.

The horizontal axis in the four diagrams denotes the value of assets $A$. A pension fund is said to be fully funded when assets $A$ equal the value of the real liabilities $L_{R}$, the latter being the value of accrued liabilities when full indexation is always given. $L_{R}$ is calculated by discounting the accrued liabilities with the real yield curve, net of real wage growth. The value of the nominal liabilities, $L_{N}$, is the value of accrued liabilities when no indexation is given. The size of $L_{N}$ is determined by discounting the accrued liabilities with the nominal yield curve. The difference between real and nominal liabilities, $L_{R}-L_{N}$ is the required indexation reserve that is needed to meet the promise of full indexation to plan participants. The actual indexation reserve position is $A-L_{N}$ and it may be either positive or negative.

Along the vertical axis, the contribution rate and the indexation rate are set. 


\section{No risk allocation}

No risk management implies that there is always full indexation where the indexation rate $i_{t}$ is equal to the wage growth rate $\pi_{t}$ and the contribution rate $P_{t}$ is always equal to the base contribution rate $P^{*}$ :

$$
\begin{gathered}
P_{t}=P^{*} \\
i_{t}=\pi_{t}
\end{gathered}
$$

\section{Traditional DB plan}

In the traditional DB plan, displayed in diagram 2 , the indexation rate $i_{t}$ is always equal to the price inflation $\pi_{t}$ and funding risk is borne by the workers by means of adjustments in the contribution rate. The contribution rate $P_{t}$ comprises two components: the base contribution rate $P^{*}$ and the additional contribution rate $P_{t}^{a d d}$ as follows:

$$
\begin{gathered}
P_{t}=P^{*}+P_{t}^{a d d} \\
i_{t}=\pi_{t}
\end{gathered}
$$

where

$$
P_{t}^{a d d}=\frac{L_{t}^{R}-A_{t}}{\text { PV35yearPensionableWages }}
$$

Additional contributions are not necessary when assets $A_{t}$ match real liabilities $L_{t}^{R}$. A situation of real underfunding, $A_{t}<L_{t}^{R}$, or real overfunding, $A_{t}>L_{t}^{R}$, leads to a surcharge, or to a cut in the contribution rate, respectively. A situation of underfunding or overfunding is smoothed out over a period of 35 years. This is captured in the expression above by the term in the denominator, reflecting the present value of pensionable wages in the coming 35 years.

\section{Hybrid plan}

The contribution rate in the hybrid plan is stable and independent of the financial position of the fund. There is room for full indexation equal to wage growth when the value of assets is equal to or larger than the value of the real liabilities, $A_{t} \geq$ $L_{t}^{R}$. Then the actual indexation reserve $A_{t}-L_{t}^{N}$ is at least equal to the required indexation reserve $L_{t}^{R}-L_{t}^{N}$. The indexation rate will be zero when assets are equal to or even below nominal liabilities, $A_{t} \leq L_{t}^{N}$. The actual indexation reserve is then zero or even negative. Between these two points, i.e. when $L_{t}^{N}<A_{t}<L_{t}^{R}$, indexation follows wage growth partly where the given indexation is determined by 
the proportion of actual indexation reserve in relation to the required indexation reserve, as follows:

$$
\begin{gathered}
P_{t}=P^{*} \\
i_{t}=\alpha_{t} \pi_{t}
\end{gathered}
$$

where

$$
0 \leqq\left(\alpha_{t}=\frac{A_{t}-L_{t}^{N}}{L_{t}^{R}-L_{t}^{N}}\right) \leqq 1 .
$$

When assets exceed the value of indexed liabilities, there is room to provide extra indexation until there is a full catching-up of any previously missed indexation. This is reflected in diagram 3 by the dotted line.

\section{Collective DC plan}

The collective DC plan can be seen as the counterpart of the traditional DB plan regarding risk allocation. The contribution rate is set at the level of the base contribution rate, and no additional contributions are asked. Management of solvency risk is run via the indexation rate, where the yearly indexation is proportional to the funding position. Neither a cap nor a floor is applied to the indexation rate. The reference variable for the indexation rate is still wage growth. However, any funding shortage or surplus will lead to a relative adjustment in the indexation rate vis-a-vis the wage growth rate. Full indexation equal to wage growth $\pi_{t}$ is given when $A_{t}=L_{t}^{R}$; this is when the actual indexation reserve matches the required indexation reserve rate. No indexation is given when the actual indexation reserve position is zero: $A_{t}=L_{t}^{N}$.

$$
\begin{gathered}
P_{t}=P^{*} \\
i_{t}=\alpha_{t} \pi_{t}
\end{gathered}
$$

where

$$
\alpha_{t}=\frac{A_{t}-L_{t}^{N}}{L_{t}^{R}-L_{t}^{N}}
$$

\section{Results_-pension reforms and risk allocation}

We apply a classic ALM study 20 years ahead and evaluate the results using valuebased generational accounting. The asset mix for the four variants of pension plan design is composed of $50 \%$ stocks and $50 \%$ bonds. The expected real rate of return of assets for this mix is $3.75 \%$, so the outcome for the base contribution rate $P^{*}$ is $17 \%$ 
of pensionable wage income. We set the initial real funding ratio at $85 \%$, reflecting the current underfunding of many pension plans. ${ }^{10}$

The classic ALM results for the four variants of plan design are summarized in Table 5.2, columns (1) to (4). The text below the table explains the indicators.

The expected funding ratio after 20 years for all four variants improves strongly, as shown by the mean and the median at the end of the evaluation horizon, which reach values above $100 \%$. The mismatch risk for a 50-50 mix for the four variants is in between $4 \%$ and $9 \%$. The variants differ in how this mismatch risk is absorbed. The "No risk allocation" variant with no risk absorption by current members implies that risk is shifted forward in time to future members. This variant has a high spread in funding ratio as measured by the standard deviation and the within probability of underfunding. The traditional DB variant absorbs the mismatch risk by adjusting the contribution rate in order to restore a situation of underfunding or overfunding. This results in a high volatility for the contribution rate. The average year-to-year change in the contribution rate is $3.8 \%$-point. The funding ratio risk and probability of underfunding reduce strongly due to the flexible contribution rate.

The hybrid plan and collective DC variants absorb mismatch risk via indexation adjustment. The hybrid plan imposes a cap (full indexation) and a floor (zero indexation) in indexation adjustments. But the collective DC variant has no restrictions regarding the actual indexation rate. This explains why the collective DC variant has more volatility in the indexation ratio. The standard deviation for the indexation ratio is $25 \%$ for the hybrid plan and $71 \%$ for the collective DC variant, and the probability of a cumulative indexation ratio of less than $80 \%$ is, for the hybrid plan $31 \%$, and is $28 \%$ for the collective DC plan. However the collective DC plan delivers the highest median and mean for the yearly indexation ratio. The median and the mean of the indexation ratio are $104 \%$ and $137 \%$, respectively, for the collective DC plan, whereas the hybrid plan has the significantly lower values of $75 \%$ and $73 \%$ respectively.

Now we turn to analysis in value terms. Table 5.3 reports the residue option at the end of the 20-year period. The residue option $V_{t}\left[R_{t, k}\right]$ can be split up into a surplus option value $V_{t}\left[S_{t, k}\right]$ and a deficit option value $V_{t}\left[D_{t, k}\right]$, both with nominal liabilities as "exercise price". The surplus option is a European call option on the surplus for the participants written by the fund. The deficit option can be seen as

\footnotetext{
${ }^{10}$ For the stylized pension fund, this implies a nominal funding ratio of $120 \%$. A nominal funding ratio of about $140 \%$ corresponds with a real funding ratio of $100 \%$.
} 
Table 5.2: Classic ALM results for policy variants

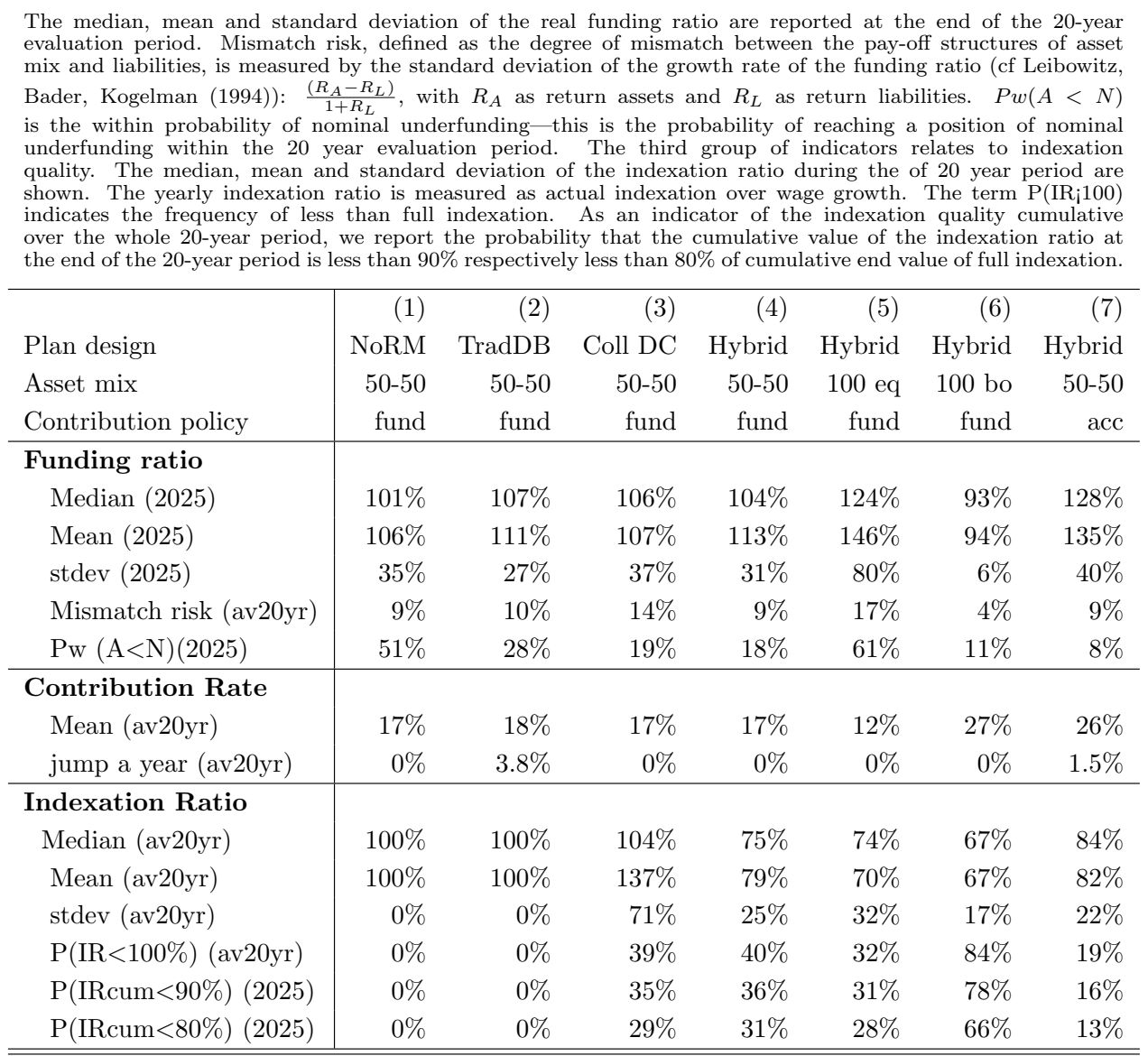

the economic value of a European put option written by the plan's members.

$$
\begin{aligned}
V_{t}\left[R_{t, k}\right] & =\mathrm{E}_{t}\left[M_{t+k}^{*}\left(A_{t+k}-L_{t+k}^{N}\right)\right] \\
& =\mathrm{E}_{t}\left[M_{t+k}^{*} \max \left(0, A_{t+k}-L_{t+k}^{N}\right)\right]+E_{t}\left[M_{t+k}^{*} \min \left(0, A_{t+k}-L_{t+k}^{N}\right)\right] \\
& =V_{t}\left[S_{t, k}\right]-V_{t}\left[D_{t, k}\right]
\end{aligned}
$$

Columns (1) through (4) report the options related to the end value of the residue for the four pension plan variants. Pension reforms lead to value transfers between current and future generations. All variants start with a residue of $20 \%$ of nominal liabilities in 2006. The value of the residue options at the end of the 20-year horizon shrinks in all cases due to the introduction of downside risks which have a 
Table 5.3: Embedded options in different pension deals

\begin{tabular}{l|rrrrrrr}
\multicolumn{8}{c}{ Option values related to residue at the end of the evaluation period as \% of nominal liabilities in 2006.} \\
\hline & $(1)$ & $(2)$ & $(3)$ & $(4)$ & $(5)$ & $(6)$ & $(7)$ \\
Plan design & NoRM & Trad DB & Coll DC & Hybrid & Hybrid & Hybrid & Hybrid \\
Asset mix & $50-50$ & $50-50$ & $50-50$ & $50-50$ & 100 eq & 100 bo & $50-50$ \\
Contribution & fund & fund & fund & fund & fund & fund & acc \\
\hline Residue $V_{t}\left[R_{t, k}\right]$ & $-36 \%$ & $-12 \%$ & $-4 \%$ & $-15 \%$ & $-30 \%$ & $+2 \%$ & $+4 \%$ \\
Surplus $V_{t}\left[S_{t, k}\right]$ & $+8 \%$ & $+12 \%$ & $+97 \%$ & $+13 \%$ & $+17 \%$ & $+16 \%$ & $+22 \%$ \\
Deficit $V_{t}\left[D_{t, k}\right]$ & $-44 \%$ & $-24 \%$ & $-101 \%$ & $-28 \%$ & $-47 \%$ & $-14 \%$ & $-18 \%$ \\
\hline \hline
\end{tabular}

high option value. The first variant leads to the largest imbalance between value transfers from current to future generations. It has the lowest residue option value of $-36 \%$. The absence of risk absorption for current generations through adjustments in contributions or benefits transfers substantial downside risks to future generations (the deficit option value is $-44 \%$ ) without a comparable transfer of upward potential (the surplus option is $8 \%$ ). The use of a flexible contribution rate in the traditional DB plan reduces the imbalance in value transfers to $-12 \%$. The deficit option reduces subtantially and future generations benefit from the higher contribution rates for current generations in financial downturns. Alternatively, the imbalance in the value transfers also reduces if the pension fund converts to a hybrid scheme with a flexible indexation rate. The upward potential is slightly higher for future generations than in the traditional DB scheme, but so is the downside risk. The collective DC scheme implies comparable transfers of downside risk and upward potential to future generations. The residue option is the smallest among the four variants $(-4 \%)$. However, the high deficit options reveals that downside risks are extremely large due to possible cuts in pensions during financial downturns.

Apart from value transfers between future and current generations in terms of downside risk and upward potential, we also incorporate what each generation gets in terms of pensions and indexation, and pays for in terms of contributions. Figure 5.4 shows the outcome for the generational account options held by the various cohorts over the 20-year evaluation period for the traditional DB plan and the hybrid plan. The horizontal axis shows the age of the cohorts at the start of the evaluation period. The oldest cohort is aged 105 and this cohort will die with certainty within 1 year. The youngest cohort (-2) will be born within two years from now. At the end of the 20-year evaluation period, these future participants will be 18 and will join the labor force.

Figure 5.4 shows that the generational account options for the younger workers 
Figure 5.4: Embedded generational options

\begin{abstract}
Embedded generational accounts for traditional DB plan and hybrid plan expressed as $\%$ of total nominal liabilities in 2006 (y-axis) for various age cohorts with age at 2006 on $\mathrm{x}$-axis.
\end{abstract}

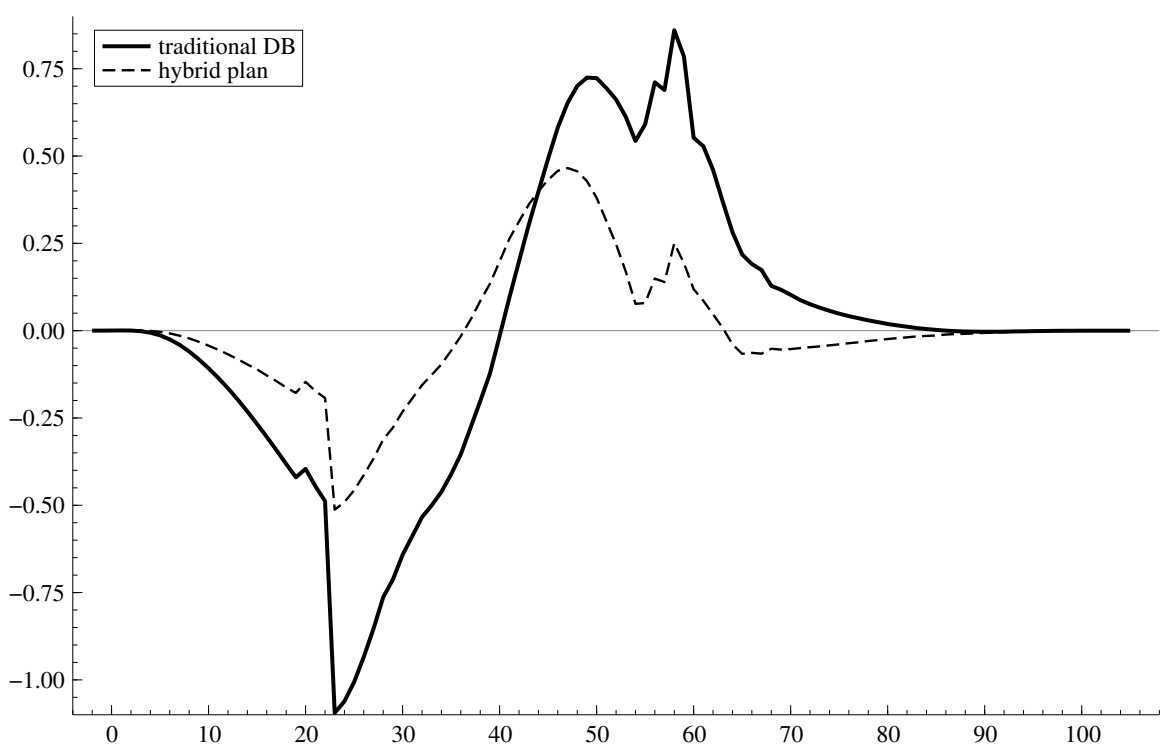

are negative, whereas the older generation of workers and retirees have a positive generational account option. The differing results for young and older workers can be explained primarily by the levying of a uniform contribution rate, whereas the value of newly accrued liabilities varies with age. The value of new liabilities is lowest for the youngest worker and highest for the oldest worker. This is the main reason why the young have negative generational account options, and older workers have positive generational account options. In this chapter, we take the practice of a uniform contribution rate and the implied redistribution from younger to older workers as given. The focus in this chapter is to evaluate the change in embedded options held by the various cohorts due to changes in pension fund policy regarding pension plan design, investment policy and the setting of the contribution rate level. These changes in embedded options will also occur when the practice of uniform contribution rate is abolished and every worker pays a contribution sum each year that exactly matches the value of new accrued liabilities in that year.

The retirees have a positive generational account option. In the traditional DB plan, they will receive full indexed pension payments, whereas the initial position 
of the pension fund is a situation of real underfunding. This also explains why the generational account option for retirees in the hybrid plan is lower as they must accept indexation cuts as long as there is a situation of real underfunding.

Table 5.4 also clarifies that the move from a traditional DB plan to a hybrid plan will lead to a considerable redistribution of value from older members to younger members. We can calculate the size of generational transfers by using the following expression, which is based on expression (9), where the term GT reflects the size of generational transfers,

$$
G T=\frac{\sum_{x}\left|\Delta G A_{\text {hybrid }}^{x}-\Delta G A_{\text {tradDB }}^{x}\right|}{2}
$$

The size of generational transfers amounts to $10.1 \%$ of nominal liabilities in 2006 .

In the remainder of this section, we explore in detail how changes in pension plan design influence the embedded options held by the various age cohorts. To this end, we decompose changes in the generational account options into changes in the underlying net benefit options and residue options as demonstrated in expression (8). The figures below display the change in embedded options for each cohort when the traditional DB plan is replaced by the hybrid plan (Figure 5.5) and when the hybrid plan is replaced by the collective DC plan (Figure 5.6).

The replacement of the traditional DB plan by the hybrid plan (Figure 5.5) would imply that the residue option for all cohorts decreases, reflecting the deterioration of the residue option for the pension fund as a whole (Table 5.3). In this case value transfers in terms of indexation and contributtions clearly dominate value transfers in terms of downside risk and upward potential of the residue. The impact on the net benefit option differs considerably between young and old plan members. This option improves strongly for the younger workers, whereas the older workers must accept a severe deterioration. Note also that the net benefit option for the retirees decreases. All workers will benefit from the replacement of the flexible contribution rate in the traditional DB plan by the fixed contribution rate in the hybrid plan. Workers no longer lose value due to contribution increases in bad times. The introduction of the hybrid plan implies that an unconditional indexation policy is replaced by a conditional indexation policy. All members lose value from this change in indexation policy. Typically, indexation cuts will occur in bad times and these cuts will then be very valuable. Catch-up indexation is provided in good times when the funding ratio is high; however, this additional indexation in good times is not as valuable in value terms. The changes in net benefit options are negative from the age of 46 onwards. Hence for workers older than 46, the loss in value due to a conversion to a conditional indexation policy more than outweighs the gain in value attributable to 
Figure 5.5: Intergenerational transfers: switch from traditional DB to hybrid plan

\begin{abstract}
Generational effects when stepping over from traditional DB plan to hybrid plan expressed as \% of total nominal liabilities in 2006 (y-axis) for various age cohorts with age at 2006 on $\mathrm{x}$-axis.
\end{abstract}

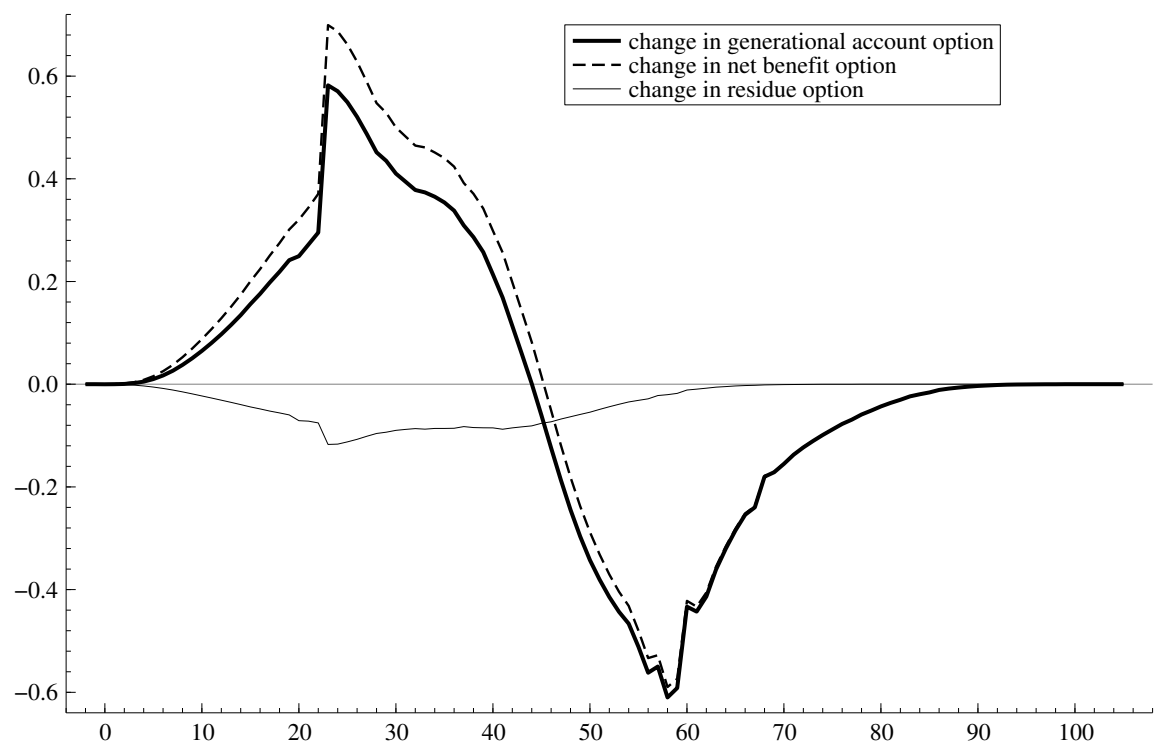

a conversion to a fixed contribution rate policy. For workers younger than 46, the contribution impact on the net benefit option is more valuable than the indexation itself.

The replacement of the hybrid plan by the collective DC plan (Figure 5.6) implies relatively minor effects on the generational account options held by the various age cohorts compared with the effects of replacing a traditional DB plan by a hybrid plan. The effects are in line with expectations. The net benefit options decrease for all cohorts. They all lose value as there is no longer a boundary on indexation cuts. Now even negative indexation is possible; this will typically occur in very bad times and hence will have a high value. From the classical ALM results, we have seen that the collective DC plan provides an average indexation ratio larger than $100 \%$ when a full indexation policy is followed. However, high levels of indexation will typically occur in good times and therefore have a low value. On balance, the loss in value due to low or even negative indexation more than outweighs the gain in value resulting from high indexation. The counterpart of the decrease in net benefit options is that the residue options improve. 
Figure 5.6: Intergenerational transfers: switch from hybrid to collective DC plan

Generational effects when stepping over from hybrid plan to collective DC plan expressed as \% of total nominal liabilities in 2006 (y-axis) for various age cohorts with age at 2006 on $\mathrm{x}$-axis.

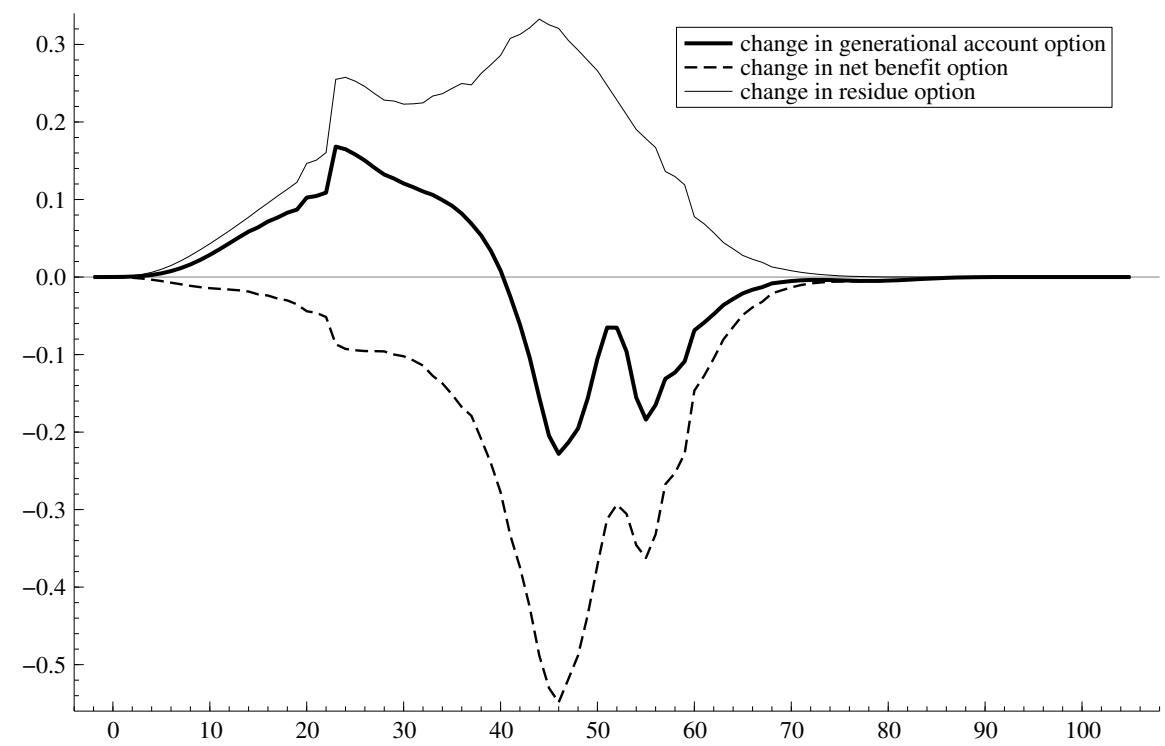

\subsubsection{Investment policy in the hybrid plan}

The various plans have up to now been evaluated using an asset mix of $50 \%$ bonds and $50 \%$ equities. Now we examine the impact on the hybrid plan of moving the asset mix toward $100 \%$ bonds or $100 \%$ equities, respectively.

In setting the contribution rate, it is common practice for pension funds to follow a funding approach of taking into account the expected rate of return on assets, net of expected indexation costs. This practice is justified by the notion that, in the long run, the sum of contributions and investment proceeds must match the stream of future indexed benefits; moreover a fixed discount rate mitigates contribution rate volatility. More risk taking therefore warrants a lower contribution rate. An important question, however, arises as to who is bearing the additional risk? When retirees bear part of the additional risk because their indexation is contingent on the financial position of the pension fund, then value transfers will inevitably occur from retirees to workers.

Columns (4), (5), and (6) of Table 5.2 report the classic ALM results for the 
hybrid plan with a 50\%-50\% asset mix, a 100\% equity mix, and a 100\% bonds strategy. The lower rate of return of the $100 \%$ bonds strategy implies an increase in the contribution rate from $17 \%$ to $27 \%$ of pensionable wages. The contribution rate in the $100 \%$ equity strategy is lowered to $12 \%$ of pensionable wages.

The expected real funding ratio of the $100 \%$ equity strategy improves strongly. The initial funding ratio is $85 \%$ and the median and mean of the funding ratio at the end of evaluation horizon are $124 \%$ and $146 \%$, respectively. This strategy implies a high level of risk. The mismatch risk is almost doubled and the within probability of nominal underfunding indicates that $61 \%$ of the scenarios have at least one year of nominal underfunding. Despite the higher average funding ratio, the mean of the indexation ratio declines in comparison with the outcome of the 50\%-50\% strategy, whereas its volatility increases sharply.

The $100 \%$ bonds strategy involves a slow, but gradual path of recovery of the funding ratio from its initial level of $85 \%$ to the aimed-for $100 \%$ real funding ratio. This mix implies a low mismatch risk exposure. The within probability of nominal underfunding of this strategy is low. The expected indexation ratio is the lowest among the variants, but the associated risks are also lower. So, the $100 \%$ bonds strategy involves much higher certainty around key variables; however, this comes at the price of higher contributions.

Once again we approach the value-based analysis with a comment value transfers between generations in terms of downside risks and upward potential of the residue option for the pension fund as a whole (see columns (5) and (6) of Table 5.3). There is a notable and heavy decline in the residue option when the asset mix is switched to $100 \%$ equities. This switch will indeed lead to a high mean for the funding ratio; however, downside risk is increased as well. In value terms, the additional downside risk outweighs the additional upside risk, and this is reflected in a larger increase in the deficit option compared with the increase in the surplus option. The difference between these two options explains the decline in the residue option itself. Value transfers of the deficit and surplus from current to future generations are more in balance if a $100 \%$ bond strategy would be followed (the residue option is $2 \%$ ). Downside risks are much smaller for future generations than with a $100 \%$ equity strategy (the deficit options are $-47 \%$ vs $-14 \%$ ). On top of that the upside of the bond strategy has a comparable surplus option value as the equity strategy.

Figure 5.7 shows the generational account options for the three investment strategies. Clearly, younger members are winners in value terms with a switch to a $100 \%$ equity strategy, whereas older members benefit from a switch to a $100 \%$ bonds strategy. Figures 5.8 and 5.9 display the changes in the generational account options for each cohort and its components, taking the hybrid plan with a 50-50 mix as the 
Figure 5.7: Embedded generational options for different asset allocations

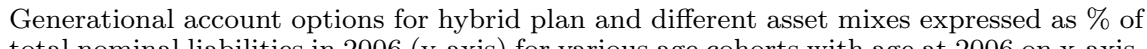
total nominal liabilities in 2006 (y-axis) for various age cohorts with age at 2006 on $\mathrm{x}$-axis.

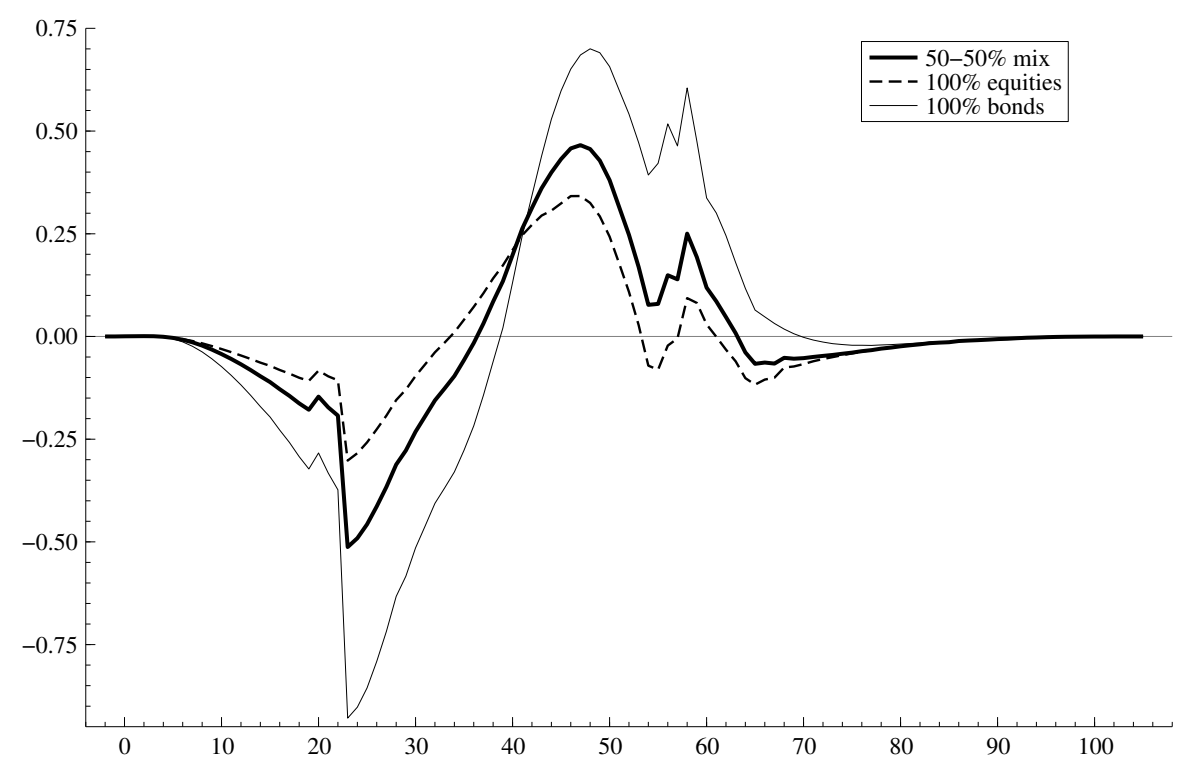

benchmark.

The $100 \%$ equities strategy leads to a lower contribution rate and this is beneficial to all workers, leading to an increase in their net benefit options. However, this strategy makes the funding ratio more volatile and so indexation risk is increased. This implies a deterioration of the net benefit option for all retired workers. For participants younger than 64 , the positive impact of lower contributions on the net benefit option is larger than the negative impact of more volatile indexation. Older workers and retirees experience a loss in their net benefit option. The $100 \%$ equity strategy makes the funding ratio at the end of the plan horizon more volatile, so the uncertainty regarding full backup of liabilities by assets is increased. Hence, all members lose value and they must accept a decrease in the residue option. The net result of the changes in the two options is that younger workers gain value whereas workers older than 41 and retirees lose value.

The $100 \%$ bonds strategy is the mirror image of the $100 \%$ equity strategy. Workers lose value as the contribution rate is increased. All members gain value due to less uncertainty around indexation, reflected by an increase in member residue op- 
Figure 5.8: Intergenerational transfers: switch to 100\% equities

Generational effects when asset mix hybrid plan is changed to $100 \%$ equities expressed as \% of total nominal liabilities in 2006 (y-axis) for various age cohorts with age at 2006 on $\mathrm{x}$-axis.

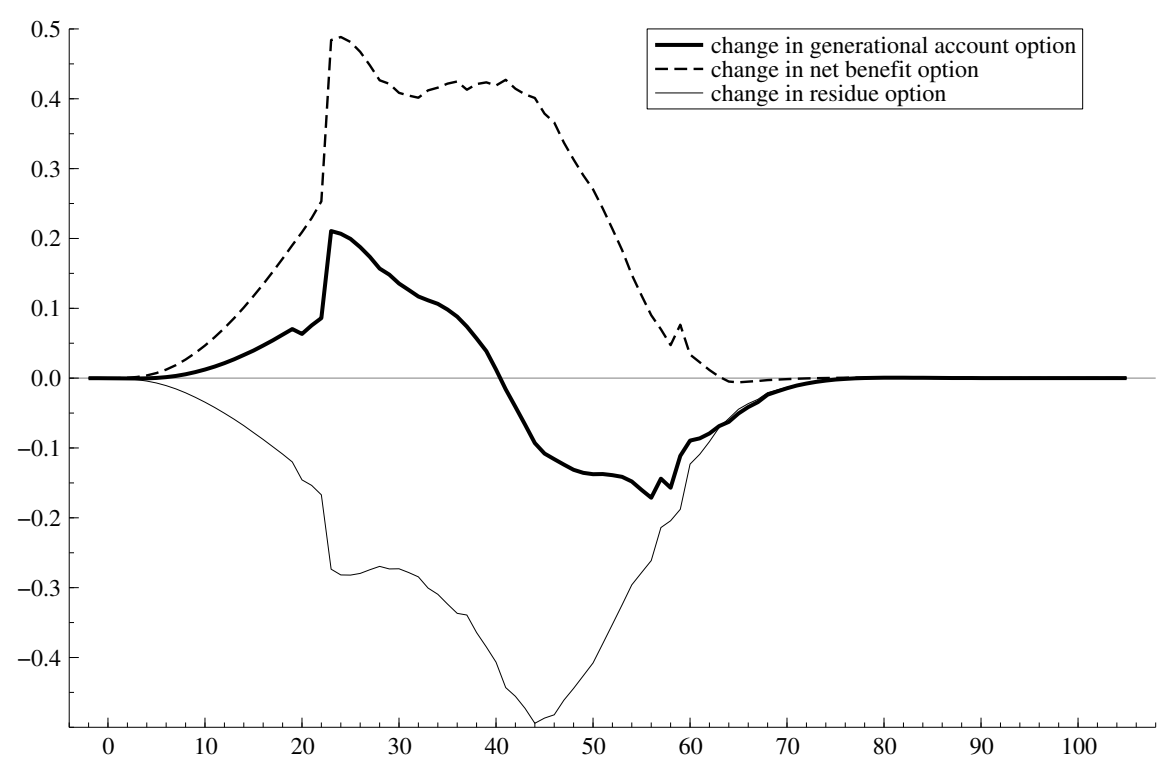

tions as future residue is characterized by low volatility. In this scenario, workers from the age of 42 onwards and retirees are, on balance, winners, whereas younger workers lose value.

\subsubsection{Base contribution rate in the hybrid plan}

Thus far, we have determined the base contribution rate by using the funding approach. For the discount factor in determining the contribution rate, we use the difference between expected rate of return on assets minus the expected growth rate of wages. However, this method is subject to scrutiny as it implies a break between reward taking and risk taking. Current workers are rewarded by more risk taking by a lowering of their base contribution rate, whereas the associated additional risk is transferred to future participants. Bader and Gold (2002) amongst others, postulated that the base contribution rate must be settled using a fair value accounting basis. Contributions must equal the fair value of new accrued liabilities. This approach - which we will call "the fair value accounting approach" - implies that the 
Figure 5.9: Intergenerational transfers: switch to $100 \%$ bonds

Generational effects when asset mix hybrid plan is changed to $100 \%$ bonds expressed as $\%$ of total nominal liabilities in 2006 (y-axis) for various age cohorts with age at 2006 on $\mathrm{x}$-axis.

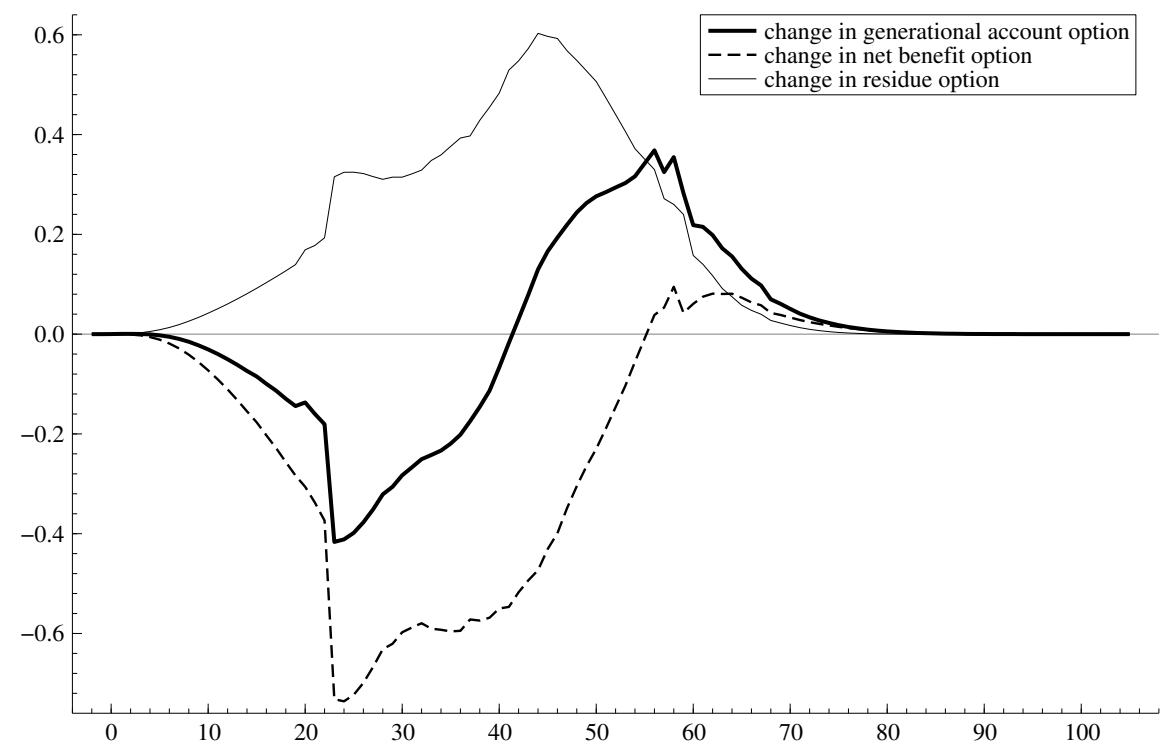

contribution rate for an indexed plan must be based on the rate of interest rather than the rate of return on assets.

For the hybrid plan with a 50-50 mix, we compare the results of classic ALM output of the funding approach and the fair value accounting approach. Compare columns (4) and (7) of Table 5.2. The base contribution rate increases from $17 \%$ to $26 \%$ when the funding approach is replaced by the fair value approach. Higher contributions lead to an improvement in the solvency position and the indexation result. The improvement of the solvency position is also evident in Table 5.3. The residue option is positive and value transfers of upward potential (22\%) and downside risk $(-18 \%)$ from current to future generations are of a similar magnitude.

Figure 5.10 delineates the changes in the embedded options. All participants see an increase in their residue options. Furthermore, retirees and near-retirees see an improvement in their net benefit options as higher contributions lead to a higher funding ratio and hence, higher indexation. Workers younger than 56 see a decrease in their net benefit options as the value loss due to higher contributions eclipses the value gain from higher indexation results. On balance, workers younger than 41 lose 
Figure 5.10: Intergenerational transfers: changing the contribution policy

Generational effects when stepping over from a contribution rate policy based on funding to fair value accounting in hybrid plan expressed as \% of total nominal liabilities in 2006 (y-axis) for various age cohorts with age at 2006 on $\mathrm{x}$-axis.

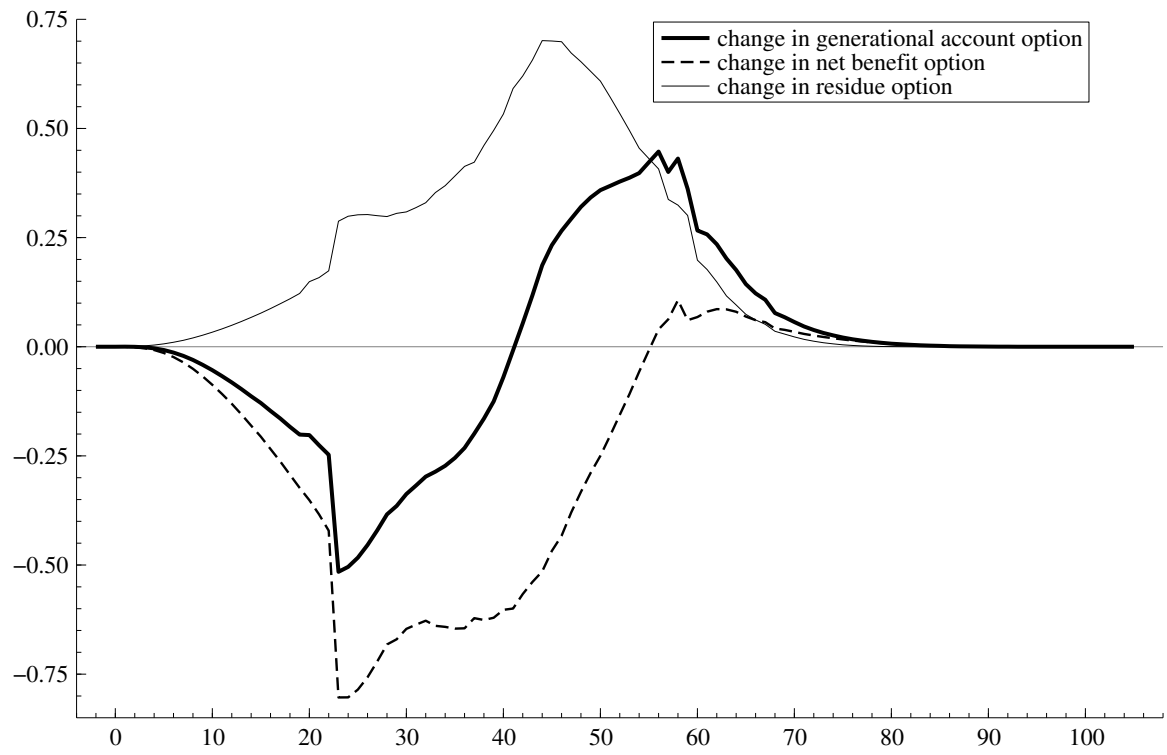

value while participants older than 41 gain value.

\subsection{Evaluation of recent Dutch pension reforms}

Since intergenerational risk sharing is a distinguishing feature of Dutch pension funds, this section illustrates value-based generational accounting to evaluate recent policy changes in the Netherlands.

Pension funds in the Netherlands play a very large role in providing retirement income ${ }^{11}$. In the postwar period - up to the beginning of the 21st century-

11 The Dutch pension fund system is very sizeable. It covers more than $90 \%$ of the labor force. The value of assets under management at year-end 2005 was 625 billion euros- $125 \%$ of national income. There are 80 pension funds operating across all industries accounting for two-thirds of assets and plan participants. An additional 600 company pension funds encompass the remainder of assets and plan participants. Employee participation is mandatory and this is governed via collective labor agreements. Most pension funds (more than 95\%) operate an indexed definedbenefit plan with indexation conditioned on the funding position of the fund. The aim of most plans is to deliver a supplementary pension income above the flat-rate public pension (payg) such that the sum of the public pension and the pension-fund pension is equal to $80 \%$ of average wage 
pension plans were predominantly employer-sponsored, wage-indexed benefit plans with funding risks primarily borne by the employer. As a result of the pension crisis in the years after 2000, employers increasingly withdrew themselves from the role of risk-bearing party in pension funds. As there was strong resistance among members against switching to individual DC plans, pension funds transformed the employersponsored defined benefit plans into stand-alone, multi-member plans based on intergenerational risk sharing. They also reconsidered the nature of the pension plan. The traditional DB plan structure with flexible contributions and fixed benefits was no longer seen as an appropriate model for managing the solvency position. The ever-increasing degree of maturity of Dutch pension funds made the steering instrument of flexible contributions highly ineffective ${ }^{12}$. The boards of trustees of many pension funds aimed to reform the traditional DB plan structure in such a way that the following three goals could be realized simultaneously: [1] improvement of solvency risk management; [2] preservation of acceptable pension results; and [3] avoiding intergenerational value transfers resulting from plan redesign as much as possible.

Pension funds introduced the hybrid plan structure, with flexible indexation and fixed contribution rate as the primary method to enhance solvency risk management. The evidence from stylized examples has clarified that this reform indeed leads to some improvement in solvency risk management, however it comes at the price of a considerable reallocation of value from older to younger members (see Figures 5.4 and 5.5).

Table 5.4 indicates the magnitude of intergenerational value transfer when the traditional DB plan is replaced by the stylized examples of pension reform discussed above. The move to a hybrid plan with a 50-50 asset mix and the associated fixing of the contribution rate based on funding principles would imply a value redistribution of $10.1 \%$ over the 20 -year period of evaluation, as discussed in section 6.2.6. The largest redistribution occurs when stepping over to a hybrid plan with a $100 \%$ equity mix. A hybrid plan with a $100 \%$ bonds asset mix leads to a maximum intergenerational transfer of $4.9 \%$, as downside risk is reduced significantly due to the

income. There is a broad discussion in the Netherlands regarding the degree of collective funding and risk sharing in pension funds. In particular, company pension funds are increasingly exploring introduction of defined contribution elements into their pension plans.

12 Pension funds in the Netherlands have been operative since the 1950s. The ratio of accrued liabilities over wages for a typical fund has now risen to approximately 5 and it is foreseen that this ratio will increase further. Given a maturity ratio of 5 , the absorption of a $1 \%$ drop in the funding ratio would require a $5 \%$ increase in the contribution rate. Restoration of the funding ratio to a higher level would then require huge additional contribution payments, that would erode the purchasing power of workers. A solution was found in the use of cuts to the year-to-year indexation of accrued liabilities. A $1 \%$ increase in funding ratio would require an indexation cut of $1 \%$ applied to all accrued liabilities. 
Table 5.4: Generational transfers due to pension reforms

Size of generational value transfers $G T$ when traditional DB plan is replaced by variants. These intergenerational value transfers are expressed as \% of nominal liabilities 2006.

\begin{tabular}{l|rrrrr}
\hline & $(3)$ & $(4)$ & $(5)$ & $(6)$ & $(7)$ \\
Plan design & Coll DC & Hybrid & Hybrid & Hybrid & Hybrid \\
Asset mix & $50-50$ & $50-50$ & 100 eq & 100 bo & $50-50$ \\
Contribution setting & fund & fund & fund & fund & acc \\
\hline$G T$ & $12.8 \%$ & $10.1 \%$ & $12.8 \%$ & $4.4 \%$ & $3.3 \%$ \\
\hline \hline
\end{tabular}

combined effects of workers paying more contributions and the decrease in mismatch risk. However this variant may be unattractive for workers as they must pay higher contributions and accept a deterioration of the pension result vis-a-vis the pension result in the hybrid plan with a 50-50 asset strategy (compare Table 5.2). A hybrid plan would justify a higher contribution level than the traditional DB plan. Contributions in the hybrid plan are no longer applied to risk bearing, so there is no reason why workers could lay claim on the rewards of risk taking. Hence, any motivation for using the expected rate of return on assets to set the contribution rate no longer exists. This would validate the replacement of the funding approach by the fair value approach in setting the contribution rate. The contribution rate in the fair value accounting approach is based on the real rate of interest. Application of the fair value approach implies higher paid contributions that will match the fair value of newly accrued liabilities, so there would be no subsidizing of contribution payments by workers.

A pension fund necessarily must be oriented toward finding the "most acceptable" policy mix with respect to the interests of its various constituent groups. Combining the hybrid plan and a 50-50 mix with the fair value approach in setting the contribution rate may be an acceptable midway position amongst the possible variants. Intergenerational value transfer is $5.9 \%$ and of limited size, downside risk as measured by the deficit option (Table 5.3) is low and the pension result, as measured by the outcomes for the indexation ratio, is relatively good (Table 5.2).

The actual pension reform experience of Dutch pension funds is very close to our reformulation of policy parameters. 


\subsection{Other applications}

The value-based generational accounting method is applied to a real existing industry pension fund. However the method is broadly applicable to the evaluation of any institutional arrangement which implies intergenerational redistribution and risk-sharing. Such arrangements typically can be found in government policies related to fiscal policy and debt management, social security, and health care (Bohn 2005). The particular mix of tax, pension and health care policies is decisive on how costs, benefits and associated risks are distributed amongst age cohorts. Valuebased generational accounting may be helpful in assessing the fairness of government programs and in preventing excessive intergenerational value transfers. We discuss some specific applications below.

\subsubsection{Public Finance}

Generational accounting stems originally from public finance with the pioneering work of Auerbach and Kotlikoff (cf. Auerbach, Kotlikoff, Leibfritz (1999)). Usually, generational accounting studies are performed in a deterministic setting. However, future projections of tax revenues and government outlays are subject to uncertainty. Generational accounts typically use a real rate of discount that exceeds the real government short-term rate, to adjust for the relative risk of future cash-flows. Sensitivity analysis for various discount rates can be carried out to analyze the impact on generational accounts of different degrees of risk. However this approach disregards the differences in relative risk of government cash flows. As the relative risk of tax income, spending and transfer payments differ, the theoretically appropriate risk-adjusted rates at which to discount these flows would also differ, and so will the impact on generational accounts. Kotlikoff (2002) notes that the size of these risk-adjustments in generational accounting remains a topic for future research. We think the use of a stochastic framework and value-based pricing with a specification of macroeconomic risks (productivity, real income growth) and financial market risks (term structure of interest rates, asset pricing) would improve generational accounting in the field of public finance.

\subsubsection{Social security reform}

Many countries have initiated conversion programs for unfunded defined social security schemes into privatized funded defined contribution schemes (cf. Chile and other countries in Latin America, countries in Eastern Europe, United Kingdom), whereas the US (Feldstein (2005)) and many other countries are considering im- 
plementation of a conversion program. Such a conversion program implies either a transition burden to be absorbed either by reduced benefits and tax increases or by replacement of implicit pay-as-you-go debt by explicit government debt. Moreover, the conversion programs often are accompanied by minimum return guarantees regarding the defined contribution results. Smetters (2002) values minimum benefit guarantees in proposals to privatize the US Social Security system and finds that the system's guarantees are very costly despite their low probability. When risks, guarantees and costs are not gauged accurately, social security reforms may easily lead to unintended hidden value transfers between generations. Value-based generational accounting may prove useful by helping to prevent undesired value transfers due to baldly design reforms.

\subsection{Conclusions}

This chapter aims to demonstrate the usefulness of value-based generational accounting for pension funds with intergenerational risk sharing. Value-based generational accounting is useful to control for the intergenerational value transfers that may arise as an inevitable by-product of policy changes. These transfers can be analyzed with the help of changes in the values of the various embedded generational options held by the participants. We have characterized the value-based approach as supplementary to the classic ALM tool kit, which is already used intensively by pension funds in decision-making on pension fund policy. Classic ALM evaluates the performance of alternative pension contracts in terms of expected results and risk measures for key variables like the funding ratio, the contribution rate, and pension benefits.

A number of stylized examples of policy changes in risk allocation, investment policy and the setting of the base contribution rate have been analyzed. We calculate intergenerational value transfers as changes in the values of embedded options resulting from these policy adjustments. We find that any policy change will inevitably lead to value transfers. A more risky asset mix is beneficial to younger members at the expense of older members, who lose value. A reallocation of risk bearing from flexible contributions to flexible benefits also leads to value redistribution from old to young.

Faced by a solvency crisis after 2000, Dutch pension funds were forced by the supervisor to modify their pension contracts, in operation since the 1950s, in order to improve solvency management. Many pension funds replaced the traditional DB plan structure consisting of fixed benefits and flexible contributions by a hybrid pension plan structure with fixed contributions and solvency-contingent indexation. 
Results from the stylized examples are used to evaluate the recent reforms by Dutch pension funds.

We have argued that a combination of the hybrid plan, a 50-50 mix and the fair value approach in setting the contribution rate may be an acceptable midway position amongst the alternatives. The intergenerational value transfers are of limited size, downside risk, as measured by the deficit option of the funding residue is low, and the pension result, as measured by the outcomes for the indexation ratio, are relatively good. Intergenerational value transfers are of limited size, downside risk, as measured by the deficit option of the funding residue is low, and the pension result, as measured by the outcomes for the indexation ratio, are relatively good. The actual reforms of many Dutch pension funds are very close to this reset of policy parameters.

We see value-based generational accounting as an important extension of the tool kit of decision making for pension funds with intergenerational risk sharing. This method is also useful in evaluating any institutional arrangement which implies intergenerational transfers, like public finance and reforms in social security systems.

\subsection{Appendix: affine real term structure of interest rates}

The price of an n-period real zero coupon bond is

$$
\hat{P}_{t}^{(n)}=\mathrm{E}_{t}\left(M_{t+1} \hat{P}_{t+1}^{(n-1)}\right)
$$

In our model real bond prices are also assumed to be affine in the state variables of the VAR such that

$$
\hat{A}_{n}+\hat{B}_{n}^{\prime} z_{t}=\mathrm{E}_{t}\left[m_{t+1}\right]+\mathrm{E}_{t}\left[\hat{p}_{t+1}^{(n-1)}\right]+\frac{1}{2} \operatorname{Var}_{t}\left[m_{t+1}+\hat{p}_{t+1}^{(n-1)}\right]
$$

In an arbitrage free economy the price of a real bond with maturity $n-1$ issued at $t$ should be equal to the price of a newly issued real bond with the same maturity next period plus the inflation over the period, in other words $\hat{p}_{t+1 \mid t}^{(n-1)}=\hat{p}_{t+1 \mid t+1}^{(n-1)}+\pi_{t+1}$. Substitution in the equation above gives

$$
\hat{A}_{n}+\hat{B}_{n}^{\prime} z_{t}=\mathrm{E}_{t}\left[m_{t+1}\right]+\mathrm{E}_{t}\left[\pi_{t+1}+\hat{p}_{t+1 \mid t+1}^{(n-1)}\right]+\frac{1}{2} \operatorname{Var}_{t}\left[m_{t+1}+\pi_{t+1}+\hat{p}_{t+1 \mid t+1}^{(n-1)}\right]
$$

Obviously, $\hat{P}_{t}^{(0)}=1$ implies $\hat{A}_{0}=\hat{B}_{0}=0$. Using equation (5.26) the one-month real yield can be expressed as

$$
\hat{y}_{t}^{1}=y_{t}^{1}-\ln \left(E_{t} \pi_{t+1}\right)-e_{\pi}^{\prime} \Sigma \lambda_{t} .
$$


The last term on the right-hand side is the one-month inflation risk premium. In line with Ang, Bekaert, Wei (2007) we obtain identification by restricting the one-period inflation risk premium to zero.

For an n-period bond (5.26) can be written as

$$
\begin{aligned}
\hat{A}_{n}+\hat{B}_{n}^{\prime} z_{t}=-\delta_{0}-\delta_{1}^{\prime} z_{t} & +\mathrm{E}_{t}\left[\hat{A}_{n-1}+\hat{B}_{n-1}^{\prime} z_{t+1}+e_{\pi}^{\prime} z_{t+1}\right] \\
+ & \frac{1}{2} \operatorname{Var}_{t}\left[\hat{B}_{n-1}^{\prime} z_{t+1}+e_{\pi}^{\prime} z_{t+1}\right]+\operatorname{Cov}_{t}\left[m_{t+1},\left(B_{n-1}+e_{\pi}\right)^{\prime} z_{t+1}\right]
\end{aligned}
$$

and

$$
\begin{aligned}
\hat{A}_{n}+\hat{B}_{n}^{\prime} z_{t}=-\delta_{0}-\delta_{1}^{\prime} z_{t} & +\hat{A}_{n-1}+\left(\hat{B}_{n-1}+e_{\pi}\right)^{\prime}\left(c+B z_{t+1}\right) \\
+ & \frac{1}{2}\left(\hat{B}_{n-1}+e_{\pi}\right)^{\prime} \Sigma \Sigma^{\prime}\left(\hat{B}_{n-1}+e_{\pi}\right)-\left(\hat{B}_{n-1}+e_{\pi}\right)^{\prime} \Sigma \lambda_{t}
\end{aligned}
$$

Matching coefficients and rearranging obtains

$$
\begin{aligned}
& \hat{A}_{n}=-\delta_{0}+\hat{A}_{n-1}+\left(\hat{B}_{n-1}+e_{\pi}\right)^{\prime}\left(c-\Sigma \lambda_{0}\right)+\frac{1}{2}\left(\hat{B}_{n-1}+e_{\pi}\right)^{\prime} \Sigma \Sigma^{\prime}\left(\hat{B}_{n-1}+e_{\pi}\right) \\
& \hat{B}_{n}=-\delta_{1}+\left(B-\Sigma \lambda_{1}\right)^{\prime}\left(\hat{B}_{n-1}+e_{\pi}\right) .
\end{aligned}
$$

Finally, the term structure of real interest rates is defined as

$$
\hat{y}_{t}^{(n)}=-\frac{\hat{A}_{n}}{n}-\frac{\hat{B}_{n}^{\prime}}{n} z_{t}
$$





\section{Chapter 6}

\section{Summary and conclusions}

This thesis contributes to two main areas of asset liability management: strategic asset allocation and embedded options in the pension contract (value-based ALM). A revived interest in strategic asset allocation emerged from several academic and practical developments. The well-documented predictability of asset returns and the accompanying time-varying risk opportunities make optimal portfolio choice horizon dependent. Long-term investors can therefore not only benefit from risk diversification between assets, but also from time diversification within an asset class. For instance, stocks exhibit a lower annualized risk at longer horizons, whereas rolling Tbills is more risky in the long run due to reinvestment risk. At the same time, pension funds can choose from a large menu of alternative asset classes (like commodities, credits, real estate and hedge funds) that goes beyond the traditional T-bills, stocks and bonds. Another development is the shift in updated regulatory frameworks towards fair valuation of both assets and liabilities on the balance sheet. Liabilities are now a predetermined component in the pension funds investment portfolio with a return that is subject to inflation and real interest rate risk. In addition, deteriorating financial positions at the beginning of this century and regulatory solvency constraints led to revived interest in liability-driven portfolio insurance strategies.

The interest in embedded options and value-based ALM is motivated by the demand of pension beneficiaries, and especially younger generations, for more transparency with regard to who pays and who benefits from the pension system in an ageing society. Although all kinds of risk sharing rules intend to make the solvency position more robust to financial downturns, value is implicitly reallocated among stakeholders. Conditionalities in pension contracts that are transparent and welldefined in terms of proceeds and costs for the contract holders are related to the underlying economic variables. As such these types of contracts can be seen equiv- 
alent to financial contracts with embedded options. These options are written to the pension fund by the beneficiaries, like the right to make the indexation conditional on the financial position of the fund. Unlike option holders in the investment world, the participants in a DB scheme are not necessarily compensated for holding or issuing such embedded options. Understanding the embedded value transfers is important to gain insights in the relationship between the various stakeholders. To that purpose we identify several embedded options in the pension deal, and reveal hidden value transfers between beneficiaries. The pricing of these embedded risks should be based on how risks are priced in the market. Similar to financial options we apply option valuation techniques as a market consistent method to value the embedded options in the pension contract.

What are the lessons of strategic asset allocation and asset liability management for long-term investors? We hope that the chapters in this dissertation have demonstrated the following points.

First, alternative asset classes can add value for long-term investors. Investors should examine whether a specific alternative asset class has a term structure of risk that is fundamentally different from that of stocks and bonds.

Chapter two considers the term structures of commodities, credits, listed real estate and hedge funds. Among these assets, commodities have the best risk diversifying properties. Its correlations with stocks and bonds are negative at short and long investment horizons. On the other hand, commodities have a flat term structure of annualized volatilities which make them relatively less attractive in the long run than the mean reverting stocks and bonds. Term structure properties of listed real estate seem to a large extent captured by the traditional asset classes. In fact, listed real estate is often seen as an equity category. Investment grade credits seem a good substitute for government bonds with a higher expected return. The term structures of investment grade credits mimic those of bonds, and the correlation between stocks and credits is slightly higher than for bonds. The hedge fund index has a high exposure to stocks and bonds.

The allocation to alternatives in the portfolio depends on the investment horizon and the risk attitude of the investor. In general, investors with a lower degree of risk aversion should drive T-bills and bonds out of the portfolio in favor of the alternatives with a higher expected return like hedge funds, commodities and credits. Commodities and credits are also interesting for more conservative investors. As in our data listed real estate has a lower Sharpe ratio than stocks and hedge funds, the allocation to listed real estate is only small. We find that the utility costs of not 
investing beyond stocks, bonds and T-bills and thus ignoring the alternatives are economically significant. Investors should therefore evaluate whether the utility loss outweighs implementation issues such as advanced risk management, advanced legal requirements, high entrance costs, high manager selection skills and reputation risk.

Second, a long-term investor should not only consider horizon effects in volatilities and risk diversification properties, but also in inflation hedge qualities.

Rolling T-bills quickly catches up with inflation changes, and therefore seems the best inflation hedge at all horizons. A constant maturity long-dated bond or credit portfolio is a good inflation hedge in the long run, but poor in the short run due to the inverse relationship between yield changes and bond prices. As such a (nominal) interest rate swap-overlay exposes investors to inflation risk. In a high inflationary regime the variable short payer rate rises with the inflation, whereas the agreed long receiver rate does not. Stocks and hedge funds are also a better inflation hedge in the long-term than in the short-term. The inflation hedge qualities of listed real estate mimic those of stocks. Commodities help in hedging inflation risk at all horizons.

Third, differences in strategic investment portfolios for asset-only and asset-liability investors are due to differences in the global minimum variance and liability hedge portfolio.

The main difference between the asset-only and asset-liability perspective shows up in the attractiveness of short-term T-bills and long-maturity bonds. Asset-only investors have a large demand for short-term instruments due to their strong positive correlation with inflation at longer horizons. Asset-liability investors not only need to deal with reinvestment risks of T-bills, but also with duration mismatch risk with respect to the liabilities. Nonetheless, they remain attractive for their low risks at short horizons and good diversification properties with stocks and bonds at longer horizons. Therefore they still have a substantial weight in the portfolio. Bonds and credits are the best real rate hedge, and therefore have a high weight in the liability hedge portfolio. Commodities are in the liability hedge portfolio for their risk diversifying qualities. The liability hedge portfolio allocates a small amount to listed real estate and does not invest in hedge funds. Another aspect of the liability hedge portfolio is that the duration of the fixed-income part is below that of the liabilities due to several reasons. With respect to the short-term vs. long-term tradeoff, short-dated bonds are a good risk diversifier in a portfolio of long-dated bonds. Furthermore, in order to tradeoff nominal inflation risk and real interest rate risk long-dated bonds are a better long real rate hedge, but short-dated bonds provide a better hedge against cumulative inflation. Finally, stocks also have positive real 
rate hedge qualities at longer horizons. As a result of the intertemporal covariance structures the duration of the fixed-income portfolio is horizon dependent. We also find that the benefits of long-term investing are larger when there are liabilities.

Fourth, the gains for an asset-liability investor are large from choosing the asset allocation in a strategic way instead of a short-term perspective.

For investment horizons beyond five years, the benefits of long-term investing are larger for an optimal mean-variance investors when there are liabilities. Apart from a different single-period portfolio, the asset-liability investor has different intertemporal hedging demands for changes in the investment opportunities at various horizons. In particular, asset-liability investors focus much more on interest rate risk and fixed-income products than asset-only investors. The diminishing correlation at longer horizons between stocks and bonds creates positive hedging demand for stocks in the long run. The increasing correlation at short and medium term horizons results in more negative hedging demand for stocks once there are liabilities. Chapter two also proposes an analytical framework that provides insights into the sources of the added value of a specific investment strategy: return enhancement, risk diversification or liability hedging. This concept can be applied by investors to evaluate the attractiveness of specific asset classes or investment strategies. Besides this, the so-called liability-driven investment solutions recently analyzed by institutional asset managers and investment banks are justified by the liability hedging demand in optimal portfolio choice and the large gains from strategic investing in the presence of liabilities.

Fifth, risk diversification properties and inflation hedge qualities are more robust to the uncertainty in the model parameters as well as prior information about expected asset returns and macro economic variables than time diversification in terms of volatilities.

Chapter three shows that the impact of parameter uncertainty on volatilities is horizon dependent. It increases with the investment horizon. Nevertheless, mean reversion in stocks and bonds still dominates parameter uncertainty, but the time diversification qualities become much weaker. Parameter uncertainty contributes as much to the risk of bonds as it does to stocks. Furthermore, prior views on the long-term mean of macro economic variables influence the predictability of stock and bond returns, and the persistency of state variables. This has also implications for the term structures of annualized volatility. We also find that mean uncertainty is a mean averting mechanism in the holding period volatility, and it dominates the asset volatilities at longer investment horizons. 
Sixth, incorporating parameter uncertainty leads to a more conservative strategic investment portfolio with a strong focus on risk diversification.

Since correlations between assets are much more robust against parameter uncertainty than volatilities of assets, we find that risk diversification becomes much more emphasized after incorporating parameter uncertainty, typically at longer horizons. An investor who accounts for parameter uncertainty allocates less to stocks and more to T-bills. For short (1-year) investment horizons it is justifiable to ignore parameter uncertainty in the asset allocation decision. Instead, the opportunity costs of ignoring parameter uncertainty are economically significant for longer investment horizons. It is recommendable that investors account for parameter uncertainty for long-term strategic asset allocation.

Seventh, indeed the optimal asset allocation varies substantially with the prior information that the investor has about the level of expected asset returns and macro economic variables, but we have found some interesting features.

Regardless of the prior precision, T-bills are an important risk diversifier in a portfolio with stocks, which results in a substantial portfolio weight for T-bills for all horizons. We find that investors who are very optimistic about stocks should also invest a substantial part of their assets in T-bills for hedging purposes. On the other hand, investors who are skeptical about stocks should still include them in their portfolio for hedging purposes, particularly for longer investment horizons. The robust portfolio choice when there are multiple experts with different prior views coincides in our example with an investor who is conservative about stocks, moderately optimistic about bonds and accounts for parameter uncertainty.

Eighth, dynamic asset allocation strategies are not necessarily in line with the inflationlinked ambition of $D B$ pension plans.

Chapter four is devoted to liability driven portfolio insurance strategies. The success of portfolio insurance strategies greatly depends on the market environment, the downside risk attitude of the investor, the initial funding ratio and upward potential of the return portfolio. Portfolio insurance strategies based on short-term solvency risks should take care of the solvency-trap. In the long run switching between the speculative and the hedge portfolio conditional on the downside risks is not automatically preferred to a constant mix strategy. As an example immunization and dynamic mix strategies achieve short-term solvency and low nominal risks, but potentially at the cost of long-term indexation quality. In our example a dynamic nominal swap-overlay strategy creates a much better balance between short-term 
risks and long-term inflation compensation, because the return potential remains. These benefits of the swap come at the expense of a high asset-only volatility due to the duration extension and large losses when interest rates rise. Although the nominal swap hedges interest rate risk, other market risks can still lead to downside risk. The short-payer rate also introduces reinvestment risk. On top of that both the payer and the receiver rate give the investor a large exposure to inflation risk.

Ninth, value-based ALM, and in particular value-based generational accounting, should be used as an important extension of classical ALM to give extra insights into the relationships between the stakeholders.

The value-based ALM approach in chapters four and five reveals the hidden value transfers between generations which cannot be identified by the classical ALM output in terms of probability distributions. As such it adapts a different perspective of ALM than welfare analyzes based on utility functions. Understanding the (embedded) options written by one group of stakeholders to another group of stakeholders is important for a fair and sustainable contract. The embedded options give insights in the relationships between the stakeholders. The first step is to identify embedded (generational) options on the balance sheet. In chapters four and five we identify embedded indexation, surplus, deficit and generational options. In the second step these embedded options are valued using option valuation techniques. This method is also useful in evaluating other collective contracts which lead to embedded intergenerational value transfers, like public finance and reforms in social security systems. We argue that value-based ALM should be part of the ALM tool kit of decision making for pension funds with intergenerational risk sharing.

Tenth, policy changes in collective pension schemes will inevitably lead to value transfers between generations.

Chapter five rewrites the balance sheet of a pension fund as embedded generational options to explore intergenerational risk sharing. We show how the method reveals intergenerational risk transfers due to changes in the investment, contribution rate or indexation policy or from pension reforms. In our example a more risky asset mix is beneficial to younger members at the expense of older members, who lose value. Since in the example higher expected investment returns lead to lower contribution rates, younger participants benefit from this, whereas the older ones are worse off due to the larger downside and indexation risks. A reallocation of risk bearing from flexible contributions to flexible benefits also leads to value redistribution from old to young beneficiaries. 
Although this thesis discussed many aspects of ALM for pension funds and strategic asset allocation for long-term investors, many topics that are relevant in these areas deserve further examination. Among these are the constituents of the liability hedging portfolio in an incomplete market with respect to wage inflation. The role of longevity risk, illiquid assets and other alternative asset classes also deserves scrutiny. The form of the utility function of a multiple-member and multiple-objective pension plan is another example. Another interesting topic is the implication of the intertemporal covariance between assets and liabilities for dynamic portfolio choice. Hedging downside risks in ALM via structured derivative solutions is another example. The insights from taking another econometric route that incorporates time-varying parameters would also be interesting for long-term investors. For instance, regime switching models could be used to verify the risk properties of the assets in different economic regimes. It would also be interesting to investigate the suitability of our findings in life-cycle models for individuals. It is well-documented that labor income and the behavior of individuals over the life-cycle have important consequences for the asset allocation decision.

The practical application of the investment insights of this dissertation is a big challenge. In practice, there are many aspects that go beyond the assumptions of the models in this thesis. The preferences of a multiple-member and multiple-objective plan are often not explicitly defined. Moreover, in practice the decision-making process is most of the time not based on a well-defined utility function, but it also depends on the governance structure and behavioral aspects. Furthermore, there are investment, regulatory and legal constraints that investors must incorporate. The investment universe goes beyond the asset classes that we considered, and investment areas such as timber, infrastructure, private equity and other illiquid investments are widely explored. Also the market of inflation-linked products is rapidly growing. We hope that the aforementioned lessons will be helpful for long-term investors when facing these practical challenges. We also hope that the models developed in this thesis can be helpful for strategic asset allocation and (value-based) ALM to balance between nominal risks, inflation compensation, long-term continuity and short-term solvency. In particular, we think that the valuation of embedded (generational) options is a valuable instrument for good pension governance to evaluate pension reforms and other changes in the pension contract in the coming years. 



\section{Bibliography}

Ackermann, C., R. McEnally, and D. Ravenscraft, 1999, The Performance of Hedge Funds: Risk, Return, and Incentives, Journal of Finance 54, 833-874.

Agarwal, V., and N.Y. Naik, 2000, Risks and Portfolio Decisions Involving Hedge Funds, Review of Financial Studies 17, 63-98.

Ambachtsheer, K.A., 2007, Pension Revolution, A Solution to the Pensions Crisis. (John Wiley \& Sons).

Ang, A., and G. Bekaert, 2004, How do Regimes Affect Asset Allocation?, Financial Analysts Journal 60, 86-99.

Ang, A., G. Bekaert, and M. Wei, 2007, The Term Structure of Real Rates and Expected Inflation, Journal of Finance, forthcoming.

Ang, A., M. Piazessi, and M. Wei, 2006, What does the Yield Curve Tell us about GDP Growth?, Journal of Econometrics 131, 359-403.

Auerbach, A.J., L.J. Kotlikoff, and W. Leibfritz, 1999, Generational Accounting around the World. (Chicago University Press).

Avramov, D., 2002, Stock Return Predictability and Model Uncertainty, Journal of Financial Economics 64, 423-458.

Avramov, D., 2004, Stock Return Predictability and Asset Pricing Models, Review of Financial Studies 17, 699-738.

Bader, L.N., and J. Gold, 2002, Reinventing Pension Actuarial Science, Working Paper.

Bajeux-Besnainou, I., J. Jordan, and R. Portait, 2003, Dynamic Asset Allocation for Stocks, Bonds and Cash, Journal of Business 76, 263-287.

Barberis, N., 2000, Investing for the Long Run when Returns are Predictable, Journal of Finance 55, 389-406.

Bauer, R., R. Hoevenaars, and T. Steenkamp, 2006, Asset Liability Management, The Oxford Handbook of Pensions and Retirement Income, eds. G.L. Clark and A.H. Munnell and J.M. Orszag, Oxford University Press. 
Bauwens, L., L.M. Lubrano, and J.F. Richard, 2003, Bayesian Inference in Dynamic Econometric Models. (Oxford University Press, New York).

Bekaert, G., and R. Hodrick, 2001, Expectations Hypotheses Tests, Journal of Finance 56, 1357-1394.

Binsbergen, J.H., and M.W. Brandt, 2007, Optimal Asset Allocation in Asset and Liability Management, Working Paper, Duke University.

Black, F., 1980, The Tax Consequences of Long-Run Pension Policy, Financial Analysts Journal pp. 3-10.

Black, F., and R. Jones, 1988, Simplifying Portfolio Insurance for Corporate Pension Plans, Journal of Portfolio Management pp. 33-37 Summer.

Black, F., and Litterman, 1992, Global Portfolio Optimization, Financial Analysts Journal 48, 28-43.

Black, F., and A.F. Perold, 1992, Theory of Constant Proportion Portfolio Insurance, Journal of Economic Dynamics and Control 16, 403-426.

Blake, D., 1998, Pension Schemes as Options on Pension Fund Assets: Implications for Pension Fund Management, Insurance: Mathematics and Economics 23, 263286.

Blake, D., A.J.G. Cairns, and K. Dowd, 2006, Living with Mortality: Longevity Bonds and other Mortality-Linked Securities, Working Paper, Pensions Institute.

Bodie, Z., 1983, Commodity Futures as a Hedge against Inflation, Journal of Portfolio Management pp. 12-17 Summer.

Boender, C.G.E., 1997, A Hybrid Simulation/Optimization Scenario Model for Asset-Liability Management, European Journal of Operations Research 99, 126135 .

Boender, C., C. Dert, F. Heemskerk, and H. Hoek, 2007, Scenario Approach of ALM, Handbook of Asset Liability Management, eds. S.A. Zenios and T.Z. Ziemba, North Holland.

Boeri, T., L. Bovenberg, B. Coeré, and A. Roberts, 2006, Dealing with New Giants: Rethinking the Role of Pension Funds, Geneva Reports on the World Economy 8.

Bohn, H., 2005, Who Bears what Risk? An Intergenerational Perspective, working paper University of California at Santa Barbara.

Brandt, M.W., A. Goyal, P. Santa-Clara, and J.R. Stroud, 2005, A Simulation Approach to Dynamic Portfolio Choice with an Application to Learning About Return Predictability, Review of Financial Studies 18.

Brandt, M.W., and P. Santa-Clara, 2006, Dynamic Portfolio Selection by Augmenting the Asset Space, Journal of Finance 61, 2187-2217. 
Brennan, M.J., 1998, The Role of Learning in Dynamic Portfolio Decisions, European Finance Review 1, 295-306.

Brennan, M.J., E.S. Schwartz, and R. Lagnado, 1997, Strategic Asset Allocation, Journal of Economic Dynamics and Control 21, 1377-1403.

Brennan, M.J., and R. Solanki, 1981, Optimal Portfolio Insurance, Journal of Financial and Quantitative Analysis 51, 279-300.

Brennan, M.J., and Y. Xia, 2002, Dynamic Asset Allocation under Inflation, Journal of Finance 57, 1201-1238.

Brown, S.J., 1979, Optimal Portfolio Choice under Uncertainty: A Bayesian Approach, Estimation Risk and Optimal Portfolio Choice, eds. V.S. Bawa, S.J. Brown and R.W. Klein, North-Holland, Amsterdam.

Buiter, W.H., 1997, Generational Accounts, Aggregate Saving and Intergenerational Distribution, Economica 64, 605-626.

Cairns, A.J.G., D. Blake, and K. Dowd, 2005, Pricing Death: Frameworks for the Valuation and Securitization of Mortality Risk, Working Paper, Pensions Institute.

Campbell, J.Y., 1987, Stock Returns and the Term Structure, Journal of Financial Economics 18, 3-37.

Campbell, J.Y., G. Chacko, J. Rodriquez, and L.M. Viceira, 2004, Strategic Asset Allocation in a continuous-time VAR model, Journal of Economic Dynamics and Control 28, 2195-2214.

Campbell, J.Y., Y.L. Chan, and L.M. Viceira, 2003, A Multivariate Model for Strategic Asset Allocation, Journal of Financial Economics 67, 41-80.

Campbell, J.Y., A.W. Lo, and A.C. MacKinlay, 1997, The Econometrics of Financial Markets. (Princeton University Press).

Campbell, J.Y., and R.J. Shiller, 1987, Cointegration and Tests of Present Value Relations, Journal of Political Economy 95, 1062-1088.

Campbell, J.Y., and R.J. Shiller, 1988, Stock Prices, Earnings and Expected Dividends, Journal of Finance 43, 661-676.

Campbell, J.Y., and R.J. Shiller, 1991, Yield Spreads and Interest Rate Movements: A Bird's Eye View, Review of Economic Studies 58, 495-514.

Campbell, J.Y., and S. Thompson, 2007, Predicting the Equity Premium Out of Sample: Can Anything Beat the Historical Average?, Review of Financial Studies, forthcoming.

Campbell, J.Y., and L.M. Viceira, 2001, Who Should Buy Long-Term Bonds?, American Economic Review 91, 99-129. 
Campbell, J.Y., and L.M. Viceira, 2002, Strategic Asset Allocation: Portfolio Choice for Long-Term Investors. (Oxford University Press).

Campbell, J.Y., and L.M. Viceira, 2005, The Term Structure of the Risk-Return Tradeoff, Financial Analysts Journal 61, 34-44.

Campbell, J.Y., and M. Yogo, 2004, Efficient Tests of Stock Return Predictability, Journal of Financial Economics 81, 27-60.

Carino, D.R., T. Kent, D.H. Myers, C. Stacy, M. Sylvanus, A.L. Turner, K. Watanabe, and W.T. Ziemba, 1994, The Russel-Yasuda Kasai Model: An Asset Liability Model for a Japanese Insurance Company using Multistage Stochastic Programming, Interfaces 24, 29-49.

Chapman, R.J., T.J. Gordon, and C.A. Speed, 2001, Pensions, Funding and Risk, British Actuarial Journal 74, 605-663.

Chopra, V.K., and W.T. Ziemba, 1993, The Effect of Errors in Means, Variances, and Covariances on Optimal Portfolio Choice, Journal of Portfolio Management pp. 6-11 winter.

Clark, G.L., 2004, Pension Fund Governance: Expertise and Organizational Form, Journal of Pension Economics and Finance 3, 233-253.

Clark, G.L., A.H. Munnell, and J.M. Orszag, 2006, The Oxford Handbook of Pensions and Retirement Income. (Oxford University Press).

Claus, J., and J. Thomas, 2001, Equity Premia as Low as Three Percent? Evidence from Analysts' Earnings Forecasts for Domestic and International Stocks Markets, Journal of Finance 56, 1629-1666.

Cochrane, J.H., 2001, Asset Pricing. (Princeton University Press).

Cochrane, J.H., 2006, The Dog That Did Not Bark: A Defense of Return Predictability, Working Paper, University of Chicago.

Cochrane, J., and M. Piazzesi, 2002, Bond Risk Premia, American Economic Review 95, 138-160.

Cochrane, J., and J. Saa-Requejo, 2000, Beyond Arbitrage: Good Deal Asset Price Bounds in Incomplete Markets, Journal of Political Economy 108, 79-119.

Constantinides, G.M., J.B. Donaldson, and R. Mehra, 2005, Junior must pay: pricing the implicit put in privatizing social security, Annals of Finance 1, 1-34.

Cremers, K.J.M., 2002, Stock Return Predictability: A Bayesian Model Selection Perspective, Review of Financial Studies 15, 1223-1249.

Cui, J., F. de Jong, and E. Ponds, 2006, The Value of Intergenerational Transfers within Pension Funds, Working Paper, Tilburg University. 
Dai, Q., and K. Singleton, 2002, Expectation Puzzles, Time-Varying Risk Premia, and Dynamic Models of the Term Structure, Journal of Financial Economics 63, 415-441.

Dai, Q., and K. Singleton, 2003, Term Structure Dynamics in Theory and Reality, Review of Financial Studies 16, 631-678.

De Jong, F., 2004, Deflators: An Introduction, VBA Journaal pp. 22-26.

De Jong, F., 2005, Valuation of Pension Liabilities in Incomplete Markets, Working Paper, University of Amsterdam.

De Jong, F., 2007, Pension Fund Investments and the Valuation of Liabilities under Conditional Indexation, Insurance: Mathematics and Economics, forthcoming.

De Jong, F., and J. Driessen, 2005, Liquidity Risk Premia in Corporate Bond Markets, Working paper, University of Amsterdam.

DeMiguel, V., L. Garlappi, and R. Uppal, 2006, How Inefficient is the 1/N AssetAllocation Strategy?, Review of Financial Studies forthcoming.

Dert, C.L., 1995, Asset Liability Management for Pension Funds: A Multistage Chance Constrained Programming Approach. (PhD. Thesis Erasmus University Rotterdam).

Dert, C.L., 1998, A Dynamic Model for Asset Liability Management for Defined Benefit Pension Funds, Worldwide Asset and Liability Modelling, eds. W.T. Ziemba and J.M. Mulvey, Cambridge University Press, Cambridge.

Detemple, J., R. Garcia, and M. Rindisbacher, 2003, A Monte Carlo Method for Optimal Portfolios, Journal of Finance 58, 401-446.

Detemple, J., R. Garcia, and M. Rindisbacher, 2005, Intertemporal Asset Allocation: A Comparison of Methods, Journal of Banking and Finance 29, 2821-2848.

Dimson, E., P. Marsh, and M. Staunton, 2002, Triumph of the Optimists. (Princeton University Press).

Duffee, G.R., 2002, Term Premia and Interest Rate Forecasts in Affine Models, Journal of Finance 57, 405-443.

Duffie, D., and R. Kan, 1996, A Yield Factor Model of Interest Rates, Mathematical Finance 6, 379-406.

Elton, E.J., M.J. Gruber, D. Agrawal, and C. Mann, 2001, Explaining the Rate Spread on Corporate Bonds, Journal of Finance 56, 247-277.

Enders, W., and H. Lapan, 1982, Social Security Taxation and Intergenerational Risk Sharing, International Economic Review 23, 647-658. 
Engel, J.P.W., H.M. Kat, and T.P. Kocken, 2005, Strategic Interest Rate Hedged Or How Derivatives Can Help Solve The Pension Fund Crisis Part II, Working Paper.

Ewijk, C., B. Kuipers, H. ter Rele, M. van de Ven, and E. Westerhout, 2000, Ageing in the Netherlands, CPB, the Hague.

Fabozzi, F.J., and P.F. Christensen, 2001, Bond Immunization an Asset/Liability Optimization Strategy, Handbook of Fixed Income Securities, 6th edition, F. Fabozzi.

Fabozzi, F.J., L. Martellini, and P. Priaulet, 2005, Hedging Interest Rate Risk with Term Structure Factor Models, Handbook of Fixed Income Securities, 7th edition, F. Fabozzi.

Fama, E.F., 1981, Stock Returns, Real Activity, and Money, American Economic Review 71, 545-565.

Fama, E.F., and K.R. French, 1989, Business Conditions and the Expected Returns on Stocks and bonds, Journal of Financial Economics 25, 23-49.

Fama, E.F., and K.R. French, 2002, The Equity Premium, Journal of Finance 57, $637-659$.

Feldstein, M.S., 2005, Structural Reform of Social Security, Journal of Economic Perspectives 9, 33-55.

Fong, H.G., and E.M.P. Tang, 1988, Immunized Bond Portfolios in Portfolio Protection, Journal of Portfolio Management pp. 63-68 Winter.

Fong, H.G., and O.A. Vasicek, 1984, A Risk Minimizing Strategy for Portfolio Immunization, Journal of Finance 34, 1541-1546.

Froot, K.A., 1995, Hedging Portfolios with Real Assets, Journal of Portfolio Management pp. 60-77 Summer.

Fugazza, C., M. Guidolin, and G. Nicodano, 2007, Investing for the Long-Run in European Real Estate: Does Predictability Matter?, Journal of Real Estate Finance and Economics forthcoming.

Fung, W., and D.A. Hsieh, 1997, Empirical Characteristics of Dynamic Trading Strategies: The Case of Hedge Funds, Review of Financial Studies 10, 275-302.

Fung, W., and D.A. Hsieh, 2000, Performance Characteristics of Hedge Funds and Commodity Funds: Natural vs. Spurious Biases, Journal of Financial and Quantitative Analysis 35, 291-307.

Geltner, D., 1991, Smoothing in appraised-based returns, Journal of Real Estate Finance and Economics 4, 327-345. 
Geltner, D., 1993, Estimating market values from appraised values without assuming an efficient market, Journal of Real Estate Research 8, 325-345.

Geweke, J., 1996, Monte Carlo Simulation and Numerical Integration, The Oxford Handbook of Pensions and Retirement Income, eds. H. Amman and D. Kendrick and J. Rust, North-Holland.

Goldfarb, D., and G. Iyengar, 2003, Robust Portfolio Selection Problems, Mathematics of Operations Research 28, 1-38.

Gollier, C., 2006, Intergenerational Risk Sharing and Risk Taking of a Pension Fund, Working paper, Toulouse.

Gordon, R.H., and H.R. Varian, 1988, Intergenerational Risk Sharing, Journal of Political Economy 14, 1-29.

Gorton, G., and K.G. Rouwenhorst, 2006, Facts and Fantasies about Commodity Futures, Financial Analysts Journal 62, 47-68.

Goyal, A., 2004, Demographics, Stock Market Flows, and Stock Returns, Journal of Financial and Quantitative Analysis 39, 115-142.

Goyal, A., and I. Welch, 2003, Predicting the Equity Premium with Dividend Ratios, Management Science 49, 639-654.

Guidolin, M., and A. Timmermann, 2007, Strategic Asset Allocation and Consumption Decisions under Multivariate Regime Switching, Journal of Economic Dynamics and Control, forthcoming.

Guillen, M., P.L. Jorgensen, and J.P. Nielsen, 2006, Return Smoothing Mechanisms in Life and Pension Insurance: Path-Dependent Contingent Claims, Insurance: Mathematics and Economics 38, 229-252.

Hari, N., R. Koijen, and T. Nijman, 2006, The Determinants of the Money's Worth of Participation in Collective Schemes, Working paper, Netspar.

Hoevenaars, R.P.M.M., R.D.J. Molenaar, P.C. Schotman, and T.B.M. Steenkamp, 2007a, Strategic Asset Allocation for Long-Term Investors: Parameter Uncertainty and Prior Information, LIFE working paper, Maastricht University.

Hoevenaars, R.P.M.M., R.D.J. Molenaar, P.C. Schotman, and T.B.M. Steenkamp, 2007b, Strategic Asset Allocation with Liabilities: Beyond Stocks and Bonds, Journal of Economic Dynamics and Control, forthcoming.

Hoevenaars, R.P.M.M., R.D.J. Molenaar, and T.B.M. Steenkamp, 2003, Simulation For The Long Run, Asset and Liability Management Tools, eds. B. Scherer, Risk Books.

Hoevenaars, R.P.M.M., and E.H.M. Ponds, 2006, Waardeoverdrachten tussen generaties binnen een bedrijfstakpensioenfonds, Kosten en Baten van Collectieve Pensioensystemen, eds. O. Steenbeek and F. van der Lecq, Kluwer. 
Hoevenaars, R.P.M.M., and E.H.M. Ponds, 2007a, Intergenerational Value Transfers within an Industry-Wide Pension fund - a Value-Based ALM analysis, Costs and Benefits of Collective Pension Systems, eds. O. Steenbeek and F. van der Lecq, Springer.

Hoevenaars, R.P.M.M., and E.H.M. Ponds, 2007b, Valuation of Intergenerational Transfers in Funded Collective Pension Schemes, Insurance: Mathematics and Economics, forthcoming.

Hoevenaars, R.P.M.M., O.C.H.M. Sleijpen, and O.W. Steenbeek, 2005, Het Financiele Toetsingskader onder de Loep, Economisch Statistische Berichten 90, 434437.

Hollifield, B., G. Koop, and K. Li, 2003, A Bayesian Analysis of a Variance Decomposition for Stock Returns, Journal of Empirical Finance 10, 583-601.

Jorion, P., 1986, Bayes-stein Estimation for Portfolio Analysis, Journal of Financial and Quantitative Analysis 21, 279-292.

Jurek, J.W., and L.M. Viceira, 2006, Optimal Value and Growth Tilts in LongHorizon Portfolios, Harvard Business School Working Paper.

Kadiyala, K.R., and S. Karlsson, 1997, Numerical Methods for Estimation and Inference in Bayesian VAR-Models, Journal of Applied Econometrics 12, 99-132.

Kan, R., and G. Zhou, 2006, Optimal Portfolio Choice with Parameter Uncertainty, Journal of Financial and Quantitative Analysis forthcoming.

Kandel, S., and R.F. Stambaugh, 1996, On the Predictability of Stock Returns: An Asset Allocation Perspective, Journal of Finance 51, 385-424.

Klein, R.W., and V.S. Bawa, 1976, The effect of estimation risk on optimal portfolio choice, Journal of Financial Economics 3, 215-231.

Kocken, T., 2006, Curious Contracts. (PhD. Thesis, Vrije University Amsterdam).

Koijen, R.S.J., and T.E. Nijman, 2006, Valuation and Risk Management of InflationSensitive Pension Rights, Fair Value and Pension Fund Management, eds. N. Kortleve, T.E. Nijman and E. Ponds, Elsevier Publishers.

Kortleve, N., T.E. Nijman, and E. Ponds, 2006, Fair Value and Pension Fund Management. (Elsevier).

Kortleve, N., and E. Ponds, 2006, Pension deals and Value-Based ALM, Fair Value and Pension Fund Management, eds. N. Kortleve, T.E. Nijman and E. Ponds, Elsevier Publishers.

Kotlikoff, L., 2002, Generational Policy, Handbook of Public Economics, eds. A.J. Auerbach and M.S. Feldstein, North Holland. 
Kouwenberg, R.R.P., 2001, Scenario Generation and Stochastic Programming Models for Asset Liability Management, European Journal of Operations Research 134, $51-64$.

Krueger, and Kubler, 2006, Pareto Improving Social Security Reform when Financial Markets are Incomplete, American Economic Review 96, 737-755.

Leibowitz, M.L., 1987, Pension Asset Allocation Through Surplus Management, Financial Analysts Journal 43, 29-40.

Leibowitz, M.L., and L.N. Bader S. Kogelman, 1994, Funding Ratio Return, Journal of Portfolio Management pp. 39-47.

Leland, H.E., 1980, Who Should Buy Portfolio Insurance, Journal of Finance 35, $581-594$.

Lettau, M., and S. Ludvigson, 2001, Consumption, Aggregate Wealth and Expected Stock Returns, Journal of Finance 56, 815-849.

Lewellen, J., and J. Shanken, 2002, Learning, Asset-Pricing Tests, and Market Efficiency, Journal of Finance 57, 1113 - 1145.

Lioui, A., and P. Poncet, 2001, On optimal portfolio choice under stochastic interest rates, Journal of Economic Dynamics and Control 25, 1841-1865.

Litterman, R., 2003, Modern Investment Management: An Equilibrium Approach. (Wiley).

Martellini, L., 2006, Managing Pension Assets: From Surplus Optimization to Liability-Driven Investment, Working Paper, Edhec Business School.

Merton, R.C., 1969, Lifetime Portfolio Selection Under Uncertainty: The Continuous Time Case, Review of Economics and Statistics 51, 247-257.

Merton, R.C., 1971, Optimal Consumption and Portfolio Rules in a ContinuousTime Model, Journal of Economic Theory 3, 373-413.

Merton, R.C., 1983, Theory of Rational Option Pricing, Financial aspects of the United States pension system, eds. Z. Bodie and J.B. Shoven, Chicago.

Michaud, R., 1998, Efficient Asset Management: A Practical Guide to Stock Portfolio Optimization and Asset Allocation. (Harvard Business School Press).

Mulvey, J.M., 1994, An Asset-Liability Investment System, Interfaces 24, 22-33.

Mulvey, J.M., G. Gould, and C. Morgan, 2000, An Asset and Liability Management System for Towers Perrin-Tillinghast, Interfaces 30, 96-114.

Munell, A., 2006, Employer-Sponsered Plans: The Shift from Defined Benefit to Defined Contribution, pp. 359-380 The Oxford Handbook of Pensions and Retirement Income, eds. G.L. Clark and A.H. Munnell and J.M. Orszag, Oxford University Press. 
Nijman, T.E., N. Hari, and A. De Waegenaere B. Melenberg, 2006, Longevity Risk in Pension Annuities, Working Paper, Tilburg University.

Pastor, L., 2000, Portfolio Selection and Asset Pricing Models, Journal of Finance $55,179-223$.

Pastor, L., and R.F. Stambaugh, 1999, Cost of Equity Capital and Model Mispricing, Journal of Finance 54, 67-121.

Pastor, L., and R.F. Stambaugh, 2000, Comparing Asset Pricing Models: An Investment Perspective, Journal of Financial Economics 56, 335-381.

Perold, A.F., and W.F. Sharpe, 1988, Dynamic Strategies for Asset Allocation, Financial Analysts Journal pp. 16-27 January/February.

Ponds, E.H.M., 2003a, Pension Funds and Value-Based Generational Accounting, Journal of Pension Economics and Finance 2, 295-325.

Ponds, E.H.M., 2003b, The Policy Ladder as a Tool to Manage Pension Fund Risk, Tijdschrift voor Corporate Finance.

Ponds, E.H.M., and B. Van Riel, 2007, Sharing Risk: The Netherlands' New Approach to Pensions, Working paper, 2007-5, Center For Retirement Research, Boston University.

Posthuma, N., and P.-J. Van der Sluis, 2003, A Reality Check on Hedge Fund Returns, Research memorandum, Free University Amsterdam.

Poterba, J., 2001, Demographic Structure and Asset Returns, Review of Economics and Statistics 83, 565-584.

Samuelson, P., 1969, Lifetime Portfolio Selection by Dynamic Stochastic Programming, Review of Economics and Statistics 51, 239-246.

Schotman, P.C., 1994, Priors for the AR(1) Model: Parameterization Issues and Time Series Considerations, Econometric Theory 10, 579-595.

Schotman, P.C., and M. Schweitzer, 2000, Horizon Sensitivity of the Inflation Hedge of Stocks, Journal of Empirical Finance 7, 301-315.

Schrager, D., 2007, Essays on Asset Liability Modeling. (PhD. Thesis, Vrije University Amsterdam).

Shanken, J.A., and A. Tamayo, 2005, Dividend yield, risk, and mispricing: A Bayesian analysis, Working paper, Emory University and London Business School.

Sharpe, W.F., 1976, Corporate pension funding policy, Journal of Financial Economics 3, 183-193.

Sharpe, W.F., and L.G. Tint, 1990, Liabilities: A New Approach, Journal of Portfolio Management Winter. 
Shiller, R.J., 1999, Social Security and Institutions for Intergenerational, Intragenerational and International Risk Sharing, Carnegie-Rochester Conference Series on Public Policy 50, 165-204.

Smetters, K., 2003, Controling the Cost of Minimum Benefit Quarantees in Public Pension Conversions, NBER Working paper, no. 8732.

Stambaugh, R.F., 1997, Analysing Investments whose Histories Differ in Length, Journal of Financial Economics 45, 285-331.

Stambaugh, R.F., 1999, Predictive Regressions, Journal of Financial Economics 54, $375-421$.

Steehouwer, H., 2005, Macroeconomic Scenarios and Reality. (PhD Thesis, Vrije University Amsterdam).

Steenbeek, O.W., and S.G. van der Lecq, 2006, Kosten en Baten van Collectieve Pensioensystemen. (Kluwer).

Steenbeek, O.W., and S.G. van der Lecq, 2007, Costs and Benefits of Collective Pension Systems. (Springer).

Steenkamp, T.B.M., 1998, Het Pensioenfonds in een Corporate Finance Perspectief. (PhD. Thesis, Vrije University Amsterdam).

Steenkamp, T.B.M., 1999, Contingent Claims Analysis and the Valuation of Pension Liabilities, Research Memorandum Vrije University Amsterdam.

Sundaresan, S., and F. Zapatero, 1997, Valuation, Optimal Asset Allocation and Retirement Incentives of Pension Plans, Review of Financial Studies 10, 631-660.

Tepper, I., 1981, Taxation and Corporate Pension Policy, Journal of Finance 36, $1-13$.

Uhlig, H., 1994, On Jeffreys Prior When Using the Exact Liklihood Function, Econometric Theory 10, 633-644.

Uppal, R., and T. Wang, 2003, Model Misspecification and Underdiversification, Journal of Finance 58, 2465-2486.

Wachter, J., 2002, Optimal Consumption and Portfolio Allocation under MeanReverting Returns: An Exact Solution for Complete Markets, Journal of Financial and Quantitative Analysis 37, 63-91.

Wachter, J., and M. Warusawitharana, 2007, Predictable returns and Asset Allocation: Should a Skeptical Investor Time the Market?, Working Paper, University of Pennsylvania.

Waring, M.B., 2004, Liability-Relative Investing II, Journal of Portfolio Management pp. 40-53 Fall. 
Welch, I., 2001, The Equity Premium Consensus Forecast Revisited, Cowles foundation discussion paper 1325 .

Wilkie, A.D., 1987, A stochastic Investment Model for Actuarial Use, Transactions of Actuaries 39, 391-403.

Wilkie, A.D., 1995, More on a Stochastic Asset Model for Actuarial Model, Presented to the Institute Actuaries and Faculty of Actuaries, London.

Xia, Y., 2001, Learning about Predictability: the Effect of Parameter Uncertainty on Dynamic Asset Allocation, Journal of Finance 56, 205-246.

Yu, B., and P. Mykland, 1998, Looking at Markov samplers through cusum path plots: A simple diagnostic idea, Statistics and Computing 8, 275-286.

Zellner, A., 1971, An Introduction to Bayesian Inference in Econometrics. (Wiley).

Ziemba, T.Z., 2003, The stochastic programming approach to asset, liability and wealth management. (The Research Foundation of the Association for Investment Management and Research).

Ziemba, T.Z., and J.M. Mulvey, 1998, Worldwide Asset and Liability Modelling. (Cambridge University Press).

Ziemba, T.Z., and S.A. Zenios, 2007, Handbook of Asset Liability Management. (North Holland). 


\section{Nederlandse samenvatting}

Institutionele vermogensbeheerders beheren miljarden Euro's voor vele mensen met een lange-termijn doelstelling zoals een goed pensioen. Nederlandse bedrijfstak-, beroeps-, en ondernemingspensioenfondsen beleggen bijvoorbeeld gezamenlijk meer dan 600 miljard Euro. De groei van het aantal beleggingsmogelijkheden maakt het beleggingsproces steeds uitdagender. Naast beleggingen in aandelen, obligaties, onroerend goed en cash, krijgen alternatieven als grondstoffen, bedrijfsobligaties, infrastructuur, hedge funds, en private equity een belangrijkere rol. Voor dergelijke lange termijn beleggers is het strategische beleggingsbeleid één van de meest fundamentele beslissingen. Hieronder verstaan we de selectie van de relevante beleggingscategorieën en de bijbehorende gewichten in de beleggingsmix. In het begin van deze eeuw werd het strategische beleggingsbeleid op de proef gesteld tijdens het barsten van de internet-zeepbel en dalende rentes. Dit heeft geleid tot een verslechtering van de financiële positie van vele pensioenfondsen. Daarbij komt dat toezichthouders in Nederland, Denemarken, Zweden en de UK hun financiële toezichtkader hebben aangepast. Solvabiliteitsrestricties hebben een belangrijkere rol, en er heeft een verschuiving plaats gevonden naar marktwaardering van zowel het vermogen als de verplichtingen op de balans van het pensioenfonds. Rente en inflatierisico hebben hierdoor een prominentere rol gekregen in het strategische beleggingsbeleid en er is veel aandacht voor "liability-driven" beleggingsoplossingen.

Het verzoek om meer transparantie in de pensioenregeling is een ander aspect dat de laatste jaren veel in de publiciteit is geweest. De kosten en baten van definedbenefit en defined-contribution pensioenregelingen zijn uitgebreid besproken tijdens conferenties en beschreven in artikelen. Deze discussies worden gevoed door zaken als waarde-overdrachten tussen generaties, de levensloop benadering en de governance structuur binnen pensioenfondsen. Inzichten in de relaties tussen de verschillende belanghebbenden lijkt cruciaal voor de houdbaarheid en continuteit van de pensioenregeling. De identificatie en de waardering van de impliciete (verborgen) afspraken in het pensioen contract (zogenaamde embedded opties genoemd) tussen de belanghebbenden lijkt een grote uitdaging voor beleidsmakers. 
In dit proefschrift doen we onderzoek naar het strategische beleggingsbeleid voor lange termijn investeerders en asset liability management (ALM) voor pensioenfondsen. Asset liability management kan worden omschreven als het integrale beheer van het vermogen en de verplichtingen op de balans van een instelling. ALM houdt integraal rekening met toekomstige onzekerheden, meerdere belanghebbenden en doelstellingen, en de beschikbare strategische beleidsinstrumenten voor het bestuur van de instelling zoals het premie-, indexatie- en beleggingsbeleid. Dit proefschrift onderzoekt twee terreinen van ALM: strategisch beleggingsbeleid en de waardering van embedded opties in het pensioenbeleid (Value-based ALM).

We onderscheiden drie thema's op het gebied van strategisch beleggingsbeleid. Het eerste thema omvat de risico eigenschappen van beleggingscategorieën over verschillende beleggingshorizonnen. Campbell en Viceira (2002) beschrijven het belang van horizon afhankelijke risico's voor lange termijn beleggers. Zo hebben cash en andere kortlopende geldleningen relatief een laag risico voor korte termijn investeerders, maar niet voor lange termijn investeerders door herbeleggingrisico. Aandelenrisico echter lijkt relatief lager voor langere dan voor kortere horizonnen. Langlopende nominale obligaties zijn weliswaar geen goede inflatie hedge, maar hebben vergelijkbare eigenschappen als inflatie-gerelateerde obligaties wanneer het inflatie risico laag is. Deze laatste categorie is de risico-vrije belegging voor lange termijn investeerders. Er is een omvangrijke literatuur die de relatie beschrijft tussen aandelenrendementen en inflatie, rentes, kredietpremies en waarderingsgrootheden als de dividend-prijs verhouding en de omzet-prijs verhouding. Fama en French (1989) relateren dergelijke macro economische variabelen aan de conjunctuur cyclus in de economie. Risico premies zijn hoog in perioden van laag conjunctuur en vice versa. Deze dynamiek zorgt voor horizon afhankelijke risico's. Investeerders met een langere horizon dienen daardoor niet alleen gebruik te maken van risicodiversificatie tussen beleggingscategorieën, maar ook van tijdsdiversificatie binnen beleggingscategorieën.

De bijdrage van dit proefschrift aan dit thema is dat we risico eigenschappen bestuderen van andere beleggingscategorieën dan aandelen, obligaties en cash. Verder verkennen we de risico eigenschappen ten opzichte van pensioenverplichtingen. We breiden het beleggingsuniversum uit tot bedrijfsobligaties, beursgenoteerd onroerend goed, grondstoffen en hedge fondsen. Naast tijds- en risicodiversificatie richten we ons op twee andere risico factoren die belangrijk zijn voor een pensioenfonds: inflatierisico en rente risico. We onderzoeken welke alternatieve beleggingen risico's, correlaties, inflatie hedge kwaliteiten en rente hedge kwaliteiten 
hebben die substantieel afwijken van aandelen en obligaties. De robuustheid van de risico eigenschappen ten aanzien van de parameter onzekerheid in de onderliggende econometrische modellen wordt ook onderzocht. Daarnaast analyseren we de invloed van een visie op toekomstige beleggingsrendementen, rentes, inflatie en macro economische variabelen op de horizon afhankelijke risico eigenschappen.

Portefeuille keuze is het tweede thema dat in dit proefschrift wordt bestudeerd. Welk gedeelte van het vermogen dient een belegger te investeren in aandelen, obligaties, cash en de alternatieven? De academische literatuur splitst de optimale belleggingsmix in twee componenten. De speculatieve component is gebaseerd op de risico rendement verhouding. De hedge component richt zich op het minimaliseren van het totale risico van de portefeuille. De verhouding tussen de twee componenten wordt bepaald door de risico aversie van de belegger. Merton (1969) en Sammuelson (1971) vonden dat de optimale beleggingsportefeuille verschillend is voor lange en korte termijn investeerders wanneer risico eigenschappen horizon afhankelijk zijn. Dit proefschrift vindt dat het verschil in portefeuille keuze zonder beleggingsrestricties van een belegger met, en een belegger zonder marktgewaardeerde pensioen verplichtingen tot uiting komt in de hedge component. De liability hedge portefeuille minimaliseert de mismatch tussen vermogen en verplichtingen, terwijl de hedge portefeuille alleen het risico van de beleggingsportefeuille minimaliseert. We splitsen analytisch het nutsverlies van suboptimaal beleggingsbeleid op in een rendements-, risico, en liability hedge gedeelte. Daarnaast beschrijft de literatuur dat de speculatieve component gevoelig is voor kleine wijzigingen in rendementen. In dit proefschrift gebruiken we bayesiaanse statistiek om deze gevoeligheid te beperken door rendementsvisies mee te nemen, maar tegelijkertijd ook de horizon afhankelijke risico's te modelleren. We definieren een robuuste beleggingsportefeuille die het verwachte nutsverlies minimaliseert wanneer er meerdere investeerders zijn met verschillende rendementsverwachtingen.

Het derde thema is beleggen voor de lange termijn met korte termijn solvabiliteitsrestricties. Dit thema speelt de laatste jaren een belangrijke rol in het beleggingsbeleid voor pensioenfondsen omdat solvabiliteit restricties centraal zijn in de aangepaste financiële toezichtkaders. Pensioenfondsen balanceren tussen korte termijn solvabiliteitsrestricties, inflatie compensatie, en lange termijn continuïteit en houdbaarheid. De financiële wereld heeft hierop gereageerd door vele dynamische beleggingsstrategieën te beschouwen om het korte termijn neerwaartse risico te beperken. In dit proefschrift analyseren we drie dynamische strategieën die representatief zijn voor de vele verschillende benaderingen die in de pensioenwereld worden gevolgd. Naast een immunizatie strategie van de nominale pensioenverplichtingen (aldus zonder inflatie garantie) komen een dynamische mix strategie conditioneel 
op het neerwaartse risico en een constante beleggingsmix met een dynamische rente swap-overlay aan de orde. Uiteraard heeft elke aanpak haar voor- en nadelen. De aantrekkelijkheid van een strategie hangt in het bijzonder af van de rendement en inflatie-compensatie doelstellingen, de risico aversie en de marktomstandigheden.

Value-based ALM is het tweede terrein dat wordt onderzocht in dit proefschrift. Transparantie en inzicht in de waarde overdrachten tussen de belanghebbenden spelen een belangrijke rol in de huidige pensioen revolutie. Inzicht in de relaties tussen verschillende groepen deelnemers is van groot belang voor veranderingen in het pensioensysteem. We zijn van mening dat de identificatie en waardering van de embedded opties extra inzicht geven in de impliciete waarde overdrachten tussen belanghebbenden. Embedded opties onstaan door afspraken en condities in het pensioencontract. Het indexatie beleid wordt bijvoorbeeld bepaald door de financiële positie van het fonds. Het kan worden geïnterpreteerd als een put optie voor het pensioenfonds die geschreven is door de deelnemers. Wanneer de financiële positie van het fonds dusdanig verslechtert dat volledige inflatie compensatie niet realistisch lijkt, komt de put optie in-the-money en kan het fonds de optie uitoefenen. Hetgeen resulteert in gedeeltelijke inflatie compensatie. Andere voorbeelden zijn premie kortingen, extra indexatie of een premiebeleid dat conditioneel is ingericht op de financiële positie. De claims van deelnemers op de enorme vermogensoverschotten in de 80 en 90-er jaren zijn ook een goed voorbeeld. Ondanks dat een conditioneel indexatie beleid het fonds robuuster maakt voor een verdere verslechtering van de positie, vinden er impliciet waarde overdrachten plaats tussen deelnemers. In tegenstelling tot opties in de financiële wereld worden de belanghebbenden in het fonds niet automatisch gecompenseerd voor de impliciete risico's en waarde overdrachten. Het is niet moeilijk voor te stellen dat een specifieke beleidswijziging beter uitpakt voor sommige groepen deelnemers dan voor andere. Verborgen waarde overdrachten zijn een bedreiging voor de houdbaarbeid en continuïteit van de pensioenregeling op de lange termijn. Met name in de huidige vergrijzende samenleving is transparantie en de waardering van dergelijke embedded opties essentieel.

Recentelijk is er in de literatuur veel aandacht voor embedded options in het pensioen contract (Ponds (2003), Kortleve, Nijman en Ponds (2006) en Kocken (2006)). In dit proefschrift identificeren we allereerst de indexatie, premie, surplus en generatie opties op de balans van een pensioenfonds. Daarna ontwikkelen we een consistent waarderingsmodel. Het vector autoregressieve model met een affine rente termijn structuur en een "pricing kernel" specificatie is niet alleen geschikt voor optiewaardering, maar tevens voor scenariogeneratie waarbij de horizon afhankelijke risico's uit het eerste terrein van dit proefschrift ook zijn gemodelleerd. Vervolgens 
illustreren we deze aanpak door in een realistisch voorbeeld waarde overdrachten tussen generaties te prijzen bij bijvoorbeeld de overgang van een traditionele definedbenefit regeling naar een collectieve defined contribution regeling. Beleidswijzigingen in collectieve pensioenregelingen leiden onvermijdelijk tot waarde overdrachten tussen generaties. We tonen hoe value-based ALM de waarde overdrachten expliciet maakt, en we zijn van mening dat value-based ALM gebruikt dient te worden naast klassiek ALM om een extra dimensie toe te voegen bij beleidswijzigingen.

We hopen dat dit proefschrift de volgende 10 lessen heeft beschreven voor het strategisch beleggingsbeleid voor lange termijn beleggers en asset liability management.

Ten eerste, alternatieve beleggingscategorieën kunnen waarde toevoegen voor lange termijn beleggers. Een kernpunt hierbij is of de horizon afhankelijke risico eigenschappen fundamenteel verschillen van die van aandelen, obligaties en cash.

Hoofdstuk twee van dit proefschrift beschrijft deze risico karakteristieken voor bedrijfsobligaties, beursgenoteerd onroerend goed, grondstoffen en hedge fondsen. Commodities lijken de beste risico diversificatie eigenschappen te hebben: ze zijn de enige categorie in ons universum met een negatieve correlatie met aandelen en obligaties voor korte en lange beleggingshorizonnen. Aan de andere kant hebben ze een vlakke termijn structuur van volatiliteit, waardoor ze relatief minder aantrekkelijk lijken dan de "mean reverting" aandelen en obligaties. Termijn structuren van beursgenoteerd vastgoed lijken sterk op die van aandelen. Beursgenoteerd onroerend goed wordt vaak beschouwd als een aandelen categorie. Bedrijfsobligaties met een hoge kredietwaardigheid lijken een goed substituut voor staatsobligaties met een hoger verwacht rendement dan staatsobligaties. De risico eigenschappen lijken veel op elkaar, waarbij de correlatie met aandelen iets hoger is voor bedrijfsobligaties. Hedge fondsen hebben als beleggingscategorie een hoge exposure naar aandelen en obligaties.

De allocatie naar alternatieve beleggingen in de portefeuille hangt af van de beleggingshorizon en de risicohouding van de investeerder. Voor beleggers met een lage risico aversie worden cash en staatsobligaties uit de portefeuille verdreven, ten gunste van alternatieven met een hoger verwacht rendement zoals hedge fondsen, grondstoffen en bedrijfsobligaties. De laatste twee beleggingsmogelijkheden zijn ook interessant voor conservatievere beleggers. Het gewicht van beursgenoteerd vastgoed blijft in onze analyzes klein doordat de Sharpe ratio achterblijft bij aandelen en hedge fondsen. We vinden ook dat het nutsverlies van het niet investeren in de alternatieven economisch significant is. Beleggers dienen echter te beoordelen of het nutsverlies opweegt tegen praktische implementatie zaken op het gebied van risico 
management, juridische vereisten, hoge instapkosten, reputatie risico en goede manager selectie vaardigheden.

Ten tweede, lange termijn beleggers dienen zich te realiseren dat naast de volatiliteit van een beleggingscategorie en de relatie tussen beleggingscategorië̈n, ook de relaties van een beleggingscategorie met inflatie afhankelijk zijn van de beleggingshorizon.

Cash lijkt de een goede inflatie hedge doordat de korte rente snel aanpast bij inflatieveranderingen. Een obligatie portefeuille met een constante lange looptijd is een goede inflatie hedge op de lange termijn, maar een slechte voor korte beleggingshorizonnen door de inverse relatie tussen de rente en de prijs van een obligatie. Een nominale rente swap-overlay stelt een lange termijn belegger hierdoor bloot aan inflatie risico. In een inflatoir regime zal de variabele korte rente die betaald dient te worden stijgen met de inflatie, terwijl de vaste lange rente is afgesproken. Aandelen en hedge fondsen zijn een betere inflatie hedge in de lange termijn dan op de korte termijn. De inflatie hedge kwaliteiten van beursgenoteerd onroerend goed lijken op die van aandelen, en grondstoffen zijn sterk gecorreleerd met inflatie voor korte en lange beleggingshorizonnen.

Ten derde, verschillen in strategisch beleggingsbeleid voor asset-only en asset-liability beleggers komt tot uiting in verschillen tussen de globale minimum variantie portefeuille en de liability hedging portefeuille.

Het belangrijkste verschil tussen asset-only en asset-liability beleggen uit zich in de aantrekkelijkheid van cash en obligaties met een lange looptijd. Asset-only investeerders hebben een grote voorkeur voor kort geld door de sterke inflatie hedge kwaliteiten. Lange termijn beleggers met marktgewaardeerde pensioen- of verzekeringsverplichtingen hebben echter niet alleen te maken met herbeleggingsrisico van kort geld, maar ook met de duration mismatch met de verplichtingen. Desondanks is ook kortlopend geld aantrekkelijk voor asset-liability beleggers door het lage risico op korte horizonnen, en de risico diversificatie met aandelen en obligaties voor langere beleggingshorizonnen. Langlopende staats- en bedrijfsobligaties zijn een betere hedge tegen de marktgewaardeerde verplichtingen en hebben daardoor een aanzienlijk gewicht in de liability hedge portefeuille. Grondstoffen maken hier ook deel van uit door hun risico diversificatie kwaliteiten. De liability hedge portefeuille alloceert een klein percentage naar beursgenoteerd vastgoed en belegt niet in hedge funds. We vinden verder dat de duration van de vastrentende waarden in de liability hedge portefeuille lager is dan de duration van de pensioenverplichtingen om een drietal redenen. In het kader van lange versus korte termijn is kortlopend geld een goed risico diversificator voor langlopende obligaties. In het kader van nominaal inflatie 
risico versus reële rente risico heeft de lange nominale rente een hoge correlatie met de lange reële rente, maar kort geld is een betere inflatie hedge. Tenslotte, hebben ook andere beleggingscategorieën als aandelen een (positieve) correlatie met reële rentes. Door horizon afhankelijke covarianties is het duration beleid ook afhankelijk van de beleggingshorizon.

Ten vierde, de toegevoegde waarde van een beleggingsbeleid dat zich richt op de lange termijn in plaats van de korte termijn is groot voor een vermogensbeheerder met marktgewaardeerde pensioenverplichtingen.

Voor beleggingshorizonnen langer dan vijf jaren is de toegevoegde waarde van een lange termijn strategisch beleggingsbeleid groter wanneer er pensioenverplichtingen zijn. Naast een ander korte termijn beleggingsbeleid heeft een dergelijke belegger andere intertemporele "hedging demands" voor veranderingen in de beleggingsmogelijkheden over de verschillende horizonnen. De afnemende correlatie tussen aandelen en obligaties op de lange termijn creëert positieve "hedging demands" voor de lange termijn. De toenemende correlatie op de korte en middellange termijn creëert echter negatieve "hedging demands" wanneer er pensioenverplichtingen zijn. Hoofdstuk twee stelt een analytisch raamwerk voor dat kan worden gebruikt bij de analyse van de toegevoegde waarde van een beleggingscategorie of -strategie in termen van rendement, risico diversificatie en liability hedging. Daarnaast lijkt de recente aandacht voor "liability-driven investment" oplossingen gerechtvaardigd vanuit de optimal portfolio choice theory, en is de toegevoegde waarde van een lange termijn strategisch beleggingsbeleid groot.

Ten vijfde, risico diversificatie en inflatie hedge kwaliteiten zijn robuuster tegen onzekerheid in model parameters en visies van investeerders op het gebied van toekomstige rendementen, inflatie, rentes en macro economische variabelen, dan tijdsdiversificatie in termen van volatiliteiten.

Hoofdstuk drie toont dat het effect van onzekerheid in de model parameters op de volatiliteit toeneemt met de beleggingshorizon. Ofschoon "mean reversion" in aandelen en obligatie rendementen parameter onzekerheid domineert, worden tijdsdiversificatie eigenschappen zwakker. De risico's van aandelen en obligaties hangen af van de visie op het gebied van macro economische variabelen. Doordat een dergelijke visie de persistentie van deze variabelen beïnvloedt heeft deze ook effect op de termijn structuur van volatiliteit. We vinden dat onzekerheid omtrent toekomstige verwachte rendementen een "mean averting" karakter heeft voor de volatiliteit op de lange termijn. 
Ten zesde, het opnemen van onzekerheid in de model parameters bij de portefeuille keuze leidt tot een conservatiever beleggingsbeleid met een sterkere nadruk op risico diversificatie.

Doordat correlaties tussen beleggingscategorieën robuuster zijn ten aanzien van parameter onzekerheid dan volatiliteiten, vinden we dat risico diversificatie extra wordt benadrukt in het strategische beleggingsbeleid. Beleggers die parameter onzekerheid opnemen alloceren minder naar aandelen en meer naar cash. Het nutsverlies van het negeren van parameter onzekerheid is klein voor korte termijn beleggers, maar aanzienlijk voor lange termijn beleggers.

Ten zevende, een belangrijke determinant voor de portefeuille keuze is uiteraard de visie omtrent verwachte rendementen, rentes en inflatie, maar we tonen enkele interessante observaties.

Kortlopend geld heeft een aanzienlijke rol in de portefeuille keuze voor zowel optimistische als pessimistische beleggers. Het lage risico voor korte horizonnen, en de risico diversificatie met aandelen en langlopende obligaties op langere horizonnen maakt kortlopend geld een interessante belegging. Een belegger die uiterst optimistisch is over toekomstige aandelen rendementen investeert ook een aanzienlijk deel van zijn vermogen in kortlopend geld als risico diversificatie. Aan de andere kant investeren lange termijn beleggers die pessimistisch zijn over aandelen ook nog een gedeelte in deze categorie voor risico diversificatie. We vinden dat wanneer er meerdere experts zijn met verschillende toekomstverwachtingen de robuuste portefeuille keuze enigszins conservatief is over aandelen, matig optimistisch over obligaties en rekening houdt met parameter onzekerheid.

Ten achtste, dynamische beleggingsstrategieën zijn niet vanzelfsprekend in lijn met de lange termijn inflatie compensatie ambitie van DB pensioenstelsels.

Hoofdstuk vier gaat over "liability-driven portfolio insurance" strategieën. Het succes van dergelijke strategieën hangt onder andere af van de markt omstandigheden, de risico houding, de dekkingsgraad en het opwaartse rendement potentieel. "Porfolio insurance" benaderingen die gericht zijn op reductie van het korte termijn solvabiliteitsrisico dienen zorg te dragen voor een solvabiliteitsval. Zo tonen we dat immunizatie en dynamische mix strategieën kunnen leiden tot een laag nominaal risico, maar dit gaat mogelijk ten koste van de lange termijn indexatie kwaliteit. In ons voorbeeld zorgt een dynamische nominale rente swap-overlay voor een betere balans tussen korte termijn risico's en lange termijn indexatie kwaliteit, omdat het rendementspotentieel van de portefeuille overeind blijft. Bij deze voordelen van de swap-overlay horen echter ook een aantal kanttekeningen. De hogere rentegevoe- 
ligheid leidt tot hogere volatiliteit van het vermogen, en grotere verliezen bij stijgende rentes. Verder dekt een swap weliswaar het renterisico af, maar kunnen andere markt risico's leiden tot onderdekking. De korte "payer rate" leidt daarnaast tot herbeleggingsrisico, en zowel de "payer rate" als de "receiver rate" verhogen het inflatie risico voor het fonds.

Ten negende, "value-based ALM" en in het bijzonder "value-based generational accounting" dienen te worden gebruikt als een belangrijke uitbreiding van klassieke ALM analyzes, omdat het extra inzicht geeft in de relaties tussen de belanghebbenden bij een collectief pensioenstelsel.

De "value-based ALM" benadering in hoofdstukken vier en vijf onthullen de verborgen waarde overdrachten tussen generaties die niet kunnen worden geïndentificeerd met klassiek ALM op basis van kansverdelingen. Inzichten in de embedded opties die een groep deelnemers schrijft aan een andere groep deelnemers zijn belangrijk voor een eerlijk en houdbaar pensioencontract, ze brengen immers de relaties tussen belanghebbenden in kaart. Allereerst identificeren we in hoofdstukken vier en vijf de embedded indexatie, surplus, tekort en generatie opties. Vervolgens gebruiken we optie waarderingstechnieken voor de waardering. De onderliggende economische omgeving is gebaseerd op een vector autoregressief model met een affine rente termijn structuur specificatie en een "pricing kernel". Deze methode is ook toepasbaar voor de beoordeling van andere collectieve contracten die leiden tot verborgen waarde overdrachten, op bijvoorbeeld het gebied van overheidsfinanciering en het sociale zekerheidsstelsel. We beweren dat "value-based ALM" deel uit zou moeten van de ALM studies bij pensioen fondsen met intergenerationele risico deling.

Ten tiende, beleidswijzigingen in collectieve pensioenstelsels leiden tot waarde overdrachten tussen belanghebbenden zoals generaties.

Hoofdstuk vijf herschrijft de balans van een pensioenfonds in termen van embedded generatie opties en verkent intergenerationele risico deling. We tonen de intergenerationele waarde overdrachten als gevolg van wijzigingen in het beleggings, premie en indexatie beleid. In ons voorbeeld lijkt een risicovollere beleggingsmix gunstiger voor jongere dan oudere deelnemers. Jongeren hebben baat bij de lagere premie door de hogere verwachte beleggingsopbrengsten, terwijl ouderen slechter af zijn door een hoger korte termijn neerwaarts en indexatie risico. De invoering van een flexibel premie en/of indexatiebeleid leidt ook tot waarde overdrachten.

De praktische toepassing van de beleggingsinzichten van dit proefschrift is een grote uitdaging. In de praktijk worden een aantal model aannames geschonden. De 
nutsfunctie van een pensioenfonds met diverse deelnemers en verschillende doelstellingen is niet expliciet gedefinieerd. Bovendien is het besluitvormingsproces vaak niet gebaseerd op een expliciet gedefinieerde nutsfunctie en spelen de organisatorische structuur en gedragsaspecten een belangrijke rol. Daarnaast dient een belegger rekening te houden met regelgeving, juridische en beleggingsrestricties. Het beleggingsuniversum gaat ook verder dan hetgeen in dit proefschrift is beschouwd: bosbouw, infrastructuur, private equity en andere illiquide beleggingen krijgen een steeds belangrijkere rol. Ook is de markt voor inflatie gerelateerde beleggingsproducten sterk in ontwikkeling. We hopen dat de zojuist besproken lessen toepasbaar zijn voor lange termijn beleggers wanneer zij deze uitdagingen aan gaan. We hopen ook dat de modellen in dit proefschrift bruikbaar zijn voor strategisch beleggingsbeleid en (value-based) ALM om te balanceren tussen nominale risico's, inflatie compensatie, lange termijn continuïteit en solvabiliteit. In het bijzonder denken we dat de waardering van embedded (generatie) opties een inzichtelijk instrument vormt bij de evaluatie van hervormingen van het pensioenstelsel en andere veranderingen in het pensioencontract in de komende jaren. 


\section{Curriculum vitae}

Roy Hoevenaars was born on September 19, 1978 in Roermond, The Netherlands. In 2001 he obtained his MSc in econometrics and operations research at the University of Maastricht. His masters thesis, Transaction costs in equity management: implementation shortfall, portfolio construction and broker allocation was researched and written during an internship at ABN AMRO Asset Management in Amsterdam, The Netherlands.

From 2003 to 2007 Roy worked part-time on his Ph.D. dissertation in financial econometrics entitled Strategic Asset Allocation and Asset Liability Management at the Departments of Quantitative Economics and Finance of the University of Maastricht. Chapter two of this dissertation has been awarded the 2005 second prize at Inquire Europe, Inquire UK and Q-group, and it is forthcoming in the Journal of Economic Dynamics and Control. Chapter five is forthcoming in the journal Insurance: Mathematics and Economics. He wrote several chapters on ALM in books like The Oxford handbook of Pensions and Retirement Income (eds. G. Clark, A. Munnell and J. Orszag, Oxford University Press), Asset Liability management Tools (eds. B. Scherer, Risk books), and Costs and Benefits of Collective Pension Systems (eds. S. van der Lecq and O. Steenbeek, Springer). Roy teaches on ALM and strategic asset allocation and regularly gives seminars and guest lectures at universities.

In 2001 Roy joined the research department of ABP Investments in Amsterdam, The Netherlands. He did quant equity research and he was in the strategic and tactical issues group. In 2004 he joined the Financial and Risk policy department at ABP Finance where he was senior policy advisor ALM and coordinator ALM modeling. In 2007 Roy joined the Global Tactical Asset Allocation fund of ABP Investments in Amsterdam as senior portfolio manager. 